



$$
J-16
$$





\section{Conspectus Psittacorum.}

\author{
Systematische
}

Uebersicht aller okanntten Papangienarten.

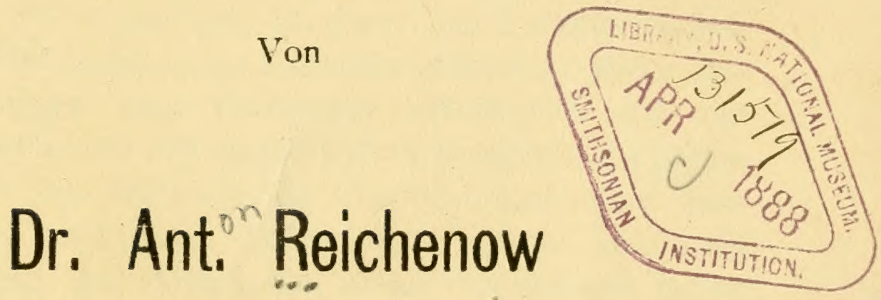

mit einer Uebersiehts-Tabelle. 


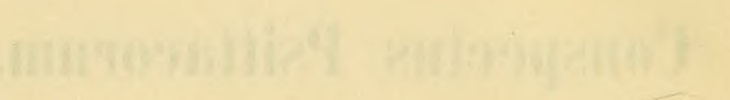

Wom: 


\section{Conspectus Psittacorum.}

Systematische

Uebersicht aller bekannten Papageienarten.

Von

\section{Or. Ant. Reichenow.}

Die Fortschritte der Ornithologie zeigen sich am deutlichsten bei der Verfolgung der Literatur einzelner Vogelgruppen durch ihre Geschichte. Es ergiebt sich bei derartigen Untersuchungen, in wie weit der fortschreitenden Kenntniss gelungen, ältere Irrthümer zu berichtigen, neue Thatsachen aufzuklären, wie viel des neuen entdeckt wurde und man erhält insbesondere ein höchst interessantes Bild des Wechsels der Anschauungen über eine Vogelgruppe, den wachsenden Erfahrungen gemäss im Laufe weniger Jahrzehnte. Die Fortschritte in der Ornithologie haben in der zweiten Hälfte dieses Jahrhunderts einen so rapiden Lauf genommen, dass monographische Arbeiten über einzelne $\mathrm{Ab}$ theilungen der Vögel beinahe schon während des Druckes veralten. Jedenfalls währt es nur wenige Monate, bis die sorgfältigst und gründlichst gearbeitete Monographie Lücken aufzuweisen hat, welche zunächst sporadische, im Laufe der Jahre aber derartig sich häufen, dass oft schon nach Verlauf eines Jahrzehntes die Neubearbeitung desselben Themas als ein dringendes Erforderniss erscheint.

Eine derjenigen Vogelgruppen, welche seit jeher in ganz besonderem Grade das Interesse der Ornithologen auf sich gezogen und dementsprechend in kurzen Intervallen Bearbeiter gefunden hat, ist die Ordnung der Papageien und gerade diese 
Gruppe illustrirt recht augenscheinlich unsere obigen Ausführungen.

Im Jahre 1801 bearbeitete Levaillant zum ersten Male eine Monographie der Papageien in seinem grossen, durch $\mathrm{Ab}$ bildungen aller abgehandelten Arten geschmückten Foliowerke: „Histoire naturelle des Perroquets." Es sind in demselben 146 Papageien auf 139 Tafeln abgebildet, von welchen jedoch nur einige 80 als Arten bestehen bleiben, während die übrigen theils als Varietäten, theils als Artefacte sich erweisen. Levaillant's Werk wurde im Jahre 1805 zum Abschluss gebracht. Bereits 15 Jahre später erschien eine neue Bearbeitung der Papageien in Kuhl's Conspectus Psittacorum (1820). Dieses weniger umfangreiche, aber bedeutend höheren wissenschaftlichen Werth beanspruchende Buch in Quartformat, mit einigen Abbildungen neuer Arten ausgestattet, giebt in gedrängter Form die Charaktere von 209 Arten, von welchen freilich etwa 50 als Synonyme oder zweifelhafte Arten zu betrachten sind. Kuhl nahm zum ersten Male eine systematische Eintheilung der Papageien vor. Er betrachtete sämmtliche Formen als Repräsentanten eines einzigen genus Psittacus, welches er in fünf Sectionen: Ara, Conurus, Psittacula, Psittacus und Kakadoe zerlegte. Der Kuhl'schen Arbeit folgte im Jahre 1832 Wagler's Monographia Psittacorum, welche viel ausführlichere Beschreibungen als jene enthält, die Synonymie kritisch sichtet, viele Irrthümer jener Uebersicht damit berichtigt und auch in systematischer Hinsicht einen bedeutenden Fortschritt bekundet. Wagler beschrieb 197 verschiedene Arten, von welchen etwa 17 zweifelhaft sind, so dass man in runder Summe 180 Arten als im Jahre 1832 bekannt annehmen darf. Wagler fasste die Papageien als Ordnung auf und zerlegte sie in 30 Gattungen, welche aber nicht in Familien zusammengefasst werden. Die Gattungen sind: Palaeornis, $P_{0-}$ lytelis, Pezoporus, Nymphicus, Prioniturus, Platycercus, Deroptyus, Euphema, Trichoglossus, Charmosyna, Eos, Coriphilus, Domicella, Eclectus, Psittacodis, Psittacus, Pionus, Psittacula, Nasiterna, Triclaria, Sittace, Tanygnathus, Coracopsis, Dasyptilus, Microglossus, Calyptorhynchus, Corydon, Cacatua, Licmetis, Nestor, Gattungen, welche wir grösstentheils auch gegenwärtig noch, wenngleich in anderer Begrenzung, anerkennen.

Das Wagler'sche Werk bedeutet den Abschluss der ersten 
Epoche in der Geschichte der Literatur der Papageien. Die Arbeiten der folgenden zweiten Epoche sind weniger ausführliche Monographien als systematische Zusammenstellungen und Untersuchungen über Synonymie. Wührend also in dem ersten Zeitabschnitt das Bestreben dahin ging, die einzelnen Arten kennen zu lernen, tritt in dem zweiten die Absicht der übersichtlichen Anordnung und natiurlichen Gruppirung der bekannten Formen hervor.

Bevor wir jedoch auf diese classificatorischen Publikationen näher eingehen, haben wir zwei Illustrationswerke zu erwähnen, welche ohne eingehende wissenschaftliche Behandlung der Gruppe nur Abbildungen von Papageien geben, aber immerhin als nicht unwichtige Beiträge zur Förderung der Kenntniss dieser Vögel anzusehen sind, nämlich: Lear, Illustrations of the Family Psittacidae or Parrots (1832) und Bourjot St. Hilaire, Histoire Naturelle des Perroquets (1837-1838), eine Ergänzung des Levaillant'schen Werkes. Von den systematischen Arbeiten, welche, wie erwähnt, der Nonographie Wagler's folgten, haben wir zwei an dieser Stelle hervorzuheben: Bonaparte's Conspectus Psittacorum (Nammamia 1856) und G. R. Gray's List of the Specimens of Birds in the Collection of the British Inseum (Pt. III, Psittci 1859). Bonaparte's Conspectus ist nur eine schematische Darstellung des Systems der Papageien. Die Untersuchungen des Autors über einzelne Arten, deren Synonymie und insbesondere über neubeschriebene Formen, befinden sich in verschiedenen kleineren Arbeiten zerstrent. Es sind in dem Conspectus 330 Arten aufgeführt, eine Zahl, welche nach unserer gegenwärtigen Beurtheilung d r damals bekannten Formen etwas erhöht werden müsste. Bonaparte fasste die Gruppe als Ordnumg auf und zerlegte sie in vier Familien: Psittacidae, Hicroglossidae, Trichoglossidae und Stringopidae. Von diesen enthält die zweite unsere Gattungen Calyptorhynchus und Mlicroglossus, die vierte eine gleichnamige, anch heut in demselben Sinne gebrauchte Gattung, während die dritte dieselbe Begrenzung hat, die wir unserer Familie der Pinselzü̈rgler oder Loris geben. Alle ïbrigen Papageienformen sind der ersten Familie zuertheilt, die in 11 Unterfamilien und 70 Gattungen zerfällt, während die ganze Ordnung 15 Unterfanilien und 83 Gattungen zählt.

Es bedarf nicht des Hinweises, dass die so bunt zusammen- 
gesetzte erste Familie den gegenwärtigen Anschaumngen in keiner Weise entspricht. Auch die Trennung der Gattungen Microglossus und Calyptorhynchus von den Kakadus ist nicht gerechtfertigt, ausserdem hat ein grosser Theil der zahlreichen Gattungen für unsere persönlichen Anschauungen nur subgenerische Bedeutung.

Unstreitig viel schärfere Beurtheilung und richtigere Erkenntniss der Charaktere liegt dem Systeme Gray's zu Grunde, welches in der oben citirten Arbeit enthalten ist. Letztere giebt nicht allein eine systematische Darstellung, sondern für jedle Art die von neuem geprïfte Synonymie und das Vaterland. Wie Wagler's Monographia Psittacorum die erste 27jährige Epoche abschloss, so bildet das Gray'sche Werk den Gipfelpunkt des zweiten Zeitabschnittes, welcher wiederum 27 Jahre, von 1832 bis 1859, umfasst. Das Gray'sche System ist das vollkommenste, welches nach Maassgabe der damals und bis auf die neueste Zeit herrschenden Principien erreicht wurde. Gray theilt die Familie der Psittacidae in sechs Unterfamilien: Pezoporinae, Arainae, Loriinae, Psittacinae, Cacatuinae und Stringopinae. Die erste, zweite, dritte, fünfte und sechste Unterfamilie entsprechen den nach unserer Auffassung durchaus natürlichen Grupluen der Plattschweifsittiche, Keilschwanzsittiche, Loris, Kakadus und Eulenpapageien. Die vierte hingegen enthält ein Conglomerat offenbar einander fernstehender Gattungen, wie Chrysotis, Psittucula (einschliesslich Agapomis), Nasiterna u. a. Ein fernerer Mangel ist nach unserer Beurtheilung die Vertheilung der von uns unter Edelpapageien zusammengefassten Gattungen unter drei der genannten Unterfamilien. So wird die Gattung Palacornis zu den Pezoporinae, Eclectus zu den Lorïnae, Tanygnathus zu den Psittacince gestellt. Auf fernere Einzelnheiten näher einzugehen verbietet uns der Raum. Trotz solcher heut als falsch sich erweisender Beurtheilung einzelner Formen, wiederholen wir, ist das Gray'sche System das vollkommenste, welches nach dem damals herrschenden Grundsatze: nach der Summe der einzelnen äusseren Charaktere, unbeachtet der natürlichen Entwickelung und der Verbreitung, die Eintheilung vorzunehmen, erreicht worden ist. Es sei noch erwähnt, dass Gray 380 Papageienarten aufführt, welche in 30 Gattungen eingeordnet sind. Nach der heutigen Kenntniss wïrde diese Zahl um einige 20 vermindert verden müssen. 
Wenden wir uns jetzt zum neuesten dritten Zeitraum, so sehen wir während des Verlaufes der letzten 20 Jahre, nachdem die Arten im grossen und ganzen festgestellt sind, ebenfalls das Bestreben vorzüglich auf Verbesserung des Systems gerichtet. Eine Verbesserung komnte nur durch Anwendung neuer Prinzipien crzielt werden, durch eingehendere Berücksichtigung der inzwischen genauer erforschten anatomischen Merkmale und ganz besonders durch den Versuch der Darstellung einer Entwickelungsgeschichte der Papageien, wofür in der geographischen Verbreitung ein wichtiger Anhalt sich bietet.

Der neuesten Zeit verdanken wir zunächst das umfassendste Werk, welches über die Papageien gearbeitet wurde, das von Finsch in den Jahren 1867 und 1868 in zwei Bänden herausgegebene Buch: „Die Papageien." Mit grossem Fleisse ist in diesem Werke ein ausserordentlich reiches Material gesammelt und besprochen. Alle :ilteren Arbeiten sind sorgfältig benutzt, so dass man in dem Buche eigentlich alles vereinigt findet, was bis zu jener Zeit über Papageien geschrieben wurde. Wenn wir aber in dieser Hinsicht dem genannten Werke unsere vollste Anerkennung zu Theil werden lassen, so können wir andererseits nicht unterlassen zu rügen, dass man in der Arbeit die sehliessliche kritische Ueberarbeitung des umfangreichen Materials, die üherisichtliche Darstellung vermisst, wodurch die Benutzung des Buches behufs Orientirung sehr erschwert ist. Wer ein eingehendes Studium den Papageien zuwendet, dem bietet Finsch's Papageienwerk ein nicht hoch genug zu schïtzendes Naterial für weitere Speculationen und erspart durch zahlreiche Citate und Excerpte das zeitraubende Durchsuchen der älteren Literatur; aber derjenige, welcher sich informiren will, ohne selbst zu prïfen, der eine fertige Ansicht vorfinden will, um sie zu der seinigen zu machen, wird nicht befriedigt. Für das System enthält das Finsch'sche Werk keine Verbesserung oder Vervollkommnung.

Im wesentlichen ist das Gray'sche System beibehalten; die als Familie aufgefasste Gruppe wird. in fünf Unterfamilien: Stringopinae, Plictolophinae, Sittacinae, Psittacinae und Trichoglossinae eingetheilt. Die erste, zweite, vicrte und fünfte Unterfamilie entsprechen ungefïhr den Stringopinue, Cacutuinae, Psittacinae mal Lomionae Gray's. In der dritten sind die 
Pexoporince und Araince Gray's zusammengezogen, was wir entschieden als Fehler bezeichnen mïssen, da diese beiden Gruppen bis auf wenige fremdartige Formen, welche Gray der ersten zuertheilte, sehr natürliche sind. Ausser dieser Zusammenziehung sind noch folgende bedeutendere Veränderungen vorgenommen, welche wir sämmtlich eher für cinen Rückschritt, denn Verbesserung halten: Die Einordnung der Gattungen Callipsittucus und Nasiterna unter die Plictolophinae, von Eclectus und Dasyptilus unter die Psittacinae, von Nestor unter die Trichoglossinae, die Vereinigung der von Gray getrennten Gattung Tunygnathes mit Eclectus, von Prionitumes mit Pionias u. a. Im Ganzen hat Finsch 350 Arten beschrieben, welche in 26 Gattungen eingetheilt sind. Während die von Gray aufgestellte Zahl als zu hoch für die damalige Zeit bezeichnet werden muss, ist diese offenbar zu nierlrig, da der Autor manche gut charakterisirte Arten als Varietïten zusammengezogen hat.

Von grosser Wichtigkeit fiir die Systematik sind die in nenester Zeit namentlich von Garlod, Alphonse MilneEdwards und W. A. Forbes ansgeführten anatomischen Untersuchungen, obwohl dic hieraus resultirenden systematischen Kennzeichen nicht die Bedeutung beanspruchen können, welche der zuerst genannte Forscher denselben beigelegt hat. Das von Garrod auf Grund anatomischer Merkmale aufgestellte System der Papageien (Proc. Zool. Soc. 1874, p. 584 ff.) leidet an dem Fehler aller einseitig auf Grund eines einzelnen Merkmals vorgenommener Eintheilungen. Die natürlichen Gruppen werden zum Theil vollständig zerrissen. Als selbstständiges System hat diese Aufstellung keine Bedeutung, wohl aber ist sie mit Vortheil für eine natürliche Gruppirung zu benutzen. Eine solche Verwerthung ist in der That bald erfolgt in der nenesten systematischen Arbeit, in Wallace's System der Papageien (Die geogr. Verbreitung der Thiere. Deutsche Ausgabe, 1876, Bd. II, p. 362). Wie oben erwähnt, war ein Fortschritt in der Classification nur durch Veränderung des befolgten Prinzips zu erzielen und ist von Wallace damit elreicht worden, dass er die geographische Verbreitung in erster Linie in Betracht zog, wodurch er zu der Darstellung der natürlichen Entwickelung und zur Abgrenzung natürlicher Gruppen gelangte. Wallace theilt die Ordnung in 8 Familien, welche wiederum in 53 Gattungen zerfallen. 
Zum ersten Male ist in diesem Systeme die natürliche Familie der Pulaeornithidae richtig erkamnt und wurden in derselben die in verschiedenen Familien zerstreuten Formen gesammelt.

Hierin liegt ganz besonders der Vorzug der Wallace'schen Eintheilung vor dem Gray'schen System. Dic aufgestellten Familien sind: Cacatuidae, Platycercidae, Palacomithidae, Trichoglossidue, Comuridae, Psittacidae, Nestoridae und Stringopidae. Die erste, zweite, vierte, siebente und achte enthalten nur australische Papageien, die dritte solche der westaustralischen und orientalischen Region, die fünfte amerikanische, in der sechsten sind die afrikanischen mit amerikanischen vereinigt.

Als jüngste Erscheinung in der Geschichte der PapageienLiteratur haben wir schliesslich unsere "Vogelbilder aus fernen Zonen“, I. Theil: Papageien (Th. Fischer, Cassel) zu erwähnen, eimen Atlas in Folio-Format, welcher auf den einzelnen Tafeln die Papageienarten in Gruplen der verwandten Formen oder Heimathsgenossen darstellt. Nach Aquarellen von G. Mützel sind die Abbildungen in Farbendruck ausgeführt und von einem kurzen, dic Charaktere kennzeichnenden Text begleitet. Zur Zeit noch in Erscheinen begriffen, wird dieser Atlas im Laufe dieses Jahres voraussichtlich zum Abschluss kommen.

In der folgenten Arbeit haben wir uns hinsichtlich des befolgten Systems auf Grund der eingehendsten Untersuchungen im Wesentlichen auf Wallace's Anordnung gestützt. Es schien uns aber nothwendig, einige der afrikanischen Formen von den Amerikanern, sowie die kleinsten Neu Guinea-Papageien als selbstständige Familien zu sondern, während wir die Trennung der Nestorpapageien von den Kakadus für nicht unbedingt geboten erachten, obwohl wir solche als durch Gründe wohl gerechtfertigt anerkennen. Hinsichtlich der Gattungen ist Wallace weniger kritisch verfahren und haben deshalb in unserer Arbeit wesentliche Aenderungen Platz gefunden, wie auch die Begrenzung der Familien im Einzelnen nirgends dieselbe geblieben ist. Die Entwickelung der Papageien, welche in unserem Systeme zum Ausdluck kommen soll, ist auf dem beigefügten Schema dargestellt.

Zur Erläuterung sei folgendes bemerkt:

Der Heert des Papageien - Lebens ist die australische 
Region*) und zwar jener untergegangene Erdtheil, dessen Reste wir heute noch in den Polynesischen Inseln, ganz besonders aber in Neu Guinea erblicken und zu welchem wir auch Neu-Seeland zı zählen haben, von wo aus dann der später entstandene Continent Australien bevölkert wurde. Ein Beweis für die Wahrscheinlichkeit dieser Annahme liegt darin, dass noch heut in der australischen Region Formen existiren, welche wir entschieden zu den niedrigst stehenden Papageien zu zählen haben, ein anderes Argument bildet die grosse Mannigfaltigkeit des Papageienlebens der australischen Region und endlich sind gegenwärtig noch die Spuren zu verfolgen, welche die Verbreitung der Papageien allmälig von Australien aus nach Westen zu bis Amerika genommen hat.

Als die ältesten Papageien betrachten wir die Eulenpapageien (Stringopidae), welche heut noch durch vier Formen auf NeuSeeland und in Sür-Australien vertreten sind. Von diesen leiten wir zunïchst die Kakadus (Plissulophidae) ab, welche durch die Nestorpapageien den Stringopidae sich anschliessen. Als ein anderer Zweig entstanden aus Formen, welche dem jetzigen Erdsittich (Pezoporus) ähnlich gewesen sind, die Plattschweifsittiche. Beide Familien der Kakadus und Plattschweifsittiche sind ausschliesslich australisch, sind bezeichnend für die australische Region. Kein Kakadu, kein Plattschweifsittich geht über die Westgrenze der australischen Region, welche durch die Philippinen, Celebes und Sumbawa gebildet wird, die also ungefähr der $241^{\circ}$ ö. L. (Gr.) bezeichnet, hinaus, keine Art verbreitet sich auf die so nahe gelegenen, zur orientalischen Region gehörenden Sundainseln, Borneo, Java, Sumatra, während hingegen jeder Theil der Region Vertreter dieser Familien aufzuweisen hat. An die Plattschweifsittiche lehnt eine kleine Gruppe zwerghafter Formen sich an, welche nur eine lokale Verbreitung haben, die Neu-Guinea und den nahe gelegenen Inseln angehörenden Zwergpapageien (Micropsittacidae). Als eine fermere Entwickelungsstufe der Plattschweifsittiche sind die Loris (Trichoglossidae) anzusehen, welche mit ersteren noch heut so eng verbunden sind, dass man hinsichtlich der Zugehörigkeit einer Form

*) Nicht Amerika, wie von anderen Autoren angenommen und auch vor diesen Untersuchungen ron uns an anderer Stelle acceptirt war. 
(Nanodes) zu der einen oder anderen Familie bis auf den heutigen Tag zweifelhaft gewesen ist und mit Grund noch gegenwärtig streiten darf. Auch die Loris gehören in ihren Hauptformen der australischen Region an, der sie entsprossen, aber mehrfach überschreiten Ausläufer der Familie die Westgrenze und verbreiten sich über die orientalische Region.

Als eine dritte Abzweigung von der Familie der Plattschweifsittiche haben wir ferner die Edelpapageien (Pulaeomithidae) anzusehen. Auch deren Heimath ist die australische Region, aber nur der westliche Theil, Neu-Guinea und die nahe gelegenen kleineren Inseln. Von hier aus haben sie sich ïber die Sundainseln und auf das Festland Asien, über den ganzen tropischen Theil der orientalischen Region verbreitet und bilden die für Asien bezeichnende Papageiengruppe. Diese Ausbreitung über Asien hat jedenfalls zu einer Zeit stattgefunden, als noch ein Zusammenhang zwischen den Mascarenen, Madagascar und Indien bezüglich den Sundainseln bestand, denn auch auf den Mascarenen existiren Arten dieser Familie, die zum Theil in neuerer Zeit ausgestorben sind. Das Vorkommen eines Edelsittichs in Afrika ist zweifellos auf eine künstliche Einführung seitens des Menschen zurückzuführen, wofür auch die lokale Verbreitung spricht. In neuester Zeit ist dieselbe schon in sehr früher Zeit und noch jetzt läufig von Indien nach Europa gefangen importirte Art nach Südafrika gebracht. Entflohene Gefangene haben unter den zusagenden Verhältnissen sich acclimatisirt und werden bald im Süden des Erdtheiles eine ähnliche Ausdehnung quer durch den Kontinent erreichen, wie dieselbe Art sie im Norden bereits lange inne hat. Als vierter Zweig endlich schliesst den Plattschweifsittichen die kleine Gruppe der Graupapageien sich an, welche in Australien keinen Vertreter mehr besitzen, sondern den Ueberresten des jetzt unter den Spiegel des indischen Oceans versunkenen Erdtheils Lemurien, Madagascas und den Mascarenen angehören, von wo aus die höchststehenden Formen, die kurzschwänzigen Graupapageien, über den Continent Afrika sich ausdehnten. Die langschwänzigen Graupapageien, die VazaPapageien, stehen den Plattschweifsittichen so nahe, dass Gray sie mit letzterer Familie vereinigte. Es ist uns aber noch eine, jetzt ausgestorbene Form bekant geworden, welche noch inniger die Verbindung herstellte und gewissermassen den Knotenpunkt 
der Vereinigung von Plattschweifsittichen, Edelpapageien und Graupapageien bildete, der Mascarenensittich (Mascarinus Duboisi). Hiermit haben wir die Skizze der Verbreitung der Papageien in der östlichen Halbkugel vollendet. Ebenso wie hier die Ausclehnung allmälig von der australischen Region aus über die westlichen Theile vor sich gegangen ist, so schliessen auch die Papageienformen der westlichen Halbkugel eng an die typischen australischen sich an. Für die östlichen Formen bildete die Familie der Plattschweifsittiche die Basis, für die westlichen ist es die andere der Kakadus.

Ein auf Neu-Guinea lebender schwarzer Kakadu, der Microglossus aterrimus, zeigt einen so deutlichen Uebergang von den Kakadus zu den Araras Amerikas, dass er sehr passend mit dem Namen Ararakakadu belegt wurde. Aber auch in diesem Falle zeigt sich recht klar, wie durch Aussterben der Zwischenformen einzelne zusammenhängende Gruppen unter’ brochen, von einander getrennt wurden. Durch glïckliche Umstände sind uns die wohlerhaltenen Reste einer längst ausgestorbenen Papageienform bewahrt worlen, welche Madagascar bewohnte, die nach den Untersuchungen Milne-Edwards zwischen dem IFicroglossus Australiens und der amerikanischen Gattung Sittace steht. Nicht allein dass durch diese Form eine enge Verbindung der Kakadus und Keilschwanzsittiche hergestellt wird, so zeigt uns das Vorkommen jener ausgestorbenen Art, der auf Mauritius gefundene Schopfarara (Lophopsittacus mauritianus), den Weg, welchen die allmälig von den Kakadus zu den Araras übergehenden Formen genommen, der von Australien durch Lemurien nach Amerika führte. Die Araras bilden somit die Grundform der amerikanischen Papageien und in der That können wir an diese Gruppe in fortlaufender ununterbrochener Reihe die übrigen Keilschwanzsittiche und endlich als eine höhere Entwickelungsstufe der letzteren die Kurzschwanzpapageien anschliessen.

Es ergiebt sich aus diesen Reflexionen, dass nur in Australien Papageien als Urbewohner vorkommen, dass aber die in Amerika eingewanderten Formen entwickelungsfïhig gewesen, zu mannigfacher und höherer Abänderung und Ausbildung gelangten, so dass wir gegenwïrtig zwei Reihen, australische und amerikanische Formen besitzen, dass aber die jetzt Asien und Afrika dürftig 
bevölkernden Papageien Abkömmlinge dieser beiden Reihen sind, welche wohl specifische Abänderungen erzeugten, aber nicht einer weiteren Entwickelung und höheren Vervollkommnung fähig waren.

Wir haben im Vorstehenden nur in kurzen Zügen die vermuthliche Entwickelung der Papageien angedeutet. Dass dieser erste Versuch, den Stammbaum der Papageienordnung darzustellen, in Zukunft viele Berichtigungen erfahren wird, davon kann niemand mehr als der Verfasser überzeugt sein. Wie immer der Zweck der Hypothese, so ist anch hier unsere $A b$ sicht, einen neuen Weg der Forschung zur Ergründung der Wahrheit anzubahnen.

In nachfolgender Uebersicht sind zwischen 430 und 440 Papageienformen beschrieben. Da zur Zeit die Publikation einiger neuer Formen noch bevorsteht, welche während des Druckes dieser Arbeit zu erwarten ist und in derselben benutzt wird, so beschränken wir uns hier auf die Angabe der ungefähren Zahl. Von diesen sind uns nur ungefïhr 50 Arten nicht durch Autopsic bekannt geworden. Drei Viertheile der Gasammtzahl besitzt das Berliner Museum, die diesem Institute fehlenden Neu-Guinea-Formen konnten wir Dank dem freundlichen Entgegenkommen des Herrn Hofrath Dr. Meyer im Dresdener Museum untersuchen, mit einzelnen Arten machten uns die so ausserordentlich reichhaltigen Ausstellungen des Deutschen Vereins für Vogelzucht und Acclimatisation in Berlin bekannt, welche auch, ebenso wie die Papageiensammlungen der zoologischen Gürten von Berlin und Dresden, Gelegenheit boten, die Farben der nackten Körpertheile und Augen zu notiren.

Hinsichtlich des Systems und der Nomenclatur sind wir in dieser Arbeit denselben Grundsätzen gefolgt, welche bei Bearbeitung der Ordnung "Gressores" (Journ. f. Ornithologie 1877) massgebend gewesen sind.

Bei der grossen Wichtigkeit, welche die praktische Vogelkunde, die Vogelpflege, für die wissenschaftliche Ornithologia erlangt hat, welche namentlich die zoologischen Gürten als Bildungsanstalten für weitere Kreise ebensowohl wie als Studienstätten für die Untersuchungen und Beobachtungen der Gelehrten beanspruchen, die in ersterer Hinsicht die Museen bereits überholt, in letzterer mehr und mehr den gleichen Rang erreichen, 
schien es geeignet, die nachfolgende Uebersicht durch Einfügung der deutschen, englischen und französischen Art-Namen für die Zwecke des Vogelwirthes und für den praktischen Gebrauch nutzbarer zu machen. Sie dïrfte somit eine willkommene Ergänzung zu Brehm's „Gefangene Vögel" (Band I, 2. Abschn., Sittiche oder Papageien) sein, welches Werk für die Pflege gefangener Papageien ausfiihrliche Anleitung giebt und in dieser Hinsicht das einzige empfehlenswerthe Handbuch ist.

Am 1. Januar 1881.

\section{Ordo: Psittaci. Papageien.}

Die Orduung der Papageien hat ihre systematische Stellung im Centrum der Entwickelungsreihe der Vögel und schliesst zunächst an die Ordnung der Raubvögel sich an. Sie ist, wie bereits oben erörtert, in neun Familien zu zerlegen, welche wiederum in 48 Gattungen zerfallen.

Von den plastischen Merkmalen, welche für die Unterscheidung der Familien und Gattungen von Wichtigkeit sind, ist in erster Linie die Form der Wachshaut zu berïcksichtigen, deren Bedeutung von früheren Systematikern noch nicht die gebührende Würdigung erfahren hatte. Dieselbe umgiebt bald bandförmig in ziemlich gleicher Breite den Oberkiefer, bald ist sie über der Firste verschmälert, bald läuft sie zum Schnabelrande in eine Spitze aus oder umgiebt nur die Nasenlöcher, nicht nach unten bis zum Schmabelrande sich fortsetzend; bald ist sie nackt, bald mehr oder weniger befiedert. Nächstdem ist die Form des Schwanzes bezeichnend, welcher bald kurz bald lang, gerade, gerundet, keilförmig oder stufig ist, das Schwingenverhältniss im Flügel und die Form des Schnabels, welcher bald seitlich zusammengedrüickt, bald aufgetrieben, höher als lang oder länger als hoch, bald mit Zahn versehen, bald ohne Spitzenauskerbung ist, dessen Dillenkante in gerader Linie oder bogig aufsteigt und dessen Oberschnabel-Spitze auf der Unterseite glatt oder mit Feilkerben versehen ist, welche dazu dienen, den Unterschnabel zu schïrfen und stets bei denjenigen Formen vorkommen, welche hartschalige Sämereien zur Nahrung wählen, dagegen denjenigen fehlen, welche weiche Früchte, Beeren und 
Blüthenhonig verzehren. Endlich besteht noch in der Bildung der Zunge, welche weich ist oder einen hornigen Ueberzug hat oder mit Papillen besetzt ist, ein wichtiges Unterscheidungsmerkmal. Mit Ausnahme Europas bewohnen die jetzt bekannten 430 bis 440 Papageienarten alle Erdtheile. Die Tropen sind das eigentliche Wohngebiet, welches jedoch nach Süden von vielen Arten iiberschritten wird. Im Norden bildet der nördliche Wendekreis die ungeführe Grenze der Verbreitung, im Süden (lagegen erst der 45. Breitengrad; einzelne Arten gehen im Norden bis zum 40., im Sürlen bis zum 55. Breitengrad. - Die Hälfte aller bekannten Papageienformen ist bereits lebend in Gefangenschaft nach Europa gebracht worden, mit verhältnissmässig wenigen Arten hingegen erst die Züchtung gelungen.

\section{Familie: Stringopidae. Eulenpapageien.}

Charakter der Familie: Nachtvögel mit weichem Gefieder. Schnabel dick, seitlich aufgetrieben, ohne Zahn, Spitze mit Feilkerben versehen. Dille gerundet, mit einer oder mehreren Leisten. Nasenlöcher in einer wulstig anfgetriebenen Wachshaut liegend; letztere nur die Nasenlöcher umgebend und sich nicht bis zur Schmabelschneide fortsetzend. Färbung grün, schwarz und gelb gebändert und marmorirt.

Gegenwärtig sind nur noch vier Arten der früher jedenfalls artenreicheren Familie bekannt und diese haben wir als Repräsentanten dreier verschiedener Gattungen aufzufassen. Sie bewohnen die Neuseeländische und Australische Subregion.

Die beiden Gattungen Stringops und Geopsittacus sind neben den genannten Merkmalen durch ihre gedrungene plumpe Gestalt und dicke Köpfe, sowie den kurzen Schwanz, welcher bedeutend kürzer ist als die Flügel, charakteristisch genugsam ausgezeichnet, so dass kein Zweifel entstehen kann, ob diese Formen etwa einer anderen Papageienfamilie zuzuzählen seien. Die Gattung Pezoporus dagegen weicht durch ihre schlankere Gestalt und den längeren Schwanz bedeutend ab und nähert sich den Plattschweifsittichen, mit denen ja auch die Bildung der Wachshaut übereinstimmt, so dass sie dieser Familie häufig zugestellt ist. Das Gefieder indessen, der Fürbungscharakter und die Lebensweise, obwohl eine weniger nächtliche, lassen 
uns diese Form zu den Stringopiden stellen, von welchen sic den Uebergang zu den Plattschweifsitti hen bildet.

In den entlegenen Alpenthälern Neuseelands führt der Eulenpapagei seine nächtliche Lebensweise. Er bewohnt trockene Abhänge von Hügeln und Waldstellen, wo die Bäume hochstämmig sind und der Boden frei von Farren und wucherndem Unterholz. Obgleich die Flügel wohl ausgebildet sind, benutzt sie der Vogel selten und legt nur kurze Strecken fliegend zurïck. Selten zeigt er sich auf Büumen, in der Regel auf dem Boden, wo er sich mit grosser Gewandtheit bewegt. In Höhlungen unter Gewurzel der Bäume und in Felslöchern hat er seine Herberge und sucht auf dem Boden, an niedrigem Gestrïpp seine Nahrung, die in Beeren, Wurzeln, Moos und Pflänzchen besteht. Er nistet in Höhlungen unter Baumwurzeln und legt in der Regel zwei Eier.

Im Allgemeinen der Lebensweise des Eulenpapagei ähnlich scheint die des Geopsittacus occidentalis zu sein, doch fehlen zur Zeit eingehendere Beobachtungen.

In mancher Beziehung verschieden ist das Betragen des Erdsittichs (Pezoporus).

Noch mehr als die genannten ist er als Erdvogel durch die langen, geraden Nägel der Hinterzehe gekennzeichnet. Unfruchtbare, sandige Gege -den, welche mit niedrigen Gräsern und Kräutern bestanden sind, Moorland, das von kurzen Binsen bedeckt wird, bilden seine Aufenthaltsorte. Hier läuft er mit grosser Schnelligkeit umher. Aufgeschreckt benutzt er die Flügel und fliegt dann reissend schnell über den Boden hin, führt wie eine Schnepfe Zickzackwendungen in der Luft aus, fällt aber bald wieder ein und rennt dann eiligst weiter. Er britet nicht in Höhlungen, sondern legt seine Eier frei auf den nackten Boden.

Genus: STRINGOPS. Eulenpapagei.

Strigops (1845) G. R. Gray Gen. Birds Pt. II, t. 105 f. 3 und (1847) Proc. Zool. Soc. p. 62 (Typus: Strigops habroptilus Gray). - Stringopsis (1852-1856) von der Hoeven Handbuch der Zoologie (Deutsche Ausgabe) I, p. 466. - Stringops (1867) Luchs, Finsch's Papageien I, p. 241.

Charakter der Gattung: Federn des Gesichtes lang und starr, einen Schleier bildend. Flügel kurz, gerundet; vierte und 
fünfte orler vierte bis sechste Schwinge am längsten, erste etwa gleich der neunten; Dillenkante des Unterkiefers mit vier senkrechten Rinnen verschen, welche durch fünf hervortretende Leisten gebildet werden. Schwanz kurz, gerundet, dic Federn am Ende zugespitzt. Zehen-Nägel mässig lang, etwas gestreckt. Zwei Arten, die auf Neuseeland leben.

\section{Stringops habroptilus. - Eulenpapagei.}

Kakapo. - Englisch: Night-Parrot. - Französisch: Perroquet de nuit.

Stringops habroptilus (1845) G. R. Gray Gen. Birds II, t. 105, f. 3 und (1847) G. R. Gray, Proc. Z. S. p. 62.

Abbildungen: Gould, Birds of Austral. Suppl. - G. R. Gray Gen. Birds pl. 105. - Reichenow, Vogelbilder aus fernen Zonen t. 18, f. 7 .

Diagnose: Olivaceo-viridis, fusco et flavido-fasciolatus et undulatus, gastraco flavescente; fronte et capitis lateribus olivaceofulvis; rectricibus olivaceo-flavis fusco-fasciolatis; remigibus fuscis olivaceo-flavo fasciatis; rostro albido; pedibus et iride brunneis. Long. c. 550, ala 250, cauda 210, culmen $46 \mathrm{Mm}$.

Pull: plumulis cinereo-brunneis.

Vorkommen: Neuseeländische Subregion (Westseite der Alpen des sïdlichen Neu-Seeland, Chatam Inseln).

\section{Stringops Greyi. - Grey's Eulenpapagei.}

Englisch: Grey's Ow1-Parrot.

Strigops Greyii (1862) G. R. Gray, Ibis p. 230.

Abbildung fehlt.

Diagnose: String. harboptilo similis sed notaeo coerulescente (limbis apicalibus plumarum latis thalassinis); gastraeo pallidiore; fronte et capitis lateribus fulvescente albidis.

Torkommen: Neuscelïndische Subregion (Nördliches NeuSeeland). [Ausgestorben!?].

Genus: GEOPSTTTACUS. Höhlenpapagei.

Geopsittacus (1861) Gould Proc. Zool. Soc. p. 100 (Typus: G. occidentalis Gould).

Charakter der Gattung: Durch einen unverhältnissmässig dicken Kopf ausgezeichnet. Ganzer Körper kurz und gedrungen. Schwanzfederu kurz, am Ende zugespitzt, die äussersten stufig abnehmend, 
die mittelsten gleich lang. Nägel sehr kurz.*) — sine Art in Australien.

3. Geopsittacus occidentalis. - Höhlenpapagei.

Englisch: Western Ground-Parrakeet. - Französisch: Pezopore occidental.

Geopsittacus occidentalis (1861) Gould P. Z. S. p. 100.

Abbildung: Gould Birds of Australia Suppl.

Diagnose: Viridis, pileo nigro-striolato, notaeo et alis nigro et flavido-maculatis, gutture flavescente striis et guttis nigris sparsim notato; abdomine unicolore flavo; rectricibus mediis olivascente fuscis maculis marginalibus flavis, externis olivascente fusco- et flavo-fasciolatis; rostro fusco; pedibus carneis.

Long. c. 260, ala 140, cauda 125, culmen $13 \mathrm{Mm}$.

Vorkommen: Australische Subregion (Süd- und WestAustralien).

Genus: PEZOPORUS. Erdsittich.

Pezoporus (1811) Illig. Prodr. mam. et av. p. 201. (Typus: Psittacus formosus Lath.)

Charakter der Gattung: Flïgel lang und spitz, zweite und dritte Schwinge am längsten, erste gleich der vierten und wenig kürzer als die längsten; Schwanz lang, stufig, die Federn allmälig scharf zugespitzt, Dille des Unterkiefers $n^{*}$ t einer Mittelleiste. Zehennägel lang und gestreckt. - Eine Art in Australien.

4. Pezoporus formosus. - Erdsittich.

Englisch: Ground Parrakeet. - Französisch: Pezopore terrestre, Perruche ingambe.

Psittecus formosus (1790) Lath. Ind. Ornith. I, p. 103. Psittacus terrestris (1792) Shaw Lev. Mus. p. 217, t. 53. Perruche ingambe (1801-1805) Levaillant Hist. Nat. Perr. pl. 32.

Abbildungen: Shaw Gen. Zool. VIII, pl. 66. - Gould Birds of Austral. V, pl. 46. - Jard. and Selby Nat. Libr. V, pl. 29. Levaillant Hist. Nat. Perr. pl. 32. -- Reichenow Vogelbilder t. 14, f. 8 .

Diagnose: Viridis, pileo nigro-striolato, notaeo et alis nigroet Havo-maculatis, gutture striis et guttis nigris sparsim notato;

*) Obiges entnehme ich der Beschreibung Gould's, da ich die interessante Form nicht selbst untersuchen konnte. Die dicke, gedrungene Gestalt, die langen Flügel bei verhältnissmässig kurzem Schwanze und die kurzen Nägel rechtfertigen durchaus die generische Trennung von Pezoporus.

A. R. 
abrlomine siigro- et flavo-transversim fasciolato; fronte miniato; "emigibus fuscis, pogonio interno macula flavescente-alba, externo flavida notatis; rectricibus mediis obscure viridibus plus minusve conspicue flavido-fasciolatis; rectricibus exterioribus pogonio interno flavo- et fusco-, externo flavo- et viridi-fasciolatis; iride et rostro fuscis; pedibus carneis.

Long. c. 310 , ala 120 , cauda 185 , culmen $14 \mathrm{Mm}$.

Juv. fascia frontali miniata nulla.

Vorkommen: Australische Subregion (Süd- u. West-Australien, Van Diemensland, Inseln der Bass-Strasse).

\section{Familie: Plissolophidae. Kakadus.}

Charakter der Familie: Schnabel stark, mehr oder weniger seitlich zusammengedrïckt, in der Regel mit starker Auskerbung vor der Spitze (Ausnahmen: Nestor und Licmetis), mit gerundeter, bisweilen mit einer Längsrinne versehener oder scharfer Firste und mit abgeplatteter, bisweilen mit einer Mittelleiste versehener Dille, die in der Regel bogenförmig gekrümmt ist und ausgekerbte Schneide hat, seltener (Nestor) in fast gerader Linie ansteigt und gerale Schneide zeigt. Die bald nackte, bald befiederte Wachshaut umgiebt bandförmig die ganze Basis des Oberkiefers, ist, aber auf rer Firste stark eingezogen und schmal (mit Ausnahme von Nestor, wo sie auf der Firste etwa ebenso breit als auf den Schmabelseiten ist und vor den Nasenlöchern bogig hervortritt). Im Flügel dritte und vierte Schwinge am längsten, zweite gleich der fünften und nur wenig kürzer als die längsten, erste ungefähr gleich der sechsten (eine Ausnahme in der Flügelbildung macht nur Microglossus, bei welchem vierte und fünfte Schwinge am längsten sind, vergl. unten). Schwanz kurz oder lang, gerade oder gerundet, aber niemals stufig oder keilförmig. Federn des Kopfes in der Regel zu einer Haube verlüngert (Ausnahme: Nestor). Vorherrschende Färbung weiss, schwarz oder braun (Nestor). Die weisse Färbung kommt bei keiner anderen Papageienfamilie wieder vor, die schwarze noch vereinzelt bei Chalcopsittacus und nuancirt bei Coracopsis. Schnabelfürbung schwärzlich oder weisslich. Die Weibchen sind wie die Männchen gefärbt und unterscheiden sich nur durch etwas geringere Grösse und kürzere Federhaube. Alle Arten sind grosse, 
starkf; Vögel von Taubengrösse und darüber, von gedrungener, kräftiger Gestalt mit dicken Küpfen. Die Familie umfasst fünf Gattungen mit 32 Arten, welche die Australische, Austromalayische und Indomalayische Subregion bewohnen. Dic abweichende Gattung Nestor bevölkert hingegen noch dic Neuscelïndische Subregion.

Bezeichnend für die Kakadus ist vorzüglich an Schnabel die starke Auskerbung vor der Spitze, die ausgekerbte DillenSchneide und die auf der Firste stark eingezogene, sonst ziemlich gleich breite Wachshaut. Eine ähnliche Schnabelhildung zeigen nur die Gattungen Calopsittacus, Hicropsittacus und Cyclopsittacus, alle drei weichen abcr durch die Bildung der Wachshaut $a b$, welche der typischen Form der Plattschweifsittiche oder der Edelpapageien entspricht und sind kleine, sogar zwerghafte Formen. Die Gattung Licmetis, welche durch eine gestrecktere Schnabelform mit entsprechend schwacher Zahnauskerbung abweicht, zeigt auch die charakteristische Bildung der Wachshaut. Viel abweichender ist hingegen die Gattung Nestor. Die grossen Unterschiede der Schnabel- und Wachshautbildung und die bedeutenden Verschiedenheiten des Scelettes im Vergleich zu den typischen Kakadus würden eine Abtrennung dieser Vögel als Familie durchaus rechtfertigen. Jedenfalls zeigen sie aher einen Anschluss an die Plissolophidae, insbesondere an dic Grattung Licmetis. Wir fassen die Gattung als Wurzel des KakaduStammes auf und vereinigen sie deshall) auch mit dieser Familie.

Die Kakadus sind sehr gesellige Vögel. Sie vereinigen sich nicht nur während der Führung ilırer Jungen zu grösseren Schaaren, die gemeinsam auf den höchsten Büumen des Urwaldes Nachtruhe halten und vereint auf die Nahrungsplätze ziehen, sondern nisten auch in oft grossen Colonien beisammen in hohlen Bäumen oder an Felswänden. Die echten Kakadus, wie die Rabenkakadus, welche letzteren mehr in kleineren Gesellschaften als in grossen Schaaren zusammen leben, bewohnen den Urwald; die Nestoriden gehen hoch in dic Gehirge hinauf bis an die Grenze des höheren Banmwurhses, wo zu Zeiten der Schnee ihren Tisch verhüllt und sie zu grossen Gesellschaften vereint $z u$ Wanderungen zwingt. Eine einsamere Lebensweise führt der Ararakakadu (Microglossus), welcher nur paarweise angetroffen wird. Die Nahrung besteht in Körnern und S:imereien, insbesondere Mais und Früchten, einige nehmen auch Knollen 
und 7wiobeln, die sie geschickt aus der Erde graben (Licmetis), andere bevorzugen Insekten, Raupen und Maden, die sie mit ihrem starken Schnabel aus Rinde und morschem Holze herausschälen (Calyptorhynchus), wieder andere sind geradezu als Raubthiere anzusehen, da sie nicht allein Aas von Wirbelthieren, z. B. Schaafen, angehen, sondern solche sogar überfallen und zerreissen (Nestor). Besondere Vorliebe haben die Nestoriden auch für Pflanzenhonig. Sie nehmen diesen aus den Blüthen odler schälen die Rinde der Bäune an, um den ausfliessenden Saft aufzusaugen. Das Gelege besteht bei den echten Kakadus aus zwei bis drei, bei den Rabenkakadus aus drei bis fünf, bei den Nestorpapageien in der Regel aus vier weissen Eiern.

Zu den Kakadus ist wahrscheinlich auch die ausgestorbene Form Lophopsittacus muritianus von Mauritius zu stellen, welche nach den wenigen Ueberresten, die von derselben bisher gefunden wurden, zunächst an Mirroglossus sich anschliesst und einen noch engeren Uebergang zu den amerikanischen Arten der Gattung Sittace vermittelt.

Genus: NESTOR. Nestorpapageien.

Nestor (1831) Lesson Traité d'Ornithologie p. 190. (Typus: Psittucus Nestor Lath.). - Centrourus (1837) Swains. Classif. Birds II, p. 303. (Typus: Psittacus australis Shaw). - Centrurus (1841) Strickl. Ann. Mag. Nat. History p. 34.

Charakter der Gattung: Schuabel gestreckt, länger als hoch, in der Regel mit deutlichem Zahn vor der Spitze, ohne Feilkerben. Wachshaut nackt, üher der Firste ungefülı ebenso breit als auf den Schmabelseiten unter den Nasenlöchern, vor den letzteren bogig hervortretend. Schwanz kurz, wenig länger als die halbe Flügellänge, gerade. Kopffedern nicht verlängert. Die Gattung zerfällt in zwei Untergattungen, Nestor und Dasyptilus.

\section{Subgenus: NESTOR.}

Charakter der Untergattung: Kopf ganz befiedert. Färbung vorherrschend unbestimnt olivenbraun mit gelben und rothen Tönen an einzelnen T'heilen. 6 Arten, welche alle die Neuseeländische Subregion bewohnen, zum Theil, wie es scheint, schon ausgestorben sind.

Wir erblicken in diesen Formen einen Anschluss an den Eulenpapagei und zugleich die Wurzel der Familie der Kakadus. 


\section{Schlüssel der Untergattung:*)}

Oberkopf grau; Torderbauch wie Brust olivenbraun: meridionulis. Breite gelblichweisse Binde auf dem Torderbauche:

[Esslingi.

Oberkopf gelb; Ganzer Kï̈rper gelb und roth gefürbt: s'upertus. Oberkopf olivenbram oder olivengrün wic der Rücken: Kehle gelb; Flügeldecken olivenbraun: productus.

$" \quad \begin{aligned} & \text { Kehle gelb; Flügeldecken olivengrün mit } \\ & \text { schwarzem dreieckigen Spitzenfleck: nor- } \\ & \text { folrensis. }\end{aligned}$
$\quad \begin{aligned} & \text { Kehle olivengrün wie der übrige Körper: } \\ & \text { notabilis. }\end{aligned}$

1. Nestor meridionalis. - Kaka.

Englisch: Kaka-Parrot. - Französisch: Nestor te la Nouvelle Zélande.

Psittacus meridionalis (1788) Gml. S. N. II, p. 333. Psittucus Nestor (1790) Lath. Ind. Ornith. I, p. 110. -- Psittacus anstratis (1792) Shaw Lev. Ius. 1. 87. - Nestor Norde Zelandice (1831) Less. Traité d"Ornitlı. p. 191. - Vestor Tępropolius (1832) [Forst.] Wagl. Mon. Ps. p. 505 und 696.

Abbildungen: Bourjot St. Hilaire, Hist. Nat. Purr. j)l. 68. Jard. and Selhy Nat. Libr. vol. YT, pl. 12. - Grould Birds of Austral. Suppl. - Reichenow, Vogelbilder t. 18, f. 3.

Diagnose: Olivascente fuscus, plumis simgulis obsente limbatis; pileo albescente cinereo; ablomine, mopyrio, tectricibus superioribus, fascia tenui auchenii et rostri basis plumarum rigidarum apicibus sanguineis; auricularibus fulvis: rectricilus subtus pogonii interni basi rubris; remigibus pogonio interno dilute miniato-fasciatis: subalaribus miniato- vel coccinco- et fusco-trausversim fasciolatis: rostro et pedilus nigricantilus; iride fusca. Long. c. 500, ala 290, ciutla 170, rostrum 53 Mm.

Juv. fascia auchenii fulva.

Vorkommen: Westliche Theile der Gebirge Neuseclands.

2. Nestor superbus. - Pracht-Nestor.

Englisch: Mountain-Kaka.

Nestor superbus (1865) Buller Essay on the Ornith. of $\mathrm{X}$. Zealand p. 11.

Abbildung fehlt.

*) Zum schnellen Auffinden der Arten nach den auffallendsten FarbenCharakteren. 
Diagnose: Pileo, cervice, interscapulio et scapularibus, pectore et alarum tectricilus superioribus luteis, coceineo-imbutis; tergo, uropygio et supracaudalibus, guli, capitis lateribus, fascia auchenii et ablomine coceineis; alis albirlo-flavis, canda cinereo-flava; remigihns pogonio interno maculis luteis et coccineis; rectricibus pogonio interno rubris (teste Finsch).

Torkommen: Die höehsten Gebirgslïnder Neu Seclands.

3. Nestor Esslingi, - Weissbinden-Nestor.

Englisch: Prince of Essling's Parrot. Essings's Brown Parrot. Französisch: Nestor à bandeau blanc.

Nestor Esstineti (1856) Souancé Iiev. Mag. Zool. No. 2, p. 223.

Abhildungen: (iould Lirds of Austral. Suppl. - Reichenow Vogelbilder t. 18 , f. 5.

Diagnose: N. meridimeli similis sed epigastrio flavido-albo; pectoris plumis cinereis fusco-limbatis, genis et regione parotica luteis, inferius miniatis (teste Gould).

Vorkommen: Neuseeland.

4. Nestor productus. - D ïnnschnabel-Nestor.

Englisch: Philip Island Parrot. - Französisch; Nestor au bec allongé.

Plyctuluplere piotluctus (1836) Gould, Proc. Z. S. IV, p. 19.

Ahbihmen: Imongt St. Hilaire, Hist. Nat. Perr. pl. 69. -

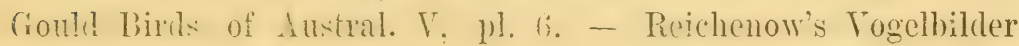
t. 18 , f. 6 .

Diagnose: Totaco olivaceo-fusco: mopygio, ventre et subcaudalibus rubris; capitis lateribus, gula et subalaribus miniatis; pectore et epigastrio ochuareis: reminibus et rectricibus pogonio interno maculis pallirle rubris: rostro et pedibus nigricantibus; iride fusca (teste Gould).

Vorkommen: Philipıs Inseln (nörollich von Nell-Seeland), ausgestorben.

5. Nestor norfolcensis. - Norfolk-Nestor.

Englisch: Norfolk-Island Parrot.

Nestor norfolecusis (1860) v. Pelz. Sitzungsbericht K. K. Ac. Wiss. Bd. XLI, p. 322.

Abbildung fehlt.

I) iagnose: N. producto similis sed pileo et cervice viridibus; interscapulio et alarum tectricibus olivaceo-viridi?us, his maculis apicalibus triangulis nigris notatis; genis flavis (t. v. Pelzeln). 
Vorkommen: Norfolk-Inseln (Ausgestorben).

6. Nestor notabilis. - Kea.

Englisch: Kea-Parrot, Notable Parrot. - Französisch: Nestor olivâtre.

Nestor notabilis (1856) Gould P. Z. S. XXIV, p. 94.

Abbildungen: Gould Birds of Austral. Suppl. - Reichenow Vogelbilder t. 18 , f. 4.

Diagnose: Olivaceo-viridis, plumis singulis nigro-limbatis; uropygio et subalaribus dilute coccineis; remigibus nigris, pogonio externo thalassino-imbutis, interno flavo-fasciatis; rectricibus olivaceis fascia subapicali nigra, pogonio interno fasciis marginalibus flavis; pedibus olivaceis; maxilla fusca, mandibula flavicante; iride fusca.

Long. c. 480, ala 330 , cauda 170 , rostrum $53 \mathrm{Mm}$.

Vorkommen: Mittleres Nen-Seeland.

Subgenus: DASYPTILUS. Borstenköpfe.

Psittrichas (1831) Less. Bull. univ. p. 241 (Typus: Psittucus Pesqueti Less.). - Dasyptilus (1832) Wagl. Mon. Ps. p. 502 (Typus desgleichen).

Charakter der Untergattung: Durch einen grösstentheils nackten Kopf von Nestor unterschieden. Schnabel olne deutlichen Zahn. Färbung vorherrschend schwarz. - Nur eine Art auf Neu-Guinea bekannt.

7. Nestor Pesqueti. - Borstenkopf.

Adlerpapagei. - Englisch: Pecquet's Parrot. - Französisch: Perroquet Pecquet.

Psittacus Pesqueti (1831) Less. Bull. Sc. Nat. XXV, p. 241.Banksianus fulgidus (1831) Less. Traité d'Ornith. p. 181 (Wahrscheinlich synonym!)

Bourjot St. Hilaire, Hist. Nat. Perr. pl. 67. - Jard. et Selby, Nat. Libr. VI, 1836, pl.17. - Reichenow Vogelbilder t. 18, f. 2.

Diagnose: Niger, pectoris plumis gilve brunneo-limbatis; ventre, crisso, hypochondriis, supracaudalibus, tectricibus alarum superioribus partim et remigum mediarum pogoniis externis coccineis; capite anteriore nudo, rostro et pedibus nigricantibus; iride fusca.

Long. c. 540, ala 320, cauda 190, rostrum $50 \mathrm{Mm}$.

Vorkommen: Austro-Malayische Subregion (Neu-Guinca). 
Genus: LICMETIS. - Nasenkakadus.

Licinetis (1832) Wagl. Non. Psitt. p. 695. (Typus: Psittacus temuirostris Kuhl).

Charakter der Gattung: Schnabel gestreckt, lünger als hoch, mit deutlicher Auskerbung vor der Spitze, Wachshaut befiedert. Grosser mackter Augcnkreis. Schwanz kurz, gerade, etwa gleich der halben Flügellänge. Federn des Kopfes zu einer Haube verlïngert, aber von gewöhnlicher Form. Feilkerben vorhanden. Färbung weiss. - Nur zwei Arten in der Australischen Subregion.

8. Licmetis nasicus. - Nasenkakadu.

Engl.: Slender-billed Cockatoo. - Franz.: Cacatois Nasique.

Psittacus nasicus (1819) Temm. Linn. Trans. Bd.XIII, p. 115. Psitucus temirostris (1820) Kuhl Consp. Psitt. p. 88.

Abbildungen: Temm. Pl. Col. pl. 331. - Gould Birds Austral. V, pl. 5. - Reichenow Vogelbilder taf. 4, fig. 7. Bourjot St. Hilaire, Hist. Nat. Perr. pl. 76 (schlecht, pastinator?).

Diagnose: Albus, loris et fascia tenui frontali miniatococcineis; capitis collique plumis basi miniato-roseis; remigibus et rectricibus subtus sulphureo-imbutis; aunulo orbitali nudo cicsio; rostro pallide cinereo, pedibus griseis; iride fusca. Long. c. 400 , ala 280 , cauda 135 , culmen $45 \mathrm{Mm}$.

Vorkommen: Australische Subregion (Süd-Australien).

9. Licmetis pastinator. - Wühler-Kakadu.

Englisch: Digging Cockatoo, Western Slender-billed Cockatoo. Französisch: Grand Cacatois nasique.

Licmetis pustinutor (1840) Gould Proc. Z. S. VIII, p. 175.

Abbildung fehlt.

Diagnose: Lirmeti nasicae simillima, sed major, fascia frontali, lori set capitis collique plumis basi dilute miniato-roseis, annulo orbitali nudo latiore obscuriore, cyaneo-plumbeo-tincto.

Long. c. 450 , ala 340 , cauda 180 , culmen $50 \mathrm{Mm}$.

Vorkommen: Austratische Subregion (West-Australien).

Genus PLISSOLOPHUS. - Echte Kakadus.

Cacutus (1815) Rafinesque (?). - Cacatua (1818) Vieill. Nouv. Dict. XVII (?). - - Krekadoë (1820) Kúnl Consp. Psitt. p. 11. Plyctuloplus (1826) Vig. et Horsf. Trans. Lin. Soc. XV, p. 268 (Typus: Psittecus galeritus Lath.). - Plissolophus (1842) Gloger Gemeinn. Hand- und Hilfs-Buch p. 193. - Plictolophus (1853) 
Le Maout Hist. Nat. Ois. p. 106. - Lophochroa (1857) id. Compt. Rend. T. XLIV 16. et 23. Mars p. 537 (Typus: Plyctolophus Leadbeateri Vig.).

Charakter der Gattung: Schnabel kurz und hoch, so hoch als lang, mit deutlicher Auskerbung vor der Spitze und mit Feilkerben. Firste gerundet oder mit Lüngsrinne versehen. Wachshaut nackt oder befiedert. Nackte Augengegend. Schwanz kurz, gerade, wenig länger als die halbe Flügellänge. Kopffedern zu einer Haube verlängert. Färbung weiss (ausgenommen roseicapillus und Leadbeateri). - Die Gattung umfasst 15 bekannte Arten, welche nach der Form der Haube in zwei Untergattungen einzuordnen sind.

Subgenus: CAMPTOLOPHUS. Breithauben-Kakadus.

Eolophus*) (1856) Bonap. Naumannia Beilage (Typus: Cacatua rosea Vieill.). -- Ducorpsius**) (1857) Bonap. Compt. Rend. T. XLIV 16. et 23. Mars, p. 537 (Typus: Caratua Durorpsi Hombr. Jacqu.). - Camptolophus (1872) Sundevall Méth. nat. av. disp. tent. p. 69 (Typus: Psittacus philippinarum Gm.).

Charakter der Untergattung: Die verlängerten Iraubenfedernn von gewöhnlicher Form. - Neun Arten aus der Australischen, westlichen Austromalayischen und östlichen Indo-Malayischen Subregion. - Je nachdem die Wachshaut befiedert ist oder nackt, trennen wir die Arten in zwei Sectionen.

\section{Schlüssel der Untergattung:}

Sectio I: Wachshaut befiedert, Schnabel hell:

Weiss, Steiss roth: philippinarum.

"Steiss weiss, Zügel und Stirn rosa; breiter blau-grauer nackter Augenkreis: gymnopis.

Weiss, Steiss weiss, Zügel rosa oder weiss, Stirn weiss; schmaler bläulich weisser Augenkreis: sanguineus (siehe auch: Goffini und Ducorpsi).

Kopf und Unterseite rosa, Oberseite grau: roseicapillus.

Sectio II: Wachshaut nackt, Schmabel schwarz.

Haubenfedern rein weiss, nackter Augenkreis bläulich weiss: albus.

Lüngste Haubenfedern schwefelgelb; grosser nackter Augenkreis schön hellblau: ophthalmicus.

*) Als unpassender Name zu verwerfen.

**) Personen-Namen werd $n$ in der Zoologie als Gattungsnamen nicht angewendet (Report des Congresses in Manchester 1842 , §. A. ${ }_{1}$.). 
Längste Haubenferlern mennigroth; nackter Augenkreis hell bläulich-grau: moluccensis.

Sectio I: Wachshaut befiedert. Schnabel hell gefärbt.

10. Plissolophus gymnopis. - Nacktaugen-Kakadu.

Englisch: Bare-eyed Cockatoo.

Cacatua gymnopis (1871) Sclat. Proc. Z. S. p. 490.

Abbildung: Kopf, Proc. Z. S. 1871, p. 493.

Diagnose: Albus; fronte et loris rosaceis; capitis, cervicis et ventris plumis basi dilute roseis; remigibus et rectricibus pogonio interno sulfureo-imbutis; periophthalniis nudis infra dilatatis caerulescente-plumbeis (teste Sclater). Long. c. $420 \mathrm{Mm}$.

Vorkomiren: Australische Subregion (Süd-Australien).

11. Plissolophus philippinamum. -- Rothsteiss-Kakadu.

Englisch: Red-vented Cockatoo. - Französisch: Cacatois des Philippines.

Cacetua Minor (1760) Briss. Ornith. IV, p. 212, t. XXII. Psittacus haematuropygius (1776) S. Müll. Lin. N. S. Suppl. p. 77. - Petit Kakatoës à bec coleur de chair (1783) Buff. Hist. Nat. des Ois. p. 77. - Petit Kakatoës des philippines (1783) id. Pl. Enl. t. 191. - Psittacus philippinarum (1788) Gm. S. N. I, p. 331. - Lophochrod minor (1863) Finsch, Ned. Tijdschr. Dierk. Ber. p. 23. -

Abbildungen: Buffon Pl. Enl. pl. 191. - Bourjot St. Hilaire, Hist. Nat. Perr. pl. 8!.

Diagnose: Albus, subcaudalibus miniatis; genis dilute roseo imbutis; cristae plumis subtus miniato-flavescentibus, remigibus et rectricibus pogonio interno sulfureo-imbutis; rostro plumbeo apice flavicante; pedibus griseis; annulo orbitali nudo albo; iride fusca. Long. c. 310, ala 220, cauda 110, culmen $29 \mathrm{Mm}$.

Vorkommen: Oestl. Indo-Malayische Subregion (Philippinen).

12. Plissolophus sanguineus. - Rothzügel-Kakadu.

Englisch: Blood-stained Cockatoo. - Französisch: Cacatois à front rouge.

Cacatua sanguinea (1842) Gould Proc. Z. S. X, p. 138. Plictolophus rhodolome (1867) Finsch Pap. I, p. 307.

Abbildung: Gould Birds Austral. V, t. 3.

Diagnose: Albus; loris, interdum quoque stria tenui frontali roseis; cristae, capitis et gulae plumis basi dilute roseis; remigibus 
et rectricibus pogonio interno sulfureo-imbutis; rostro albicante; pedibus griseis; annulo orbitali albo.

Long. c. 400, ala 300, cauda 150, culmen $32 \mathrm{Mm}$.

Vorkommen: Australische Subregion.

13. Subspec. Goffini. - Goffin's Kakadu.

Engl.: Goffin's Cockatoo. - Französ.: Cacatois Goffin.

Lophochroc Goffini (1863) Finsch Nederl. Tijdschr. Dierk. Berigt. p. 22.

Abbildung fehlt.

Diagnose: $P l$ sanguineo simillimus, sed minor, loris et fronte semper albis, cristae plumis subtus pallide sulfureo-imbutis, annulo orbitali nudo coerulescente albo.

Long. c. 350 , ala 260, cauda 125 , culmen $32 \mathrm{Nm}$.

Vorkommen unbekannt.

14. Subsp. Ducorpsi. - Ducorps Kakadu.

Engl.: Ducorps's Cockatoo. - Franz.: Cacatois Ducorps.

Cacatua Ducorpsi (1842-1853) Hombr. Jacqu. Voy. an Pôle Sud Zool. I, p. 108. - Ducorpsius typus (1857) Bp. Compt. Rend. T. XLIV, 16. et 23. Mar's, p. 537. - Lophochou Lecrii (1863) Finsch Nederl. Tijdschr. Dierk. Ber. I, p. 23.

Abbildungen: Hombr. u. Jacqu. 1. c. t. 26, f. 1. - Proc. Zool. Soc. 1864, t. 27.

Diagnose: Subspec. Goffuni simillimus sed capitis et gulate plumis quoque basi albis et cristae plumis subtus conspicue sulfureo-imbutis.

Mensurae Plissolophi Goffini.

Vorkommen: Oestliche Austro-Malayische Subregion (Salomons Inseln).

15. Plissolophus roseicapillus. - Rosenkakadu.

Englisch: Roseate Cockatoo, Rose Cockatoo. - Französisch: Cacatois Rosalbin.

Cacatua roseicapilla (1818) Vicill. N. D. XVIJ, p. 12. Cacatua rosec ibid. - Psittecus Eos (1820) Kuhl Consp. Psitt. p. 88 .

Abbildungen: Bourjot St. Hilaire Hist. Nat. Perr. pl. 74. Temm. Pl. Col. pl. 81. - Gould Birds Austral. V, pl. 4. Reichenow, Vogelbilder t. XII, f. 3.

Diagnose: Dorso, alis candaque canis; uropygio, supra- et subcaudalibus, crissi lateribus, remigibus secundariis cortumque 
tectricibus majoribus albidis; pilei plumis basi roseis apice albis; capitis lateribu:, cervice, gastraeo et subalaribus roseis; rostro cinerascente albo, basi plumbeo; pedibus cinerascente carneis; annulo orbitali nudo albido; iride rufa. Long. c. 370, ala 275, cauda 145 , culmen $28 \mathrm{Mm}$.

Vorkommen: Ausstralische Subregion (Ostaustralien).

Sectio II. Wachshaut nackt, Schnabel schwarz.

16. Plissolophus albus. - W eisshauben-Kakadu.

Englisch: White-crested Cockatoo. - Französisch: Cacatois à huppe blanche.

Cacatuce (1760) Briss. Ornith. IV, p. 204, t. 21. - Psittacus albus (1776) S. Müll. Lin. X̃. S. Suppl. p. 76. - Kakatoës à huppe blankhe (1783) Buff. Hist. Nat. Ois. VII, p. 74. - Kakatoës des Moluques (1783) id. Pl. Enl. pl. 263. - Psittacus cristatus (1783) Lath., Bodd. Tabl. Pl. Enl. p. 16. - Cacutua leucolophus (1831) Less. Traité d'Orn. p. 182. - Kakadoë albocristata (1837 bis 1838) Bourj. St. Hilaire Hist. Nat. Perr. pl. 82. - Cacutua cristatella (1864) Wall. Proc. 'Z. S. p. 279.

Abbildungen: Buffon Pl. Enl. pl. 263. - Bourjot St. Hilaire Hist. Nat. Perr. pl. 82. - Reichenow, Vogelbilder t. 4, f. 3.

Diaguose: Totus albus; periophthahniis nulis coerulescente albis; remigibus et rectricibus pogonio interno sulfureo-imbutis; rostro et pedibus nigris; iride fusca.

Long. c. 450, ala 290, cauda 160, culmen $40 \mathrm{Mm}$.

Vorkommen: Westl. Austro-Malayische Subregion (Moluccen).

17. Plissolophus ophthalmicus. - Brillen-Kakadu.

Engl.: Blue eyed-Cockatoo. - Franz: Cacatois à lunettes.

Cacatua ophthalmica (1864) Sclat. Proz. Z. S. p. 188.

Abbildung: Proc. Zool. Soc. 1862, t. 14.

Diagnose: Albus; cristae plunis longioribus sulfureis; remigibus et rectricibus pogonio interno sulfureo-imbutis; annulo orbitali nudo pulchre dilute coeruleis; rostro et pedibus nigricantibus; iride fusca.

Long. $P l$. moluccensi parum minor; culmen $47 \mathrm{Mm}$.

Vorkommen: Oestliche Austro-Malayische Subregion (NeuBritannien).

18. Plissolophus moluccensis. -- Rothhauben-Kakadu.

Molukken-Kakadu. Englisch: Rose-crested oder Red-crested Cockatoo. - Französisch: Cacatois à huppe rouge. 
Cacatua rubrocristata (1760) Briss. Ornith. IV, p. 209. Kakatoës à huple ronge (1783) Bufl. Hist. Nit. Ois. YII, j) it und Pl. Enl. pl. 498. - Psittans molucensis (1788) Gm. S. N. II, p. 331. - Psittacus rosaceus (1790) Lath. Ind. Orn. I, p. 108. - Cucutua empthotophe (18:3) Less. Traité d'Oru. 1). 183.

Abbildumgen: Buffon 1. c. - Lear pl. 2. - Reichenow Vocelbilder t. IV, f. 4. - Bourjot St. Hilaire, Hist. Nat. Perr. pl. 78.

Diagnose: Albus, pallide flarescente roseo-imbutus; cristac plumis longioribus miniatis; rectrieum pogoniis internis flaveseente roseo-, remigum sulfureo - imbutis; periophthalmiis nulis dilute coerulescente cincreis; rostro et pedibus nigris; irile fusca.

Long. c. 550, ala 330, cauda 200, culmen $55 \mathrm{Mm}$.

Vorkommen: Westl. Austro-Yalayische Subregion (Nolucen).

Subgenus: PLISSOLOPHUS. Spitzhauben-Kakadus.

Charakter der Untergattung: Die verlïngerten Haubenfedern am Ende zugespitzt und mit dem Ende aufwirts gekrümmt. 6 Arten aus der Australisehen und westlichen Austromalayischen Subregion. Je machdem die Wach hant befiedert ist oder nackt, unterscheiden wir wiederum zwei Sectionen.

\section{Schlüssel der Untergattung:}

Sectio I: Wachshant befiedert, Schnabel hell:

Kopfsciten und Unterseite gelblich rosemoth: Lemedtuteri.

Sectio II: Wachshaut nackt, Schnabel schwarz.

Weiss, Haube schwefelgelb, wrösser, Flïgel :300-350 Mm. lang, immer ohne gelben Ohrfleck: galeritus (s. auch triton).

Weiss, Haube schwefelgell, kleiner, Flïgel kiuzer als "200 Mm., in der Regel gelber Ohrffeck: sul Jlunems (s. anch Buïmi). Weiss, Haube goldgelb, Ohrfleck golldgelb: citrim-cristutus.

Sectio I: Wachshant befiedert, Schmabel hell gefürbt.

19. Plissolophus Leadbeateri. - In ka-Ka k a d u.

Engl.: Learlbeater's Cockitoo. - Franz: (acatois Leadbeater.

Plyctolophus Leculbenteri (1831) Vig. P'roc. Zool. S. I, p. (31. Plyctolophes enythopteres (18:37) Sws. Class. Birts II, 1. 302.Kakatoë crista tricolorate (18:37-1838) Bonrj. St. Hil. Perr. pl. 77.

Abbildungen: Lear Iliustr. Parr. pl. 5. - Bonrjot St. Hil. 1. c. - Jard. Selhy Nat. Libr. VI, pl. 13. - Goulk Birds Austral. V, pl. 2. - Reichenow Vogelbilder t. IV, f. 6.

Diagnose: Dorso, alis, cauda et subeaulalibus allis: (appitis et colli lateribus, gastraco et subalinibus dilute miniato-roscis; 
remiwilus et rectricibus pogonio interuo et fascia frontali miniato-roseis; pileo albo; cristac plumis apice albis, basi coccincis, fascia media lutea. Tostro nigro; pelibus nigricantibus. Annulo orbitali nudo canescente; iride fusca.

Long. c. 370, ala 270, cauda 150, culmen $32 \mathrm{Mm}$.

Torkommen: Australische Subregion (Süd- u. Westaustralien).

Sectio II: Wachshaut nackt. Schnabel schwarz.

20. Plisentophes eitrinocristetus. - Gold wa ngen - K a k a du.

Orangehauben-Kakarh. -- Engl.: Citron-crested Cockatoo. Französisch: Cacatois à huppe orangée.

Plyctolophus citrino-cristatus (1844) Fras. P. Z. S. p. 38.Plyctuluphe croms (1860) v. Homeycr Jonru. f. Ornith. p. 357. Psitturus citvinus (1863) v. Rosenb. Naturk. Tijelschr. Nederl. Ind. p. 146.

Abbildungen: Hombr. Jacqut. Yoy. au Pôle sud. Zool. pl. 26, f. 2. - Fras. Zool. Typ. 1849, pl. 58. - Reichenow, Vogelbilder t. IV, f. 2.

Diagnose: Alhus, crista et regione parotica croceis; remigibus et rectricibus pogonio interno sulfureo-imbutis; rostro et pedibus nigris; iride fusca; annulo orbitali nudo canescente albo.

Long. c. 400, ala 250, cauda 140, culmen $40 \mathrm{Mm}$.

Torkommen: Westl. Austro-Malayische Subregion (Timorlaut).

21. Plissolophus crisiatus. - Gelbwangen-Kakadu.

Klemer Gelbhabun-Liakarlu. - Englisch: Lesser Sulphurcresterl Cockatoo, Jara-ockatoo. - Französisch: Petit Cacatois à huppe jaume.

Cacatua luteo- cristata (1760) Briss. Ornith. IV, p. 206. Psittacus cristatus (1766) Lin. S. N. XII, p. 143 (ohne Synonymie, welche sich auf : $\%$, ullus bezieht). - Petit Kakatoës à huple jaune (1783) Buff. Hist. Nat. Ois. VII, p. 75 und Pl. Enl. t. 14. - Psittacus sulphureus (1788) Gm. S. N. I, p. 330. Liskadoë sulphureus mini, vel molucensis (1837-1838) Bourjot St. Hilaire Hist. Nat. Pcrr. pl. 80.

Abbildungen: Buffon Pl. Enl. pl. 14. - Lear Illustr. Parr. pl. 4. - Bourjot 1. c. - Dubois Ornith. Gal. 1839, pl. 83. Jard. Selby Nat. Libr. YI, pl. 129. - Reichenow, Vogelbilder aus fernen Zonen t. IV, f. 1.

Diannse: Albus, wista of perione parotica sulphurea, re- 
migibus et rectricibus pogonio interno sulfureo-imbutis; 1 ostro et pedibus nigris; amnulo orbitali nudo dilute caesio; iride fusca. Long. c. 370 , ala 235 , cauda 115 , culmen $40 \mathrm{Mm}$.

Vorkommen: Westliche dustro-Malayische Subregion (Celebes, Lombock, Flores, Sumbawa).

22. Subspec. Buffoni. - Kleiner Gelbwangen-Kakadu.

Engl.: Buffon's Cockatoo, - Franz.: Cacatois Buffon.

?Pyctolophus parvulus. (1850) Bp. Compt. Rend. p. 139. Plictolophus Buffoni (1867) Finsch Pap. I, p. 300.

Abbildung fehlt.

Diagnose: Praecedenti simillimus sed minor, macula parotica sulphurea indistincta vel nulla.

Vorkummen: Westl. Austro-Malayische Subregion (Timor).

23. Plissolophus galeritus. - Gelbhauben-Kakadu.

Grosser Gelbhauben-Kakadu. - Englisch: Greater Sulphurcrested Cockation, Yellow-crested Cockatoo. - Französisch: Cacatois à crête jaune.

Psittacus galeritus (1790) Lath. Ind. Ornith. I, p. 109. Cacatuce chrysolophus (1831) Less. Traité d'Ornith. p. 182. Kakutoë sulphureus major vel australensis (1837-1838) Bourjot St. Hil. Hist. Nat. Perr. pl. 79. - Plyctolophers licmetorhynchus (1850) Bonap. Compt. Rend. p. 139.

Abbildungen: Lear Illustr. Parr. pl. 3. - Bourjot 1. c. Gould Birds Austral. V, pl. 1. - Reichenow Vogelbilder t. IV, f. 5.

Diagnose: Albus: cristae plumis sulfureis; remigibus et rectricibus pogonio interno sulfureo-imbutis; rostro et pedibus nigris; annulo orbitali albo.

Long. c. 550, ala 360, cauda 210 , culmen $45 \mathrm{Mm}$.

Vorkommen: Australische Subregion (Australien mit Ausnahine des Westens, Van Diemensland).

24. Plissolopleus triton. - Triton-Kakadu.

Engl.: Triton-Cockatoo. - Französisch: Cacatois Triton.

Cucutur Triton (1849) Temm. Coup d'oeil gé sur les poss. néer. dlans l'Jsle arch. Tome III, p. 405 Note. - Cacatua

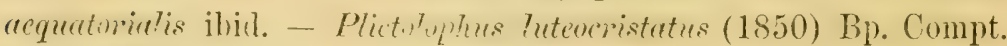

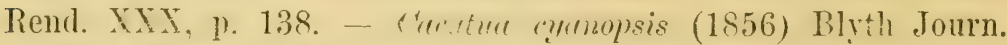
As. Soc. Beng. XXV, 1. 4ti. - Plyctolophers macrotophese (1861) v. Rosenb. Journ. f. Ornith. 1). 45. - Cacatue Elconore (1863) Finsch Nederl. Tijdschr. Dierk. p. 21. 
Abbildung fehlt.

Diagnose: Pl. gaterito simillimus sed minor, annulo orbitali nudo caesio. - Long. c. 490 , ala $280-310$, cauda 150--180, culmen $35-40 \mathrm{NIm}$.

Torkommen: Austro-Malayische Subregion (Neu-Guinea, Goram, Moluccen, Aru-Inseln).

Genus: CAL YPTORHYNCHUS. Raben-Kakadus.

Calyptorhynchus (1826) Vig. et Horsf. Linn. Trans. XV, p. 269. - Banksianus (1831) Less. Traité d'Ornith. p. 179 (Typus: Psittacus Banksi Temm.).

Charakter der Gattumg: Schnabel sehr kurz und hoch, höher als lang, mit dentlicher Auskerbung vor der Spitze, an der Basis dick, gregen die Firste hin stark zusammengedrückt. Fürbung vorlierschend schwarz. Das Jugendgefieder ist durch gelbliche (Querbinderung auswezeichnet. Die sieben hierher gehörenten Formen tremen wiץ in zwei Subgenera, je nachdem die Haube zerschlissen orler ron gewöhnlicher Form, der Schwanz kurz oder lang ist.

Subgenus: CALLOCEPHALA. Helmkakadus.

ronydon*) (1832) Wagl. Mon. Psitt. p. 504 (Typus: Psittacus gatertus Lath.). - Callocephutom (1837) Less. Compl. des oeuvres de Buffon.

Charakter der Lntwattung: Wachshaut ganz befiedert. Schwanz kurz, wenig liumer als die Hülfte des Flügels, gerade. Haubenfederu zerschliswn. - Eine Art in der Austral. Subregion.

25 Calyptorhynchus galeatus. - Helm kakadu.

Engl.: Ganga-Cockatoo. - Franz.: Banksien à tête rouge.

Psittucus galeutus (is02) Lath. Ind. Orn. Suppl. 1) XXIII und (1804) Syrst. Orniti:. II. Ed. p. 126. - Callocephalon australe (1837) Lass. Toy. Thetis pl. 47. - Krekadvë murogaleatus (1837 bis 1838) Bourj. St. Inii. Hist. Nat. Perr. pl. 75. - Psittacus phoenicocephulus (1849) (. R. Grix Gen. Birds Text zu Taf. 105. Psitterus fimbriatus (185) Grant, G. R. Gray List Spec. Birds Pt. III, Sect. II, Psitt. p. 99.

Abhildungen: Bomrjot 1. c. - Gould Birds Austral. V, pl.14.Reichenow Vogelbilder-t. XII, f. 2.

*) Bereits früher bei den Todidae angewendet. 
Diagnose: Schistaceo-niger, plumis albido-limbatis; pileo genisque coccineis; remigibus secundariis pogonio externo viridiimbutis; remigibus primariis et rectricibus cinereo-farinosis; rostro albicante; pedibus griseis; iride fusca.

Long. c. 360 , ala 250, cauda 140, culmen $29 \mathrm{Mm}$.

Juv. Pileo genisque schistaceis; gastraeo miniato - fasciato; remigibus et rectricibus dilute transversim fasciatis.

Vorkommen: Australische Subregion (Suid-Australien).

Subgenus: CAL YPTORHYNCHUS. Langschwanzkakadus.

Charakter der Untergattung: Wachshaut zum Theil befiedert, meist bis zum hinteren Rande der Nasenlöcher. Schwanz lang, drei Viertel so lang als der Flïgel oder lünger, stark gerundet. Verlängerte Haubenfedern von gewöhnlicher Form. - Sechs verschiedene Formen in der Australischen Subregion.

Schlüssel der Un tergattung:

Ohrfleck und Schwanzbinde weiss: Baudini.

Ohrfleck und Schwanzbinde schwefelgelb: funereus (siehe auch xanthonotus).

Kein Ohrfleck, Schwanzbinde roth, Kopf braun: Solendri.

Kein Ohrffeck, Schwanzbinde roth, Kopf schwarz wie der Körper:

Banksi (siehe auch stellatus).

26. Calyptorhynchus Baudini. - Weissohr-Kakadu.

Englisch: Baudin's Cockatoo, White-tailed Cockatoo. Französisch: Calyptorhinque Baudin.

Calyptorhynchus Baudini (1832) Vig. Lears Ill. Parr. t. 6. Abbildungen: Lear Illustr. Parr. pl. 6. - Bourjot St. Hil. Hist. Nat. Perr. pl. 73. - Gould Birds Austr. V, pl. 13. Reichenow Vogelbilder t. 18, f. 1.

Diagnose: Fuscus, viridi-resplendens, plumis gilvo-limbatis; macula parotica et caudae fascia albis; rostro albido; pedibus griseis; iride fusca.

Vorkommen: Austral. Subregion (West- u. Süd-Australien).

27. Calyptorhynchus funereus. - G e lb o h r-Kak a du.

Engl.: Funereal Cockatoo. - Französisch: Cacatois Duse. Psittacus funereus (1789) Shaw Nat. Misc. t. 186.

Abbildungen: Bourjot St. Hilaire, Hist. Nat. Perr. pl. 70. Gould Birds Austr. T, pl. 11. - Reichenow Vogelbilder t. XII, f. 4.

Diagnose: Fuscus viridi-resplendens; macula parotica et fascia caudae dilute sulfureis; rostro plumbeo; perlibus griseis. 
Long. c. 630, ala 420, cauda 360, culmen $48 \mathrm{Mm}$.

Juv. notaei plumis gilvo-, gastraei et subalaribus olivaceoflavo-limbatis; caudae fascia nigro-marmorata; rostro albicante, apice griseo; pedibus fulvis.

Vorkommen: Australische Subregion (Sïd-Australien, Neu Süd-Wales).

28. Subspecies: vanthonotus. - Kleiner Gelbohr-Kakadu.

Englisch: Yellow-eared Black Cockatoo.

Calyptorhynchus ranthonotus (1837) Gould P. Z. S. V, p. 151.

Diagnose: $C$. funereo simillimus sed minor.

Long. c. 550, ala 360, cauda 290, culmen $47 \mathrm{Mm}$.

Vorkommen: Australische Subregion (Van Diemensland).

29. Culyptorhynchus Solandri. - Braunköpfiger Rabenkakadu.

Engl.: Solander's Cockatoo. - Franz.: Cacatois à tête brun.

Cacatua viridis (1818) Vieill. Nouv. Dict. Hist. Nat. X VII, p. 13. - Psittacus Solandri (1819) Tem. Lin. Trans. XIII, p. 113. - Psittans Temmincki (1820) Kuhl Consp. Psitt. 1). 89.Calyptorlumetus stellatus (1836) Jard. Selby Nat. Lilnr. VI, p. 184.

Abbildungen: Bourjot St. Hil. Hist. Nat. Perr. pl. 71, b. Jard. Selby Nat. Libr. VI, pl. 15. - Gould Birds Austral. V, pl. 10. - Reichenow Vogelbilder t. XII, f. 1.

Diagnose: Niger, chalybeo-resplendens; capite colloque fuscis; caudae fascia coccinea; rostro plumbeo; pedibus griseis; irile fusca.

Long. c. 500, ala 360, cauda 260, culmen $47 \mathrm{Mm}$.

Juv. caudae fascia miniata nigro-fasciolata et marmorata; capite flavo-punctulato; rostro albicante.

Vorkommen: Australische Subregion (Süd-Australien, Neu Süd-Wales).

30. Calyptorhynchus Banksi. - Bart-Kakadu.

Engl.: Banksian Cockatoo. - Franz.: Banksien austral.

Psittacus Banksii (1790) Lath. Ind. Ornithol. p. 107. Psittacus magnificus (1789-1813) Shaw Nat. Misc. pl. 50. Psittacus Cookii (1819) Temm. Trans. Lin. Soc. XIII, No. 12, p. 111. - Psittacus Leachii (1820) Kuhl Consp. Ps. p. 91. Banksianus australis (1831) Less. Traité d'Ornithol. p. 180. Calyptorhynchus masrorhynchus (1842) Gould P. Z. S. p. 138.

Abbildungen: Bourjot St. Hilaire, Hist. Nat. Perr. pl. 71 Cab. Journal f. Ornithol, XXIX. Jahrg. No. 153. Januar 1881 
und 72. - Reichenow Vogelbilder taf. XII, fig. 6-7. - Kuhl Consp. Psitt. t. 3. - Gould Birds Austral. Pt. V, pl, 7 и. 8.

Diagnose: Niger, chalybeo-resplendens; fascia caudae coccinea; rostro plumbeo, mandibula dilutiore; pedibus nigris; iride fusca.

Long. tot. c. 670 , ala 460, cauda 340 , culmen $50 \mathrm{Mm}$.

Juv. crista, capitis lateribus et tectricibus pallide flavomaculatis; gastraeo obsolete flavescente- vel brumneo-fasciato; caudae fascia latiore flava vel coccinea, nigra-fasciolata et marmorata; rostro albicante.

Vorkommen: Australische Subregion.

31. Subspec. stellatus. - Kleiner Bart-Kakadu.

Englisch: Lesser Banksian Cockatoo.

Calyptorhynchus stellatus (1832) Wagl. Mon. Ps. p. 685. Calyptorhynchus naso (1836) Gould P. Z. S. IV, p. 106.

Abbildungen: Gould Birds Austral. pt. V, t. 9.

Diagnose: C. Banksi simillimus sed minor, rostro validiore. Ala 380 , cauda 260, culmen $55 \mathrm{Mm}$.

Vorkommen: Australische Subregion.

Genus: MICROGLOSSUS. Arara-Kakadus.

Microglossum (1809) Geoffr. Ann. du Mus. XIII. - Probosciger (1820) Kuhl Consp. Psitt. p. 12 (Typus: Psittacus goliath Kuhl). - Solenoglossus (1821) Ranz. Elem. di Zool. III, pl. 2, p. 18 (Typus: Solenoglossus seylanicus Ranz.). - Eurhynchus (1825) Latr. Fam. du règne anim. - Microglossus (1832) Wagl. Mon. Psitt. p. 503 (Typus: Psittacus aterrimus Gm.). - Macroglossa (1849) Temm. Coup d'oeil gén. sur les poss. néerl. Tome III. -

Charakter der Gattung: Sehr grosser, seitlich stark zusammengedrückter Schnabel mit fast scharfer Firste und deutlichem Zahn. Wachshant befiedert. Backen nackt. Schwanz etwa halb so lang als der F'lügel und gerundet. Im Flügel vierte und fünfte Schwinge am längsten, die dritte gleich der sechsten und wenig kürzer als die lüngsten, erste etwa gleich der siebenten. Verlängerte Haubenfedern bandförmig. Färbung schwarz, in der Jugend wie bei den Rabenkakadus gelblich gebändert. - Nur eine Art in der nördlichen Australischen und Austro-Malayischen Subregion. 
32. Microglossus aterrimus. - Arara-Kakadu.

Englisch: Great Black Cockatoo, Great Palm Cockatoo, Französisch: Ara noir à Trompe, Microglosse noir.

Le Kakatoës noir (1783) Buff. Hist. Nat. Ois. VII, p. 79. Psittacus atcrimus (1788) Gm. S. N. II, p. 330. - Psittrecus gigas (1790) Lath. Ind. Orn. I, p. 107. - Ara gris à Trompe (1801-1805) Levaillant Hist. Nat. Perr. t. 11, Ara noir à Trompe ibid. pl. 12 und 13. -- Psittacus grisens (1811) Bechst. kurze Uebers. p. 87. - Psittacus goliuth (1820) Kunhl Consp. Psitt. p. 92. - Solenoglossus zeylanicus (1821) Ranz. Elem. di Zool. III, pp. 2, 21. -- Microglossum ater (1831) Less. Traité l'Orn. p. 184. - Eurhynchus alecto (1838) Less. Compl. Buff. Ois. p. 603. - Ara Alecto (183?) Temm. Disc. Famna Japon. p. XVII (teste Salvadori). - Cacatua intermedia (1861) Schleg. Journ. f. Ornith. p. 380 .

Abbildungen: Jard. Selby Nat. Libr. Vol. VI (1836) pl. 16.Lev. Hist. Nat. Perr. pl. 11 bis 13. - Gould Birds Austral. Suppl. - Shaw Gen. Zool. VIII, pl. 71. - Reichenow Vogelbilder t. XII, f. 5 .

Diagnose: Schistaceo-niger, vivus griseo-farinosus; rostro pedibusque nigris; genis nulis carneis, statu affectionis rubris; iride saturate brunnea. Long. c. $600-800$, ala $300-400$, caud. 200-270, culınen 70-115 Mm.

Juv. Ventre crissoque flavescente-fasciatis, rostro apicem versus plus minusve albido.

Vorkommen: Austro-Malayische und nördliche Australische Subregion (Nordküste Australiens).

\section{Familie: Platycercidae. Plattschweifsittiche.}

Charakter der Familie: Der Schmabel ist kurz und dick, höher als lang, der Unterkiefer wird oft durch die Backenfedern vollständig verdeckt, Oberkiefer seitlich aufgetrieben (eine Ausnahme machen dic Gattungen Cullipsittacus, Nanodes und Porphyreiceplutus durch einen schmaleren, letztere Gattung auch längeren Schnabel). Firste gerundet, Dille in bogenförmiger Krümmung aufsteigend und gerundet; Oberkiefer bald mit, bald ohne Zahn, Spitze mit Feilkerben. Die Wachshaut ist klein, häufig bis zu den Nasenlöchern befiedert, mehr oder weniger wulstig aufgetrieben, umgiebt nur die Nasenlöcher und bildet 
zwischen den Nasenlöchern einen Sattel über der Firstenbasis, erstreckt sich aber nicht bis zur Schnabelschneide herunter oder wenn sie (bei einigen abweichenden Formen) nach unten in eine Spitze bis zu dieser verläuft, so ist der Theil unter den Nasenlöchern befiedert (eine Ausnahme macht Melopsittacus, bei welcher Gattung die dicke nackte Wachshaut die ganze Schnabelbasis umgiebt). Der Schwanz ist lang, in der Regel länger als die spitzen Flügel (Ausnahmen: Callipsittacus, Eupheme und Ptistes), die einzelnen Federn stufig verlängert, bei den typischen Formen aber die vier mittelsten Schwanzfedern gleich lang.*) In dem spitzen Flügel sind häufig einige der ersten Handschwingen an der Spitzenhälfte oder am Spitzendrittel verschmälert. Wir unterscheiden 66 Formen, welche in sechs verschiedene Gattungen einzuordnen sind.

Die Plattschweifsittiche verbreiten sich über die ganze Australische Region und gehen am weitesten sïdwärts auf der östlichen Halbkugel, bis zu den unter dem $50^{\circ}$ und $55^{\circ}$ sdl. Br. gelegenen Auckland- und Macquarie-Inseln, ebenso durch die ganze Polynesische Subregion ostwärts bis Tahiti. Während die Kakadus den Urwald bewohnen, bevölkern die Plattschweifsittiche die weiten Grassteppen. Weniger als andere Papageien sind sie im klettern geschickt, aber bessere Läufer, da sie ihre Nahrung, die Samen der mannigfachen Grasarten, auf dem Boden suchen oder, an den Stauden sich anhäkelnd, aus den Rispen klauben. In dem ebenso eleganten wie reissend schnellen Fluge übertreffen sie die meisten Papageien. Die meisten Arten führen ein unstätes Wanderleben. Wo der reifende Grassamen ihnen reichliche Nahrung verspricht, erscheinen sie in ungeheuren Schaaren. In den Löchern und Spalten der Gummibäume und Euphorbien, welche in kleinen Gehölzen die Steppe durchsetzen, legen sie jetzt ihre Nester an und ziehen ihre Jungen gross. Sobald aber anhaltende Dürre den Graswuchs versengt und die Wasserbecken austrocknet, sind die ruhelosen Wanderer verschwunden; unstät eilen sie reissenden Fluges durch das Land, die Getreideschober der Ansiedler plündernd, bis sie

*) Ausser dem dicken Schnabel und der Bildung der Wachshaut unterscheidet diese Eigenschaft die typischen Plattschweifsittiche ron allen anderen stufenschwänzigen Papageien, bei welchen immer die beiden mittelsten Schwanzfedern die längsten sind. 
andere Nahrungsplätze gefunden. Die Stimme der meisten Plattschweifsittiche ist angenehm. Bei manchen Arten sogar wohlklingend, gestalten sich die Töne zu einem bescheidenen Gesang. Die Färbung ist ausserordentlich bunt, aus den verschiedensten Farben zusammengesetzt. Die Geschlechter sind in der Regel verschieden gefürbt, das Weibchen auch gewöhnlich etwas kleiner als das Männchen; das Kleid der jungen Vögel ähnelt meistens dem der Weibchen.

Genus: MELOPSITTACUS. Wellensittiche.

Melopsittacus (1840) Gould Birds Austral. V, pl. 44.

Charakter der Gattung: Schnabel ohne Zahn. Wachshaut sehr stark wulstig aufgetrieben; auf den Schnabelseiten, in eine Spitze verschmälert, bis zur Schnabelschneide herablaufend, ganz nackt. Die vier äussersten Schwanzfedern gleichmässig stufig, die zweiten stärker, die beiden mittelsten am stärksten verlängert, alle nach dem Ende zu allmälig verschmälert. Im Flügel zweite Schwinge am längsten, erste lïnger als dritte, keine an der Spitze verschmälert. - Nur eine Art in der Australischen Subregion.

1. Melopsittacus undulatus. - Wellensittich.

Englisch: Undulated Grass Parrakeet. - Französisch: Perruche ondulée.

Psittacus undulatus (1789-1813) Shaw Nat. Misc. pl. 673. Sagittifer minor undulatus (1837-1838) Bourj. St. Hilaire Hist. Nat. Perr. pl. 8.

Abbildungen: Lear Hllustr. Parr. pl. 13. - Bourj. St. Hil. I. c. - Jard. and Selby Nat. Libr. VI, pl. 28. - Shaw 1. c. Gould Birds of Australia V, pt. 44. - Reichenow Vogelbilder taf. 14, fig. 4.

Diagnose: Fronte, loris et genis inferioribus flavis, his utroque guttis duobus vel tribus nigris notatis; gastraeo, tergo, uropygio, supracaudalibus et subalaribus viridibus; occipite, cervice, interscapulio, regione parotica et genis superioribus nigro flavoque undulatis; stria genali cyanea; tectricibus majoribus primariis viridi-coeruleis, apice pallide limbatis; remigibus pogonio externo viridi-coeruleis, primis exceptis medio macula pallidiore notatis, pogonio interno fuscis, medio macula flavescente-alba; rectricibus mediis coeruleis, subtus nigris, reliquis basi et apice 
coeruleis, medio luteis; rostro et pedibus plumbeis; iride flava; cera cyanea.

Long. c. 180, ala 96, cauda 100, culmen $13 \mathrm{Mm}$.

오: Parum pallidior, cera caesia.

Vorkommen: Australische Subregion.

Genus: CALIIPSITTACUS. Nymphensittiche.

Calopsitta (1832) Less. Ill. de Zool. p. 49. - Leptolophus (1832) Swains. Zool. Illustr. pl. 112. - Callipsittaus (1846) Agassiz Nomenclator Ind. univ. p. 59.

Charakter der Gattung: Schnabel weniger dick, seitlich etwas zusammengedrückt, mit schmaler Firste und deutlicher Auskerbung vor der Spitze. Die Wachshaut setzt sich verschmälert bis zur Schnabelschneide herab fort, ist aber unter den Nasenlöchern hefiedert. Schwanz etwa so lang als der Flügel, die beiden mittelsten stärker verlüngert, die übrigen in gleichmässiger Stufenfolge, alle am Ende verschmälert. Im Flügel erste und zweite Schwinge am längsten, keine am Ende verschmälert. Kopffedern zum spitzen Schopf verlüngert. Nur eine Art in der Australischen Subregion.

2. Callipsittacus Novae Hollandiae. - Nymphensittich.

Englisch: Crested Ground-Parrakeet. - Franz.: Perruche calopsitte.

Psittacus Noude Hollandiae (1788) Gmel. S. X. II, p. 328. Leptolophes auricomis (1831-1832) Sws. Zool. Ill. II. sér. p. 522, pl. 112. - Calopsitta Greyi (1832) Less. Ill. de Zool. pl. 49 et 50.

Abbildungen: Lear Illustr. Parr. pl. 27. - Swainson l. c. Gould Birds Austral. Vol. V, pl. 45. - Bourjot St. Hilaire Hist. Nat. Perx. pl. 11 und 11b. - Reichenow, Vogelbilder aus fernen Znnen t. 14 , f. 5 .

Diagnose: Fuscus; occipite, uropygio, crisso, supra- et subcaudalibus pallidioribus cinerascentibus; remigibus et rectricibus superne canescente-farinosis; sincipite, crista genisque pallide sulfureis; regione parotica crocea, postice et subtus albo-circumdato; macula magna alari alba; rostro et pedibus nigricantibus; iride fusca.

Long. c. 280 , ala 170 , cauda 160 , culmen $17 \mathrm{Mm}$.

९: pallidior, sincipite, crista genisque sordide flavescente brumneis; uropygio, supracaudalibus et rectricibus mediis trans- 
versim cano-fasciolatis vel marmoratis; rectricibus reliquis, crisso et subcaudalibus pallide sulfureo-fasciolatis vel marmoratis.

Vorkommen: Australische Subregion.

Genus: NANODES. Schwalbensittiche.

Nenodes (1826) Vig. Horsf. Trans. Lin. Soc. XV, p. 274.

Charakter der Gattung: Schnabel schlank, seitlich zusammengedrïckt, mit deutlichem Zahn. Wachshaut frei. Schwanz kaum länger als der Flügel. Schwanzfedern schmal, nach dem Ende lanzettlich zugespitzt, alle gleichmässig stufig verlängert. Zweite Schwinge am lüngsten, erste länger als die dritte, keine an der Spitze verschmälert. Zungen nicht mit Papillen besetzt, sondern mit hornigem Ueberzug versehen, wie die anderer Plattschweifsittiche.*)

Nur eine Art in der Australischen Subregion.

3. Nanodes discolor. - Schwalbensittich.

Englisch: Swift Lorikeet. - Fragzösisch: Perruche Latham.

Psittacus discolor (1790) Shaw, White's Journ. of a voy. to New South Wales p. 263. - Perruche Banks (1801-1805) Levaill. Hist. Nat. Perr. pl. 50. - Perruche Latham ibid. p1. 62. Psittacus Lathrmi (1811-1812) Bechst. Lath. Uebers. p. 81. Psittacus austrulis (1820) Ḱnhl Consp. Psitt. p. 48. - Psittacus humerulis (1811--1812) Bechst. Lath. Uebers. 1). 85. - Psittacus Banksianus (1819) Vieill. Nouv. Dict. H. N. 25, p. 342 und Enc. Méth. p. 1383. - Lathomus rubrifrons (1831) Less. Traité d'Ornith. p. 205.

Abbildungen: Levaillant 1. c. - Swains. Zool. Ill. I, pl. 62. Gould Birds Austral. V, t. 47.

Diagnose: Viridis; sincipite cyanescente; regione parotica thalassino, hypochondriis flavescentibus; fascia frontali, gula et subalaribus coccineis; loris flavis; flexura cerasina; sub-

*) Die Schnabelbildung nähert diese Form den Loris, die Spitze des Oberschnabels zeigt nur schwache Feilrinnen; ganz besonders aber ist die Lebensweise übereinstimmend mit den letztgenannten Papageien; in der Form der Wachshaut aber und in den anatomischen und pterylologischen Verhältnissen (vergl. Forbes, On the Genus Lathamus, Proc. Zool. Soc. 1879 , p. r66) finden wir so bezeichnende, der Familie der Plattschweifsittiche eigenthümliche Merkmale, dass wir die Gattung der letztgenannten Familie einordnen, wo sie den Anknüpfungspunkt, die Uebergangsform für die Loris bildet. 
caudalibus pallide coccineis, viridi-flavescente-limbatis; remigibus nigris, primariis extus et intus stramineo-limbatis, secumdariis pogonio externo viridibus, ultimis pogonio interno pallide coccineis, interdum remigibus pogonio interno macula pallide flava notatis; pteryllio et manus tectricibus cyaneis; rectricibus mediis rufis, apice cyaneis, ceteris cyaneis pogonii externi basi rufis; rostro pallide plumbeo apice fulvescente; pedibus sordide carneis; iride crocea.

Long. c. 250, ala 125, cauda 135 , culmen $16 \mathrm{Mm}$.

오 minor, dilutius tincta, subcaudalibus viridibus rubroimbutis.

Juv. subalaribus et subcaudalibus viridibus.

Vorkommen: Australische Subregion.

Genus: CYANORHAMPHUS. I a ufsittiche.

Charakter der Gattung: Schnabel ohne deutlichen Zahn. Wachshaut zum Theil befiedert, nur ein schmaler Streif vor den Nasenlöcherı frei. Schwanzfedern verhältnissmässig breit, am Ende lanzettförmig zugespitzt. Zweite bis vierte Schwinge am lïngsten, zweite bis fünfte an der Spitzenhälfte zugespitzt. Die Gattung umfasst 15 verschiedene Formen, die sich grösstentheils nur in geringem Grade unterscheiden und nur als subspecies aufgefasst werden können. Die Mehrzahl gehören der Neuscelündischen, einige der südlichen Polynesischen Subregion an. Wir spalten die Gattung in zwei subgenera.

\section{Subgenus: CYANORHAMPHUS. Ziegensittiche.}

Charakter der Untergattung: Alle Schwanzfedern gleichmässig stufig verlängert, auch die mittelsten. Erste Schwinge länger als 5. oder gleich lang. - 14 Formen.

Schlüssel der Untergattung:

Einfarbig grün: unicolor.

Mit braunem Kopf: ulietanus.

Stirn schwärzlich roth, Bürzel und Augenstreif roth: erythronotus. Vorderkopf und Augenstreif roth: noue zeelundiae (s. auch sechs Unterarten).

Scheitel goldgelb, Stirubinde roth: arriceps (s. auch subspecies Mallherbii).

Scheitel hell grünlich gelb, Stirnbinde roth: alpinus (s. auch subspec. intermedia). 
4. Cyanorhamphus unicolor. - Einfarbsittich.

Englisch: Uniform Parrakeet. - Französisch: Perruche unicolore.

Platycercus unicolor (1831) Vig. Proc. Zool. Soc. p. 24. Psittucus platycercus viridis unicolor (1837-1838) Bourjot St. Hilaire pl. 34.

Abbildungen: Lear Illustr. Parr. pl. 25. - Bourj. St. Hil. Hist. Nat. Perr. pl. 34 .

Diagnose: Viridis, uropygio et gastraeo flavescentibus; manus tectricibus et ala spuria cyaneis; rostro et pedibus plumbeis; iride rufa. Ala 140, cauda $140 \mathrm{Mm}$.

Vorkommen: Unbekannt.

5. Cyanorhamphus ulietanus. -- Braunköpfiger Laufsittich.

Englisch: Society Parrakeet.

Psittacus ulietanus (1788) Gm. S. N. I, p. 328. - Platycersus tannaensis (1868) Finsch Papageien II, p. 272.

Abbildung fehlt.

Diagnose: Capite brunneo; notaeo olivaceo-brunneo, uropygio rubro; gastraeo olivaceo-flavo; rostro et pedibus plumbeis; iride lutea. Ala 130, cauda 145, culmen $20 \mathrm{Mm}$.

Vorkommen: Polynesische Subregion (Ulietea, GesellschaftsInseln? nach Latham, 'T'mnna, Neu Hebriden? nach d. Brit. Mus.). 6. Cyanorhamphus erythronotus. - Rothbürzel-Laufsittich.

Englisch: Red-rumped Parrakeet, Pacific Parrakeet. Französisch: Platycerque phaëton.

Psittacus novae Seelandiae (1788) Gm. S. N. I, p. 328. Psitfacus Zealandicus (1790) Lath. Ind. Ornithol. I, p. 102. Psittacus erythronotus (1820) Kuhl Consp. Psitt. p. 45. - Psittacus pacificus (1844) Forst. Licht. Descr. An. p. 238. - Conums phaëton (1845) Des Murs Rev. Mag. Zool. p. 449. -

Abbildung: Des Murs Iconogr. Ornith. pl. 16.

Diagnose: Viridis, dorso olivascente; fronte rubente nigra; fascia oculari et uropygio coccineis; rectricibus coeruleis viridimarginatis; ala spuria coerulea; remigibus fuscis, pogonio externo coeruleis; rostro et pedibus plumbeis; iride lutea. - Ala 145, cauda $150 \mathrm{Mm}$.

Vorkommen: Oestliche Polynesische Subregion (Tahiti, Gesellschaftsinseln). 
7. Cyanorhamplus novae-zeelandiae. - Ziegensittich.

Englisch: New-Zealand Parrakeet. - Französisch: Perruche de la Nouvelle Zélande.

Psittacus novae-zeelandiae (1787) Sparrm. Mus. Carls. t. 28. Psittucus pasificus (1788) Gmel. S. N. I, p. 329. - Lathamus Sparrmanii (1831) Less. Traité d'Orn. p. 206. - Cyanorhamphus frontatus (1856) Lchtst. Naum. Extrah. - Cyanorhamplus novae Guineae (1856) Bonap. Naum. Beilage. - Platycercus Cooki (1859) G. R. Gray, List Psitt. Br. Mus. p. 13.

Abbildungen: Lear Illustr. Parr. pl. 26. - Bourj. St. Hil. Hist. Nat. Perr. pl. 36 (subspec. erythrotis). - Reichenow Vogelbilder taf. 16, fig. 7 .

Diagnose: Viridis, subtus dilutior; sincipite et vertice, stria per oculum et regionem paroticam ducta, macula uropygii lateris utroque carmineis; remigibus fuscis, extus cyaneo- vel coeruleoviridi limbatis, subtus interlum fascia flavescente notatis; tectricibus majoribus primariis et pteryllio cyaneis; subalaribus coeruleo-viridibus; rostro plumbeo; pedibus brumnescentibus; iride lutea. - Long. c. 280-300, ala 135-140, cauda 145-150, culmen $18 \mathrm{Mm}$.

Vorkommen: Neuseeländische Subregion (Neu Seeland).

8. Subspec. Rowleyi. - Rowley's Ziegensittich.

Engl.: Rowley's Parrakeet. - Franz.: Perruche Rowley.

Platycercus Rowleyi (1874) W. L. Buller, Trans. Proc. N. Zealand Inst. VII, p. 219.

Diagnose: C. novae zeelandiae simillimus sed minor.

Long. c. 240, ala 123, cauda 128, culmen $14 \mathrm{Mm}$.

Abbildung: Rowley Ornith. Misc. II, t. 50.

Vorkommen: Neu-Seeland.

9. Subspec. Rayneri. - Rayner's Ziegensittich.

Engl.: Rayner's Parrakeet. - Franz.: Perruche Rayner.

Platycercus Rayneri (1862) G. R. Gray Ibis p. 228.

Diagnose: $C$. nov'ce zeelandiae simillimus sed major, rostro robustiore; sincipitis colore dilutiore, coccineo et magis extenso; macula parotica inconspicua, obscure carminea.

Long. c. 330, ala 150, cauda 170, culmen $22 \mathrm{Mm}$.

Vorkommen: Norfolk Inseln.

10. Subsp. aucklandicus. - A u ckland-Sittich.

Englisch: Auckland Parrakeet. 
Cyanorhamphus aucklandicus (1856) Bonap. Naum. Beilage.

Diagnose: C. nove zeelandiae simillimus sed minor, colore carmineo sincipitis minus extenso.

Long. c. 240 , ala 118, cauda 130 , culmen $15 \mathrm{Mm}$.

Vorkommen: Auckland Inseln.

11. Subsp. erythrotis. - Macquarie-Sittich.

Englisch: Maquary Parrakeet.

Platycerus erythrotis (1832) Wagl. Mon. Psitt. p. 526.

Diagnose: C. movce zeelandiae simillimus sed colore dilutiore, magis flavescente viridis; sincipite (nec vertice), stria oculari et uropygii maculis coccineis.

Vorkommen: Macquarie Inseln.

12. Subspec. Saisseti. - Caledonischer Ziegensittich.

Englisch: Caledonian Parrakeet. - Französisch: Perruche de la Calédonie.

Cyanorhumphus Saisseti (1860) Verr. Des Murs Rev. Mag. Zool. p. 387.

Diagnose: C. novae zeelandiae simillimus sed remigibus primariis pogonio externo usque ad apicem fere coeruleis, rectricibus apice cyanescentibus.

Vorkommen: Neu Caledonien.

13. Subspec. Forsteri. - Forster's Ziegensittich.

Psittacus pacificus (1844) Forst. Licht. Descr. An. p. 73.Platycercus Forsteri (1868) Finsch Pap. II, p. 287.

Diagnose: C. novere reelandice simillimus sed maculis uropygii laterum rubris nullis.

Vorkommen: Süd Neu-Seeland.

14. Cyanorhamphus auriceps. - Springsittich.

Englisch: Golden-headed Parrakeet.

Psittacus auriceps (1820) Kuhl Consp. Psitt. p. 46.

Abbildung: Buller Birds New Zealand. - Rehw. Vogelb. t. 21.

Diagnose: Viridis; fascia frontali ad oculos ducta et macula uropygii lateris utroque carmineis; vertice aurantiaco; remigibus fuscis, pogonio interno macula alba notatis, primariis pogonio externo cyaneo-, secundariis viridi-limbatis; tectricibus majoribus primariis et pteryllio cyaneis; rostro plumbeo; pedibus fulvis; iride rufa. Long. c. 240 , ala 180 , cauda 128 , culmen $15 \mathrm{Mm}$.

Vorkommen: Neuseeländische Subregion (nördlicher Theil von Neuseeland). 
15. Subspec. Malherbii. - Malherbe's Springsittich.

Engl.: Malherbe's Parrakeet. -- Franz.: Perruche Malherbe. Cyanorhamphus Malherbi (1857) Souancé Rev. M. Z. p. 98. Abbildung fehlt.

Diagnose: C. auricipiti simillimus sed minor.

Long. c. 220 , ala 100, cauda 120 , culmen $12 \mathrm{Mm}$.

Vorkommen: Auckland Inseln.

16. Subspec. intermedia. - Mittlerer Springsittich.

Cyanorhamphus intermedia (1881) Reichenow.

Diagnose: C. auricipiti simillimus, sed verticis colore dilutiore, virescente luteo (ut in $C$. alpino, sed fronte carminea).

Long. c. 250, ala 113, cauda 133, culmen $14 \mathrm{Mm}$.

Vorkommen: Neu Seeland.

17. Cyanorhamphus alpinus. - Alpensittich.

Englisch: Alpine Parrakeet.

Platycercus novae zeelandiae (1837-1838) Bourjot St. Hil. Hist. Nat. Perr. pl. 37. - Platycercus alpinus (1869) W. Bull. Ibis p. 39 .

Abbildungen: Bourjot 1. c. - Reichenow Vogelbilder t. XXI.

Diagnose: Viridis; fascia frontali ad oculos ducta et macula lateris utroque miniatis; vertice virescente flavo; remigibus fuscis, pogonio interno macula alba notatis, primariis extus cyaneo-, secundariis viridi-limbatis; tectricibus majoribus primariis et pteryllio cyaneis; rostro plumbeo.

Long. c. 230, ala 102, cauda 126, culmen $14 \mathrm{Mm}$.

Exemplum major Musei berolinensis: Long. c. 250, ala 112, cauda 128 , culmen $15 \mathrm{Mm}$.

Vorkommen: Neuseeländische Subregion (Alpen des siidlichen Neu-Seeland).

Subgenus: NYMPHICUS. Horns it tich e.

Nymphicus (1832) Wagl. Mon. Psitt. p. 490 (Typus: Psittarus bisetis Forst.).

Charakter der Untergattung: Die vier mittelsten Schwanzfedern ziemlich gleich lang, die anderen gleichmässig stufig verlängert. Erste Schwinge kürzer als fünfte. Zwei bandförmige Federn auf dem Kopfe. - Nur eine Art auf Neu-Caledonien.

18. Cyanorhamphus cornutus. - Hornsittich.

Engl.: Horned Parrakeet. - Franz.: Perruche cornue. 
Psittacus cornutus (1788) Gmel. S. N. II, p. 327. - Psittacus bisetis (1844) Forst. Descr. Anim. p. 258.

Abbildungen: Bourjot St. Hilaire Hist. Nat. Perr. pl. 12. G. R. Gray Gen. Birds. - Proc. Z. S. 1879, pl. 44.

Diagnose: Viridis; subtus dilutior; occipite, regione parotica et crisso lutescentibus; pileo rubro; regione ophthalmica et loris nigricantibus; pilei plumis duabus elongatis nigris, rubro-apicatis; remigibus primariis eorumque tectricibus majoribus et pteryllio pogonio externo cyaneis, interno nigris; rostro plumbeo apice dilutiore; pedibus plumbeis; iride miniata. Lg. c. 330, ala 155, cauda 160 , culmen $20 \mathrm{Mm}$. 오: Sine capitis plumis elongatis.

Vorkommen: Südl. Polynesische Subregion (Neu-Caledonien).

Genus: EUPHEMA. Grassittich e.

Euphema (1832) Wagler Monographia Psittacorum p. 542 (Typus: Psittacus pulchellus Shaw).

Charakter der Gattung: Die vier mittelsten Schwanzfedern ungefähr gleich lang, alle gegen das Ende zu verschmälert. Flügel ungefähr so lang als der Schwanz; erste und zweite Schwinge am längsten oder zweite am lïngsten und erste gleich der dritten; zweite und dritte oder zweite bis vierte Schwinge am Enddrittel verschmälert. - Sieben Arten in der Australischen Subregion.

\section{Schlüssel der Gattung:}

Oberseite braun, Unterseite hell rosenroth: Bourki.

Oberseite grün, Stirn und Kopfseiten blau, Kehle und Brust roth: splendida.

Kehle und Brust wie die übrige Unterseite gelb, rothbrauner Flügelfleck: pulchella.

Nur schmale Stirnbinde blau, Kopfseiten grün, Zügel hellblau: petrophila.

Zügel grün: chrysogastra.

Zügel gelb, alle Flïgeldecken dunkelblau: venustı.

Nur Flïgelrand dunkelblau, nach innen in hellblau übergehend: elegans.

19. Euphema Bourloi. - Rosenbauchsittich.

Englisch: Bourke's Gras-Parrakeet. - Französisch: Perruche Bourke.

Nanodes Bourkii (1800) Gould et Mitch. Austr. Exp. I, p. 18. 
Abbildungen: Gould Birds of Austral. V, pl. 43. - Reichenow Vogelbilder t. 14, f. 2.

Diagnose: Notaeo obsolete olivaceo-brunneo; gastraeo dilute roseo; crisso et subcaudalibus dilute coeruleis; fronte, flexura et margine alarum, tectricibus majoribus primariis et subalaribus azureis; loris et periophthalmiis albidis; tectricibus fuscis pallide limbatis; remigibus fuscis pogonio exterso coerulescentibus; rectricibus mediis olivaceo-fuscis, reliquis apice albis, pogonii interni basi nigris, externi caesiis; rostro nigricante; pedibus cinerascente brunneis; iride fusca.

Long. c. 230, ala 113, cauda 120, culmen $14 \mathrm{Mm}$.

\&: Dilutius tincta, sine fascia frontali azurea.

Vorkommen: Australische Subregion (Südliches Australien).

20. Euphema venusta. - Feinsittich.

Englisch: Blue-banded Grass-Parrakeet, - Französisch: Perıuche vénuste, Perruche à bouche d'or.

Psittacus venustus (1819) Temm. Lin. Trans. Vol. XIII, p. 121. - Psittacus chrysostomus (1820) Kuhl Consp. Psitt. p. 50.

Abbildungen: Bourjot St. Hilaire Hist. Nat. Perr. pl. 10. Kuhl Consp. Psitt. t. 1. - Gould Birds of Austral. V, pl. 37. Reichenow Vogelbilder t. 14, f. 7.

Diagnose: Olivaceo-viridis; abdomine sulfureo; fascia frontali, alarum tectricibus et subalaribus cyaneis; loris luteis; remigibus et tectricibus primariis majoribus nigris, extus cyanescentibus, tertiariis notaeo simile-tinctis; rectricibus merliis caesiis, subtus nigris, reliquis apice pallide flavis, pogonii externi basi caesiis, interni nigris; rostro, pedibus et iride brumneis.

Long. c. 200, ala 105, cauda 110, culmen $13 \mathrm{Mm}$.

우: mari simillima.

Vorkommen: Australische Subregion (Südliches Australien, Van Diemensland).

21. Euphema elegans. - Schmucksittich.

Englisch: Elegant Grass-Parrakeet. - Französisch: Perruche élégante.

Nanodes elegans (1837) Gould Proc. Z. S. V, p. 25.

Abbildung: Gould Birds of Austral. V, pl. 38.

Diagnose: Olivaceo-viridis; abdomine flavo, ventre medio croceo; loris luteis; fronte et stria superciliari cyaneis, postice caeruleo limbatis; tectricibus manus antice cyaneis, postice dilute 
coeruleis; subalaribus cyaneis; remigibus et tectricibus majoribus primariis cyanescente nigris, primis extus coeruleo-limbatis; rectricibus mediis caesiis, reliquis apice flavescente albis, basi pogonii externi caesiis, interni cyaneis; rostro, pedibus et iride fuscis. Long. c. 230, ala 110, cauda 130, culmen $13 \mathrm{Mm}$.

오: Fascia frontali cyanea angustiore, sine macula ventrali crocea.

Vorkommen: Australische Subregion (Südliches und Westl. Australien, Van Diemensland).

22. Euphema petrophila. - Klippensittich.

Engl.: Rock-Parrakeet. - Franz.: Perruche pétrophile.

Euphema petroplila (1840) Gould Proc. Z. S. VIII, p. 148.

Abbildung: Gould Birds Austral. Vol. V, pl. 40.

Diagnose: Olivaceo-viridis, crisso et subcaudalibus olivaceoflavis, macula ventrali crocea; loris et periophthalmiis coeruleis; fascia frontali et campterio cyaneis; remigibus nigris, pogonio externo coeruleo-viridibus; rectricibus mediis coeruleo-viridibus, ceteris apice Iuteis, basi pogonii interni fuscis, externi viridibus; rostro nigro-rufo, mandibula flavescente; iride fusea; pedibus brumneis. Long. c. 200, ala 105, cauda 105, culmen $13 \mathrm{Mm}$.

\section{우: mari simillima.}

Vorkommen: Australische Subregion (Süd-Australien).

23. Euphema chrysogastra. - Goldbauchsittich.

Englisch: Orange-bellied Parrakect. - Französisch: Perruche à lunettes vertes.

Psittacus shrysogaster (1790) Lath. Ind. Ornith. I, p. 97. -Euphema aurantia (1840) Gould Proc. Z. S. VIII, p. 148.

Abbildungen: Gould Birds Austral. V, t. 39. - Reichenow Vogelbilder taf. 14, fig. 6.

Diagnose: Viridis, gutture olivascente; abdomine flavo, ventre medio croceo; fronte, flexura, campterio, tectricibus primariis et subalaribus cyaneis; remigibus primariis pogonio externo cyaneis, interno fuscis macula media flavescente alba notatis, tenuiter flavido limbatis; remigibus secundariis pogonio interno fuscis, externi basi cyaneis apice viridibus; rectricibus mediis viridibus, apice coerulescentibus, subtus nigris; reliquis apice luteis, pogonii externi basi viridi - caeruleis, interni nigris; rostro, pedibus et iride fuscis.

Long. c. 200, ala 105, cauda 105, culmen $13 \mathrm{Mm}$. 
오 Macula ventrali crocea minus extensa et dilutiore.

Vorkommen: Australische Subregion (Süd- und WestAustralien und Van Diemensland).

24. Euphema pulchella. - Schönsittich.

Türkisin. - Englisch: Turquoisine Parrakeet. - Französisch: Perruche turquoise, Perruche Edwards.

Psittucus pulchellus (1789-1813) Shaw Nat. Misc. t. 96. Perruche Edwards (1801-1805) Levaill. Hist. Nat. Perr. pl.68. Psittacus Edwardsii (1811-1812) Bechst. Lath. Uebers. p. 74. Lathamus azureus (1831) Less. Traité d'Orn. p. 205.

Abbildungen: Gould Birds of Austral. V, t. 41. - Reichenow Vogelbilder taf. 14, fig. 3. - Levaillant 1. c.

Diagnose: Olivaceo-viridis; gastraeo luteo, macula ventrali (interdum quoque altera jugulari) crocea; facie tota, tectricibus minoribus et minimis coeruleis; macula cubitali cerasina ; tectricibus majoribus cyaneis; remigibus pogonio externo cyaneis; interno nigris; subalaribus cyaneis; rectricibus mediis obscure viridibus, reliquis apice luteis, basi pogonii interni nigris, externi obscure viridibus; rostro, pedibus et iride fuscis.

Long. c. 200, ala 105, cauda 110, culmen $12 \mathrm{Mm}$.

오 Sine macula ventrali crocea atque cubitali cerasina.

Vorkommen: Australische Subregion.

25. Eriphema splendida. - Glanzsittich.

Englisch: Splendid Grass-Parrakeet. - Franz.: Euphème resplendissante, Perruche splendide.

Erphema splendida (1840) Gould P. Z. S. p. 147.

Abbildungen: Gould Birds of Austral. V, t. 42. - Reichenow Vogelbilder t. 14, f. 1.

Diagnose: Notaeo viridi; facie tota et regione parotica caerulea, antice obscuriore, cyanea; gutture miniato; abdomine luteo; tectricibus dilute caeruleis; tectricibus majoribus primariis nigris, pogonio externo cyanescentibus; remigibus nigris, extus coeruleo- viridi- vel cyaneo-limbatis; rectricibus mediis viridibus, ceteris apice luteis, basi pogonii interni nigris, externi viridibus.

Long. c. 200, ala 110, cauda $95 \mathrm{Mm}$.

\&: Facie et alarum tectricibus dilutius coeruleo-tinctis, gutture viridi.

Vorkommen: Australische Subregion (Süd- und WestAustralien). 
Genus: PLATYCERCUS. Platts $\mathrm{ch}$ w e ifsitt iche.

Platederens (18:5) Vicr. Yool. Journ. 1. 527. -- Pledoluphus (1837-1838) Bourjot St. Hilaire Hist. Nat. Perr.

Charakter der Gattung: Schwanzfedern in der ganzen Ausdehnung gleich breit oder regen das Ende wenig versehmïlert (bei Polytelis stärker), aber nie zurespitzt, die vier mittelsten immer ungefïh gleich lang (bei Ptistes alle fast gleich lang). Flüggel kürzer als der schwanz (ausgenommen Ptistes), zweite mnd dritte oder dritte und ricrte schwinge am längsten. einige Handschwingen am Ende verschmälert, dritte schwinge häufigr spitz, hisweilen auch erste und zweite (Psephotus). Wachshatut meist bis zu den Nasenlöeher'n befiedert. - 41 Irten, welche der Australischen, Austro - Malayischen und Polynesischen Subregion angehören. Die Gattung zerfältt nach Form des Schnabels, Schwanzes und der Flïgel in 7 Untergattungen.

\section{Schlüssel der Gattung.}

Fodern des Rückens schuppenartig gefärbt, schwïrlich mit helleu farbigen Saum, mit blanem Fleck jederseits am Unterschnabel:

Kopf und Unterseite karminroth: Pennanti.

$\begin{array}{lll}" & " & \text { hyacinthroth: adelaidensis. } \\ " & " & \text { hochgelb: flaviventris. }\end{array}$

Kopf blassgelb, Unterseite bläulich: Amuthusine.

Cab. Journ. f. Onrithol. XXIX. Jahrg. No, 154. April 1881. 
Mit weissem Backenfleck:

Kopf blassgelb, Unterseite bläulich: pallidiceps.

Kopf u. Brust roth, Bauch blaugrün: eximius (s. auch splendidus).

Kopf und ganze Unterseite roth: ignitus.

Kopf schwarz, Unterkörper blassgelb: Browni.

Mit gelbem Backenfleck: icterotis.

Rücken einfarbig grün:

Kopf und Unterseite scharlach-, karmin- oder kirschroth:

Oberschnabel an der Basis roth:

Oberrïcken und Flügel grün; Nacken grün :

Grösser, Flügel circa $210 \mathrm{Mm}$. lang, Kopf und Unterseite scharlachroth: scapulatus.

Kleiner, Flügel höchstens $200 \mathrm{Mm}$. lang, Kopf und Unterseite karminroth: ambinensis (s. auch sulaensis, bumensis, dorsalis).

Oberrücken und Flügel grün, Nacken blau: chloropterus.

Oberrücken blau, Flügel grün: callopterns.

Oberrücken grün, Flügel blau: hypophonius.

Ganzer Schnabel schwarz (sehr dick):

Kopf und Unterseite karminroth: splendens.

" taviuensis, vergl. ferner dorsalis).

Nur Oberkopf und Unterseite roth, grosser relber Flügelfleck: insignissimus.

Oberkopf roth, Brust und Bauch violet-blau: spurius.

Vorzugsweise grïn gefärbt:

Mitte von Brust und Bauch gelb, des Steisses memigroth, Gesicht schwarz: personatus.

Mit gelber Nackenbinde:

Rücken schwarz: Barnardi.

Rücken gxün, gelbes Querband über den Bauch: zonurius.

Rücken grïn, Bauch griin wie der übrige Unterkörper: semitorquatus.

Mit rothem Flügelfleck, Oberrücken schwalz: erythropterus (s. auch coccineopterus).

Mit roth und gelbem Flügelfleck, Oberrücken grün: jonquillaceus.

Mit kleinem gelbem Flügelfleck. Rothbramer Nacken- und Bürzelfleck: multicolor.

Ohne Nackenfleck. Rothbraune Bürzelbinde: haemutonotus.

Mit gelben Wangen und rothem Kehlschild: Barrabandi.

Rücken einfarbig olivengelb:

Oberkopf und Bürzel hellblau: Alexandrae.

Oberkopf wie der Rücken olivengelb: melanurus.

Rücken graubraun:

Rother Flügelfleck, braume Kopfplatte: pulcherrimus. 
Gelber Flïgelfleck, schwarzbraune Kopfplatte: chrysopterygius. Olivengelber Flügelfleck, blaues Gesicht, gelbe Unterschwanzdecken: haematogaster.

Braunrother Flügelfleck, blanes Gesicht, rothe Unterschwanzdecken: haematorrhous.

\section{Subgenus: PSEPHOTUS. Singsittiche.}

Prephotus (1845) Gould Birds of Australia Vol. V. (Typus: Platycercus haematogaster Gould).

Charakter der Untergattung: Schnabelzahn kaum bemerkbar. Zweite und dritte Schwinge am längsten, vierte länger als erste, die zweite bis vierte oder bis fünfte sind an der Endhälfte verschmälert, die dritte meist spitz (bei Ps. haematogaster die fünf ersten spitz). Wachshaut aufgetrieben und nackt. -Sechs Arten in der Australischen Subregion.

26. Plutycercus huematonotus. - Blutrumpfsittich, Singsittich.

Englisch: Blood-rumped Parrakeet. - Französisch: Perruche à croupion rouge.

Psephotus hamatonotus (1837) Gould P. Z. S., p. 151.

Abbildungen: Gould Birds Austral. V, pl. 36. - Reichenow Vogelbilder taf. XXIII, fig. 1.

Diagnose: Thalassinus; cervice, pectore et supracaudalibus prasinis; uropypio rufo-coccinco; epigastrio et ventre luteis: subcaudalibus albis; campterio, remigibus primariis carumque tectricibus pogonio externo et subalaribus cyaneis: macula parva alari sulfurea; rectricibus mediis sordide virescentibus, apice cyanescentibus; ceteris basi coeruleis, pogonio interno nigricantibus, apice albidis; rostro nigricante; pedibus cinereo brunneis, iride fusca.

Long. c. 270 , ala 130 , cauda 150 , culmen $15 \mathrm{Mm}$. ㅇ: Cinerascente olivacen-viridis; uropygio concolore.

Vorkommen: Australische Subregion.

27. Platycereus multicolor. - Vielfarbensittich.

Einglisch: Many-coloured Parrakeet. - Französ.: Perruche impériale.

Psittacus multicolor (1819) T'emm. Trans. Linn. Soc. XIII, p. 119 .

Abbildungen: Gould Birds Austral. V, pl. 35. - Reichenow Vogelbilder t. XXIII, f. 8. 
Diagnose: Thalassinus; fronte, fascia alae superioris, crisso et subcaulalibus luteis; occipite rufo-cimnamomeo; ventre medio coccineo; fascia supracaudalium transversa rufescente rubra: rectricibus mediis cyaneis, apice nigris, basi sordide viridibus; ceteris basi thalassinis, fascia transversa nigra, parte apicali coeruleis, apice ipsa albis; remigibus primariis earumque tectricibus pogonio externo, campterio et subalaribus cyaneis. Rostro pallide plumbeo; pedibus et iride brunneis.

Long. c. 260, ala 130, cauda 145, culmen $14 \mathrm{Mm}$.

오: Olivaceo - viridis, partim brunnescens vel cinerascens, fascia alari obscure rubra.

Vorkommen: Australische Subregion (Süd-Australien).

28. Platycercus chrysopterygius. - Goldschultersittich.

Englisch: Golden shouldered Parrakeet. - Französisch: Perruche aux ailes d'or.

Psephotus chrysopterygius (1857) Gould P. Z. S., p. 220.

Abbildungen: Gould Birds Austral. Suppl. - - Reichenow Vogelbilder t. XXIII, f. 6.

Diagnose: Coeruleus, partim virescente-imbutus; interscapulio et scapularibus brumnescente canis; pileo nigro-fuseo; fascia frontali et periophthalmiis flavis; alarum tectricibus luteis; ventre, crisso et subcaudalibus dilute coccineis; remigibus fuscis, extus cyaneo-limbatis; rectricibus duabus mediis bisi obscure viridibus, apice cyaneis; ceteris thalassinis, fascia nigra notatis, apice albis; rostro et pedibus dilute plumbeis; iride fusca.

Long. c. 275 , ala 115 , cauda 175 , culmen $18 \mathrm{Mm}$.

오: Dilutius tincta; cervice, interscapulio et scapularibus olivascente cinereis.

Vorkommen: Australische Subregion (Nordwest-Australien).

29. Platycercus pulcherrimus. - Paradiessittich.

Englisch: Beautiful Parrakeet. - Französisch: Perruche du paradis.

Platycercus pulcherrimus (1818) Gould Ann. Mag. N. Hist. XV, p. 114 (teste Gould Birds Austr. V).

Abbildungen: Gould Birds Austral. V, pl. 34. - Reichenow Vogelbilder t. XXIII, f. 4.

Diagnose: Pileo, cervice, dorso et alis brunneis; fascial frontali, alarum tectricibus minoribus, ventre, crisso et subcaudalibus coccincis; capitis et colli lateribus, gutture et pectore 
thalassinis; uropygio et supracaudalibus coeruleis; periophthalmiis flavis; rectricibus duabus mediis cyaneis, basi virescentibus; ceteris coeruleis, apice albis; exterioribus tribus basi fascia nigra notatis: rostro plumbeo, apice albo; pedibus plumbeis; iride fulva.

Long. c. 300, ala 130, cauda 185, culmen $20 \mathrm{Mm}$.

오: Fascia frontali flavida; gutture cinerascente viridi; macula alari obscurius rubro-tincta.

Vorkommen: Australische Subregion (Neu Süd Wales).

30. Platycernes haematogaster. - Gelbsteiss-Sittich.

Englisch: Blue bonnet Parrakeet. - Französisch: Perruche à bonnet bleu.

Platycerns hatematogaster (1835) Gould Proc. Zool. Soc. V, p. 89. - Psephotus xanthorrhous (1850) Bonap. Compt. Rend. p. 133.

Abbildung: Reichenow Vogelbilder t. XXIII, f. 3.

Diagnose: Notaeo, gutture et pectore cinerascente olivaceobrunneis; facie, flexura, campterio, tectricibus majoribus primariis et subalaribus azureis; abdomine dilute sulfureo; ventre medio coccineo; macula magna alari olivaceo-fulva; remigibus nigrofuscis, pogonio externo azureis; rectricibus mediis cinerascente olivaceo-viridibus, apice azureis; ceteris apice albis, basi azureis, margine interno nigris; rostro plumbeo apice albicante; pedibus brunneis; iride fusca.

Long. c. 330 , ala 130 , cauda 190, culmen $17 \mathrm{Mm}$.

우: Non satis cognita.

Vorkommen: Australische Subregion (Inneres von Neu Süd Wales).

31. Platycerns haematorrhous. - Rothsteiss-Sittich.

Englisch: Red-vented Parrakeet. - Französisch: Perruche à ventre rouge.

Psephotus haematomhous (1856) Bp. Naumannia Beilage. Psephotus haematogaster Gould Birds Austral. V, pl. 33.

Abbildung: Gould Birds of Austral. V, pl. 33 (Psephotus haematogaster).

Diagnose: Pl. hatmatogastri similis sed subcaudalibus coccineis, nec sulfureis; flexura thalassina; campterio azureo: macula alarum rufescente rubro.

오: Non satis cognita. 
Vorkommen: Australische Subregion (Süd- und WestAustralien).

Subgenus: PLATYCERCUS. Buntsittiche.

Platycercus (1825) Vig. Zool. Journ. p. 527. - Bamardius (1854) Bonap. Ann. Sc. Nat. p. 108. - (Typus: Platycereus Barnardi Vig.)

Charakter der Untergattung: Dritte Schiwinge am längsten, zweite gleich der vierten und wenig kürzer als die längste, bisweilen gleich derselben, erste kürzer als fünfte. Zweite bis fünfte Schwinge an der Spitzenhälfte verschmälert. - Schnabelzahn ziemlich deutlich. - 14 Arten in der Austral. Subregion.

[Wahrscheinlich gehört hierher auch Platycercus Mastersianus Ramsay, über welchen wir nicht volle Klarheit zu gewinnen vermögen und den wir deshalb unter Vorbehalt mit der OriginalBeschreibung in der Note*) aufnehmen.]

32. Platycercus Browni. - Schwarzkopfsittich.

Englisch: Brown's Parrakeet. - Franz.: Perruche Brown.

Psittacus Brouni (1819) Temm. Trans. Linn. Soc. XIII, p. 119. - Psittacus vemustus (1820) Brown Kuhl Consp. Psitt. p. 52.

Abbildungen: Lear Illustr. Parr. pl. 20. - Bourj. St. Hil. Hist. Nat. Perr. pl. 33. - Gould Birds Austral. V, pl. 31. Reichenow Vogelbilder t. XXIII, f. 5.

Diagnose: Capite nigro; macula utroque mandibulari alba, subtus azureo-limbata; fronte interdum rubro-imbuta; cervicis

\section{*) Platycercus Mastersianus.}

E. P. Ramsay, Proc. Linn. Soc. N. S. Wales II, 1878, p. 27.

Adult. - Total length about 11 inches, wing 5,8, inches, tail 6,3 inches, tarsus 0,8 inches, bill 0,7 inches. The front top of the head, nape and ears coverts crimson, mottled with yellow on the sides of the head; feathers of the hind neck and back yellowish at the tips, blackish on concealed portions, those on the neck washed with red and tinged on the sides with bluish green, rump and upper tail coverts crimson, the outer series of the latter greenish; scapulars black; broadly margined with yellowish; shoulders deep blue centered, with black margins, with blue median coverts; underside of the wing black, traversed about the middle of the quills with an indistinct brown white band. Under surface yellowish green. (Bezüglich der zuletzt erwähnten weissen Flügelbinde sei auf die Note zu Platycercus ignitus p. 57 verwiesen. Verf.) 
et interscapulii plumis et scapularibus nigris, pallide sulfureo limbatis; tergi, uropygii et gastraei plumis pallide sulfureis, tentiter nigricante limbatis; supracaudalibus basi nigris, apice pallide sulfureis; subcaudalibus coccineis; alarum tectricibus superioribus et inferioribus dilute azureis; macula cubitali nigra: remigibus et tectricibus majoribus primariis fuscis, pogonio externo azureis; rectricibus mediis virescente azureis; ceteris parte apicali coerulescente albis, apice ipsa alba, ad basin extus azureis, intus nigricantibus; rostro et pedibus plumbeis, rostri culmine et apice pallidis; iride fusca.

Long. c. 280 , ala 140 , cauda 150 , culmen $17 \mathrm{Mm}$.

: Capite fusco; notaeo et gastraeo cinereo-, nec sulfureo-. tinctis (teste Gould).

Vorkommen: Australische Subregion (Nördl. Australien).

33. Platycercus pallidiceps. - Blasskopfsittich.

Englisch: Pale headed Parrakeet; Mealy Rosella. - Franz.: Perruche à tête blanchâtre.

Psittacus adscitus (?) (1790) Lath. Ind. Ornith. I, p. 126. Commurus palliceps (1829) Cuv. Règne Anim. par Guérin. Platycercus coelestis Less. Echo Monde (teste Finsch Pap. II, p. 195).

Abbildungen: Lear Illustr. Parr. pl. 19. - Bourj. St. Hil. Hist. Nat. Perr. pl. 31. - Gould Birls Austral. V, pl. 26. Reichenow Vogelbilder t. XIV, f. 6.

Diagnose: Capite pallide flavo; macula utroque mandibulari alba, subtus azureo limbata; cervicis et interscapulii plumis scapularibusque nigris, citrino marginatis; gastraeo, tergo, uropygio et supracaudalibus dilute coeruleis; subcaudalibus coccineis: alis, cauda, rostro, perlibus et iride ut in Pl. Broumi tinctis.

Long. c. 310 , ala 145 , cauda 175 , culmen $18 \mathrm{Mm}$.

오: Parum dilutius tincta, uropygio cinerascente.

Vorkommen: Australische Subregion (Ost-Australien).

34. Platycercus Amathusic. - Nördlicher Blasskopfsittich.

Englisch: Blue-cheeked Parrakeet.

Platycercus Amathusia (1850) Bonap. Comptes Rendus p. 133. Platycercus cyanogenys (1855) Gould Proc. Z. S. XXIII, 1) 165.

Abbildung: Gould Birds Australia Suppl.

Diagnose: $P l$. pallicipiti similis sed genis inferinribus azureis, tergo et gastraeo flavescente thalassinis: interscapulii plumis et 
scapularibus flavescente thalassino-limbatis; supracaudalibus flavidis.

Vorkommen: Nord-Australien (Cap York).

35. Platycersus icterotis. - Scharlachsittich.

Englisch: Stanley Parrakeet. - Franzissisch: Perruche à nreilles jaunes.

Platycerrus icterotis (1819) Temm. Trans. Linn. Soc. XIII, p. 120. - Platycercus Stanleyi (1830) Vig. Zool. Journ. V, p. 274.

Abbildungen: Jear Illustr. Parr. pl. 23 und 24. - Gơnould Birds Austral. V, pl. 29. - Bourj. St. Hilaire Hist. Nat. Perr. pl. :30 (jun.). - Jard. Illustr. Ornith. III, pl. 108 jun. Reichenow Vogelbilder t. XIV, f. 5.

Diagnose: Capite et gastraeo coccineis; genis et regione parotica sulfureis: cervicis et interscapulii plumis scapularibusque nigris, illis miniato-, his coerulescente viridi-limbatis; tergo, uropygio et supracaudalibus olivaceo-viridibus; ala et cauda ut in $P \%$. Brouni sed obscurius tinctis; rostro, pedibus et iride non diversis.

Long. c. 310 , ala 138 , cauda 170 , culmen $17 \mathrm{Mm}$.

우: Ignota.

Vorkommen: Australische Subregion (Swan River, WestAustralien).

36. Platycercus eximius. - Rosella, Buntsittich.

Englisch: Rose Hill Parrakeet. - Französisch: Perruche omnicolore.

Psittacus eximius (1789-1813) Shaw. Nat. Misc. VIII, pt. II, p. 411. - Permelie mmicolore $(1801-1805)$ Levail. Hist. Nat. Perr. pl. 28 und 29. - Psittucus copitatus (1812) Shaw. Gen. 7ool. VIII, p. 466. - Psittacus omnicolor (1811-1812) Bechst. Lath. Uebers. p. 68.

Abbildungen: Levaillant 1. ‘.-- Gould Birds Austral. Y. p1. 27. - Reichenow Vogelbilder t. XIV, f. 7.

Diagnose: Capite, colli lateribus, pectore et subcaudalibus coccineis, macula magna utroque mandibulari alba; epigastrio croceo, medio coccineo; ventre thalassino; cervice croceo; interscapulii plumis of scapularibus nigris, sulfuren limbatis; tergo, uropygio et supracaudalibus flavescente viridibus; alis, cauda, rostro, pedibus et iricle ut in $\mathrm{Pl}$. Browni tinctis. 
Long. c. 330, ala 145 , cauda 180 , culmen $18 \mathrm{Mm}$.

\$: Ventre viridi-, nec thalassino-tincto.

Vorkommen: Austral. Subregion (Neu Süd-Wales Tasmanien).

37. Subspecies: splendidus. - Glänzender Rosella.

Jamrach's Rosella (im Handel). - Engl.: Splendid Parrakeet.

Platycercus splendidus (1845) Gould P. Z. S. XIII, p. 105.

Abbildung: Gould Birds Austral. V, pl. 28.

Diagnose: $P$. eximio simillimus, sed interscapulii plumis et scapularibus splendide luteo-limbatis; pectoris lateribus croceis; uropygio, supracaudalibus crissoque thalassino-albis; cervice coccineo, nec croceo.

Vorkommen: Australische Subregion (Inneres von Neu SüdWales).

38. Platycercus ignitus. - Feucrittich.

Englisch: Fiery Parrakeet.

Platycercus ignitus (1837) Leadb. Proc. Zool. Soc. V, p. 8.

Abbildung: Gould Birds Austral. V, pl. 30.

Diagnose: Miniato-coccineus; interscapulii plumis et scapularibus nigris miniato-limbatis; macula magna utroque mandibulari alba; ala ut in $\mathrm{Pl}$. Bromni tincta, sed remigibus basi albis; rectricibus duabus mediis dilute miniatis, ceteris dilute azureis, basi obscurioribus, apice albidis; rostro, pedibus et iride ut in Pl. Browni tinctis. Mensurae Pl. eximii (teste Gould).

[Diese Art ist noch immer zweifelhaft, Gould betrachtet sie, nachdem dieselhe in den „Birds of Australia“ abgebildet, später als Spielart von $\mathrm{Pl}$. eximius. Die Abbildung macht in der That den Eindruck einer Spielart. Eine weisse Fliigelbinde kommt in der Weise, wie die in Rede stehende Form dieselbe zeigt, bei keiner verwandten Art vor, wohl aber zeigt sich oft individuell und mehr oder minder deutlich ein weisser Fleck auf der Mitte der Innenfahne der Schwingen, wodurch eine weisse Binde auf der Flïgelunterseite gebildet wird.]

Vorkommen: Australische Subregion (Moreton Bay, OstAustralien).

39. Platycercus tlaveolus. - Strohsittic h.

Englisch: Yellow-rumper Parrakeet. - Franziosisch : Perruche à couleur de paille.

Platyremers flaveolus (1837) Gould Proc. Zool. Soc. p. 26. 
Abbildungen: Gould Birds Austral. V, pl. 25. - Reichenow Vogelbilder t. XIV, f. 3.

Diagnose: Stramineus; cervicis et interscapulii plumis scapularibusque nigris stramineo-marginatis; fronte et loris hyacinthinis; macula utroque mandibulari dilute azurea: ala, cauda, rostro, pedibus et iride praecedentibus simillimis.

Long. c. 350, ala 165, cauda 190, culmen $20 \mathrm{Mm}$.

ㅇ: Non satis congnita.

Vorkommen: Australische Subregion (Inneres von Neu SürWales).

40. Platycercus flaviventris. - Gelbbauchsittich.

Port Linkoln Sittich. - Englisch: Yellow bellied Parrakeet. Französisch: Perruche à ventre jaune.

Psittacus flavigaster (!) (1819) Temm. Lin. Trans. XIII, p. 116. - Psittacus flaviventris ibid. p. 117. - Psittacus caledonius (1788) Gmel. S. N. I. p. 318. - Platycercus ranthogaster (1826) Shaw. Gen. Zool. XIV, p. 120.

Abbildungen: Levaillant Hist. Nat. Perr. pl. 80. - Gould Birds Austral. V, pl. 24. - Bourjot St. Hilaire Hist. Nat. Perr. pl. 29. - Reichenow Vogelbilder t. XIV, f. 2.

Diagnose: Capite et gastraeo sordide luteis, sincipite rubro, macula utroque mandibulari azurea; cervicis et interseapulii plumis scapularibusque nigris, olivaceo-viridi limbatis, tergo, uropygio et supracaudalibus olivascente flavis; ala, cauda, rostro, pedibus et iride praecedentibus simillimis.

Long. c. 320, ala 170, cauda 180, culmen $17 \mathrm{Mm}$.

오: Interscapulio et scapularibus unicoloribus virescente nigris; gastraeo virescente flavo.

Vorkommen: Australische Subregion (Südliches Australien, Tasmanien, Inseln der Bass-strasse).

41. Platycercus adelaidensis. - Fasansittich.

Adelaide Sittich. -- Englisch: Adelaide Parrakeet. - Franz.: Perruche hyacinthe.

Platycercus Adelaidice (?) (1840) Gould Proc. Z. S. VIII, p. 161. - Platycercus adelaidensis (1865) Gould Handbuch Austral. II, p. 46.

Abbildungen: Gould Birds Austral. V, pl. 22. - Reichenow Vogelbilder t. XIV, f. 4.

Diagnose: Capite, gastraeo, tergo, uropygio et supracaudali- 
bus hyacinthinis; cervicis et interseapulii plumis scapularibusque nigris, sordide flavido-, vel pallirle hyacinthino-limbatis; macula utroque mandibulari azurea; alis, cauda, rostro, pedibus et iride praecedentibus simillimis.

Long. c. 380 , ala 180, cauda 220, culmen $20 \mathrm{Mm}$.

오: Non satis cognita.

Vorkommen: Australische Subregion (Südaustralien).

42. Platycercus elegans. - B us chw alds it tich.

Pennant-Sittich. - Englisch: Pennant's Parrakeet. Französisch: Perruche purpure.

Psittams elegans (1788) Gm. S. N. 1, p. 318. - Psittacus gloviosus (1789-1813) Shaw. Nat. Misc. pl. 53. - Psittacus Pemnanti (1790) Lath. Ind. Ornith. I, p. 90. - Psittucus splendidus (1792) Shaw. Lev. Mus. p. 27.

Abbildungen: Levaill. Hist. Nat. Perr. pl. 78, 79. - Gould Birds Austral. V, pl. 23. - Reichenow Vogelbilder t. XIV, f. 1.

Diagnose: Carmineus; interscapulii plumis et scapularibus nigris, carmineo-marginatis; macula utroque mandibulari azurea: ala caudaque ut in $P$. Browni sed obscurius tinctis; rectricibus mediis obscure azureis; rostro et pedibus plumbeis, culmine et apice pallidis; iride fusca.

Long. c. 370, ala 175, cauda 200, culmen $19 \mathrm{Mm}$.

ㅇ: Non satis cognita.

Vorkommen: Australische Subregion (Neu Süd-Wales).

43. Platycercus Barnardi. - Gelbna cken-Sit t ch.

Engl. , Barnard's Parrakeet. - Franz.: Perruche Barnard. Platycercus Barmardi (1826) Vig. Horsf. Trans. L. S. XV, p. 283. - Barnardius typicus (1854) Bp. Rev. Mag. Hist. Nat. p. 153.

Abbildungen: Lear Illustr. Parr. pl. 18. - Bourjot St. Hilaire Hist. Nat. Perr. pl. 32. - Gould Birds Austral. Y, pl. 21. - Reichenow Vogelbilder t. XVI, f. 2.

Diagnose: Thalassinus; interscapulio et scapularibus cyanescente nigris; fascia occipitali fusca; fronte rubra; fascia auchenii, interdum medio interrupta, sulfurea; epigastrio medin croceo; mandibula dilute caeruleo-circumscripta; subalaribus coeruleis; flexura cyanea; remigibus primariis earumque tectricibus fuscis, pogonio externo cyancis: cauda, rostro, pedibus et iride ut in $P$. zonario tinctis. 
Long. c. 350, ala 160, caud. 180 , culmen $20 \mathrm{Mm}$.

오: Parum dilutior, interscapulio et scapularibus obscure viridibus.

Vorkommen: Australische Subregion (Süd-Australien, Neu Süd-Wales).

44. Platycercus semitorquatus. - Kragensittich.

Englisch: Yellow-collared Parrakeet, Twenty-eight Parrakeet. Französisch: Perruche barbe bleu.

Psittacus semitorquatus (1830) Qu. Gaim. Voy. Astrol. p. 237. Comume coevuleo-borbutus $(1837-1838)$ Bourjot St. Hil. Hist. Nat. Perr. pl. 40.

Abbildungen: Lear Illustr. Parr. pl. 17. - Bourjot St. Hil. 1. c. - Qu. Gaim. 1. c. pl. 23. - Gould Birds Austral. V, pl. 19. - Reichenow Vogelbilder t. III, f. 2.

Diagnose: Viridis; campterio, crisso et subcaudalibus dilutioribus; capite nigro-fusco, macula mandibulari azurea; fronte rubro; fascia auchenii sulfurea; subalaribus coeruleis; remigibus primariis earumque tectricibus fuscis, pogonio externo cyaneis; cauda etc. ut in $P l$. zonario tinctis.

Hace species $P l$. zonario similis est, sed epigastrio ventreque viridibus, nec luteis, fronte semper rubra et mensuris majoribus diversa.

Long. c. 410, ala 190, cauda 225, culmen 25 Mn.

ㅇ: Fascia frontali et maculis mandibularibus minus extensis. Vorkommen: Australische Subregion (West-Australien).

45. Platycercus zonarius. - Ringsittich.

Englisch: Bauer's Parrakeet. - Franz.: Perruche Bauer.

Psittacus zonarius (1789-1813) Shaw. Nat. Misc. pl. 657. Psittacus viridis (1811) Shaw. Gen. Zool. VIII, p. 465. - Psittacus Baueri (1819) Tem. Trans. L. S. XIII, p. 118. - Psittacus cyanomelas (1820) Kuhl. Consp. Ps. p. 53. -

Abbildungen: Gould Birds of Austral. V, pl. 20. - Reichenow Vogelbilder t. XVI, f. 3.

Diagnose: Viridis; campterio, crisso et subcaudalibus dilutioribus; capite nigro-fusco, macula mandibulari azurea; fascia auchenii sulfurea; epigastrio et ventris lateribus luteis; subalaribus virescente cyaneis; remigibus primariis earumque tectricibus fuscis, pogonio externo cyaneis; cauda, rostro, pedibus 
et iride ut in $\mathrm{Pl}$. Browni tinctis, sed rectricibus mediis fere totis viridibus (interdum fronte rubro-imbuta).

Long. c. 390 , ala 175 , cauda 220 , culmen $22 \mathrm{Mm}$.

ㅇ: Maculis mandibularibus minus extensis, epigastrii fascia lutea angustiore.

Vorkommen: Australische Subregion (Suid-Australien).

Subgenus: PURPUREOCEPHALUS. D ïnnschnäbler.

Purpureicephalus (1854) Bonaparte Ann. Sc. Nat. p. 108 (Typus: Psittacus spurius Kuhl).

Charakter der Untergattung: Schnabel gestreckter, länger als hoch und etwas seitlich zusammengedrïckt, mit deutlichem Zahn. Zweite und dritte Schwinge am längsten, fünfte etwa gleich der ersten und beide kürzer als die vierte. Zweite bis fünfte Schwinge an der Spitzenhälfte verschmälert. - Nur eine Art in der Australischen Subregion.

46. Platycercus spurius. - Kappensittich.

Englisch: Pileated-Parrakeet. - Französisch: Perruche à tête pourpie.

Psittacus spurius (1820) Kuhl Consp. Psitt. p. 52. - Platycercus pileatus (1830) Vig. Zool. Journ. V, p. 274. - Psittacus purpureocephalus (1830) Qu. Gaim. Voy. Astrol. I. Zool. p. 235. Platycercus vufifrons (1831) Less. Traité d'Orn. p. 208.

Abbildungen: Bourj. St. Hilaire Hist. Nat. Perr. pl. 39 et 9 (jun.). - Qu. Gaim. 1. c., pl. 22. - Gould Birds Austral. V, pl. 32. - Reichenow Vogelbilder t. XVI, f. 6.

Diagnose: Pileo carmineo; tibiis, crisso medio et subcaudalibus coccineis; gutture, pectore, epigastrio et subalaribus azureis; capitis et crissi lateribus flavo-viridibus; cervice, interscapulio, tergo et alarum tectricibus viridibus; uropygio et supracaudalibus viridi-Havis; flexura, campterio et remigibus primariis earumque tectricibus pogonio externo cyaneis; cauda etc. ut in $P l$. zonario tinctis.

Long. c. 390 , ala 155 , cauda 210 , culmen $25 \mathrm{Mm}$.

ᄋ: Gutture, pectore ventreque violascente canis.

Vorkommen: Australische Subregion (West-Australien).

Subgenus: PTISTES. Kurzschwänze.

Ftistes (1865) Gould Handb. Birds of Australia II, p. 37 (Typus: Psittacus erythropterus, Gm.). 
Charakter iler Untergattung: Schwanz kürzer als der Flügel, die Federn in ihrer ganzen Länge ziemlich gleich breit, alle mit Ausnahme der beiden äussersten, kürzeren ziemlich gleich lang. Im Flügel sind die zweite und dritte Schwinge am längsten; die erste ist gleich der vierten; zweite bis vierte an dem Spitzendrittel verschmälert. - Drei verschiedene Formen in der Australischen und Austromalayischen Subregion.

47. Platycercus jonquillaceus. - Timorsittich.

Englisch: Red spotted Parrakeet. - Französisch: Perruche Jonquille.

Psittacus jonquillaceus (1823) Vieill. N. D. 25, 1. 352. Psittucus vulneratus (1832) Wagl. Mon. Ps. p. 533. -- Psittucus rubripennis (1857) Schleg. Handleid. p. 183 (teste Finsch Pap. II, 1. 265).

Abbildungen: Bourjot St. Hilaire H. Nat. Perr. pl. 35, b. Qu. Gaim. Voy. Astrol. 1829, pl. 27.

Diagnose: Viridis, interscapulio obscuriore; tergo coeruleo; alarum tectricibus anterioribus coccineis, posterioribus olivaceoflavis; rectricibus pogonio interno et subtus nigris, apice flavidis; rostro coccineo; pedibus nigricantibus, iricle fusca.

Long. c. 320 , ala 210 , cauda 160 , culmen $18 \mathrm{Mm}$.

오 : Rectricibus pogonio interno flavo-limbatis.

Vorkommen: Westliche Austro-Malayische Subregion (Timor).

48. Platycercus erythropterus. - Scharlachflügel.

Englisch: Rerl-winged Parrakeet. - Französisch: Perruche érythroptère.

Psittucus erythropterus (1788) Gmel. S. N. I, p. 343. Psittacus melanotus $(1789-1813)$ Shaw. Nat. Mise. pl. 653.

Abbildungen: Lear Illustr. Parr. pl. 14. 15. - Bourjot St. Hilaire Hist. Nat. Perr. pl. 35 et 35, b. - Gould Birds Austral. V, pl. 18. - Reichenow Vogelbilder t. III, f. 3.

Diagnose: Viridis, gastraeo flavescente; interscapulio et scapularibus nigris; tergo coeruleo; alarum tectricibus coccineis; rectricibus pogonio interno et subtus nigris, apice flavidis; rostro coccineo; pedibus nigricantibus; iride coccinea.

Long c. 330 , ala 200 , cauda 155 , culmen $18 \mathrm{Mm}$.

\&: Macula alari coccinea angustiore et dilutiore, tergo lilute coeruleo; rectricibus exterioribus intus roseo-limbatis.

Vorkommen: Australische Subregion (Ost-Australien). 
49. Subspecies: cocineoptems. - Kleiner Scharlachfliigel.

Fnglisch: Crimson-winged Parrakeet. -- Französisch: Petit Perruche érythroptère.

Ptistes coccineopterus (1865) Gould Handb. Birds Austral. II, p. 39.

Abbildung fehlt.

Diagnose: $P l$. enythroptero simillimus sed parum minor, rostro parum robustiore, alarum tectricibus dilutius coccineotinctis.

Long. c. 300, ala 190, cauda 130, culmen $19 \mathrm{Mm}$.

Vorkommen: Australische Subregion (West-Australien).

Subgenus: APROSMICTUS. Königssittiche.

Aprosmictus (1842) Gould Proc. Z. Soc, p. 111. - (Typus: Psittacus scapulatus Bechst.).

Charakter der Untergattung: Der schwache Schnabel mit ziemlich deutlichem Zahn. Schwanzfedern breit, in ihrer ganzen Ausdehnung ziemlich gleich, in der Mitte des Endsaumes eine kleine Spitze. Zweite und dritte Schwinge am längsten oder zweite wenig kiirzer, erste kürzer als vierte. Dritte Schwinge spitz, zweite bis vierte an der Spitzenhälfte verschmälert. Neun verschiedene Formen in der Austromalayischen und (zwei davon) Australischen Subregion.

50. Platycercus insignissimus. - Kaisersittich.

Englisch: Beautiful King-Parrot.

Aprosmictus insignissimus (1875) Gould P. Z. S. p. 314.

Abbildung: Gould Birds New Guinea Pt. I.

Diagnose: Viridis, alis caudaque obscurius tinctis; vertice, occipite, plumis cervicis nonnullis et gastraeo coccineis; tergo et uropygio cyaneis; macula magna alari lutea, plumis singulis coccineo-limbatis; subalaribus coeruleo-viridibus; hypochondriis viridi- et coccineo-variis; rostro miniato; pedibus griseis; iride brunnea.

Long. c. 420, ala 220, cauda $200 \mathrm{Mm}$. (teste Gould).

Vorkommen: Australische Subregion (Queensland).

51. Platycercus scapulatus. - Königslori.

Englisch: King Parrakeet. - Französisçh: Platycerque à croupion bleu.

Perruche à collier et croupion bleu (1801-1805) Lev. H. 
Nat. Perr. pl. 55. 56. - Psittueus scapulatus (1820) Bechst. Kuhl Consp. Psitt. p. 56. - Psittacus cyanopyyius (1823) Vieil. Nouv. Dict. XXV, p. 339. - Platycercus scapularis (1829) Sws. Zool. Ill. Second. series pl. 26.

Abbildungen: Levaillant Perr. pl. 55 et 56. - Swainson 1. c. - Gould Birds Austral. V, pl. 17. - Reichenow Vogelbilder t. III, f. 4 ( $\sigma$ und 오).

Diagnose: Capite, collo et gastraeo toto coccineis; interscapulio et alis obscure viridibus; macula scapulari thalassina; uropygio et torque angusta nuchali cyaneis; subcaudalibus cyaneis, apice coccineis; cauda et supracaudalibus nigris; subalaribus viridi-coeruleis; rostro coccineo, apice et mandibula nigricante; pedibus nigricantibus; iride flavi.

Long. c. 420, ala 210, cauda 210, culmen $24 \mathrm{Mm}$.

\&: Capite et collo viridibus; rostro toto nigricante.

Vorkommen: Australische Subregion (Süd-Australien).

52. Platycercus amboinensis. - Amboina-Sittich.

Englisch: Amboina Red-Parrakeet. - Französisch: Perruche d'Amboine.

Psittecene amboinensis cocinere (1760) briss. Ornith. IV, p. 378, t. 28, f. 2. - Psittucus amboinensis (1766) Lin. S. N. p. 141. - Perruche rouge d'Amboine (1783) Buffon Pl. EnI. pl. 240. - Comurus dorso- ceverelés (1837-1838) Bourjot St. Hilaire Hist. Nat. Perr. pl. 41. (Könnte der hellen rothen Farbe wegen sich vielleicht eher auf callopterus beziehen.)

Abbildungen: Buffon 1. c. - Bourjot St. Hil. 1. c.

Diaguose: Capite, collo et gastraeo toto carmineis; subcaudalibus basi eyanescente griseis; alis totis obseure viridibus; dorso toto, campterio et subalaribus eyaneis; rectricibus obscure cyaneis, intus et apice roseo-limbatis, subtus nigris; rostro nigricante, maxillae basi miniato; pedibus nigricantibus; iride Hava. Long. c. 350--400, ala 190-200, caudia 210-220, culmen 22 Mm. Junior: Interscapulio viridi, cyaneo-variegato.

Vorkommen: Austro-Malayische Subregion (Neu-Guinea, Ceram, Buru.

53. Subspecies sulaensis. - Sula-Sittich. Aprosmictus sulaensis (1881) Reichenow.

Abbildung fehlt. 
Diagnose: $P l$. amboinensi simillimus, sed parum minor; rectricum limbis roseis indistinctis, alis viridibus dilutiore-tinctis.

Ala 175, cauda 200, culmen $19 \mathrm{Mm}$.

Vorkommen: Westliche Austro-Malayische Subregion (SulaInseln).

54. Subspecies: buruensis. - Buru-Sittich.

Aprosmictus buruensis (1876) Salvadori Ann. Mus. Civ. Gen. VIII, p. 371 .

Abbildung fehlt.

Diagnose: $P l$. cmboinensi simillimus sed major et rostro toto nigro, vel apice miniato.

Long. tot. 450 , ala 215 bis 230 , cauda 250 bis 270 , culmen $25 \mathrm{Mm}$.

Vorkommen: Westliche Austro-Malayische Subregion (BuruInseln).

55. Subspecies: dorsalis. - Neu Guinea-Sittich.

Psittacus (Platycercus) dorsalis (1830) Qu. Gaim. Voy. Astrol. Zool. p. 234.

Abbildung: Qu. Gaim. 1. c., pl. 21, f. 3.

Diagnose: $P l$. amboinensi simillimus; rectricum limbis roseis nullis; subcaudalibus basi cyaneis; campterio cyanescente.

Long. tot. c. 400, ala 190, cauda 210, culmen $22 \mathrm{Mm}$.

Jun.: Interscapulii plumis viridibus, cyaneo marginatis; rectricum apicibus roseis.

Vorkommen: Oestliche Austro-Malayische Subregion (NeuGuinea).

56. Platysercus calloptemus. - Gelbflügel.

Englisch: Yellow - winged King - Parrot. - Französisch: Perruche à dos bleu.

Aprosmictus callopterus (1879) d'Albertis e Salvadori, Ann. Mus. Civ. Genova XIV, 10. Marzo, p. 29.

Abbildung: Gould Birds New Guinea Pt. X.

Diagnose: Capite, collo et gastraeo toto rubro - puniceis; dorso toto et subcaudalibus pulchre cyaneis; scapularibus nigris, cyaneo-marginatis; alis viridibus, tectricibus minoribus, mediis et majoribus dorso proximis laetissime flavo-viridibus; cauda superne atro-caerulea, inferne nigra; maxilla rubra, apice nigra, mandibula nigra; pedibus nigris; iride aurantia.

Long. c. 375, ala 195, cauda 230, culmen $23 \mathrm{Mm}$.

Cab. Journal f. Ornithol. XXIX. Jahrg. No. 154. April 1881. 
우: Viridis; abdomine rubro; collo antico et pectore summo olivascentibus, plumarum marginibus rubris; uropygio et supracaudalibus laete caeruleis; rostro nigro, maxillae basi superne rubescente.

Vorkommen: Oestliche Austro-Malayische Subregion (NeuGuinea).

57. Subspecies: chloropterus. - Kleiner Gelbflügel.

Englisch: Smaller yellow-winged Parrakeet. - Französisch: Perruche chloroptère.

Aprosmictus chloropterus (1879) E. P. Ramsay Proc. L. Soc. N. S. Wales, Vol. III, p. 251 (gelesen am 30. September 1878). Aprosmictus Broadbenti (1879) R. B. Sharpe, Anu. Mag. Nat. Hist. Vol. 3, No. 16 (April), p. 313.

Diagnose: Pl. calloptero similis, sed occipite nuchaque laete caeruleis, subcaudalibus caerulescente-nigris, coccineo terminatis distinguendus.

Vorkommen: Oestliche Austro-Malayische Subregion (NeuGuinea).

58. Platycercus hypophonius. - Halmahera-Sittich.

Englisch: Gilolo Parrot. - Französisch: Perruche de Gilolo.

Psittacus hypophonius (1839-1844) Müller et Schlegel Verh. Nat. Gesch. Land und Völkerk., p. 181. - Platycercus hypophonicus (1846) G. R. Gray Gen. B. II, p. 408.

Abbildung fehlt.

Diagnose: $P l$. amboinensi similis, sed alis cyaneis nec virilibus. L. c. 400 , ala $190-20$, cauda 200--210, culm. $23 \mathrm{Mm}$.

오: Ignota.

Juv.: Interscapulii plumis viridi-marginatis; rectricibus apice rubris; rostro miniato.

Vorkommen: Westliche Austro-Malayische Subregion (Halmahera, Moluccen).

Subgenus: PYRRHULOPSIS. Dickschuabel-Plattschweifsittiche.

Pyrrhulopsis (1850) Reichenbach (teste Gray List. Spec. B. Brit. Mus. Pt. III, Sect. II, 1859, p. 3). (Typus: Coracopsis personatus Gray). - Prosopeia (1854) Bonap. Rev. Mag. Zool. p. 153 (Typus: C. personatus Gray).

Charakter der Untergattung: Durch auffallend dicken Schnabel mit mehr oder weniger deutlichem Zahn ausgezeichnet. 
Schwanzfedern sehr breit und ihre Kiele nach aussen gebogen, wodurch der Schwanz an der Basalhälfte breite fächerartige Form erhält. Dritte und vierte Schwinge am längsten, zweite gleich der fünften, erste gleich der sechsten, zweite bis sechste an der Spitzenhälfte verschmälert. - Fünf Arten und Unterarten in der Polynesischen Subregion.

59. Platycercus splendens. - S maragd-Sittich.

Engl.: Shining Parrakeet. - Franz.: Perruche brillante.

Platycercus splendens (1848) Peale Un. St. Exp. p. 127.

Abbildungen: Peale 1. c., pl. 34, f. 1. - Finsch u. Hartl. Centralpolyn. t. 2, f. 2 (Ei). - Reichenow Vogelbilder t. XVI, fig. 4 .

Diagnose: Capite et gastraeo carmineis; nucha cyanea; dorso et alis omnino viridibus; subalaribus cocrulescente-viridibus, rubro-apicatis; manus tectricibus et pteryllio coerulescentibus; remigibus et tectricibus primariis majoribus nigris, pogonio externo cyaneis; rectricibus mediis viridibus, apice cyaneis; ceteris cyaneis, intus nigris, basi extus virescentibus; omnibus subtus nigris; rostro et pedibus nigris; iride rubra.

Long. c. 460, ala 235, cauda 245, culmen $33 \mathrm{Mm}$.

Vorkommen: Südliche Polynesische Subregion (Viti Levu und Kandavu, Fidji-Inseln).

60. Platycercus tabuensis, - Pompadour-Sittich.

Englisch: Tabuan Parrakeet. - Französisch: Perruche Anna Tabuane, Perruche marron.

Psittacus tabuensis (1788) Gmel. S. N. I, p. 317. Psittecus atropurpureus (1792) Shaw Lev. Mus. p. 142. Platycereus atrogularis (1848) Peale Un. St. Expl. Exp. p. 129. Abbildungen: Peale 1. c., pl. 35. - Lear Illustr. Parr. pl. 16.

Diagnose: Capite et gastraeo cerasinis, facie nigricante; torque nuchali cyanea, dorso et alis omnino viridibus; uropygii plumis nonuullis cerasino-limbatis; manus tectricibus et pteryllio coeruleis; remigibus et tectricibus majoribus primariis nigris, pogonio externo cyaneis; subalaribus coeruleo-viridibus, cerasinolimbatis; rectricibus mediis viridibus, apice cyaneis; ceteris cyaneis, intus nigris, basi extus virescentibus; omnibus subtus nigris; rostro et pedibus nigris; iride lutea.

Long. c. 490, ala 255, caud. 250, culmen $35 \mathrm{Mm}$. 
Vorkommen: Südliche Polynesische Subregion (Vanua Levu, Fidji Inseln).

61. Subspecies: hysginus. - Koro-Sittich.

Psittacus hysginus (1844) Forst. Lcht. Descr. Anim. p. 159. Platycercus koroensis (1876) Layard Ibis, p. 143 und 391.

Abbildung fehlt.

Diagnose: $P$ l. tabuensi simillimus, sed torque nuchali cyanea tenuissima, indistincta.

Vorkommen: Südl. Polynesische Subregion (Koro, Fidji Inseln).

62. Subspecies: Anna. - Anna-Sittich.

Englisch: Anna Parrakeet. - Franz.: Perruche Anna.

Conurus Anna (1837-1838) Bourj. St. Hil. H. N. P. pl. 38. Platycercus taviunensis (1876) Layard Ibis, p. 141.

Abbildungen: Bourjot St. Hil. 1. c. - Reichenow Vogelbilder t. XVI, f. 1.

Diagnose: $P l$. tabuensi simillimus, sed torque nuchali nulla.

Vorkommen: Südliche Polynesische Subregion (Taviuni, Fidji Inseln).

63. Platycercus personatus. - Maskensittich.

Engl.: Masked Parrakeet. - Franz.: Perruche masqué.

Coracopsis personatus (1848) G. R. Gray, Proc. Z. Soc. p. 20.

Abbildungen: Proc. Zool. Soc. 1848, Aves pl. 3. - Peale Un. St. Expl. Exp. pl. 34, f. 4. - Cass. Un. St. Expl. Exp. II, Ed. 1858, t. 20. - Reichenow Vogelbilder t. XVI, f. 5.

Diagnose: Smaragdino-viridis; facie nigro; pectore et epigastrio mediis luteis; ventre medio croceo; rectricibus viridibus, margine interiore et subtus nigris; remigibus nigris, primariis pogonio externo coeruleis, secundariis extus viridibus; pteryllio et tectricibus primariis majoribus coeruleis; rostro et pedibus nigris; iride fusca.

Long. c. 490 , ala 335 , cauda 250 , culmen $33 \mathrm{Mm}$.

Vorkommen: Südl. Polynesische Subregion (Fidschi Inseln).

Subgenus: POLYTELIS. Prachtsittiche.

Polytelis (1830) Wagl. Mon. Psitt. p. 489 (Typus: Psittacus Barrabandi Sws). - Barrabandius (1849) Bonap. Consp. Av. I, p. 2 (Typus: Psittacus Barrabandi Sws.).

Charakter der Untergattung: Sehr langer Schwanz, die beiden mittelsten Federn über die anderen hinaus sehr stark 
verlängert; alle schmal, nach dem Ende zu allmälig verengt. Schnabel schwach. Zweite und dritte Schwinge am längsten, vierte kürzer als erste, zweite und dritte an dem Spitzendrittel verengt. - Irei Arten in der Australischen Subregion.

64. Platycercus Alexandrae. - Blaukappe.

Englisch: Princess of Wales's Parrakeet. - Französisch: Perruche à calotte bleue.

Polytelis Alexandrae (1863) Gould Proc. Zool. Soc. p. 232. Abbildung: Gould Birds Austral. Suppl.

Diagnose: Olivaceo-flavus, dorso brunnescente olivaceo, tectricibus alarum flavidis; pileo et uropygio coeruleis; genis guttureque roseis; tibiis coccineis; rectricibus pogonio externo viridibus, interno roseis, apice flavidis; rostro coccineo; pedibus cinereis; iride crocea.

Ala 180, cauda $220 \mathrm{Mm}$. (teste Gould).

Vorkommen: Australische Subregion (Central-Australien).

65. Platycercus Barrabandi. - Schildsittich.

Englisch: Barraband's Parrakeet, Green Leek. - Französisch: Perruche Barraband.

Psittacus Barrabandi (1820-1821) Sws. Zool. Illustr. Vol. I, pl. 59. - Palaeornis rosaceus (1830) Vig. Zool. Journ. V, p. 274. Psittacus sagittifer Barrabandi (1837-1838) Bourj. St. Hilaire Hist. Nat. Perr. pl. 4. -- Psittacus sagittifer rosaceus ibid. pl. 6. (우). - Psittacus Swainsoni (1859) Desm. Gray List Sp. B. Brit. Mus. Psitt. p. 9.

Abbildungen: Lear Illustr. pl. 30. - Swainson 1. c., pl. 59. - Bourjot 1. c., pl. 4 und 6. - Gould Birds Austral. V, pl. 15. - Reichenow Vogelbilder t. III, f. 1.

Diagnose: Viridis; occipite, remigibus, tectricibus primariis et rectricibus exterioribus coerulescente imbutis; sincipite, genis, gula et colli lateribus luteis; scuto gulari coccineo; tibiis interdum coccineis; rostro miniato; pedibus nigricantibus; iride miniata.

Long. c. 360, ala 180 , cauda 190 , culmen $17 \mathrm{Mm}$.

\&: Capite et collo totis viridibus, dilute coerulescente imbutis; rectricibus pogonio interno roseo-limbatis.

Vorkommen: Australische Subregion (Inneres von Neu SüdWales). 
66. Platycercus melamums. - Bergsittich.

Englisch: Black-tailed Parrakeet, Rockpeplar. - Franz.: Perruche sagittifère.

Palacornis melanume (1832) Lear Illustr. Parr. pl. 28. Palaeomis anthopeplus (1832) ibicl. jun. pl. 29. - Psittacus sagittifer melanure (1837-1838) Bourjot St. Hilaire Hist. Nat. Perr. pl. 5. - Psittacus sagittifer anthopeplus ibid. pl. 7 (jun.).

Abbildungen: Lear Illustr. Parr. pl. 28 und 29. - Bourj. St. Hilaire 1. c., pl. 5 und 7 (var.). - Gould Birds Austral. V, pl. 16. - Reichenow Vogelbilder t. III, f. 6.

Diagnose: Sulfureus, pileo olivascente; interscapulio et scapularibus olivaceo-brunneis; remigibus, tectricibus majoribus, pteryllio et rectricibus nigris, extus cyanescente-imbutis, his pallide apicatis; tectricibus majoribus ultimis apice rubris; rostro coccineo; pedibus nigricantibus; iride rubra.

Long. c. $38 v$, ala 198, cauda 205, culmen $31 \mathrm{Mm}$.

ㅇ: Parum obscurius, viridius tincta; macula alari obseuriore; plerumque rectricibus apice et pogonio interno roseo-limbatis.

Vorkommen: Austral. Subregion (Süd- und West-Australien).

\section{Familie: Micropsittacidac. Zwergpapageien.}

Charakter der Familie: Papageien von sehr kleiner, gedrungener Gestalt mit verhültnissmässig starkem Schnabel, welcher höher als lang ist und in der Regel eine deutliche Auskerbung vor der Spitze mit Feilkerben oder ohne solche hat. Wachshaut wie bei den Plattschweifsittichen gebildet oder in Form eines Bandes die ganze Schnabelwurzel umgebend. Flügel spitz. Erste bis dritte Schwinge am längsten, seltener die erste etwas kürzer. Der Schwanz ist kurz, inmer kürzer als der Flügel, gerade, schwach gerundet oder keilförmig, nur bei Psittacella stufig.

Wir vereinigen in dieser Familie drei Gattungen, von welchen wir jedoch eine, Psittacella, nur unter Vorbehalt hierher rechnen können, da sie in wesentlichen Punkten von den beiden anderen sich unterscheidet. Sie scheint uns den Uebergang von den Plattschweifsittichen zu den Zwergpapageien zu vermitteln und dürfte vielleicht noch geeigneter als eine aberrante Form jener Familie zugezählt werden.

Ueber die Lebensweise der in Rede stehenden Formen ist 
so gut als nichts bekannt, womit ein wichtiger Anhalt für die systematische Einreihung uns fehlt. Weiche Früchte sollen vorzugsweise ihre Nahrung bilden; jedenfalls nehmen sie auch Insekten-Nahrung. Sie gehören zum grössten Theile der Austro-Malayischen Subregion, insbesondere Neu-Guinea und den nahe gelegenen Insein an, mit Ausnahme zweier (Cyclopsittacus Coxeni und Maccoyi), welche Australien bewohnen und einer (loxias) indo-malayischen Art.

Genus: PSITTACELLA. Bindensittiche.

Psittacella (1871) Schleg. Ned. Tijdschr. Dierk. IV, p. 35 (Typus: Psittacus Brehmii v. Rosenb.).

Charakter der Gattung: Schnabel und Wachshaut wie bei den Plattschweifsittichen gebildet, ersterer ohne Zahn. Schwanz stufig, aber von mässiger Länge, bedeutend kürzer als die Flügel, welche, angelegt, wenig die Mitte des Schwanzes überragen.

Wie erwähnt, bilden die Bindensittiche den Anschluss der vorstehenden Familie an die Plattschweifsittiche. Fernere Untersuchungen, insbesondere die Erforschung der Lebensweise, werden lehren, ob diese Vögel nicht viehmehr der letzteren Familie einzuordnen sind. Wir kennen gegenwärtig nur zwei Arten, welche Nell-Guinea bewohnen.

1. Psittacella Brehmii. - Grosser Bindensittich.

Psittacus Brehmii (1871) v. Rosenb. Schleg. Ned. Tijdschr. Dicrk. IV, p. 35.

Abbildung: Gould Birds New Guinea IV, pl. 4.

Diagnose: Viridis, notaeo nigro-transfasciolato; capite olivaceofusco; torque gulari flava; crisso rubro; alarum margine cubitali et carpali caeruleis; rostro plumbeo, apice albido; pedibus fuscis; iride lutea.

Long. c. 280, ala 130, cauda- 90, culmen $20 \mathrm{Mm}$.

\$: Paullo minor, collare jugulari flavo nullo; pectore Havescente, nigro-transfasciato.

Vorkommen: Austro-Malayische Subregion (Neu-Guinea, Arfak Berge).

2. Psittacella modesta. - Kleiner Bindensittich.

Psittucus modestus (1871) v. Rosenb. Schleg. Ned. Tijdschr. Dierk. IV, p. 36 . 
Abbildung fehlt.

Diagnose: Viridis; uropygio flavescente, plus minusve conspicue nigro-transfasciato; pectore sordide olivaceo; capite et collo olivaceo-fuscis; subcaudalibus rubris; alarum margine cubitali et carpali coeruleis; rostro plumbeo; pedibus fuscis; iride lutea.

Long. c. 160 , ala 90, cauda 60 , culmen $14 \mathrm{Mm}$.

우: Pectore fasciis transversis rubris, flavo-marginatis et fuscis notato; abdomine flavo-virescente, fasciis fusco-virescentibus transversis notato.

Vorkommen: Austro-Malayische Subregion (Neu-Guinea, Arfak Berge).

Genus: CYCLOPSITTACUS. Z w erg pa pag e i e n.

Cyclopsitta (1853) Jacq. et Puch. Voy. Pole Sud Zool. III, p. 107 (Typus: Psittacule diophthalma Hombr. Jacq.). - Opopsitta (1860) Sclat. Proc. Zool. Soc. p. 227 (Typus: Psittacula diophthalma Hombr. et Jacq.). - Cyclopsittecus (1872) Sund. Met. av. disp. tent. p. 69 (Typus: Psittacus Desmaresti Less.).

Charakter der Gattung: Schnabel seitlich aufgetrieben, Firste etwas abgeflacht, starke Auskerbung vor der Spitze. Wachshaut entweder ein schmales Band um die ganze Basis des Oberkiefers oder nur die Nasenlöcher ungebend, wie bei den Plattschweifsittichen. Schwanz in der Regel kurz und keilförmig, seltener (lumulatus, suavissimus) schwach gerundet, Steuerfedern nicht von besonderer Form.

Sämmliche bekannten 13 Arten sind kleine Vögel, welche ihres kurzen Schwanzes wegen recht eigentlich zwerghaft erscheinen. Sie bewohnen Neu-Guinea und einige der nahe gelegenen Inseln, ausser $C$. Coxeni und Macoyi, welche auf dem Festlande Australien heimisch sind und $C$. loxias, welcher die östliche Indo-Malayische Subregion bewohnt.

\section{Schlüssel der Gattung.}

Stirn wie der ganze Kopf grün: lunulatus.

Stirn bläulich grün: Salvadorii.

Stirn blau, Zügel und Strich unter dem Auge weiss, grosser schwarzer Backenfleck: suavissimus.

Stirn blau, Zügel gelblich, Strich unter dem Auge blau, kleiner oder undeutlicher schwarzer Backenfleck: Gulielmi tertii.

Stirn schwarz: melanogenys. 
Stim roth, ganzer Oberkopf goldgelb: Iosmerestii (siche anch: occidentalis, blythii, cervicalis).

Stirn roth, Hinterkopf grïn:

Nur schmaler rother Stirniand: Coxeni.

Rothe, blau eingefasste Stirnbinde: Maccoyi.

Sanzer Vorderkopf roth: diophtlutmus (s. anch: amensic).

3. Cyclopsittacus loxias. - Schupenband-Papagei.

Englisch: Collared Parrakeet. - Französisch: Psittacule ¿i collier écaillé.

Psittacus loxic (1831) Cur., Less. Traité d'Orn. 1) 204 (c').I'sittacus lumulatus (1786) Scop. Del. Fl. F. Insubr. p. Sl; ( . ). Psittacus torquatus (1788) Gm. S. N. I, p. 351 (우).

Abbilduigen: Bourjot St. Hilaire Hist. Nat. Perr. pl. 94 (屯). - Sonnerat Voy. à la Nouv. Guinée (1776) pl. 39 (우).

Diagnose: Viridis, uropygio flavescente; ammulo orbitali, loris; ucnis, mento et fascia auchenii coeruleis; rostro et pedibus nigricantibus. Long. c. 180, aln 105, canda 35, rostrum $20 \mathrm{Mm}$.

온 Loris genisque viridibus: fascia auchenii flava, nigrofasciolata.

Vorkommen: Oestliche Indo-Malityische Suhregion (Luzon). 4. Cyclopsittacus Salualorii. -- Salvadori's Zwergpapagei.

M. E. Oustalet, Bull. hepdom. No. 11, 10. Juin 1580, p. 172.

De la taille du Cyclopsittucus Desmarestii Garn; mais les plumes des jones et des côtés du cou allongées, lancéolées et divergentes; le front n'est pas d'un rouge vif passant en arriere au jaune orangé, mais d'une couleur cendre verte fortement mélangée de bleu d'outremer et ils portent en arrière de l'oeil une tache d'un blen vif. - Hab.: La côte septentrionale de la Nouvelle Guinée entre $136^{\prime \prime}$ et $137^{\prime \prime}$ de longitude est.*)

5. Cyclopsittecus Desmaresti. - Kothkappen-Zwergpapagei.

Engl.: Desmarest's Parrot. - Franz.: Psittacule Desmarest.

Psittacus Desmaresti (1828) Garn Voy. de la Coqu. Zool. I. 1). 600 .

Abbildungen: Garn Voy. Coquille Zool. I, pl. 35. - Bourj. St. Hilaire Hist. Nat. Perr. pl. 85.

Diagnose: Viridis, subtus flavescens, uropygio olivascente;

*) Da wir die Art nicht untersuchen konnten und die kurze Beschreibung uns nicht völlige Klarheit verschafft, so geben wir vorbchaltlich die OriginalDiagnose wieder.

Verf. 
fronte coccinca; vertice et occipite miniato-aurantiis, hoc postice cyaneo-limbato, regione parotica genisque aurantio-virescentibus: loris et stria suboculari coeruleis; hypochondris coeruleis: fiscia pectorali cocrulea, altera inferiore aurantio-hrumnea; subalaribus thalassinis; remigibus pogonii interni basi pallide flavis: rostro nigricante; pedibus nigro-virescentibus; iride Iutea.

Long. c. $210-220$, ala $110-115$, cauda $60-70$, culmen $22 \mathrm{Mm}$. - : : Genis magis virescentibus.

Vorkommen: Austro-Malarische Subregion (Xeu-(ininea).

(i. Sulspecies: mecidentelis. - Westlicher \%werglatpacei.

Gyclopsitlaces vecielentalis (1875) Salv. Aun. Mus. Gen. VII. 1). 10 .

\section{Abbildung fehlt.}

Diagnose: C. Desmaresti simillimus, sed genis, auricularibus mentogue aneo-fiavis et macula cacrulea suboculari dibutione et minore; fascia occipitali cyanea nulla.

Vorkommen: Austro-Malayische Subregion (Westliches XenGuinea, Salavatti, Batanta, Doré).

7. Subspecies. Blythii. - Misol-Zwergpalpagei.

Cyclopsittaces Blythii (1864) Will. Proc. Zool. Sore 1. 2sit. Abbildung fehlt.

Diagnose: C. Desmeresti simillimus, sed stria subosulari cyula nulla; fascia pectorali cocruleal et alteral aurantio-brumeal angustioribus et pallidioribus.

Vorkommen: Austro-Malayische Sulnegion (Misol).

8. Subspecies: cervicalis. - Sii d licher Zwergpapagei.

Englisch: Southern ringed Parrakeet.

Cyclopsittacus cevicalis (1875) Salv, et d'Alb, Ann. Mus. Gen. VII, p. 811.

Abbildung: Gould Birds New Guinea Pt. 10, pl. 2.

Diagnose: $\because$ Desmaresti simillimus sed stria suboculari cyanea nulla: pileo miniato-aurantiaco: genis luteis; torque nuchali aurantiaca; fascia pectorali una tantum lacte cacrulea: fascia auchenii cyanea nulla.

Juv.: Fascia nuchali caerulea, regione parotica inferiore caerulescente.

Vorkommen: Mustro-Malayische Subr. (Südl. Neu-Guinea).

9. Cyclopsittucus Coxeni. - Blauwangen-Zwergpapagei.

Englisch: Coxen's Parrakeet. 
Cyclopsitte coxeni (1867) Gould Proc. Zool. Soc. p. 182. Abbildung: Gould Birds Austral. Suppl. (1867).

I)iagnose: Viridis; fascia frontali, genis superioribus et regione parotica coccineis, genis inferioribus caeruleis; fascia frontali coccinea, postice coeruleo-limbata; lypochondris flavis; remigibus primaris earumque tectricibus pogonio ext rno crancis: romigm pogonii interni basi pallide flara, ultimarum coccinea; maxilla et peribus plumbeis: mandibula albida; iride brumnei.

o: Mari simillima.

Long. c. 180 , ala 100 , cauda 50, culmen $17 \mathrm{Mm}$.

Vorkommen: Australische Subregion.

10. Cyclopsittacus Maccoyi. - Diadem- $/ 2$ wergpapagei.

Englisch: M'Coy's Parrakeet.

ryelopsitte maceledyana (1874) E. P. Ritmsay Sythey Morning Ilerald - Newspaper Nor. 15. - Proceedings Zool. Soc. 1875, 1. 602. - Cyclopsitte Haceoyi (1875) Gould Proc. Zool. Soc. 1). 314 (April). - Cyclopsitte Lendheuteri (1875) M'Coy Ann. X. 1I. XVI, p. 54 (July).

Abbildungen: Gould Birds New Guinea Pt. I, pl. 10. Reichenow Vogelbilder t. XXV, f. 7.

I)iagnose: Viridis; fascia frontali coecinea, thalassino-cirrmucincta; bris et regione ophthalmira thalissinis; genis suplat coccincis, infra azureis; hypochomdris luteis: rostro ot pedibus

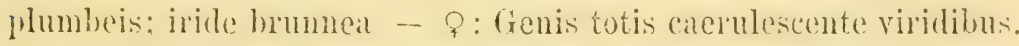

Long. c. 140 , ala $8 j$, cauda $45 \mathrm{Mm}$

Vorkommen: Australische Subregion (Australien).

11. Cycopsittans diophthatmus. - Masken-Zw wergpapagei.

Englisch: Double-eyed Parrakeet. - Franz.: Cyclopsite double oeil.

Psitterula diophethelma (1841) Hombr. et Jacqu. Ann. Sc. Nat. XVI, p. 318.

Abbildungen: Hombr. et Jacqu. Toy. an Pôle Sud pl. 25, 1. 4 et 5. - Gould Birds New Guinea Pt. IX, pl. 4.

Ilagnose: Virilis: sincipite genisque rubris, vertice rubruanratio; macula para antegeulari vel supraculari cobaltina: manka postuenali cyanea; hypochondris flavis: remigibus pri-

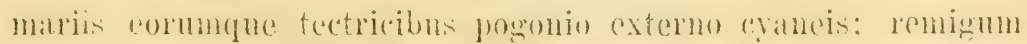
fogonii interni basi dilute flava, ultimarum cocineal rostro et pedibus nigricantibus. 
I.011. c. 160 , ala 90, canda 55, culmen 15 Mm.

우: Sincipite et linea angusta suboculari rubris; macula anteoculari vel supraoculari aerulea: genis fulvis, his subtus et postice cyanco-cinctis.

Vorkommen: Austro-Malayische Subregion (Nen-Guinea. Salavatti, Misol).

12. Subspecies: aruensis. - Aru-Zwergpapagei.

Englisch: Aru-Parrakeet.

Psittacula diophthalma amensis (187t) Schleg. Mus. PaysMals Psittaci. Revue 1).33. -- Cychosittacus armonsis (1874) Salv. Ann. Mus. Civ. Gen. VI, p. 73.

Abbildung: Gould Birds New Guinea Pt. IX, pl. 5.

Diagnose: $\therefore$ dioplethulmo similis, sed vertice viridi, vix vel minime flavicante: sincipite genisque coccineis, his subtus fascia cyanea cinctis; macula minima anteoculari cacrulea.

Long. c. 150, ala 85, cauda 50, culmen $15 \mathrm{Mm}$.

o: Sincipite, loris et regione ophthahmica caeruleis; genis anterioribus fulvis, rectricibus cyaneis.

Vorkommen: Austro-Malayische Subregion (Süd Teu-Guinea, Aru Inseln).

13. Cyclopsittues suctissimus. - Schwarzwangen-Zwergpapagei.

Engl.: D'Albertis Parrakect. - Französisch: Cyclopsitte l'Albertis.

Cyclopsitta sucuissima (1876) Sclat. P. Z. S. London p. 520.

Abbildungen: Proc. Zool. Soc. 1876, pl. 54 (우 et $\sigma^{7}$ ). Gould Birds Vew Gninea Pt. VII, pl. 11. - Reichenow Vogelbilder t. XXV, f. 9 .

Diagnose: Viridis: sincipite azureo; loris et fascia :uboculari albis; genis superioribus nigris, inferioribus flavido-albis; pectore ut gutture miniato-aurantiis; campterio, remigibus primariis eorumque tectricibus pogonio externo cyancis; remigum pogonii interni basi Hava; rostro, perlibus et iride nigricantibus.

Long. c. 130 , ala $78-80$, cauda 35 , culinen $13 \mathrm{Mm}$.

오: Sincipite, stria superciliari genisque azureis; loris albidis; regione frarotica anrea; pectore viridi, aurantiaco-imbuto.

Vorkommen: Austro-Malayische Subr. (Südost Nen-Guinea).

14. Cyclopsitterus Grulielmi terti. - Golibrust-Zwerglapagei.

Englisch: Golden-breasted Parrakect. - Französisch: Cyclopsitte Guillitume. 
Psittacula Grulishini III (1810ii) Schleg. Nerlerl. Tijidschr. Dierk. III, p. 252.

Abbildung fellt.

Diagnose: Viridis, subtus flarescens: sincipite. fascia superriliari, linea subtili suboculari et macula postoculari caeruleis: loris, capitis lateribus gulaque pallicle flavis. macula genarum medio plus minusve conspicua nigricante: gutture pectorepue laete aurantiacis; rostro et pedibus nigricantibus.

Long. c. $150-160$, ala 90-95, cauda 45, culmen $16 \mathrm{Mm}$.

ㅇ: Gutture pectoreque flavescente viridibus: genis antice flavis: regione parotica aurantia, fascia perpendiculari nigra medio capitis laterum a genis anterioribus divisa.

Vorkommen: Austro-Malayische Subregion (Salavatti, NenGuinea).

15. Cyclopsittucus melanoyenys. - Schwarzstimiger Zwergpapagei.

Englisch: Black-cheeked Parrakeet. - Franzïsis ho Crclopsitte à front noir.

Psittacula melanogenia (1866) v. Rosenberg, Schleg. Nederl. Tijdschr. Dierk. III, p. 330. - Psittuculu melunngenys (1868) Finsch Pap. II, p. 626. - Cyclopsittucus fuscifions (1876) Salv. Ann. Mus. Civ. IX, p. 14.

Abbildung: Gould Birds New Guinea VII, pl. 12.

Diagnose: Viridis; loris et stria suboculari albis; genis anterioribus nigris, posterioribus flavo-albidis; fronte et regione ophthalmica nigris; gutture et pectore miniato-aurantiis; margine alari, remigibus primariis eorumque tectricibus pogonio externo cyaneis; remigibus intus basin versus flavidis: rostro nigro; pedibus olivaceis; iride saturate brunnea.

Long. c. 120, ala 75-80, cauda 30, culmen $12 \mathrm{Mm}$.

of: Loris et stria suboculari pallide flavidis; genis posterioribus aurantiis; gula caerulescente viridi; pectore aurantiaco pallidiore.

Vorkommen: Austro-Malayische Subregion (Sü̈l Neu-Guinea, Ar'u Inselu).

Genus: NASTTERNA. Spechtpapageien.

Mieropsitte [!] (1831) Lesson Traité d'Orn. p. 646 (Typus:

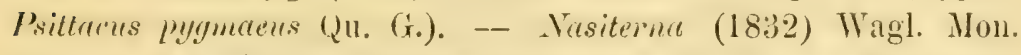
Psitt. p. 498 (Typus: Psittacus pygmaeus Qu. G.). - Micropsites 
(1836) Geoffroy St. Hil. Cours d'Ornith., Mus. Hist. Nat. Paris | firle: Bourjot St. Hilaire| (Typus: Ps. Pyemancens (qu. G.).

Charakter der frattung: Schmabel wie hei den Kakadus gebildet: an der Basis breit, an der Firste zusammengedrückt. mit starker Auskerbung vor der Spitze. Wachshaut ehenfalls wie bei den Kakadus gebildet: cin hreites Band, welches über der Firste eingezogen ist. um den Nasenlöchern aber sich verdickt, was nicht in gleichem Grade hei den hakarlus hervortritt, dagegen bei den Plattschweifsittichen sich findet. Höchst bezeichnend ist der kurze gerade Schwanz, dessen Federn vexlängerte, stachelartio iiher das Ende der Ferlerfahne her 'orragende Schaftspitzen haben. Dic verhïltnissmïssig langen Flïgel haben die doppelte Länge des Schwanzes und reichen, angelegt, fast bis zur Spitze desselben. Die Zehen sind auffallend lang und düm. Alle acht bekannten Arten sind winzig kleine Vögelchen, die kleinsten aller Papageien. Sie bewohnen Neu-Guinea und einige rer nahe gelegenen Inseln. Ueber dic Lebensweise sind leider bisher nur düftige Notizen publicirt worden, nach welchen diese Papageien nach Art der Spechte an den Bäumen umherklettern, worauf auch einerseits die langen Zehen hinweisen, wie andererseits die Form der Stenerfedern, bei welchen, wie es scheint, die Spitzen der Fahnen dureh das Anliegen an der Bamminde beim Klettern aborieben werden, während die härteren Schäfte mehr Wislerstand leisten mul ihre deshalb erhaltenen Spitzen das Fahmenende üherragen. E. muss hierbei indessen darauf aufmerksim gemacht werden, dass bei den Spechten der ungekehrte Vorgung beobalchtot wird. Bei diesen nutzen dic Spitzen fle Schilte der Schwanzferlern, welche dem Vogel beim Klettern zur Stüt»r dienen. sich ab, während die Fahnenspitzen erhalten hleiben und den kiirzeren Schaft ïberragen.

\section{Schlüssel der Gattung.}

Nitte des Unterkörpers gelblich grïn, Oberkopt gelb, Koptseiten grïll: keiensis.

Oberkopt blau, Kopfseiten braun: pusio siehe auch pusille und Becearii).

Mitte des Unterkörpers orange- oder ockergell); ganzer liopf braun: misoriensis.

Oberkopf blau, Kopfseiten braun: maforensis. 
Mitte des Unterkörpers roth, Stirn gelb, röthlich angeflogen: pygmaea.

Oberkopf und Backen roth, hinten blau gesäumt: Bruijnii.

11. Nasiterna keiensis. - Gelbkappen-Spechtpapagei.

Englisch: Ké-Island Pygmy Parrot.

Nasiterna keiensis (1875) Salv. Ann. Mus. Civ. Gen. VII, p. 984. - Nasiterna amensis (1875) Salv. ibid. p. 985.

Abbildungen: Gould Birds New Guinea pt. VI, pl. 13. Reichenow Vogelbilder t. XXV, f. 4.

Diagnose: Viridis; plumis tenuissime nigro-limbatis, subtus dilutior; pileo flavo-ochraceo, plumarum marginibus rubrotinctis; genarum plumis fuscescentibus, partim obsolete caerulescente marginatis; subcaudalibus mediis flavis; cauda, rostro et pedibus ut in $N$. maforensi tinctis.

Long. c. 95 , ala 65 , cauda 28, culmen $9 \mathrm{Mm}$.

오 Pileo pallide Havo.

Vorkommen: Austro-Malayische Subregion (Neu-Guinea, Kei-Inseln, Aru-Inseln).

12. Nasiterna pusio. - Blauscheitel-Spechtpapagei.

Englisch: Solomon-Isslands Pygmy Parrot. - Französisch: Micropsitte.

Nasiterna pusio (1865) Sclat. Proc. Zool. Soc. p. 620. Vasiterna pygmaeu solomonensis (1871) Schleg. Ned. Tijdschr. Dierk. IV, p. 1.

Abbildungen: Proc. Zool. Soc. 1865, pl. 35. - Rowley Ornith. Misc. pl. 21. - Gould Birds New Guinea pt. VI, pl. 12. Reichenow Vogelbilder t. XXV, f. 5.

Diagnose: Viridis; gastraeo medio flavicante; subcaudalibus mediis flavis; fronte et capitis lateribus mentoque rufescente brunneis; vertice coeruleo; alarum tectricibus medio nigris, late viridi-marginatis; rectricibus duabus mediis caeruleis, apice nigris; ceteris nigris, pogonio interno macula apicali flava ornatis, extus viridi-marginatis; rostro pedibusque fuscis; iride brunuea.

Long. tot. c. 85 , ala 60, cauda 30, culmen $9 \mathrm{Mm}$.

Vorkommen: Austro-Malayische Subregion (Salomon-, St. George-, Duke of York Inseln). 
13. Subspecies: pusilla. - Kleiner Blauscheitel.

Englisch: Ramsay's Pygmy Parrot.

Nasiternc pusilla (1877) Ramsay Proc. Lin. Soc. New SouthWales II, p. 105.

Abbildung fehlt.

Diagnose: N. pusioni simillima sed minor; genis dilutius, vertice obscurius tinctis.

Long. tot. c. 85, ala 57, cauda 25, culmen $8 \mathrm{Mm}$.

Vorkommen: Austro-Nalayische Subregion (Neu-Guinea).

14. Subspecies: Becerii. - Beccari's Spechtpapagei.

Englisch: Beccari's Pygmy Parrot.

Nasitema Becearii (1876) Salv. Ann. Nus. Civ. Gen. VIII, p. 396 (오).

Abbildung: Gould Birds New Guinea pt. VI, pl. 11.

Diagnose: N. pusioni simillima, sed gastraeo medio dilute viridi, pileo obscuriore, cyaneo; fronte et capitis lateribus obscurius brunnco-tinctis; nucha quoque obscure brumnea.

Vorkommen: Austro-Malayische Subregion (Nen-Guinea).

15. Nasiterna misoriensis. - Braun köpiger Spechtpapagei.

Englisch: Misori Pygmy Parrot.

Vasiterue mannere geeleinkiuna part. (1871) Schleg. Ned. Tijdschr. Dierk. IV, 1. 7. - Vasiteme misoriensis (1875) Salv. Ann. Mus. Civ. Gen. VII, p. 909.

Abbildungen: Gould Birds New Guinea pt. VI, pl. 9. Reichenow Vogelbilder t. XXV, f. 6.

Diagnose: Viridis; pectore et abdomine medio miniatoochraceis; capite omnino fusco, macula occipitali flava conspicua excepta; torque collari vix conspicuo caerulescente; subcaudalibus Havis; rectricibus duabus mediis caeruleis, scapo nigro; ceteris nigris, pogonio interno macula apicali flava ornatis, extus viridimarginatis; rostro pedibusque cinereo-brumneis; iride miniata.

Long. tot. c. 90, ala 60, cauda 30 , culmen $10 \mathrm{Mm}$.

ㅇ: Pectore et abdomine flavescente viridibus; verticis plumis caeruleo-marginatis.

Vorkommen: Austro-Malayische Subregion (Misore).

16. Nasitema muforensis. - O rangebrüstiger Spechtpapagei. Englisch: Mafor Pygmy Parrot.

Vasiternepygmaeugeelvinkiena part.(1871)Schleg.ed. NTijdschr. 
Dierk. IV, p. 7. - Nasiterna maforensis (1875) Salv. Ann. Mus. Civ. Gen. VII, p. 908.

Abbildungen: Rowley Ornith. Mise. pl. 18. - Gould Birds New Guinea pt. VI, pl. 8. - Reichenow Vogelbilder t. XXV, f. 3.

Diagnose: Viridis; pectore et abdomine medio ochraceis; pileo fusco, plumarum marginibus cacruleis; macula occipitali parum conspicua pallide Hava; genis mentoque fuscis, plumarum marginibus caerulescentibus; subcandalibus citrinis; rectricibus duabus mediis caeruleis, scapo nigro; ceteris, rostro et pedibus ut in $N$. pusione tinctis. L. t. c. 90 , ala 58 , cauda 36 , culm. $10 \mathrm{Mm}$.

오: Pectore et abdomine flavescente viridibus, subcaudalibus flavis.

Vorkommen: Austro-Malayische Subregion (Mafor).

17. Nasitema pygmete - Rothbrïstiger Spechtpapagei.

Engl.: Pygmy-Parrot. - Franz: Psittacule pygmée.

Psittacus (Psittuculu) pygmueus (1830) Quoy et Gaim. Voy. de l'Astrol. Zool. I, p. 232.

Abbildungen: Quoy et Gaim. 1. c., pl. 21. - Rowley Orn. Misc. I, pl. XIX and XX. - Bourjot St. Hilaire Hist. Nat. Perr. pl. 100. -- Gould Birds New Guinea pt. VI, pl. 7. Reichenow Vogelbilder t. XXV, f. 2.

Diagnose: Viridis; plumis fusco-limbatis, subtus dilutior, pectore et abdomine medio rubro-miniatis: pileo flavido, plumarum frontalium marginibus rubescentibus; subcaudalibus mediis Havis; rectricibus duabus mediis caeruleis; ceteris nigris, pogonio interno macula apicali Hava ornatis, extus viridimarginatis; rostro fusco-cinereo; pedibus fulvis; iride fusca.

Long. tot. c. 80 , ala 58, cauda 25, culmen $9 \mathrm{Mm}$.

우 Pileo virescente flavo; pectore et abdomine flavescente viridibus.

Vorkommen: Austro-Malayische Subregion (Neu-Guinea, Salwatty, Waigiou, Misol u. a.).

18. Nesiternu Bruijuie. - Rothköpfiger Spechtpapagei.

Englisch: Bruijn's Pygmy Parrot.

Nesiterna Bruijnii (1875) Salv. Ann. Mus. Civ. Gen. VII, p. 715 (nota), 753 б, 907 우.

Abbildungen: Gould Birds New Guinea pt. VI, pl. 10. A. M. C. G. VII, 1875, pl. 21. - Reichenow Vogelb. t. 25, f. 1. Diagnose: Viridis; plumis tenuissime nigro-limbatis; pileo. 
genis, gastraeo medio et subcaulalibus rubris, pileo postice in colorem fuscum vergente; fascia nuchali post oculos orta, faciem et colli latera cingente, pulchre caerulea; subcaudalibus rubris; rectricibus duabus mediis cacruleis, macula subapicali nigra; ceteris nigris, pogonio interno macula apicali rubra ornatis, extus viridi-marginatis; rostro et pedibus cinereo-brunneis; iride brunnea.

Long. tot. c. 90 , ala 70 , cauda 29 , culmen $8 \mathrm{Mm}$.

우: Gastraeo flavescente viridi; pileo azureo, genis et margine frontali griseo - rubescentibus; subcaudalibus viridi-flavescentibus.

ơ jun.: Pilco genisque fulvis, roseo tinctis; rectricum macula apicali lutea; abdominis colore rubro dilutiore.

Vorkommen: Austro-Malayische Subregion (Nell-Guinea).

\section{Familie: Trichoglossidae. Loris.}

Charakter der Familie: Das bezeichnende Merkmal für die Loris ist die Form des Schnabels und die Bildung der Zunge. Der erstere ist lünger als hoch oder ebenso hoch als lang, glatt, meistens ohne deutlichen Zahn. Die Firste ist gerundet aber schmal; der Unterkiefer gestreckt; die Dille steigt — was leicht in die Augen füllt - in fast gerader Linie von der Basis zur Spitze an und hat keinen Kiel. Die Schnabelspitze hat keine Feilkerben. Die Zunge ist an der Spitze mit faserigen Papillen besetzt, wovon nur die Gattung Coryllis eine Ausnahme macht. Die Wachshaut ist über der Firste am breitesten und zieht sich längs der Oberschnabelbasis, allmälig nach unten in eine Spitze auslaufend, bis zur Schnabelschneide herab. Der Schwanz ist bei den einzehnen Gattungen sehr abweichend geformt, bald stufig, bald gerundet, bald gerade, selten lïnger als der Flügel, meistens kürzer. Der Flügel ist spitz, dic drei ersten Schwingen sind gewöhnlich die längsten.

Durch die Gattung Glossopsittacus schliessen sich die Loris an die Plattschweifsittiche und zwar zunächst an die Gattung Nanodes an, welche, wie bereits vorher erwähnt, cinen Uebergang zwischen beiden Familien darstellt. Wir kennen gegenwärtig 87 Arten, welche wir in vier Gattungen einreihen.

In der Lebensweise der Loris zeigen sich viele eigenthümliche, von dem Betragen anderer Papageien abweichende Momente. 
Die typischen Formen klettern nicht, bewegen sich auch nicht laufend auf den Zweigen wie die Plattschweifsittiche, sondern vielmehr hüpfend. Reissend schnell ist der Flug und in mannigfachen Schwenkungen abwechselnd, wobei die Vögel häufig ihre laute, kreischende Stimme vernehmen lassen. Die Nahrung besteht in saftigen Früchten, vorzüglich aber in Blumenhonig, den sie vermittelst ihrer dazu organisirten Zunge aus den Blïthen saugen. Sie sind dadurch so recht eigentlich geschaffen für die vielen Nektar liefernden Stauden und Bäume der australischen Vegetation, für die Eucalypten- und Gummi-Wälder, welche ihre bevorzugten Wohngebiete bilden. Die Loris verbreiten sich durch die ganze Australische Region mit Ausnahme der neuseeländischen Subregion und gehen am weitesten von allen Papageien in der Polynesischen Subregion nach Osten. Einige Formen der in mancher Beziehung, auch hinsichtlich der Lebensweise, abweichenden Fledermauspapageien überschreiten die Grenzen der Australischen Region nach Westen und verbreiten sich über die Sundainseln, Hinter- und Vorderindien.

Die Geschlechter der Loris unterscheiden sich nur selten und nur in geringem Grade von einander.

Genus: TRICHOGLOSSUS. Ke ils $\mathrm{ehw}$ a n $\mathrm{l}$ or is.

Trichoglossus (1826) Vig. et Horsf. Linn. Trans. XV, p. 287 (Typus: Tr. haematodus Vig. et Horsf.). - Australasia (1831) Less. 'Traité d'Ornith. p. 209 (Typus: Australasia Novae-Hollandiae Less.).

Charakter der Gattung: Schwanz stufig, die Steuerfedern, wenigstens die mittelsten, am Ende mehr oder weniger zugespitzt. Je nach der Form derselben und dem Schwingenverhältnisse des Flügels theilen wir die 39 bekannten Arten und Unterarten in fünf Untergattungen. Sie bewohnen die Australische, Austro-Malayische und Polynesische Subregion.*)

\section{Schlüssel der Gattung:}

Vorzugsweise grün gefärbt, insbesondere Hals und Brust grün:

Stirn roth, Scheitel grün:

Unterflügeldecken grün:

*) Während des Druckes des vorstehenden wird von Herrn Dr. Sclater eine (40.) Art: Trichoglossus rufigularis publicirt. Dieselbe wird im Nachtrage aufgeführt werden.

Cab. Journ. f. Onrithol. XXIX. Jahrg. No. 154. April 1881. 
Rother Strich hinter dem Auge, Wangen und Kehle grün: concinnus.

Kein Fleck hinter dem Auge:

Wangen und Kehle roth wie die Stirn: pusillus.

Wangen und Kehle bläulich: Verreauxi.

Unterflügeldecken roth:

Bürzel und Bauch grün, Wangen, Brust und Kehle blaugrau: porphyreocephalus.

Bürzel grün, rother Bauchfleck: Arfaki.

Rother Bürzelfleck, Bauchmitte grün: mbronotatus (siehe auch Kordoanus).

Ganzer Oberkopf roth.

Graublaues Nackenband, Kropf weinroth, gelb gestrichelt: versicolor.

Blaues Band hinter dem Auge, Kropf grün: iris.

Stirn grün, gelblich oder bläulich:

Unterflügeldecken grïn:

Kehle roth, unten von einem goldgelben Bande gesäumt: aureicinctus.

Kinn und schmaler Saum am Schnabel roth: palmarum. Kein Roth am Kopfe:

Oberkopf und Kopfseiten bläulich: pygmaeus.

Wangen und Kehle gelblich, Scheitel in der Mitte blau: diadematus.

Kopf und ganze Unterseite grünlich gelb: euteles.

Brust grün, gelb geschuppt, Kopf oliven - gelbbraun oder olivengelb: flavoviridis (s. auch Meyeri).

Unterflügeldecken roth:

Kein Roth am Körper, Brust gelb geschuppt: chlorolepidotus.

Bürzel, Brust oder Körperseiten roth:

Bauch grün:

Bürzel blau: placens.

Bürzel grün: subplacens.

Unterrücken roth, Bürzel violet: Wilhelminae.

Bauch und Brust roth: Muschenbroeki.

Vorzugsweise roth gefärbt, insbesondere Kopf, Hals und Brust roth:

Mit gelbem Halsband: Margaritae.

Mit schwarzem Nackenband: papuensis.

Ohne Hals- oder Nackenband:

Unterriicken und Oberschwanzdecken roth, Bürzel blau: Josephinae.

Unterrïcken und Oberschwanzdecken grün, Bürzelfleck blau: pulchella.

Ganzer Kopf pflaumenblau oder wenigstens Oberkopf blan, Kropf und Brust gelb oder roth, meistens schwarz gebändert:

Oberseite des Körpers grün: 
Kropf und Brust nicht gebändert, scharlachroth: Forsteni. Kropf und Brust nicht gebändert, mennigroth oder orange: Grünes Nackenband: Novae Hollandiae.

Rothes Nackenband: rubritorquatus.

Kropf und Brust nicht gebändert, gelb: haematodes.

Kropf und Brust gebändert:

Nur Oberkopf blau, Wangen roth, goldgelbes Band hinter den Kopfseiten: ornatus.

Kopfseiten wie der Oberkopf pflaumenblau:

Brustbinden breit:

Kopf hinten roth gesäumt: Rosenbergi.

Hinterkopf ohne rothen Saum: cyanogrammus (s. auch nigrogularis und caemleiceps).

Stirn roth: coccineifrons.

Brustbinden sehr schmal: Massenae.

Oberseite des Körpers olivengelb: flavicans. Ganz roth oder braunroth gefärbt:

Dunkel braunroth mit orangefarbenem Schnabel: rubiginosus. Dunkel scharlachroth mit orangefarb. Schnabel: cardinalis.

Subgenus: GLOSSOPSITTACUS. Hon ig-Sittich e.

Glossopsitta (1854) Bp. Rev. Mag. Zool. p. 157 (Typus: Psittacus australis Lath.).

Charakter der Untergattung: Schwanzfedern breiter und weniger spitz. Erste und zweite Schwinge am längsten, dritte deutlich kürzer. In der Färbung grün vorherrschend. - Vier Arten in der Australischen und südlichen Polynesischen Subregion.

1. Trichoglossus diadematus. - Diadem-Lori.

Psitteuteles diadema [!] (1860) Verr. et Des Murs Rev. Mag. Zool. p. 387.

\section{Abbildung fehlt.}

Diagnose: Viridis; subtus dilutior; genis gulaque subflavis; vertice medio cyaneo; crissi macula rubra; rectricibus extimis quarternis partim rubris (teste Finsch).

Long. c. 180, ala 90, cauda $90 \mathrm{Mm}$.

Vorkommen: Südwestliche Polynesische Subregion (NeuCaledonien).

2. Trichoglossus porphyreocephalus. - Blauscheitel-Lori.

Englisch: Porphyry-crowned Lorikeet. - Französisch: Perruche de florent.

Psittacus porphyreocephalus (1823) Dietr. Lin. Trans. XVII, p. 553. - Psittacus purpureus (1832) Dietr. Phil. Mag. XI, 
p. 387. - Psittacula Florentis (1837-1838) Bourjot St. Hilaire Hist. Nat. Perr. pl. 84.

Abbildungen: Bourjot St. Hilaire 1. c. - Gould Birds Austral. V, pl. 53.

Diagnose: Viridis; interscapulio olivaceo-flavo; gula pectoreque caesiis; fronte et regione parotica aurantiis; loris miniatis; vertice violascente-cyaneo; subalaribus coccineis; alae flexura coerulea; rectricum exteriorum pogonii interni basi rubra, apice flavo; iride crocea; rostro nigro; pedibus cinereis.

Long. c. 190, ala 103, cauda 65, culmen $12 \mathrm{Mm}$.

Vorkommen: Australische Subregion (West-Australien).

3. Trichoglossus concinnus. - Moschus-Sittich.

Engl. : Musky Lorikeet. - Franz. Perruche à bandeau rouge.

Psittacus conrinnus (1789) Shaw. Nat. Misc. III, pl. 87. Psittarus pacificus (1811) Shaw. Gen. Zool. VIII, p. 419. Psittacus rubrifrons (1811-1812) Bechst. Kurze Uebers. p. 84. Psittanus velatus (1823) Vieil. N. D. XXV, p. 373.

Abbildungen: Levail. Hist. Perr. pl. 48. - Jard. and Selby Ill. Orn. I, pl. 34. - Gould B. Austr. V, pl. 52.

Diagnose: Viridis; sincipite et fascia parotica rubris; pileo caesio; cervice olivascente fulva; pectoris lateribus luteis; rectricibus, mediis exceptis, pogonii interni basi rubris, apice flavidis; iridi crocea; rostro basi plumbeo, apice croceo; pedibus fulvescentibus.

Long. c. 260, ala 130, cauda 110, culmen $16 \mathrm{Mm}$.

Vorkommen: Australische Subregion (Süd-Australien, Neu Süd-Wales, Van Diemensland).

4. Trichoglossus pusillus. - Masken-Lori.

Engl.: Small Lorikeet. - Franz.: Perruche à face rouge.

Psittacus pusillus (1790) Shaw. White's Journ. Voy. N. S. Wales, p. 262. - Psittanus muchalis (1811-1812) Bechst. Kurze Uebers. p. 81 .

Abbildungen: Levaillant Hist. Nat. Perr. pl. 63. — Gould Birds Austral. V, pl. 54.

Diagnose: Viridis; facie rubra; cervice et interscapulio olivaceo-fulvis; rectricibus, mediis exceptis, pogonii interni basi rubris, apice flavis; iride crocea; rostro nigro-cinereo; pedibus brunneis.

Long. c. 190, ala 100, cauda 70, culmen $12 \mathrm{Mm}$. 
Vorkommen: Australische Subregion (Süd-Australien, Neu Süd-Wales, Van Diemensland).

Subgenus: CHARMOSYNA. Schmuckloris.

Charmosyna (1832) Wagl. Mon. Psitt. p. 493 (Typus: Psittacus papuensis Gm.). - Pyrrhodes (1837) Sw. Class. B. II, p. 304 (Typus: Ps. papuensis Gm.). - Charmosynopsis (1877) Salvad. Ann. Mus. Civ. Gen. X, p. 37 (Typus: Chermosyma pulchella Gray).

Charakter der Untergattung: Schwanzfedern schmal und scharf lanzettlich zugespitzt, bisweilen länger als der Flügel. Schwacher Schnabel. Zweite und dritte Schwinge am längsten, erste etwas kürzer oder erste bis dritte Schwinge am lïngsten. In der Färbung bald grün, bald roth vorherrschend. - Zwölf Arten in der Austro-Malayischen und westlichen Polynesischen Subregion.

5. Trichoglossus aureicinctus. - Rothhöschen.

Engl.: Red-legged Lorikeet. - Franz.: Lori à bandeau d'or. Trichoglossus aureicinctus (1875) Layard Ann. Nat. Hist XVI, p. 344 .

Abbildungen: Rowley, Orn. Misc. IV, p. 261. - Reichenow Vogelbilder t. XXI, f. 6.

Diagnose: Viridis; regione anteoculari, gula et tibiis roseis; cingulo infragulari aurantiaco ; rectricibus luteo-apicatis, exterioribus pogonii interni basi rubris; iride crocea; rostro miniato; pedibus carneis.

Long. c. 200, ala 100, cauda 85 , culmen $13 \mathrm{Mm}$.

Juv. an \&: Tibiis viridibus, faciei colore roseo pallidiore.

Vorkommen: Polynesische Subregion (Fidji Inseln).

6. Trichoglossus palmarum. - P a lm e $\mathrm{n} 10 \mathrm{ri}$.

Englisch : Palm Lorikeet.

Psittasus palmarum (1788) Gm. S. N. I, p. 329. - Psittucus peregrinus (1790) Lath. Ind. Orn. I, p. 105.

Abbildung: Brenchley Jottings during the cruise of the Curaçoa (1873) pl. 16.

Diagnose: Viridis, subtus flavescens; margine rostrali mentoque roseis; rectricum apicibus luteis; iride et rostro miniatis; pedibus carneis.

Long. c. 180 , ala 90 , cauda $85 \mathrm{Mm}$.

Vorkommen: Südwestl. Polynes. Subregion (Neu-Hebriden). 
7. Trichoglossus pygmaeus. - Zwerg-Lori.

Englisch: Pygmy Lorikeet. -- Franz.: Perruche pygmée.

Psittacus pygmaeus (1788) Gm. S. N. I, p. 330. - Psittacus australis (1790) Lath. Ind. Orn. p. 104.

Abbildung: Ibis 1873, pl. 1.

Diagnose: Viridis, capitis lateribus pileoque coerulescentibus; rectricum apicibus luteis; iride et rostro miniatis; pedibus carneis.

Long. c. 210, ala 95, cauda 80, culmen $13 \mathrm{Mm}$.

Vorkommen: Polynesische Subregion (vermuthlich Sandwichs-Inseln).

8. Trichoglossus subplacens. - Zart-Lori.

Englisch: Green-rumped Lorikeet.

Trichoglossus subplacens (1876) P. L. Sclater Proc. Zool. Soc. p. 519 .

Abbildung: Gould Birds New Guinea pt. V, pl. 10.

Diagnose: Viridis, pileo flavicante; genis, subalaribus et pectoris lateribus rubris; regione parotica cyanea; rectricibus, rostro pedibusque ut in $T r$. placente tinctis.

(Tr. placenti simillimus, sed pileo flavescente, uropygio viridi, nec cyanee diversus).

Vorkommen: Oestliche Austro-Malayische Subregion (NeuGuinea, Duke of York Inseln).

9. Trichoglossus placens. - Schön-Lori.

Englisch: Beautiful Lorikeet.

Psittacus placentis [!] (1835) Tem. Pl. Col. pl. 553. Conurus placens $(1837-1838)$. Bourjot St. Hilaire Hist. Nat. Perr. pl. 46.

Abbildungen: Temm. Pl. Col. pl. 553. - Bourjot St. Hil. 1. c. - Gould Birds of New Guinea pt. III, pl. 17.

Diagnose: Viridis; genis, subalaribus et pectoris lateribus rubris; regione parotica et uropygio cyaneis; rectricibus, mediis exceptis, pogonii interni basi rubris, omnibus apice luteis, medio rubentibus, fascia ante apicem nigra; rostro rubro, iride et pedibas croceis.

Long. c. 210 , ala 95, cauda 85 , culmen $13 \mathrm{Mm}$.

오: Genis, alarum tectricibus inferioribus et pectoris lateribus flavescente viridibus; regione parotica striis flavis ornata. 
Vorkommen: Austro-Malayische Subregion (Neu-Guinea, Molukken, Aru-Inseln u. a.).

10. Trichoglossus rubronotatus. - Rothbürzel-Lori.

Englisch: Red-rumped Lorikeet.

Coriphilus rubronotatus (1862) Wall. Proc. Z. S. p. 165.

Abbildung: Gould Birds New Guinea pt. V, pl. 9.

Diagnose: Viridis; sincipite, macula uropygiali, pectoris lateribus et subalaribus rubris; regione parotica cyanea; rectricibus, rosto et iride ut in $T r$. placente tinctis; pedibus brunnescente rubris.

Long. c. 180 , ala 80, cauda 65 , culmen $13 \mathrm{Mm}$.

오 Pileo omnino viridi; pectoris lateribus et subalaribus viridi-flavescentibus; regione parotica viridi; genis striis flavis ornatis.

Vorkommen: Oestliche Austro-Malayische Subregion (NeuGuinea, Salwatti u. a.).

11. Subspecies: Kordoanus. - Mysore-Lori.

Charmosyna Kordoanus (1874) Meyer Verh. Zool. Bot. Ges. Wien XXIV, p. 38. Abbildung fehlt.

Diagnose: Tr. mutronotato simillimus, at sincipite et uropygii macula dilutioribus, coccineis; pectoris lateribus superne tantum rubris, hypochondriis flavidis.

ㅇ: Tr. rubronotati feminae simillima, sed regione parotica thalassino-striata.

Vorkommen: Oestliche Austro-Malayische Subregion(Mysore).

12. Trichoglessus Wilhelmince. -.. Wilhelminen-Lori.

Englisch: Wilhelmina Lorikeet.

Trichoglossus Wilhelminae (1874) A. B. Neyer, Journal für Ornithol. p. 56.

Abbildung: Gould Birds of New Guinea pt. III, pl. 6.

Diagnose: Viridis; vertice rufescente-violaceo; occipite superne rufescente-violaceo, striis scapalibus caeruleis oruato, inferne brunnescente; tergo coccineo; uropygio violaceo; pectore fuscotincto, striis scapalibus flavis ornato; remigibus pogonio interno et subalaribus coccineis; rectricibus mediis ad basin viridibus, dimidio apicali violascente-cyaneis, ceteris ad basin coccineis, apice viridi, fascia anteapicali violascente nigra.

Long. c. 140, ala 70, cauda 50, culmen $13 \mathrm{Mm}$.

ㅇ: Tergo et subalaribus viridibus. 
Vorkommen: Oestliche Austro-Malayische Subregion (NeuGuinea).

13. Trichoglossus pulchellus. - Goldstrichel-Lori.

Englisch: Pectoral Lorikeet.

Charmosyna pulchella (1859) G. R. Gray, List of the Specimens of Birds in Brit. Mus. III, Psitt. p. 102. -- Charmosyna pectoralis (1862) v. Rosenb., Journ. f. Ornith. p. 64.

Abbildungen: Rowley Ornith. Misc. III, pl. 17, p. 149. Gould Birds New Guinea pt. III, pl. 4.

Diagnose: Carmineus; dorso et alis obscure viridibus, uropygio nigricante viridi; pectore luteo-striato; occipite violascente nigro; tibiis viridibus luteo-lineolatis; rectricibus basi rubris, extus viridi - limbatis, apice luteis; rostro miniato; iride lutea; pedibus carneis.

Long. c. 190, ala 90, cauda 90, culmen $13 \mathrm{Mm}$.

오: Uropygii lateribus luteis.

Vorkommen: Oestliche Austro-Malayische Subregion (NeuGuinea und einige nahe gelegene Inseln).

14. Charmosyna Margaritae. - Margarethen-Lori.

Englisch: Margaretha-Lorikeet.

Charmosyna margarethae (1879) Tristr. Ibis p. 492. - Charmosynopsis margaritae (1880) Salv. Ornith. Papuas. I, p. 319.

Abbildung: Ibis 1879, pl. 12.

Diagnose: Carmineus; occipite nigro; torque collari luteo, arcte nigro-fimbriato; dorso et crisso viridibus, uropygio aurantiaco-imbuto; rectricibus mediis carmineis, croceo-terminatis, ceteris pogonii externi basi viridibus, interni rubris, apice croceis.

Long. c. 190, ala 90, cauda 100, culmen $15 \mathrm{Mm}$.

Vorkommen: Austro-Malayische Subregion (Neu-Guinea).

15. Trichoglossus papuensis. - Papua-Lori.

Engl.: Papuan Lorikeet. - Franz.: Perruche papou.

Psittacus papou [!] (1786) Scop. Del. F. Fl. Ins. p. 86. Psittacus papuensis (1788) Gm. S. N. I, p. 313. - Psittacus omnicolor (1793) Lchtst. Cat. rer. nat. Hamb. p. 5. - Psittacus Lichtensteini (1811-1812) Bechst. Kurze Uebersicht p. 83. Charmosyna papua (1845) Gray Gen. B. II, p. 416. - Charmosyna papuana (1858) Sclat. Journ. Pr. Linn. Soc. II, p. 165. 
Abbildungen: Levaillant Hist. Nat. Perr. pl. 77. - Gould Birds New Guinea Pt. II, pl. 1.

Diagnose: Carmineus; interscapulio, tergo alisque obscure viridibus; verticis fascia transversa azurea, postice vitta nigra circumdata, altera cervicali nigra; ventre medio et tibiis violascente nigris; pectore et hypochondriis macula utrinque lutea notatis; uropygio carmineo, medio longitudinaliter azureo; rectricibus mediis basi viridibus, apice croceis, medio rubescentibus; ceteris basi pogonii externi viridibus, interni rubris; omnibus apice croceis; rostro et pedibus miniatis; iride rubra.

Long. c. 330 , ala 120 , cauda 180 , culmen $17 \mathrm{Mm}$.

क: Plumis rubris uropygii laterum ad basin conspicue flavescentibus; lateribus supra maculam flavam cruralein late flavis.

Vorkommen: Austro-Malayische Subregion (Neu-Guinea).

16. Trichoglossus Josephinae. - Josephinen-Lori.

Englisch: Josephina Lorikeet.

Trichoglossus Josephinae (1873) Finsch Atti Soc. It. Sc. Nat. $\mathrm{XV}$, Fasc. V, p. 427.

Abbildungen: Atti Soc. It. Sc. Nat. XVI, pl. 7 (ㅇ). Gould Birds New Guinea III, pl. 3.

Diagnose: Carmineus; interscapulio, tergo alisque viridibus; macula uropygiali obscure cyanea; macula occipitali obscure cyaneo-lilacina, postice vitta nigra circumdata; ventre tibiisque violascente nigris; rectricibus mediis carmineis, croceo-terminatis, ceteris basi rubris, pogonio externo sordide viridibus, apice croceis; iride, rostro et pedibus miniatis; regione oculari nuda cinerea.

Long. c. $240-260$, ala 120 , cauda 130 , culmen $18 \mathrm{Mm}$.

: Uropygio et hypochondriis flavis nee rubris.

Vorkommen: Oestliche Austro-Malayische Subregion (NeuGuinea).

Subgenus: OREOPSTTTACUS. B erg-Loris.

Oreopsittacus (1877) Salvad. Ann. Mus. Civ. Gen. X, p. 37 (Typus: Trichoglossus arfaki Meyer).

Charakter der Untergattung: Mit Charmosyna im allgemeinen übereinstimmend aber vierzehn Federn im Schwanze, 
während die Arten jener Gattung 12 Steuerfedern haben. - Eine Art in der Austro-Malayischen Subregion.

17. Trichoglossus Arfaki. - Arfak-Lori.

Englisch: Arfak Lorikeet.

Charmosyna Arfaki (1874) Meyer Verh. Zool. Bot. Ges. Wien XXIV, p. 37.

Abbildungen: Rowley Ornith. Misc. Pt. III, 1876, p. 147. Gould Birds New Guinea pt. III, pl. 5.

Diagnose: Viridis; pileo, ventre medio, hypochondriis et subalaribus coccineis; capitis lateribus cyaneis; fascia suboculari usque ad aures producta e maculis albo-caerulescentibus; remigibus intus fascia obliqua flava notatis; rectricibus mediis basin versus viridibus, medio obscure caerulescentibus, apice pallide roseis; ceteris dimidio basali nigris, apice rubris; extimis ad apicem fusco-viridi - limbatis; rostro nigro, pedibus plumbeis; iride fusca.

Long. c. 180 , ala 76 , cauda 85, culmen $12 \mathrm{Mm}$.

오: Pileo omnino viridi.

Vorkommen: Oestliche Austro-Malayische Subregion (NeuGuinea).

Subgenus: NEOPSITTACUS. Grün-Loris.

Psitteuteles (1854) Bonap. Ann. Sc. Nat. p. 152 (Typus: Psittacus euteles Tem.). - Ptilosclera (1857) Bp. Compt. Rend. (Typus: Trichoglossus versicolor Vig.). - Neopsittacus (1875) Salvadori Ann. Mus. Civ. Gen. VII, p. 761 (Typus: Nanodes Muschenbroekii Rosenb.).

Charakter der Untergattung: Schwanzfedern breiter und weniger spitz am Ende. Erste bis dritte Schwinge am längsten oder zweite etwas länger als erste und dritte. In der Färbung grün vorherrschend. Einige Arten (ivis, euteles, versicolor) zeichnen sich durch verhältnissmässig stärkeren Schnabel aus. Acht Arten in der Austro-Malayischen und Austral. Subregion.

18. Trichoglossus Muschenbroekii. - Gua.

Englisch: Muschenbroek's Lorikeet. - Französisch: Lori Muschenbroek.

Nanodes Muschenbroekii (1871) Schleg. Tijdschr. Dierk. IV, p.34.

Abbildungen: Rowley Ornith. Misc. V, pl. 44, p. 61. Gould Birds New Guinea pt. V, pl. 8. 
Diagnose: Viridis; pileo et cervice olivaceo-aurantiis, his capitisque lateribus striis flavis ornatis; hypochondriis et crisso flavescente viridibus; pectore, epigastrio, ventre, subalaribus et remigum margine interiore coccineis; rectricibus exterioribus pogonio interno rubris, omnibus subtus et apicibus croceis; rostro luteo; iride flava; pedibus fuscis.

Long. c. 200, ala 105, cauda 90, culmen $15 \mathrm{Mm}$.

Vorkommen: Oestliche Austro-Malayische Subregion (NeuGuinea).

\section{Trichoglossus versisolor. - Werol.}

Engl.: Variegated Lorikeet. - Franz.: Perruche versicolore.

Trichoglossus versicolor (1832) Vig. Lears. Ill. Parr pl. 36.

Abbildungen: Lear 1. c., pl. 36. - Jard. and Selby Nat. Lib. VI, pl. 21. - Gould Birds Austral. V, pl. 51. - Hombr. und Jacqu. Voy. Pôle Sud Atlas pl. 24 bis fig. 1.

Diagnose: Viridis; striis scapalibus flavis; pileo rubro; fascia nuchali caesia; gutture et pectore vinaceis, striis scapalibus flavis; rectricibus pogonio interno et subtus flavis; rostro croceo.

Long. c. 180 , ala 118 , cauda 73 , culmen $15 \mathrm{Mm}$.

Vorkommen: Westl. Austro-Malayische Subregion (Timor).

20. Trichoglossus iris. - Iris - Lori.

Englisch: Iris-Lorikeet. - Französisch: Perruche iris.

Psittacus iris (1820-1839) Temm. Pl. Col. Pt. V, pl. 567.

Abbildung: Temm. Pl. Col. V, pl. 567.

Diagnose: Viridis; gastraeo flavescente, pectore sparsim transversim viridi - lineolato; pileo coccineo; fascia postoculari violascente-cyanca; nucha olivaceo-flava; rectricibus exterioribus pogonio interno, omnibus subtus flavis; rostro croceo.

Long. c. 200, ala 120, cauda 80, culmen $17 \mathrm{Mm}$.

Vorkommen: Westliche Austro-Malayische Subregion (Timor).

21. Trichoglossus Verreanxi. -. Brauen Lori.

Englisch: Verreaux's Lorikeet.

Trichoglossus verreauxius (1854) Bonap. Rev. Mag. Zool. p. 157. - Trichoglossus verrecuxi (1856) Bonap. Naumannia Beilage. Abbildung fehlt.

Diagnose: Viridis; genis gulaque coerulescentibus; abdomine transversim flavo-lineato; sincipite superciliisque rubris. (Teste Bonaparte).

Vorkommen unbekannt. 
22. Trichoglossus euteles. - Gelbkopf-Lori.

Englisch: Yellow-headed Lorikeet. - Franz.: Perruche eutèle.

Psittacus euteles (1820-39) Temm. Pl. Col. Pt. V, pl. 568. Trichoglossus ochrocephalus (1858) Blyth. Journ. As. S. Beng. p. 279 .

Abbildung: Temm. Pl. Col. V, pl. 568.

Diagnose: Viridis; capite et gastraeo olivascente flavis; rectricibus exterioribus pogonio interno, omnibus subtus flavis; remigibus pogonio interno flavis; rostro croceo.

Long. c. 240, ala 125, cauda 105, culmen $16 \mathrm{Mm}$.

Vorkommen: Westliche Austro-Malayische Subregion (Timor). 23. Trichoglossus flavoviridis. -- Gelbgrüner Lori.

Trichoglossus flavoviridis (1862) Wall. Proc. Z. S. p. 337.

Abbildung: Proc. Z. S. 1862 pl. 39.

Diagnose: Viridis; capite, hypochondriis et pectore flavis, pectoris plumis viridi-marginatis; abdomine flavo-viridi; fascia nuchali obscura; genis et mento nigro-olivaceis, flavo-fasciolatis; cauda subtus fuscescente-flavo; rostro et iride croceis, pedibus plumbeis.

Long. c. 180, ala 100, cauda $70 \mathrm{Mm}$.

Vorkommen: Austro-Malayische Subregion (Sula-Inseln).

24. Subspecies: Meyeri. - Kleiner Schuppenlori.

Englisch: Meyers Lorikeet. - Franz.: Perruche Meyer.

Trichoglossus Meyeri (1871) Wall. Ann. Mag. Nat. H. p. 281.

Abbildungen: Trans. Zool. S. London 1874 pl. 4. - Rchw. Vogelbilder t. XV. f. 3.

Diagnose: $P$. flavoviridi simillimus, sed pileo flavo-olivaceo, auricularibus flavis; fascia nuchali nulla; pectore ventreque flavis, viridi-fasciatis; interscapularibus basi flavis.

Long. c. 180, ala 100, cauda 65, culmen $16 \mathrm{Mm}$.

Vorkommen: Westl. Austro-Malayische Subregion (Celebes).

25. Trichoglossus chlorolepidotus. - Schuppenlori.

Englisch: Scaly breasted Parrakeet. - Franz.: Perruche écaillée.

Psittacus chlorolepidotus (1820) Kuhl Consp. Psitt. p. 48. Trichoglossus matoni (1826) Vig \& Horsf. Trans. Lin. Soc. p. 291. - Australasia viridis (1831) Less. Traité d'Orn. p. 210. Abbildungen: Gould B. Austr. V. pl. 50. - Reichenow, Vogelbilder t. VIII. f. 3. 
Diagnose: Viridis; pectoris ventrisque et interscapulii plumis flavis, viridi-limbatis; subalaribus rubris; macula pogonii interni remigum dilute rubra; rostro et iride miniatis; pedibus brunneis.

Long. c. 280, alo 140, cauda 120, culmen $19 \mathrm{Mm}$.

Vorkommen: Australische Subregion (Neu Süd-Wales).

Subgenus: TRICHOGLOSSUS. Eigentliche Keilschwanzloris.

Charakter der Untergattung: Der vorangegangenen Untergattung sehr ähnlich, nur durch den Färbungscharakter abweichend. Schwanzfedern breit und wenig spitz. Erste bis dritte Schwinge am längsten oder erste etwas kürzer als zweite und dritte. Als Färbungscharakter ist namentlich der pflaumenblaue Kopf und die rothe oder orangefarbene Brust bezeichnend. Vierzehn Arten in der Austro-Malayischen und Australischen Subregion.

26. Trichoglossus Forsteni. - Scharlachbrust-Lori.

Psittacus forsteni (1850) Temm. Bonap. Consp. I, p. 3. Trichoglossus mitchelli (1859) G. R. Gray, List Spec. of Birds in Brit. Mus. Pt. III, Sect. II, p. 62.

Abbildung: Proc. Z. S. 1871 pl. 41.

Diagnose: Jorso, alis et cauda viridibus; capite, dorsi fascia transversa et abdomine medio violaceis; pectore et gutture coccineis, fasciis transversis nullis; remigibus, rectricibus etc. $T r$. massenae simile tinctis (teste Finsch).

Long. c. 300 , ala 148, cauda $130 \mathrm{Mm}$.

Vorkommen: Westl. Austro-Malayische Subregion (Sumbava).

27. Trichoglossus Massenae. - Sch malbinden-Lori.

Englisch: Massena's Lorikeet. — Franz.: Perruche Massena.

Trichoglossus massena (1854) Bonap. Rev. Mag. Zool. p. 157. - Trichoglossus Deplanchei (1860) Verr. Des Murs. Rev. Mag. Zool. p. 388.

Abbildungen: Brenchley, Jottings during the Cruise of the Curaçoa among the South See-Islands 1873 pl. 15. Reichenow, Vogelbilder t. VIII, f. 2.

Diagnose: Dorso, alis, cauda ventreque viridibus; sincipite lorisque azureis; occipite, capitis lateribus mentoque rufoviolaceis, partim virescentibus; fascia nuchali viridi-flava; gutture et pectore coccineis, tenuiter nigro-fasciatis; crisso et subcaudalibus flavo-variis; interscapulii plumis interdum medio 
rubris; subalaribus coccineis; rectricibus pogonio interno luteis, subtus sordide flavescentibus; remigibus pogonio interno macula magna lutea; rostro et iride miniatis; pedibus brunneis.

Long. c. 270, ala 150, cauda 130, culmen $21 \mathrm{Mm}$.

Vorkommen: Austro-Malayische Subregion (Molukken).

28. Trichoglossus flavicans. - Gelber Lori.

Englisch: Yellow-coloured Lory.

Trichoglossus flavicans (1876) Cab. Rch. Sitzungsb. Nat. Fr. Berlin, p. 73 und Journ. f. Ornith. 1876, p. 324.

Abbildung: Journ. f. Ornith. 1877, t. 5 .

Diagnose: Dorso, alis caudaque olivaceo-flavis; ventre olivaceo - viridi; crisso et subcaudalibus flavis, olivaceo - variis; sincipite lorisque azureis; occipite, capitis lateribus mentoque rufo-violaceis, partim virescentibus; fascia nuchali flava; gutture et pectore coccineis, tenuiter nigro-fasciatis; subalaribus coccineis; interscapulii plumis medio interdum rubris; rectricibus pogonio interno Iuteis; remigibus pogonio interno macula magna lutea.

Long. c. 340 , ala 140, cauda 120 , culmen $22 \mathrm{Mm}$.

(Tr. massenae simillimus, sed coloribus hujus viridibus olivascente-flavis).

Vorkommen: Oestliche Austro-Malayische Subregion (NeuHannover, Admiralitäts-Inseln).

29. Trichoglossus cyanogrammus. - Breitbinden-Lori.

Engl.: Green-naped Lori. - Franz.: Perruche à calotte verte.

Psittaca Amboinensis varia (1760) Briss. Ornith. IV, p. 364. Perruche à face bleue (1783) Buff. Pl. Enl. VII, pl. 61. Perruche d'Amboine (1783) Buff. Hist. Nat. VII, p. 121. Psittacus haematodus (1783) Bodd. Tabl. Pl. Enl. p. 4, No. 61. Psittacus haematotus (1788) Gm. S. N. I, p. 316 (partim). Psittacus haematopus (1820) Kuhl Consp. Ps. p. 34. - Trichoglossus cyanogrammus (1832) Wagl. Mon. Psitt. p. 554-Psittacus capistratus (1839 - 1844) Müll. Verh. Land. Völkerk. p. 107.

Abbildungen: Buffon Pl. Enl. pl. 61. - Levaillant Hist. Nat. Perr. pl. 15 (ㅇ) et 27 (var.). - Reichenow Vogelbilder taf. VIII, fig. 1.

Diagnose: Dorso, alis, cauda ventreque viridibus; facie genisque azureis, vertice virescente, occipite et regione parotica violascente fuscis; interscapulio rubro-maculato; crisso et subcaudalibus viridibus, flavo-variegatis; fascia nuchali viridi-Hlava; 
gutture pectoreque coccineis, transversim cyanescente nigrofasciatis; subalaribus rubris; rectricibus pogonio interno luteis; remigibus pogonio interno macula magna lutea, ultimis pogonio interno pallide coccineo-limbatis; rostro et iride miniatis; pedibus fuscis.

Long. c. 300 , ala 140 , cauda 130 , culmen $22 \mathrm{Mm}$.

(Obs.: Tr. Massenae similis sed gutturis et pectoris fasciis latioribus).

Vorkommen: Austro - Malayische Subregion (Neu - Guinea, Molukken u. a.).

30. Subspec.: nigrogularis. - Südlicher Breitbinden-Lori.

Trichoglossus nigrogularis (1858) G. R. Gray, Proc. Zool. Soc. p. 183.

Diagnose: Tr. cyunogrammo simillimus, sed vertice ut sincipite et genis azureo; occipite virescente- et violascente-fusco; pectore rubro dilutius tincto; mento nigricante.

Vorkommen: Austro-Malayische Subregion (Südliches NeuGuinea, Aru- und Ké-Inseln).

31. Subspecies: caemleiceps. - Kleiner Breitbinden-Lori.

Englisch: Smaller green-naped Lori.

Trichoglossus caeruleiceps (1879) d'Albert. et Salv. Anu. Mus. Civ. Gen. XIV, p. 41.

Abbildung fehlt.

Diagnose: $T r$. nigrigulari simillimus, sed minor et capite omnino caeruleo distinguendus.

Long. c. 270, ala 135, cauda 105, culmen $21 \mathrm{Mm}$.

Vorkommen: Austro-Malayische Subregion (Südliches NeuGuinea).

32. Trichoglossus Rosenbergi. - Schwarzbauch-Lori.

Englisch: Rosenberg's Lorikeet.

Trichoglossus Rosenbergi (1871) Schleg. Ned. Tijdschr. Dierk. 4, p. 9 .

Abbildung: v. Rosenberg Reist. naar Geelwinkb. pt. 15, f. 2 (1875).

Diagnose: Viridis; capite toto azureo, occiput versus violascente, postice rubro-marginato; fascia nuchali viridi-flava postice interdum rubro-varia; interscapulio rubro-vario; pectore coccineo, late cyanescente nigro - fasciato; subalaribus coccineis; ventre medio cyanescente nigro; ventris lateribus, crisso, tibiis 
et subcaudalibus flavo-variis; remigibus dimidio basali pogonii interni dilute coccineis; rectricibus pogonio interno et subtus flavescentibus; rostro miniato.

Long. c. 250, ala 130, cauda 100, culmen $20 \mathrm{Mm}$.

Vorkommen: Austro-Malayische Subregion (Misori).

33. Trichoglossus coccineifrons. - Rothstirn-Lori.

Englisch: Scarlet-fronted Lorikeet. — Französisch: Lori à front rouge.

Trichoglossus coccineifrons (1858) G. R. Gray, Proc. Zool. Soc. p. 183. - Trichoglossus immarginatus [?] (1858) Blyth Journ. As. Soc. Beng. p. 279.

Abbildung fehlt.

Diagnose: Capite cyaneo; fronte, fascia nuchali et plumis nonnullis verticis rubris; lateribus colli, pectore, magine alari, tectricibus alarum inferioribus rubris; pectoris plumis cyaneomarginatis; macula abdominali cyanea; pogoniis rectricum internis aurantio-cinnabarinis (teste Salvadori).

Long. c. 280, ala 150, cauda 95, culmen $23 \mathrm{Mm}$.

Vorkommen: Oestliche Austro-Malayische Subregion (AruInseln).

34. Trichoglossus ornatus. - Schmuck-Lori.

Englisch: Ornamental Lori. - Franz.: Perruche ornée.

Psittaca indica varia (1760) Briss. Ornith. IV, p. 366. Psittacus omatus (1766) Lin. S. N. I, p. 143. - Psittacus inquinatus (1776) Müller, Lin. Natursyst. Suppl. p. 79. Perruche Lori (1783) Buff. Hist. Nat. VII, p. 117. - Perruche variée des Indes Orientales ibid. Pl. Enl. pl. 552. - Australasia Malaisiae (1831) Less. Traité d'Orn p. 210.

Abbildungen: Buff. Pl. Enl. pl. 552. - Reiçhenow Vogelbilder t. VIII, f. 7 .

Diagnose: Dorso, alis, cauda ventreque viridibus, crisso et subcaudalibus dilute viridibus; interscapulio, ventre et hypochondriis luteo-variis; pileo et fascia postoculari obscure cyaneis; occipite coccineo, cyaneo-fasciato; genis mentoque coccineis; fascia postgenali transversa lutea; gutture et pectore coccineis, late nigro-cyaneo-fasciatis, subalaribus luteis; rectricibus pogonii interni basi coccineis, apice flavidis; rostro miniato, iride crocea.

Long. c. 230, aia 125 , cauda 90 , culmen $20 \mathrm{Mm}$.

Vorkommen: Westl. Austro-Malayische Subregion (Celebes). 
35. Trichoglossus rubritorquatus. - Rothnacken-Lori.

Englisch: Red-naped Lory. - Französisch: Perruche à collier rouge.

Trichoglossus mubitorquis (1826) Vig. et Horsf. Trans. Lin. Soc. XV, p. 291. - Trichoglossus rubritorquatus (1868) Finsch Papageien II, p. 824.

Abbildungen: Gould Birds Austral. V, pl. 49. - Reichenow Vogelbilder t. VIII, f. 5 .

Diagnose: Dorso, alis caudaque viridibus; capite toto et fascia auchenii cyaneis; hac rubro-varia; fascia nuchali, pectore et hypochondriis miniatis; subalaribus coccineis; ventre medio virescente nigro; crisso et subcaudalibus viridi- et luteo-variis; rectricibus pogonio interno luteis; remigibus pogonii interni parte basali flavis; rostro miniato; pedibus griseis; iride rubra.

Long. c. 300, ala 145, cauda 140, culmen $20 \mathrm{Mm}$.

Vorkommen: Australische Subregion (Nord-Australien).

\section{Trichoglossus Novae Hollandiae. - Gebirgslori.}

Pflaumenkopf. - Englisch: Swainson's Lorikeet. - Franz.: Perruche à bouche d'or, Perruche Swainson.

Perruche de Moluques (1783) Buff. Pl. Enl. pl. 743. Psittacus Novae Hollandiae (1788) Gm. S. N. I, p. 316. Psittacus moluceanus ibid. - Psittacus cyanogaster (1812) Shaw Gen. Zool. VIII, p. 413. - Trichoglossus Swainsoni (1825-39) Jard. et Selby Ill. Ornith. III, pl. 112.

Abbildungen: Buffon 1. c. - Levaillant Hist. Nat. Perr. pl. 24. - Jard. et Selby 1. c. -- Gould B. Austral. V, pl. 48. Reichenow Vogelbilder t. VIII, f. 4.

Diagnose: Dorso, alis et cauda viridibus; capite toto et ventre medio violascente azureis; fascia nuchali flavo-viridis; interscapulio crocen-vario; pectore miniato, lateribus croceis; ventris lateribus rubro-, viridi- et azureo-variis; subalaribus coccineis; crisso, tibiis et subcaudalibus viridibus, luteo- et coccineo - variis; rectricibus pogonio interno luteis; remigibus pogonio interno medio flavis; rostro miniato; pedibus griseis; iride crocea.

Long. c. 300, ala 155, cauda 140 , culmen $20 \mathrm{Mm}$.

Vorkommen: Australische Subregion. 
37. Trichoglossus haematodes. - Blauwangen-Lori.

Englisch: Blue-faced Lorikeet. - Französisch: Perruche à face bleue.

Psittacus hacmatodus (1771) Lin. Mantissa plantarum altera generum editionis VI, specierum editionis II (Holmiae) p. 524. Psittacus haematotus (1788) Gm. S. N. I, p. 316 (partim).

Abbildungen: Levaillant Hist. Nat. Perr. pl. 47. - Reichenow Vogelbilder t. VIII, f. 6.

Diagnose: Dorso, alis caudaque viridibus; sincipite, genis mentoque obscure violascente azureis, vertice obscure viridi; occipite dilutius viridi - tincto; fascia nuchali viridi-flava; interscapulio croceo-vario, pectore croceo; ventre nigro-viridi; subalaribus miniatis; crisso, tibiis et subcaudalibus luteo-variis; rectricibus subtus flavescentibus; remigibus pogonio interno medio luteo; rostro miniato; pedibus griseis; iride crocea.

Long. c. 300, ala 160, cauda 140, culmen $22 \mathrm{Mm}$.

Vorkommen: Westl. Austromalay. Subregion (Timor, Samao). 38. Trichoglossus cardinalis. - Kardinal-Lori.

Englisch: Cardinal-Lory. - Französisch: Lori Cardinal.

Lorius cardinalis (1845) Hombr. Jacq. Voy. Pôle Sud Atlas pl. 24 bis f. 2. - Eos unicolor (1864) Wall. Proc. Zool. Soc. p. 291 .

Abbildungen: Hombr. Jacq. Voy. Pôle S. 1. c. - Proc. Zool. Soc. 1869 , pl. 11.

Diagnose: Totus sordide ruber; capite, collo et subcaudalibus dilutioribus; uropygio et supracaudalibus obscurioribus; tergo, cauda et alis brumnescentibus; campterio et flexura obsolete coerulescentibus; rostro croceo; pedibus nigris; iride miniata.

Long. c. 300, ala 170, cauda 150, culmen $20 \mathrm{Mm}$.

Vorkommen: Oestl. Austro-Malayische Subregion (Salomons Inseln, Duke of York Inseln).

39. Trichoglossus muiginosus. - Kirschbrauner Lori.

Englisch: Rusty-coloured Lory.

Chalcopsitte rubiginosa (1850) Bonap. Consp). av. I, p. 3.

Abbildung: Proc. Zool. Soc. 1850, pl. 16.

Diagnose: Cerasinus, loris nigricantibus, gutture et pectore nigro-fasciatis; remigibus nigris, pogonio externo viridi-imbutis; rectricibus superne olivascente flavis, subtus pure flavis; rostro croceo; pedibus nigris; iride miniata. 
Long. c. 230, ala 140, cauda 100, culmen $20 \mathrm{Mm}$.

Vorkommen: Nordwestl. Polynesische Subregion (Carolinen).

Genus: DOMTCELLA. Breits chwanz-Loris.

Lorius [!] (1760) Briss. Orn. IV, p. 222 (Typus: Psittacus domicella L.). - Domivella (1832) Wag]. Mon. Psitt. p. 495 (Typus: Psittacus domicella L.).

Charakter der Gattung: Schwanz kürzer als der Flügel, stark gerundet oder schwach stufig (nur bei Chalcopsittacus ausgesprochen stufig); die einzelnen Federn des Schwanzes breit, auch am Ende, niemals zugespitzt wie bei den Keilschwanzloris; erste bis dritte Schwinge am längsten oder erste kürzer, etwa gleich der vierten; Vögel von gedrungenerer Gestalt als die Keilschwanzloris. Wir kennen 22 Arten und Unterarten, welche nach dem Fürbungscharakter in drei Untergattungen zu gruppiren sind. Sie bewohnen sämmtlich die Austro-Malayische Subregion.

\section{Schlüssel der Gattung:}

Vorzugswcise grün gefärbt: scintillata.

Vorzugsweise schwarz gefärbt:

Stirn und Wangen schwarz: atra (s. auch Stevorini).

Stirn und vordere Wangen roth: insignis.

Vorzugsweise schwarzbramn; Scheitel, Brust- und Kropfbinde und Bauchmitte mennigroth: fuscata.

Vorzugsweise roth gefärbt:

Flügel hauptsächlich schwarz:

Breites blaues Band hinter dem Auge und über die Ohrgegend: cyanogenys.

Nur Ohrgegend blau: reticulata.

Flügel roth:

Kein blau am Kopfe: rubra.

Breites Scheitelband und Binde hinter dem Auge blan : coccinea.

Blaues Band unter dem Auge: semilarvata.

Hinterkopf blau: riciniata (s. auch Wallacii).

Flügel grün:

Oberkopf roth:

Schenkel grün, in der Regel gelber Fleck zwischen den Schultern: garrula (s. auch flavopalliata).

Schenkel blau, gelbes Brustband: tibialis.

Oberkopf schwarz:

Ganzer Oberkörper roth, gelbes Kropfband:

Schwanzspitze grün: chlorocerca.

Schwanzspitze blau: atricapilla. 
Violet-schwärzliche Binde zwischen den Schultern, Nacken roth: hypoenochrous.

Nacken blau:

Die blaue Färbung unmittelbar an das Schwarz des Oberkopfes sich anschliessend: cyanauchen.

Die blaue Färbung des Nackens durch eine rothe Binde von dem Schwarz des Oberkopfes getrennt:

Unterflügeldecken und Brustseiten roth:

Schwarzblaue Färbung des Unterkörpers mit der des Nackens verbunden: tricolor.

Schwarzblaue Färbung des Unterkörpers nicht mit der des Nackens zusammenhängend, Oberbrust roth: erythrothorax.

Unterflügeldecken und Brustseiten blau: jobiensis.

\section{Subgenus: CHALCOPSTTTACUS. Glanzloris.}

Chalcopsitta (1850) Bonap. Consp. Av. I, p. 3. - Chalcopsittacus (1876) Salvadori Ann. Mus. Civ. Gen. IX, p. 15.

Charakter der Untergattung: Schwanz deutlich stufig. Kein roth in der Färbung des Gefieders oder einzelne Theile roth gefärbt, aber nicht die rothe Farbe vorherrschend. 5 Arten.

40. Domicella fuscata. - Weissbürzel-Lori.

Englisch: White-rumped Lory. - Französisch: Lori brun. Eos fuscatus (1858) Blyth Journal A siatic Soc. Bengal XXVII, p. 279. - Eos (Chalcopsitta) torrida (1859) G. R. Gray List Spec. Birds Psitt. III, p. 102. - Eos leucopygialis (1862) v. Rosenb. Journ. f. Ornith. p. 64.

Abbildung: Finsch Pap. II, t. 6.

Diagnose: Fuscus; vertice obsolete miniato; cervicis plumis obsolete miniato-limbatis; fascia jugulari, altera pectorali, ventre medio, campterio, subalaribus majoribus et remigibus basi pogonii interni miniatis; pectoris plumis fuscis cinerascentelimbatis; uropygio albido; subcaudalibus cyanescentibus; rectricibus violascentibus, pogonii interni basi miniatis, subtus apice lutescentibus; rostro miniato; pedibus nigris; iride alba.

Long. c. 290, ala 160, cauda 100, culmen $23 \mathrm{Mm}$.

Juv.: Partibus in adulto miniato-tinctis luteis; uropygio flavescente albido.

Vorkommen: Austro-Malayische Subregion (Neu Guinea, Salvatti, Jobi). 
41. Domicella atra. - Trauer-Lori.

Englisch: Black-Lori. - Französisch: Lori noir.

Lori de la Nouvelle Guinée (1776) Sonnerat Voy. à la Nouv. Guin. p. 175, pl. 110. - Psittacus ater (1786) Scopoli Deliciae florae faunae Insub. p. 87. - Psittacus Novae Guineae (1788) Gmel. S. N. I, p. 319. -- Chalcopsitta Bernsteini (1861) v. Rosenb. Journ. f. Ornith., p. 46.

Abbildungen: Levaillant Hist. Nat. Perr. pl. 49. - Reichenow Vogelbilder t. XI, f. 5 .

Diagnose: Nitide violascente nigra, uropygio azureo-tincto; rectricibus subtus basi rubris, apice flavis; rostro pedibusque nigris; iride rufa.

Long. c. 350, ala, 180, cauda 150, culmen $23 \mathrm{Mm}$.

Vorkommen: Austro-Malayische Subregion (Neu-Guinea und nahe gelegene Inseln).

42. Domicella insignis. - S a mmet-Lori.

Chalcopsitta insignis (1878) Oust. Assoc. Sc. France Bull. No. 533, 1. 247. - Chalcopsittacus bruijnii (1878) Salvadori Atti Ac. Sc. Tor, XIII, p. 310.

Abbildung fehlt.

Diagnose: Praecedenti similis, omnino violascente-nigro tincta, sed fronte et genis antice rubris, colli antici et pectoris summi plumis intus pulcherrime rubris, tibiis omnino rubris, scapularibus brunneo-violaceis; campterio et subalaribus rubris; remigibus area lata rubra in dimidio basali pogonii interni praeditis.

Vorkommen: Austro-Malayische Subregion (Westliches NeuGuinea).

\section{Domicella Stavorini. - Blutbauch-Lori.}

Französisch: Lori stavorin.

Psittacus stavorini (1826) Less. Voy. Coq. Zool. I, p. 355. (1826) id. Dumont, Dict. Sc. Nat. XXXIX, p. 60. - Eclectus parague part. (1845) G. R. Gray Gen. B. II, p. 418.

Abbildung fehlt.

Diagnose: Species non satis cognita: atra, aeneo-nitens, abdomine rubro; magnitudine Lorii tricoloris.

Vorkommen: Austro-Malayische Subregion (Insel Waigiou?).

[Die Beschreibung wurde von Lesson nach einem auf der Reise der "Coquille" gesammelten Exemplare, welches später 
auch noch verloren ging, gegeben. Seitlem ist die Art nicht wieder gefunden worden und bleibt vorläufig zweifelhaft].

44. Domicella scintillata. - Schimmel-Lori.

Englisch: Carmine-fronted Lory. - Französisch: Lori flamméchée.

Psittacus bataviensis [!] (1790) Lath. Ind. Ornith. I, p. 126. Psittacus scintillatus (1835) Temm. Pl. Col. V, pl. 569. - Chalcopsitta rubrifrons (1858) G. R. Gray. Proc. Zool. Soc. p. 182. Cholcopsittacus chloropterus (1876) Salvadori Ann. Mus. Civ. Genova IX, p. 15.

Abbildungen: Temm. Pl. Col. V, pl. 569. - Bourjot St. Hilaire Hist. Nat. Perr. pl. 51. - Proc. Zool. Soc. 1858.

Diagnose: Viridis; abdomine et cervice croceo-striatis; sincipite, tibiis et subalaribus rubris; vertice et capitis lateribus nigro fuscis; rectricibus pogonii interni basi rubris, apice subtus flavescentibus; remigibus pogonio interno macula pallide crocea notatis; rostro et pedibus nigris; iride crocea.

Long. c. 340, ala 180, cauda 130, culmen $22 \mathrm{Mm}$.

Vorkommen: Austro-Malayische Subregion (Neu-Guinea, Aru Inseln).

Subgenus: EOS. Rothflügel-Loris.

Eos (1832) Wagl. Mon. Psitt. p. 494 (Typus: Psittacus inelicus Gm.).

Charakter der Untergattung: Färbung vorzugsweise roth, auch der Flügel roth, (dieser nur in zwei Fällen schwarz). Sieben verschiedene Formen.

45. Domicella riciniata. - Kapuzen-Lori.

Englisch: Cochin-China Lori. - Französisch: Lori à chaperon bleu.

Psittacus variegatus (1788) Gm. S. N. I, p. 319 (var!). Psittacus cochinchinensis [!] (1790) Lath. Ind. Orn. p. 116. Psittacus riciniatus (1811-1812) Bechst. Kurze Uebers. p. 69. Psittacus cucullatus (1812) Shaw. Gen. Zool. VIIl, p. 461. Lorius Isidorii (1829) Sws. Zool. Illustr. ser. 2, Vol I, pl. 8. Eos indice var. (1859) G. R. Gray List spec. B. Brit Mus. III, p. 51 .

Abbildungen: Levaillant 1. c. - Sws. Zool. Illustr. 1. c.

Diagnose: Coccinea; occipite, cervice, torque lato collari, 
ventre et crisso mediis violaceis; subcaudalibus violascente-imbutis; remigibus primariis fuscis, pogonii interni basi coccineis, secundariis basi coccineis, apice fuscis; tectricibus majoribus fuscis, basi coccineis; rectricibus superne sordide fuscescentibus; rostro miniato; pedibus nigricantibus.

Long. c. 250, ala 140, cauda 100, culmen $16 \mathrm{Mm}$.

Vorkommen: Westliche Austro-Malayische Subregion (Moluccen).

46. Subspecies: Wallacii. - Gueby-Lori.

Englisch: Gueby Lory. - Französisch: Lori écaillé.

Lory de Gueby (1783) Buff. Pl. Enl. pl. 684 (jun.). - Lory rouge et violet (1783) Buft. Hist. Nat. Ois. VII, p. 109 (jun.). Psittacus squamatus (1783) Bodd. Tabl. Pl. Enl. p. 42 (jun.). Psittucus guebiensis (1788) Gm. S. N. I, p. 318 (part.). - Lory écaillé (1801) Le Vaill. H. N. Perr. pl. 51. - Psittucus squameus (1811) Shaw Gen. Zool. VII, p. 463 (jum.). - Eos Wallacei (1864) Finsch Journ. f. Ornith. p. 411.

Abbildungen: Buffon 1. c. - Levaillant 1. c.

Diagnose: D. riciniatue simillima, sed capite toto rubro et torque collari violaceo stricto, minime supra occiput producto diversa.

Vorkommen: Austro-Malayische Subregion (Waigiou, Guebe, Batanta).

47. Domicella cyanogenys. - Blauohr-Lori.

Engl.: Bluc-cheeked Lory. -- Franz.: Lori ì joues bleux.

Eos cyanogenia (1850) Bonap. Consp. I, p. 4.

Abbildung: Proc. Zool. Soc. 1850, pl. 14.

Diagnose: Carmineus; fasuia utroque lata per oculum ducta et regione parotica azureis; alarum tectricibus et scapularibus, remigum apicibus, tibiis parte exteriore et rectricibus pogonio externo (mediis omnino) nigro-fuscis; rostro miniato; pedibus nigricantibus; iride rubra.

Long. c. 340 , ala 163 , cauda 120 , culmen $25 \mathrm{Mm}$.

Vorkommen: Austro-Malayische Subregion (Misori, Mafor).

48. Domicella histrio. - Diadem-Lori.

Englisch: Indian Lory. - Französisch: Lory rouge et violet.

Psittace indica cocinea (1760) Briss. Orn. IV, p. 376. Psittacus histrio (1776) S. Mïll. S. N. Suppl. 1. 76. - Psittacus indicus (1788) Gm. S. N. I, p. 318. - Lori Perruche violet 
et rouge (1783) Buffon Hist. Nat. Ois. VII, p. 111. - Perruche des Indes Orientales id. Pl. Enl. pl. 143. - Psittacus coccineus (1790) Lath. Ind. Orn. p. 89.

Abbildungen: Buffon 1. c. - Levaillant H. N. Perr. pl. 53.

Diagnose: Coccineus; vertice, fascia postoculari, auchenio, interscapulio et pectore cyaneis; tibiis nigro-cyaneis; scapularibus, remigum apicibus et rectricibus pogonio externo (mediis omnino) nigro-fuscis; rostro miniato; pedibus nigricantibus.

Long. c. 330, ala 150, cauda 130, culmen $22 \mathrm{Mm}$.

Vorkommen: Westliche Austro-Malayische Subregion (Sangir Inseln).

49. Domicella reticulata. - Strichel-Lori.

Englisch: Blue-streaked Lory.

Lorius borneus [!] (1831) Less. Traité d'Ornith. p. 192. Psittacus reticulatus (1839) Müller Verh. Land- en Volkenk. p. 107, 108. - Eos cyanostriata (1845) G. R. Gray Gen. B. II, p. 417, No. 9. - Psittacus cyanostictus (1857) Schleg. Handb. I, p. 184. - Psittecus (Eos) guttatus (1863) v. Rosenb. Naturk. Tijdschr. Ned. Ind. XXV, p. 145.

Abbildung fehlt.

Diagnose: Carmineus; pectore, tibiis latere exteriore et interscapulio obscure violascente imbutis, hoc striis scapalibus cyaneis ornato; auricularibus obscure cyaneis; alarum tectricibus nigro-fuscis, rubro-limbatis; remigum apicibus et rectricibus pogonio externo (mediis omnino) nigro-fuscis; rostro croceo; annulo orbitali, cera et pedibus nigris; iride brunnea (teste Salvadori).

Long. c. 335, ala 150 [?], cauda $130 \mathrm{Mm}$.

Vorkommen: Westl. Austro-Malayische Subregion (Tenimber Inseln, Timorlaut).

50. Domicella semilarvata. - Halbmasken-Lori.

Englisch: Half-masked Lory.

Eos semilarvata (1850) Bonap. Consp. I, p. 4.

Abbildung: Proc. Zool. Soc. 1850, pl. 15.

Diagnose: Carmineus; macula scapularium postremarum, crisso et vitta a mandibulae basi sub oculos usque ad auriculares producta cyaneis; remigibus primariis earumque tectricibus nigris, intus rubris; remigibus secundariis rubris, apice nigris; rectrici- 
bus subtus apicem versus fuscescentibus; rostro miniato; pedibus fuscis.

Long. c. 280, ala 130, cauda 100, culmen $20 \mathrm{Mm}$.

Vorkommen unbekannt.

51. Domicella rubra. - Rother Lori.

Englisch: Moluccan Lory. - Französisch: Lori rouge.

Psittacus chinensis (1776) Müll. S. N. Suppl. p. 77. Lory de la Chine (1783) Buff. Pl. Enl. pl. 519. - Lory rouge id. Hist. Nat. Ois. VII, p. 108. - Psittacus mere (1788) Gm. S. N. I, p. 335. - Psittacus caeruleatus (1789-1813) Shaw Nat. Misc. pl. 937. - Psittacus cyanonotus (1823) Vieill. N. D. XXV, p. 334 .

Var. scapularibus, abdomine, crisso, remigum secundariarum et tectricum alarum majoribus caeruleis.

Psittacus moluccensis (1790) Lath. Ind. Orn. I, p. 116.

Var. cauda caerulea (avis artefacta).

Psittacus cyanurus (1812) Shaw Gen. Zool. VIII, p. 538.

Var. plumis lateris inferioris violaceo-cyaneo limbatis; macula parotica cyanea.

Psittacus guebuensis part. (1839-1844) Müll. Verh. Land- en Volkenk. p. 107. - Psittucus Bernsteinii (1863) v. Rosenb. Nat. Tijdschr. Ned. Ind. XXV, p. 145. - Lorius squamatus (1864) Schl. Mus. P. B. Psittaci 1. 124. - Domicella Schlegelii (1868) Finsch Pap. II, p. 792.

Var. margine alarum, apice tectricum majorum, remigum secundariarum, et rectricum viridibus.

Psittaca coccinea Bonarum fortunarum insulae (1760) Briss. Orn. IV, p. 273. - Psittacus borneus (1766) Lin. S. N. I, p. 141 (teste Salvadori).

Abbildungen: Shaw Nat. Misc. pl. 937. -- Levaillant Hist. Nat. Perr. pl. 44, 93 et 97. - Bufion Pl. Enl. l. c. - Shaw Gen. Zool. VIII, pl. 67.

Diagnose: Coccinea; subcaudalibus et scapularibus azureis; renigibus et manus tectricibus apice fuscis, remigibus tribus longissimis quoque pogonio externo fuscis; rectricibus superne rufescentibus; fascia utrinque regionis analis a tibiis ad crissum cyanea; rostro miniato; pedibus fuscis.

Long. c. 340 , ala 160 , cauda 120 , culmen $26 \mathrm{Mm}$.

Vorkommen: Westl. Austromalayische Subregion (Molukken). 
Subgeuus: DOMICELLA. G i ï $\mathrm{n} \mathrm{f} l$ ï $\mathrm{g}$ e $1-\mathrm{L}$ or is.

Charakter der Untergattung: Färbung vorzugsweise roth, Flügel grün. Zehn verschiedene Formen.

52. Domicella garrula. - Gelbmantel-Lori.

Englisch: Ceram Lory. - Französisch: Lori noira.

Lorius ceramensis (1760) Briss. Ornith. IV, p. 215. Lorius moluccensis ibid. p. 219. - Psittacus gamulus (1764) Lin. Mus. Av. Fr. II, p. 14. - Psittacus aurorae (1766) Lin. S. N. I, p. 144. - Lori noira (1783) Buff. Hist. Nat. Ois. VII, p. 102. - Lory des Moluques (1783) Buff. Pl. Linl. pl. 216.

Abbildungen: Buffon 1. c. - Levaillant Hist. Nat. Perr. pl. 96. -- Shaw Nat. Misc. pl. 925. -- Sws. Zool. Ill. Ser. II, pl. 12 (1829). -- Reichenow Vogelbilder t. III, f. 5.

Diagnose: Coccinea; alarum tectricibus et tibiis viridibus, illis olivascentibus; caudae apice obscure viridi; interscapulii macula (interdum absente), flexura, campterio et subalaribus luteis; remigibus fuscis, viridi-imbutis, pogonii interni basi dilute coccincis; rostro miniato; pedibus nigricantibus; iride fulva.

Long. c. 350 , ala 180, cauda 120, culmen $26 \mathrm{Mm}$.

Vorkommen: Westl. Austro-Malayische Subregion (Molukken: Halmahera).

53. Subspecies: flavopalliata. - Pracht-Lori.

Lorius flavopalliatus (1877) Salv. Ann. Mus. Civ. Genova, Vol. X, p. 33 .

Abbildung fehlt.

Diagnose: D. garvelo simillima, sed interscapulio omnino flavo diversa.

Vorkommen: Westl. Austro-Malayische Subregion (Molukken: Obi, Batjan).

\section{Domicella tibialis. - Blauschenkel-Lori.}

Englisch: Blue-legged Lory.

Lorins tibialis (1871) Sclater Proc. Zool. Soc. p. 499.

Abbildung: Proc. Zool. Soc. 1871, pl. 40.

Diagnose: Coccinea; alis viridibus; campterio, subalaribus et tibiis cyaneis; semitorque pectorali flavo; caudae apice nigricante; remigibus subtus flavissimis; rostro aurantiaco; pedibus pallide carneis. Crassitie Lorii gamuli (Fide Sclater).

(Obs.: Species forma et crassitie Lorii garruli, a quo differt 
plaga interscapulii nulla, semitorque pectorali flava et tibiis cyaneis).

Vorkommen unbekannt (Molukken?).

\section{Domicella chlorocerca. - Grünschwanz-Lori.}

Engl.: Green-tailed Lory. - Franz.: Lori à queue verte.

Lorius chlorocercus (1856) Gould Proc. Zool. Soc. p. 137. Lorius chloronotus (1856) Bonap. Naumannia Consp. Ps. sp. 293.

Abbildung: Proc. Zool. Soc. 1867, pl. 16.

Diagnose: Carminea; alis et caudae apice viridibus; pileo nigro; fascia gutturali transversa lutea, utroque in maculam nigram desinente; campterio, subalaribus et tibiis cyaneis; remigibus pogonii interni basi dilute carmineis; rostro miniato; pedibus nigricantibus.

Long. c. 280, ala 145, cauda 85, culmen $23 \mathrm{Mm}$.

Vorkommen: Oestl. Austro-Malayische Subregion (Salomons Inseln).

\section{Domicella atricapilla. - Erz-Lori.}

Engl.: Purple-capped Lory. - Franz.: Lori à collier.

Lorius orientalis indicus (1760) Briss. Ornith. IV, p. 222, pl. 24). - Lorius torquatus indicus ibid. p. 230. - Psittacus domicella (1766) Lin. S. N. I, p. 145. -- Lori à collier (1783) Buffon Hist. N. Ois. VII, p. 104. - Lory des Indes Orientales (1783) Buffon Pl. Enl. pl. 119 et 84. - Psittacus rex (1811) Bechst. Kurze Uebers. p. 92 [var.!]. - Psittrcus raja (1812) Shaw Gen. Zoo:. VIII, p. 537, pl. 82 [var.!]. - Psittecus radhea (1823) Vieill. N. D. XXV, 1. 337 [var.!]. - Domicella atricapilla (1832) Wagl. Mon. Psitt. p. 567.

Abbildungen: Bufion 1. c. - Levaillant Hist. Nat. Perı. pl. 94, 95 et 95a. - Shaw Gen. Zool. VIII, pl. 81 and 82. Jard. \& Selby (1843) Nat. Libr. VI, pl. 18. - Reichenow Vogelbilder t. III, f. 7 .

Diagnose: Carminea; pileo nigro, postice violascente; alarum tectricibus olivascente viridibus; subalaribus et tibiis cyaneis; flexura cyanea, albo - varia; scuto pectorali luteo; caudae apice violascente-rufo; remigibus fuscis viridi-imbutis, pogonii interni basi luteis; rostro miniato; pedibus nigricantibus; annulo orbitali cinereo-brunneo; iride fulva.

Long. c. 340, ala 180, cauda 110 , culmen $26 \mathrm{Mm}$. 
Vorkommen: Westl. Austro-Malayische Subregion (Molukken: Ceram, Amboina).

\section{Domicella hypoenochroa. - Rothnacken-Lori.}

Lorius hypoinochrous (1859) G. R. Gray List. Psitt. p. 49. Abbildung: Cruise of the Curaçoa Birds (1873) pl. 14.

Diagnose: Carminea; pectore et cervice obscurioribus; interscapulio obscure violaceo-tincto; pileo nigro; abdomine imo, tibiis et subcaudalibus violascente nigris; alis viridibus; subalaribus rubris; remigibus intus parte basali flavis; caudae dimidio basali rubro, dimidio apicali superne sordide violaceo, pogonio interno paullum virescente-tincto, inferne flavo-olivaceo nitente; rostro miniato; pedibus fuscis.

Long. c. 320, ala 180, cauda 100, culmen $27 \mathrm{Mm}$.

Vorkommen: Austro - Malayische Subregion (Neu - Guinea, Salomons Inseln, Neu-Hanover, Neu-Britannien, Neu-Spanien).

\section{Domicella tricolor. - Frau en-Lori.}

Englisch: Blue-tailed Lory. - Frauzösisch: Lori tricolor.

Ara moluccensis varia (1760) Briss. Ornith. IV, p. 197. Lorins philippensis ibid. p. 225. - Psittacus lory [!] (1766) Lin. S. N. I, p. 145. - Lori tricolor (1783) Buff. Hist. Nat. Ois. VII, p. 106. - Lory des Philippines (1783) Buff. Pl. Enl. pl. 168. Psittacus Sebanus (1812) Shaw Gen. Zool. VIII, p. 459. - Lorius tricolor (1826) Shaw Gen. Zool. XIV, p. 132.

Abbildungen: Buffon l. c. - Levaillant Hist. Nat. Perr. pl. 123 et 124. - Reichenow Vogelbilder t. XI, f. 2.

Diagnose: Pileo nigro; capitis lateribus, gula, corporis lateribus et subalaribus, tergo, uropygio et supracaudalibus coccineis; fascia nuchali dilute coccinea; auchenio, interscapulio, ventre et epigastrio mediis et pectore nigro-cyaneis, hoc fascia utroque cum auchenio conjuncto; crisso et subcaudalibus dilutius cyaneis; rectricibus basi coccineis, extus rufescentibus, apice violascente cyaneis, apice subtus lutescentibus; tectricibus alarum olivaceo-aurantiis, partim viridibus; remigibus fuscis, viridiimbutis, pogonii interni basi luteis.

Long. c. 350, ala 160, cauda 110, culmen $27 \mathrm{Mm}$.

Vorkommen: Austro-Malayische Subregion (Neu-Guinea, Batanta, Salvatti, Waigiou, Misol). 
59. Subspecies: erythrothorax. - Rothbrust-Lori.

Lorius erythrothorax (1877) Salv. Ann. Mus. Civ. Genova, Vol. X, p. 32.

Diagnose: $D$. tricolori simillima, sed pectore coccineo et colore cyaneo gastraci minime cum colore cyaneo cervicis conjuncto; fascia interscapulari indistincta dilute coccinea.

Vorkommen: Austro-Malayische Subregion (Südöstliches NeuGuinea).

60. Subspecies: jobiensis. -- Jobi-Lori.

Domicella lori var. jobiensis (1874) A. B. Meyer Sitzungsb. Ak. Wiss. Wien LXX, p. 229.

Diagnose: $D$. erythrothoraci simillima, sed pectoris lateribus et subalaribus nigro-cyaneis; flexura et campterio inconspicue obscure cyanescentibus.

Long. c. 360 , ala 180 , cauda 115 , culmen $28 \mathrm{Mm}$.

Vorkommen: Austro-Malayische Subregion (Jobi, Miosnom).

61. Subspecies: cyanaurhen. - Blaunacken-Lori.

Englisch: Blue-naped Lory.

Psittacus cyanauchen (1839-1844) Müll. Schl. Verh. Land Volkenk. p. 107; (1842) Archiv für Naturg. p. 79. - Lorius superlus (1845) Fras. Proc. Zool. Soc. p. 16. - Lorius speciosus (1863) v. Rosenb. Naturk. Tijdschr. Ned. Ind. XXV, p. 144, 225. - Lorius cyanocinctus (1863) ibid. p. 145. - Domicella lori mysorensis (1874) Meyer S. Ak. Wiss. Wien LXX, p. 233.

Abbildungen: Fraser Zool. Typ. (1849) pl. 55. - Rchw. Vogelbilder t. XI, f. 1.

Diagnose: $D$. erythrothoraci simillima, sed fascia lata interscapulii coccinea; fascia nuchali nulla, cervice toto cyaneo (hoc et epigastrio dilutius cyaneo-tinctis); flexura et campterio cyaneis; subalaribus et pectoris lateribus cyaneis.

Long. c. 370 , ala 180, cauda 120, culmen $28 \mathrm{Mm}$.

Vorkommen: Austro-Malayische Subregion (Misori).

Subgenus: CORIPHILUS. Ma id-Loris.

Coriphilus (1830) Wagl. Mon. Psitt. p. 494 (Typus: Psittacus sapphivinus Forst.). - Phigys (1831) Less. Traité d'Orn. p. 193 (Typus: Lorius phigy Less.). - Corythophilus (1848) Agassiz Nomencl. Zool. p. 292.

Charakter der Gattung: Verlängerte schmale oder zer- 
schlissene Federn auf dem Oberkopfe. Schwanz wesentlich kürzer als der Flügel, stark gerundet oder schwach stufig, die einzelnen Federn auch am Ende breit. I:ie Spitzen der ersten Schwingen verschmälert. Zweite und dritte Schwinge am längsten, vierte gleich der ersten oder etwas kürzer. - Fünf Arten in der Polynesischen Subregion.

62. Coriphilus australis. - Blaukäppchen.

Engl.: Sparrow Parrot. - Franz.: Perruche fringillaire.

Psittacus australis (1788) Gmel. S. N. p. 329. - Psittacus fringillaceus ibid. p. 337. - Psittecus porphyreocephalus (1789) Shaw Nat. Misc. pl. 1. - Psittacus pipilans (1790) Lath. Ind. Orn. p. 105. - Psittacus euchlorus (1844) Forst. Licht. Descr. Anim. p. 160.

Abbildungen: Levaillant Hist. Nat. Perr. pl. 71. - Rchw. Vogelbilder t. XXI, f. 7.

Diagnose: Viridis, subtus olivascens; vertice et occipite caeruleis; capitis lateribus, gula et ventre medio coccineo-roseis; crisso violaceo; rectricibus pogonio interno et apice luteis; rostro, pedibus et iride miniatis.

Long. c. 190, ala 108, cauda 70 , culmen $13 \mathrm{Mm}$.

Vorkommen: Polynesische Subregion (Freundschafts-, SamoaInseln).

63. Coriphilus Kuhli. - Rubin-Lori.

Eirgl.: Love Bird, Ruby Lory. - Franz.: Lori écarlate.

Psittacula Kuhlii (1824) Vig. Zool. Journ. p. 412. - Vini cocineus (1832) Less. Illustr. Zool. pl. 28. - Psittanula interfringillacea (1837-1838) Bourjot St. Hilaire Hist. Nat. Perr. pl. 83 .

Abbildungen: Lear Ill. Parr. pl. 38. - - Bourjot St. Hilaire 1. c. - Jard. Selby Nat. Libr. Vol. VI, pl. 23. - Reichenow Vogelbilder t. XXI, f. 5 .

Diagnose: Superne viridis; interscapulio olivascente, uropygio. et supracaudalibus flavescentibus; loris, genis, gutture et pectore coccineis; occipitis plumis elongatis, ventre ct crisso merliis obscure violaceis; hypochondriis et subcaudalibus lateralibus viridi-flavis; subalaribus viridibus; rectricibus coccineis, pogonio externo violaceis, apice flavo-viridibus.

Loug. c. 220, ala 135, cauda 85, culmen $15 \mathrm{Mm}$. 
Vorkommen: Polynesische Subregion (Fanning- und Washington Insel).

64. Coriphilus solitarius. - Einsiedler.

Englisch: Solitary Parrot.

Psittacus solitarius (1802) Lath. Ind. Orn. Suppl. II, p. 23. Psittacus Vaillanti (1809) Shaw Nat. Misc. pl. 909. - Psittacus coccineus (1812) Shaw Gen. Zool. VIII, p. 472. - Psittacus Phigy (1811) Bechst. Kurze Uehers. p. 81.

Abbildung: Rowley Ornith. Misc. II, pl. 41, p. 38.

Diagnose: Viridis, nucha et uropygio dilutius tinctis; auchenio, capitis lateribus, abdomine et subalaribus coccineis; pileo, tibiis et crisso nigro-violaceis, subcaudalibus viridibus; rectricibus pogonio interno macula crocea notatis; rostro et iride miniatis; pedibus flavis.

Long. c. 220, ala 125, cauda 70, culmen $15 \mathrm{Mm}$.

Vorkommen: Polynesische Subregion (Fidschi Inseln).

65. Coriphilus taitianus. - Saphir-Lori.

Englisch: Otaheitan blue Parrakeet. -- Franz.: Psittacule d'Otaïti, Perruche Arimanon.

L'Arimanon (1783) Buffon Hist. Nat. Ois. VII, p. 139. Petite Perruche de l'Isle de Taiti (1783) id. Pl. Enl. pl. 455, f. 2. -- Psittacus peruvianus (1776) S. Müll. S. N. Suppl. p. 80. Psittucus taitiunus (1788) Gmel. S. N. I, p. 329. - Psittacus varius (1788) Gmel. S. N. I, p. 337. - Psittacus porphyrio (1789) Shaw Nat. Misc. pl. 7. - Psittacus Sparrmanni (1820) Kuhl Consp. Psitt. p. 68. - Lorius vini (1831) Less. Traité d'Ornith. p. 194. - Psittarus sapphirinus (1844) Forst. Lehtst. Descr. An. p. 201. - Coriphilus notatus (1849) G. R. Gray Gen. B. II, No. 1. - Coriphilus cyaneus (1858) Cassin Un. St. Exp. p. 240.

Abbildungen: Buffon Pl. Enl. pl. 455, f. 2. - Levaillant Hist. Nat. Perr. pl. 65 et 66 (juv.). -- Reichenow Vogelbilder taf. XXI, fig. 1 .

Diagnose: Obscure cyaneus; genis guttureque albis; rostro et iride coccineis; pedibus miniatis.

Long. c. 180 , ala 110 , cauda 70 , culmen $12 \mathrm{Mm}$.

Vorkommen: Polynesische Subregion (Gesellschaftsinseln). 
66. Coriphilus smaragdinus. - Smaragd-Lori.

Englisch: Superb Lory, Goupil's Parrot. - Französisch: Psittacule bleue.

Psittarus ultramarinus [!] (1821) Kuhl Consp. Psitt. p. 49. Psittaculus smaragdinus (1841) Hombr. Jacq. Ann. Sc. Nat. 2. Sér., Vol. 16, p. 318. - Coriphilus dryas (1842) Gould Proc. Zool. Soc. p. 165. - Coriphilus Gouphili (1842-1853) Hombr. Jacq. Voy. Pôle Sud Zool. III, p. 103.

Abbildungen: Hombr. Jacq. Voy. Pôle Sud. pt. 24 bis f. 3. Voy. of Sulphur pl. 26. - Reichenow Vogelbilder t. XXI, f. 2.

Diagnose: Coeruleus; vertice, occipite, pectore et tibiis azureis; plumis pilei elongatis striis scapalibus tenuibus albis; genis, gula et ventre albis, plumis basi nigro-cyaneis; rectricibus pogonio interno albis; rostro, pedibus et iride miniatis.

Long. c. 200, ala 117, cauda 80, culmen $13 \mathrm{Mm}$.

Vorkommen: Oestliche Polynesische Subregion (Ma:quesas Inseln).

Genus: CORYLLIS. Flederma us-Pa p a g i en.

Loriculus (1849) Blyth Cat. B. Mus. A. S. B. p. 9 (Typus: Psittacus pumilus Scop.). - Licmetulus (1856) Bonap. Naumannia Beilage (Typus: Loriculus bonapartei Souancé). - Coryllis (1868) Finsch Pap. II, p. 687 (Typus: Psittacus pumilus Scop.).

Charakter der Gattung: Kurzer, gerader Schwanz, welcher nur halb so lang ist als der Flügel oder noch kürzer. Flügel spitz, angelegt bis zur Schwanzspitze reichend; erste bis dritte Schwinge am längsten. Oberschwanzdecken lang, oft bis zur Spitze der Schwanzfedern reichend. Schnabel dïnn und schwach. Zunge ohne Papillen. Färbung vorzugsweise grün.

Die Fledermaus-Papageien weichen nicht unwesentlich von allen anderen Loris ab, nehmen jedoch unzweifelhaft den richtigen Platz in der Familie der Trichoglossidae ein, wenn man sie nicht als selbstständige Familie sondern will. Das bezeichnende Merkmal, welches sie neben minder auffallenden Kennzeichen mit den Loris verbindet, ist die Form des Schnabels. Wie in der Gestalt, so unterscheiden sich auch in der Lebensweise die Fledermauspapageien von ihren Familiengenossen. Auf dem Boden, wie auf Zweigen, bewegen sie sich eiligen, trippelnden Ganges. Die Stimme ist nicht kreischend, sondern im Gegentheil 
angenehm; dic einzelnen 'Töne gestalten sich zu einem wohllautenden Geschwätz. Höchst auffallend ist die Gewohnheit dieser Papageien, wie die Fledermäuse, den Kopf nach unten, sich aufzuhängen. In solcher Stellung ruhen und schlafen sie, in solcher nehmen sie aber auch oft ihre Nahrung zu sich und verändern dieselbe auch nicht, wenn sic sich entleeren. Dic Nahrung besteht vorzugsweise in weichen Früchten und Beeren.

Die jetzt bekannten zwanzig Arten und Unterarten bewohnen hauptsächlich die ganze Austro-Malayische und Indo-Nalayische Subregion; wenige Formen finden sich auch in der Indischen, Indo-Chinesischen und Ceylonischen Subregion. Die Verbreitung der einzelnen Arten ist meistens eine sehr beschränkte; fast jede Inselgruppe oder jede abgesondert gelegene Insel des Malayischen Archipels hat ihre besondere Art aufzuweisen. Die Geschlechter unterscheiden sich in der Regel durch die Färbung von einander.

Schnabel roth:

$$
\text { Schlüssel der Gattung: }
$$

Oberkopf grün:

Kehle hellblau: vernatis.

Kehle gelb: pusilla.

Kleiner rother Kehlfleck:

Kehlfleck bläulich-grün umsäumt: exilis.

Kehlfleck ohne bläulichen Saum: flosculus. Stirn roth:

Kropf grün:

Ganzer Oberkopf roth, Kehle hellblau: indica.

Nur die Stirn roth, Kehle gelbgrün: panayensis.

Grosser rother Kropfleck:

Stirn roth, Rücken grïn: regulus (s. auch: occipitalis und melanopterus).

Stirn roth, Rücken goldgelb: chrysonota.

Ganzer Oberkopf roth: apicalis.

Schnabel schwarz:

Bürzel und Oberschwanzdecken gelb: tener.

Bürzel und Oberschwanzdecken roth:

Scheitel blau: galgulus.

Oberkopf grün:

Unterschwanzdecken grün: Sclateri.

Mittlere Unterschwanzdecken roth: catamenia.

Stirn goldgelb: aurantiifrons.

Oberkopf roth:

Cab. Journal f. Ornithol. XXIX, Jahrg. No, 155. Juli 1881. 
Hinterkopf goldgelb: Bonapartii.

Hinterkopf grün: stigmata (s. auch amabilis u. quadricolor).

67. Coryllis vernalis. - Frühlingspapagei.

Englisch: Vernal Parrot.

Psittacus vernalis (1787) Sparrm. Mus. Carls. t. 29. Psittacus indicus (1820) Kuhl Consp. Psitt. p. 65 (ㅇ). Psittacus pendulus Pearson J. As. S. Beng. X, p. 654. - Psittceus pyrrhopygia (1844) Hodgs. Gray's Zool. Misc. p. 85.

Abbildung: Reichenow Vogelbilder t. XV, f. 4.

Diagnose: Viridis; dorso olivascente; uropygio et supracaudalibus, caudae apicem non attingentibus, rubris; macula jugulari et vertice medio dilute caeruleis; rostro coccineo; pedibus fulvis; iride flava.

Long. c. 150 , ala 95 , cauda 45 , culmen $12 \mathrm{Mm}$.

오 Macula gulari cacrulea minore, verticis macula nulla.

Vorkommen: Indische, Süđlliche Indo-Chinesische und Nördl. Indo-Malayische Subregion (Vorder-Indien und Westliches HinterIndien, Malacca).

68. Coryllis pusilla. - Elfen papagei.

Englisch: Small Vernal-Parrot.

Loriculus pusillus (1859) G. R. Gray List. Psitt. p. 54. - Psittacus amoene (1868) Finsch Pap. II, p. 725 (syn.).

Abbildung: Reichenow Vogelbilder t. XV, f. 1 (오).

Diagnose: Viridis; dorso olivascente; uropygio et supracaudalibus, caudae apicem attingentibus, coccineis; macula jugulari lutea; rostro et iride miniatis; pedibus flavis.

Long. c. 130 , ala 82, cauda 37, culmen $11 \mathrm{Mm}$.

오 Macula gulari nulla.

Vorkommen: Indo-Malayische Subregion (Java). 69. Coryllis flosculus. - Blüthen-Lori.

Loriculus flosculus (1863) Wall. Proc. Z. S. p. 488.

Diagnose: Viridis; dorso olivascente; uropygio et supracaudalibus, caudae apicem attingentibus, coccincis; macula parva jugulari rubra; rostro et iride miniatis; pedibus flavis.

(Obs.: C. exili simillima, sed parum major.)

오: Ingnota.

Vorkommen: Westliche Austromalayische Subregion (Flores). 70. Coryllis cxilis. - Liliput.

Loriculus exilis (1865) Schleg. Ned. Tijolschr. Dierk. p. 185. 
Abbildungen: Rowley Ornith. Misc. II, pl. 59, p. 243. Reichenow Vogelbilder t. XV, f. 6 .

Diagnose: Viridis; dorso olivascente; uropygio, supracaudalibus, caudae apicem attingentibus, et macula parva jugulari coccineis, hac thalassino-viridi-circumdata; rostro miniato; iride flava; pedibus fulvis.

Long. c. 110 , ala 65 , cauda 30 , culmen $9 \mathrm{Mm}$.

ㅇ: Ignota.

Vorkommen: Westl. Austro-Malayische Subregion (Celebes).

71. Coryllis panayensis. - Panay-Papageichen.

Loriculus panayensis (1877) Sclat. Proc. Z. S. p. 538.

Abbildung fehlt.

Diagnose: Viridis; fronte rubra; vertice, occipite et auchenii macula aurantiacis; genis anterioribus caeruleis; uropygio et supracaudalibus, caudae apicem non attingentibus, rubris; rostro miniato.

Ala 95, cauda $55 \mathrm{Mm}$.

우: Vertice et occipite genisque totis viridibus.

Vorkommen: Nördl. Indo-Malayische Subregion (Philippinen: Panay).

72. Coryllis indica. - Blum enpapagei.

Englisch: Red and green Indian Parrot.

Psittacula indice (1760) Briss. Ornith. IV, p. 390. - Ise coulacissi (1783) Buffon Hist. Nat. VII, p. 136. - Perruche des Philippines id. Pl. Enl. pl. 520. - Psittacus indicus (1788) Gm. S. N. I, p. 349 . - Psittacus asiaticus (1790) Lath. Ind. Ornith. p. 130. - Psittacula coulaci (1831) Less. Traité d'Orn. p. 202. - Psittacula minor (1832) Wagl. Mon. Psitt. p. 628. Loriculus philippensis (1850) Blyth. Cat. B. As. Soc. Beng. App. p. 10. - Loriculus cyconolaemus (1856) Bonap. Naumannia Heft IV, Beilage. - Loriculus Edwardsi (1867) Blyth Ibis p. 295. - Loriculus puniculus (1856) Bp. Rev. Mag. Z. p. 155. Loriculus sinensis ibid.

Abbildung: Legge Birds of Ceylon.

Diagnose: Viridis; sincipite et rertice coccineis; occipite, cervice et interscapulio aurantiaco-imbutis; genis gulaque dilute caeruleis; uropygio et supracaudalibus, caudic apicem non attingentibus, cerasinis; rostro miniato; iride dilute flava.

Long. c. 170 , ala 97, cauda 45, culmen $13 \mathrm{Mm}$. 
우 an juv.: Pileo medio coccineo-imbuto; occipite, cervice et interscapulio vix aurantiacis; genis gulaque viridibus.

Vorkommen: Ceylonische Subregion (Ceylon).

73. Coryllis regulus - Königs-Papageichen.

Englisch: Chieftain Hanging Parrakeet.

Loriculus regulus (1856) Sonancé Rev. Mag. Zool. p. 222.

Abbildung: Rowley Ornith. Mise. II, pl. 58, p. 238.

Diagnose: Viridis; fronte, uropygio et supracaudalibus, caudae apicem non attingentibus, coccineis; macula maxima jugulari aurantio-coccinea; vertice aurantio; racula auchenii miniatoaurantia; rostro miniato; pedibus fulvis.

Long. c. 160, ala 95, cauda 55, culmen $16 \mathrm{Mm}$.

\&: Nacula jugulari nulla, fronte dilute coccinea; vertice viridi, aurantio-imbuto; auchenii macula inconspicua, pectore et gutture flavescente.

Vorkommen: Nördliche Indo-Malayische Subregion (Panay, Negros).

74. Subspecies: occipitalis, - Goldköpf chen.

Comyllis occipitalis (1871) Finsch Ibis p. 208.

Abbildung fehlt.

Diagnose: ¿ regulo simillima, serl occipite aurantio.

Vorkommen: Nördliche Indo-Malayische Subregion (Philippinen: Mindanao).

75. Subspecies: phitippensis. - Rothkäppehen.

Englisch: Philippine-Hanging Palrakeet. - Französisch: Psittacule à fronte rouge.

Psittacula philippensis (1760) Briss. Ornith. IV, p. 392. -Psittacus philippensis (1776) St. Müller, Lin. Nat. Suppl. p. 80. Psittacus melanopterus (1786) Scop. Del. Flor. F. Ins. II, p. 86. Psittacus minor (1788) Gmel. S. N. p. 351. - Psittecula Culccissi (1832) Wagl. Mon. Psitt. 1). 626. - Loriculus rubriforons (1854) Vig. Bp. Rev. Mag. Zool. p. 155.

Abbillungen: Bourjot St. Hilaire Hist. Nat. Perr pl. 87. Lear Illustr. Parr. pl. 41.

Diagnose: C. regulo simillima, sed vertice et occipite viridibus, aurantio-imbutis.

우: Genis caeruleis.

Vorkommen: Nördl. Indo-Malayische Subregion (Lızon). 
76. Coryllis chrysonota. - Cebu-Papageichen.

Englisch: Golden-backed Hanging Parrakeet.

Loviculus chrysonotus (1872) Sclater Ibis p. 324.

Abbildung: Ibis 1872, pl. 11.

Diagnose: Viridis; fronte, uropygio et supracaudalibus, caudae apicem non attingentibus, coccineis; macula maxima jugulari aurantio-coccinea; pileo et notaeo reliquo aurantiis; genis anterioribus caeruleis; rostro miniato; pedibus flavis.

Long. c. 170 , ala 95, cauda 60, culmen $15 \mathrm{Mm}$.

오 Gutture viridi-flavescente.

Vorkommen: Nördliche Indo-Malayische Subregion (Cebu, Philippinen).

77. Coryllis apicalis. - Pracht-Papageichen.

Englisch: Blue-tailed Hanging Parrakeet.

Loriculus apiculis (1856) Souancé Rev. Mag. Zool. p. 220. Loriculus cycentuemes (1856) Bonap. Tab. Uebers. Pap. Naumamia Heft IV, Bcilage. -- Loriculus melunopterus (1859) Scop). Gray List. I'sitt. Br. MIts. 1) 55. - Compllis Hertluedi (1868) Finsch Pap. II, p. 711.

Abbildung: Proc. Zool. Soc. 1877, pl. 82.

Diagnose: Viridis; pileo, occipite, macula magna gutturali, uropygrio et supracaudalibus, caudac apicem ferc attingentibus, coccineis; cervice aurantiaco-imbuta; rostro miniato (teste Finsch).

ㅇ: Gutture viridi; genis et mento caeruleis.

Vorkommen: Nördl. Indo-Malayische Subregion (Mindanao).

78. Coryllis tener. - Zart-Papageichen.

Loriculus tener (1877) Sclater Proc. Zool. Soc. p. 107.

Abbildung: Rowley Ornith. Misc. pt. II, p. 375.

Diagnose: Viridis; uropygio et supracaudalibus, caudae apicem attingentibus, flavis; macula parva gutturali rubra; rostro nigro.

Long. c. 100 , ala 65 , cauda $28 \mathrm{Mm}$.

Vorkommen: Oestliche Austro-Malayische Subregion (Duke of York Inseln).

79. Coryllis galgulus. - B laukrönchen.

Englisch: Blue-crowned Hanging l'arrakeet.

Psittacus galgulus (1754) Lin. Amoen. Acad. p. 236. Psittucus flavigulus (178:3) Bodd. T'abl. Pl. Enl. p. 12. - Psittucus pumilus (1786) Scop. Del. Fl. F. Ins. p. 87. - Psittacula 
cyaneopileate (1837-1838) Bourjot St. Hilaire Hist. Nat. Perr. pl. 88 .

Abbildungen: Bourj. St. 1. c. - Reichenow Vogelb. t. XV, f. 2.

Diagnose: Viridis; macula magna jugulari, urogygio et supracaudalibus, caudae apicem attingentibus, coccineis; vertice medio cyaneo; interscapulii macula, altera tergi aurantiis; rostro nigro.

Long. c. 130, ala 80, cauda 35, culmen $13 \mathrm{Mm}$.

오 Viridis, uropygio et supracaudalibus coccineis.

Vorkommen: Indo-Malayische Subregion (Malacca, Sumatra, Banca, Borneo).

80. Coryllis Sclateri. - Zierpapageichen.

Englisch: Sclater's Hanging Parrakeet.

Loriculus sclateri (1862) Wall. Proc. 'L. S. p. 336.

Abbildung: Proc. Zool. Soc. 1862, pl. 38.

Diagnose: Viridis; macula parva jugulari, campterio, uropyoio et supracaudalibus, caulae apicem fere attingentibus, rubris; interscapulio miniato-aurantio, medio rubro; rostro nigro.

Long. c. 160, ala 95, cauda 50, culmen $15 \mathrm{Mm}$.

Vorkommen: Westl. Austro-Malay. Subregion (Sula Inseln).

81. Coryllis catemenia. - Rothsteisspapageichen.

Loriculus catumene (187?) Schleg. Tijdschr. Dierk. IV, p. 7.

Abbildung: Rowley Ornith. Nisc. Pt. II, pl. 57, p. 236.

Diagnose: Viridis; macula parva jugulari et subcaudalibus mediis coccineis; uropygio et supracaudalibus, caudae apicem attingentibus, fere superantibus, rubris; rostro nigro.

Ala 80, cauda $35 \mathrm{Mm}$.

우: Subcaudalibus omnino viridibus.

Vorkommen: Westliche Austro-Malayische Subregion (Sangir Inseln).

82. Compllis aurantiifrons. - Gelbstirn-Papageichen.

Englisch: Golden-fronted Hanging Parrakeet.

Loviculus aurantiifrons (1873) Schleg. Nederl. Tijdsuhr. Dierk. IV, p. 9.

Abbildung: Rowley Ornith. Misc. pt. II, p. 375.

Diagnose: Viridis; sincipite aurantio; macula gutturali, uropygio et supracaudalibus, caudae apicem attingentibus, coccineis; rostro nigro; iride flava.

Ala 68 , cauda 33 , culmen $8 \mathrm{Mm}$. 
오: Fronte viridi. Guinea).

Vorkommen: Austro-Malayische Subregion (Misol, Neu83. Coryllis Bonapartii. - Sulu-Papageichen.

Englisch: Bonaparte's Hanging Parrakeet.

Loriculus Bonapurtei (1856) Souaucé Rev. Mag. Zool. p. 222. Abbildung fehlt.

Diagnose: Viridis; pileo, macula jugulari, uropygio et supracaudalibus, caudae apicem non attingentibus, coccineis; occipite aurantio; rostro nigro.

오 Jugulo viridi, genis caeruleis.

Vorkommen: Indo-Malayische Subregion (Sulu Insel).

84. Coryllis stigmate. - Rothplättchen.

Englisch: Sclarlet-fronted Hanging Parrakeet.

Psittecus stigmatus (1841) Mïll. Schleg. Verh. Land- en Volkenkunde p. 108.

Abbildungen: Rowley Ornith. Misc. II, pl. 60, p. 250. Reichenow Vogelbilder t. XV, f. 7.

Diagnose: Viridis; pileo, macula parva jugulari, campterio, uropygio et supracaudalibus, caudae apicem non attingentibus, rubris; interscapulio aurantio-imbuto; rostro nigro; pedibus fulvis; iride miniata.

Long. c. 170, ala 95, cauda 50, culmen $14 \mathrm{Mm}$.

ㅇ: Pilco viridi, frontis macula parra rubescente; macula gulari minore.

Vorkommen: Westl. Austromalayische Subregion (Celehes). 85. Subspecies: quadricolor. - T o g i a n - P a p a g e i c h e n.

Loriculus quadricolor (1872) Walden Ann. Mag. Nat. IIist. Vol. IX, p. 398.

Diagnose: C. stigmatae simillima, sed minor et interscapulio miniato-aurantio.

Long. c. 145, ala 90, cauda 45, culmen $10 \mathrm{Mm}$.

Vorkommen: Westliche Austro-Malayische Subregion (Togian Inseln).

86. Subspecies: amabilis. - B a tjan-Pa pag e i chen.

Loriculus amabilis (1862) Wallace Ibis p. 349.

Diagnose: C. stigmatce simillima, sed interscapulio flavescente viridi.

Long. c. 160 , ala 95 , cauda 50, culmen $14 \mathrm{Mm}$. 
Vorkommen: Austro - Malayische Subregion (Moluccen: Batjan, Halmahera).

\section{Familie: Patreomithidae. Elelpapageien.}

Charakter der Familie: Schnabel mïssig oder sehr stark ('ntwickelt, höher als lang, ohne dentlichen Zahn. Die Hornhedeckmo ist auffallend glatt, meistens roth, seltener schwarz oler bleigrau gefürbt und glïnzend, wachsartig erscheinend, wodurch die Edelpapageien leicht vor anderen Papageien kemntlich sincl. Dic Firste ist gerundet, glatt oder mit Längsrime versehen; die Dille abgeflacht, glatt oder mit schwachem Kiel. Der Schwanz ist bald lang und stufig, bald kurz und gerade oder keilförmig. Im Flügel ist in der Regel zweite und dritte, seltener erste und zweite Schwinge an längsten. Die Wachshant bilket ein schmales, die ganze Schnabelbasis ungebendes und in der ganzen Ausdehnung ziemlich gleich breites Band, das liäufig zum Theil befiedert ist, oder ist unter den Nasenlöcher'n eingezogen und lïuft nach dem Schnabelrande in eine Spitze aus. Die Färbung ist vorherrschend grün.

Die Edelpapageien verbreiten sich über die Austromalayische Subregion, über die orientalische und aethiopische Region. Ihre Verbreitung hat somit die weiteste Auslehnung von Ost nach West unter allen Papageien, indem sich dieselbe über etwa 160 Lïngengrade erstreckt. Wie bereits in der Einleitung erwähnt, schliessen sie durch die Gattung Pulueomis an die Plattschweif:ittiche sich an, unter welchen die Untergattungen Polytelis und Pyrrhlopsis die nïchstverwandten Formen enthalten. Eine Art der Familie, welche eine besondere Gattung reprïsentirte und am deutlichsten den Uebergang zwischen den Gattungen Plutycerens und Pulacornis darstellte, Psittecus mascurinus Gm., ist ausgestorben. Der Vogel bewohnte Madagascar und wurde noch vor 80 bis 90 Jahren lebend nach Europa gebracht. ('egenwärtig befinden sich Exemplare nur noch in dem Pariser und Wiener Museum.

Die Lebensweise der Edelpapageien ist nur zum Theil ausreichend erforscht und zeigt mamigfache Abwechselung und Verschiedenheiten, sogar hinsichtlich der Arten derselben Gattung, worauf an betreffender Stelle hingewiesen ist. Wir kennen 53 verschiedene Formen, die wir in 7 Gattungen einordnen. 
Genus: PAĹÉEORNIS. Edels it tiche.

Pulaeomis (1825) Vig. Zool. Journ. II, No. 5, p. 49 (Typus: Psittacus Eupatria L.). - Belocercus (18.39) Müll. Schles. Verh. p. 107 (Typus: Psittucus longicaudre Boddl.). - Belurus (18.5) Bp. Rev. Mag. Zool. 1). 108 (Typus: Psittucus longicuredu Bodd.).

Charakter der Gattung: Der lange stufige Schwanz, welcher mit wenigen Ausnahmen bedeutend länger als der Flügel und dessen mittelste Federn häufig sehr schmal sind, unterscheidet diese Gattung von allen Familiengenossen. Die Wachshaut hat die Form eines schmalen, ziemlich g]eich breit um die ganze Schnabelbasis laufenden Bandes. Die Gegend um das Auge ist niemals nackt, wie dies die lieilschwanzsittiche Amerikas in der Regel zeigen. Die Schmabelfirste ist glatt oder hat eine schwache Längsrinne.

Die 22 bekannten Formen bewohnen die Orientalische Region und die Madagassische Subregion; eine Art kommt, wahrscheinlich durch künstliche Einführung eingebürgert, auf dem Festlande Afrika vor.

Die Edelsittiche leben gesellig. Im Fluge sind sie sehr gewandt, klettern anch geschickt, bewegen sich hingegen sehr unbeholfen auf dem Erdboden. Die Stimme ist lant und kreischend. Die Fïrbung des Gefieder's ist vorherrschend grün; der Schnabel meistens roth gefiirbt. Die Geschlechter unterscheiden sich in der Regel durch abweichende Fïrbung, namentlich sind die Weibchen durch schwarze oder gelbe Schnabeltïrbung an Stelle der rothen des. Männchens unterschieden.

\section{Schlüssel der Gattung.}

Rothbrauner Schulterfleck:

Körper im allgemeinen grün gefärbt:

Kopf grün:

liosafarbenes Nackenband: eupatrius (s. auch: nipalensis, magnirostris, indoburmancus).

Nacken hellblau: Wardii.

Kopf roth:

UuterHïgeldecken und Nacken hell blaugrün: cyanocephalus.

Unterfügeldecken und Nacken gelblich grün wie der übrige Körper: rosa.

Kopf schiefergrau: Hodgsoni (s. auch Finschi).

Körper im allgemeinen grünlich blaugrau: exsul. 
Kein rothbrauner Schulterfleck:

Kopf grösstentheils grïn: torquatus (s. anch docitis) und eques. Kopf grösstentheils grau oder blaugrau:

Schmaler geschlossener schwarzer Halsring, kein schwarzer Zügelstrich: peristerodes.

Ein auf dem Nacken breit unterbrochener schwarzer Halsring, kein Zügelstrich: Gironieri.

Kein Halsring, sondern ein breiter schwarzer Bartstreif vom Untersçnnabel längs der Backen und schwarzer Strich ïber Stirn und Zügel bis zu den Augen:

Unterkörper grün: canicollis.

Vorderhals und Brust weinroth:

Ganzer Schnabel roth: Alexandri.

Oberkiefer roth, Unterkiefer schwarz: derlyanus und fasciatus.

Kopfseiten roth:

Hinterkopf grün: erythrogenys.

Hinterkopf roth: longicauda und Luciani.

1. Palaeornis eupatrius. - Alexander-Sittich.

Englisch: Alexander Parrakeet. - Französisch: Perruche d'Alexandre.

Psittacus Ginginiana (1760) Briss. Orn. IV, p. 343, t. 29, f. 1. - Psittacus Eupatria (1766) Lin. S. N. p. 140. - Perruche de Gingi (1783) Buff. Pl. Enl. VII, pl. 239 (오). Grande Perruche à ailes rougeâtres id. Hist. Nat. Ois. VII, 1. 126. - Grande Perruche à collier d'un rouge vif id. Hist. Nat. Ois. VII, p. 114. - Perruche à collier des Isles Maldires id. Pl. Enl. pl. 642. - Psittacus guianensis (1786) Scop. Del. Fl. F. Ins. p. 86. - Psittucus Sonnerati (1738) Gm. S. N. II, p. 324. - Palacornis cucullatus (1832) Lear Illustr. Parr. 1)1. 32. Pulaeornis neglectus (1859) Blyth Journ. As. Soc. Bengal.

Abbildungen: Shaw Gen. Zool. VIII, pl. 61. - Lear 1. c. Buffon 1. c. - Reichenow Vogelbilder t. V, f. 1 und 2.

Diagnose: Viridis; pectore cinerascente Iavato; fascia cervicali rosea, altera utroque mystacali nigra; macula alari magna cerasina; rostro rubro, pedibus griseis, iride dilute flava.

Long. c. 530, ala 220, cauda 280, culmen $39 \mathrm{Mm}$.

ㅇ: Absque fascia cervicali et mystacali; macula alari dilutiore.

Vorkommen: Indische Subregion (Ceylon). 
2. Subspecies: nipalensis. - Nördlicher Alexandersittich. Palaeornis nipulensis (1836) Hodgs. As. Rev. p. 177. Palaeornis sivalensis (1873) Hutton Stray Feath. I. 1) 335. -Palaeornis sacer, punjabi, vinuthiana (1873) id. ibid.

Diagnose: $P$. cupatrio simillimus, sed major et capite glaucoimbuto.

Vorkommen: Indische Subregion (Nord- und Central-Indien).

3. Subspecies: magnirostris. - Andamanen-Sittich.

Pulaeornis magnirostris (1875) Ball. Journ. As. Soc. Beng. Extran. p. 54.

Diagnose: $P$. eupatrio simillimus, sed macula alari dilutiore et rostro robustiore.

Vorkommen: Nördl. Indomalayische Subregion (Andamanen). 4. Subspecies: indoburmanicus. -- Burmesischer Alexandersittich.

Palaeornis indolumanicus (1879) A. Hume Stray Feath. Vol. VII, p. 459.

Diagnose: $P$. magnirostri simillimus, sed rostro debiliore.

Vorkommen: Indo-Chinesische Subregion (Burma).

5. Palacornis Wardi. - Seychellen-Sittich.

Palaernis wardi (1867) E. Newton Proc. Zool. Soc. p. 346. Abbildung: Ibis 1876, pl. VI.

Diagnose: Viridis, nucha dilute caerulescente; fascia utroque inystacali prolongata et in torque nuchali interdum conjuncta nigra; macula alari cerasina; rostro rubro; pedibus nigricantibus.

Long. c. 480 , ala 215, cauda 255, culmen $40 \mathrm{Mm}$.

ㅇ: Absque fascia mystacali.

Vorkommen: Madagassische Subregion (Seychellen).

6. Palacornis exsul. - Rodriguez-Sittich.

Palaeornis exsul (1872) A. Newton Ibis p. 33 (우).

Abbildung: Ibis 1875, pl. 7 (우).

Diagnose: Glaucus; macula scapulari rubra; fascia utroque lata mystacali nigra; rostro rubro; pedibus nigricantibus; iride flava.

Long. c. 420, ala 200, cauda 215, culmen $30 \mathrm{Mm}$.

ᄋ: Absque macula scapulari rubra, rostro toto nigricante. Vorkommen: Madagassische Subregion (Rodriguez).

7. Palaeornis torquatus. - Halsbandsittich.

Engl.: Rose-ringed Parrakeet.-- Franz.: Perruche à collier rose. Psittaca (1760) Briss. Ornith. IV, p. 319. - Psitlaca 
torquata ibid. p. 323. - Psittacus cubicutaris (175̄7) Lin. Hasselq. It. Palaest. p. 292. - Psittacus mfinostris (1766) Lin. S. N. I, p. 143. -- Psittacus Krameri (1769) Scop. Ann. I, p. 31. Perruche à Collier couleur de rose (1783) Buff. Hist. Nat Ois. VII, p. 123. - Buff. Pl. Enl. pl. 551. - Psittacus torquatus (1783) Bodd. Tabl. Pl. Eul. p. 32. - Psittucus sinciulo (1812) Shaw Gen. Zool. VIII, 1). 441. -- Psittacus frenatus (1823) Ill. Lcht. Dubl. Verz. p. 6. - Pulacomis inomatus (1S30) Vig. Zool. Journ. V, p. 274. - Palacomis bitorquatus (1849) Blyth Cat. B. As. Soc. p. 4. - Palaeornis Layardi ibid. App. p. 341. Psittacus streptophorus (1856) Desm. Bp. Naumannia, Beilage.

Abbildungen: Buffon 1. c. - Reichenow Vogelbilder t. V, f. 7.

Diagnose: Viridis; occipite caerulescente; torque cervicali rosea; fascia utroque mystacali nigra; linea nigra utroque a naribus ad oculum ducta; rectricibus duabis mediis caerulescentibus; maxilla rubra, apice et mandibula nigricante; pedibus griseis; iride dilute flava.

Long. c. 450, ala 170, cauda 260-280, culmen $24 \mathrm{Mm}$.

오: Absque torque cervicali fasciaque mystacali.

Juv. rostro toto nigricante.

Vorkommen: Indische und Ceylonische Subregion.

8. Subspecies: ducitis. - Afrikanischer Halsbandsittich.

Psittacus donitis (1817) Vieill. N. D. XXV, p. 343. Pulacomis parvinostris (1854) Bonap. Rev. Mag. p. 152.

Diagnose: $P$. torquato simillimus, sed alis brevioribus, rostro debiliore.

Vorkommen: Aethiopische Region (Aequatoriales Afrika).

9. Palaeornis Hodgsoni. - Schwarzkopfsittich.

Englisch: Black-headed Parrakect. - Französisch: Perruche à tête noire.

Palacornis schisticeps [!] (1836) Hodgs. As. Rev. XIX, p. 178. -- Palacomis Hodgsoni (1868) Finsch Pap. II, p. 50.

Abbildungen: Gould Birds Asia pt. X. - Reichenow Vogelbilder t. XIII, f. 4.

Diagnose: Olivaceo-viridis, subtus dilutior; capite nigricanteschistaceo; mento striaque mystacali nigris; nucha et subalaribus thalassinis; macula alari cerasina; rectricibus duabus mediis basi virilibus, medio caeruleis, apice flavis; ceteris flavis, pogonio 
externo viridibus; maxilla coccinea, apice et mandibula pallidioribus; pedibus griseis.

Long. c. 380 , ala 165 , cauda 220 , rostrum $24 \mathrm{Mm}$.

오: Mari similis, capite pallidiore.

Juv.: Totus viridis, rectricibus pogonio interno Havis; rostro miniato-flavo.

Vorkommen: Indische Subregion (Nepal).

10. Subspecies: Finschi. - Oestlicher Schwarzkopfsittich.

Palceornis Finschi (1874) Hume, Stray Feath. II, p. 509.

Abbildung fehlt.

Diagnose: $P$. Hodgsoni simillimus, sed capite dilutiore, rectricibus duabus mediis parte basali caeruleis, parte apicali flavescente albis; ala breviore; cauda longiore.

Long. c. 400, ala 150, cauda $280 \mathrm{Mm}$.

Vorkommen: Südl. Indo-Chinesische Subregion (Tenasserim).

11. Palacornis cyanocephalus. - Barettsittich.

Englisch: Blossom-headed Parrakeet. - Französisch: Perruche à tête bleue.

Psittace Ginginiana erythrocephalos (1760) Briss. Ornith. IV, p. 346, pl. 29, f. 2. - Psittace cyanocephalos (1760) ibid. p. 359, pl. 19, f. 2 (juv.). - Psittacus cyanocephalus (1766) Lin. S. N. I, p. 141. - Psittacus purpureus (1776) S. Müller S. N. Suppl. p. 74. - Perruche à tête bleue (1783) Buff. Hist. Nat. VIJ, p. 117. - Perruche à tête bleue des Indes Orientales id. Pl. Enl. pl. 192 (jur.). - Perruche à tête rouge id. Hist. Nat. VII, p. 116. - Perruche à tête rouge de Gingi id. Pl. Enl. pl. 264. -Psittacus erythrocephatus (1788) Gm. S. N. p. 325. - Psittrens indicus (1790) Lath. Ind. Orn. I, p. 86. - Psittacus ginginianus ibid. p. 99. - Psittucus anmulatus (1811-1812) Bechst. Uebers. p. 77. - Psittacus flavitorques (1812) Shaw Gen. Zool. VIII, p. 439. - Psittacus flavicollis Vieill. N. D. XXV, p. 345. Psittacus ranthosomes (1825) Vig. Zool. Journ. II, p. 51. Palaeornis flavicollaris (1831) Frankl. Proc. Z. S. p. 51.

Abbildungen: Buffon l. c. - Levaillant Hist. N. Perr. pl. 75 et 76. -- Bourjot St. Hilaire Hist. Nat. Perr. pl. 1. - Gould Birds Asia pt. 26. - Reichenow Vogelbilder t. V, f. 5 und 6.

Diagnose: Olivaceo-viridis; capite purpureo, torque tenui nigro circumdato; cervice, alarum tectricibus, uropygio et subalaribus thalassinis; macula parva alari cerasina; rectricibus 
dualus mediis caeruleis, apice albis; mandibula nigricante, maxilla miniata; pedibus griseis; iride flava.

Long. c. 400, ala 140, cauda 230, culmen $21 \mathrm{Mm}$.

: Capite caerulescente-cinereo, fascia jugulari flava.

Juv.: Totus viridis, genis et fronte cinerascentibus; rostro flavo.

Vorkommen: Indische und Ceylonische Subregion.

12. Palaeomis rosa. - Burmasittich.

Engl.: Rosy Parrakeet. - Franz.: Perruche de Burmah.

Psittaca Bengalensis (1760) Briss. Orn. IV, p. 348. - Petite Perruche à tête couleur de rose à long brings (1783) Buff. Hist. Nat. Ois. VII, p. 125. - Perruche de Mahé (1783) Buffon Pl. Enl. pl. 888. - Psittacus rosa (1783) Bodd. Tabl. Pl. Enl. p. 53.-Psittacus rhodocephalus (1792) Shaw Lev. Mus. p. 83 - Psittacus Narcissus (1802) Lath. (Gen. Syn. Suppl. II, t. 123). (1804) iol. Syst. Ornith. Sec. Ed. p. 114. - Psittacus ternatensis Vieill. N. D. tom. XXV, p. 346 .

Abbildungen: Buffon 1. c. - I,evaillant Perr. pl. 61. Shaw Gen. Zool. VIII, pl. 62. - Gould Birds As. pt. 26. Reichenow Vogelbilder t. XIII, f. 5.

Diagnose: P. cyanocephalo similis, sed minor; capite roseo; cervice, uropygio, álarum tectricibus et subalaribus corpori concoloribus. Olivaceo-viridis; capite roseo, occipite caesio, torque tenui nigro circumdato; macula parva scapulari cerasina; rectricibus duabus mediis caeruleis, apice albis; maxilla miniata, mandibula nigricante; pedibus griseis; iride flava.

Long. c. 320, ala 130, cauda 180, rostrum $19 \mathrm{Mm}$.

\&: Capite pallide cinereo, torque jugulari flavido.

Vorkommen: Indo-Chinesische Subregion (Cochinchina, SürChina, Burma).

\section{Palacornis eques. - Ritter.}

Englisch: Double ringed Parrakeet. - Französisch: Perruche à double collier.

Psittace Borbonica torquate (1760) Briss. Ornith. IV, p. 328, t. 27, f. 1. - Perruche ì double Collier (1783) Buff. Hist. Nat. Ois. VII, p. 116. - Perruche à Collier de l'Isle de Bourbon (1783) Buff. P1. Enl. pl. 215. - Psittucus eques (1783) Bodd. Tabl. Pl. Enl. p. 13. - Psittacus bitorquatus (1820) Kuhl Consp. Psitt. (Nov. Act. Phys. med. Acad. Caes. Leop. Carol. X, 1,) 
p. 92. - Psittacus bicollaris (1823) Vieill. Enc. Méth. III, p. 1385. - Palacomis Borlonicus (1854) Bonap. Rev. Mag. Zool. p. 152. - Palaeomis echo (1876) A. Newton Ibis p. 284.

Abbildungen: Buffon 1. c. -- Levaillant H. N. P. pl. 39.

Diagnose: $P$. torquato omnino similis, sed obscurius viriditinctus; rectricibus totis obscure viridibus, mediis duabus latis, earumque apicibus vix prominulis.

Vorkommen: Madagassische Subregion (Mauritius).

14. Palneornis Gironieri. - Blauschwanzsittich.

Englisch: Layard's Parrakect. - Französisch: Perruche à queue bleu.

Palacomis calthropae (1849) Lay. Journ. As. Soc. Beng. p. 800. - Palacomis Gironieri (1853) Verr. Rev. Zool. p. 195. Psittacus vividicollis (1853) Cass. Proc. As. Soc. Phil. VI, p. 373.

Abbildungen: Gould Birds $\Lambda$ sia pt. 26. - Reichenow Vogelbilder t. XIII, f. 6 .

Diagnose: Alis et gastraco viridibus; fronte, regione ophthalmica et torque collari smaragdinis; capite dorsoque caesiis; fascia utroque mystacali nigra; tectricibus minoribus flavescentibus, minimis caesiis; rectricibus cyaneis, apice luteis; maxilla coccinea, mandibula pallide brumesecnte; pedibus griseis; iride dilute flava.

Long. c. 330, ala 140, cauda 145, rostrum $22 \mathrm{Mm}$.

오: Dorso pallidiore vix flavescente; rostro nigricante.

Juv.: Totus virilis, tergo et uropygio caerulescentibus, rectricibus apice flavidis; rostro nigricante.

Vorkommen: Ceylonische Subregion.

15. Palacornis peristerodes, - Taubensittich.

Eng1.: Malabar Parrakeet. - Franz.: Perruche colomboide.

Palacornis columboides (1830) Vig. Zool. Journ. p. 274 Psittacus Himalayamus (1834) Less. Bélanger Voy. aux Indes, Zool. - Conurus sagittifer colomboides (1837-1838) Bourjot St. Hilaire Hist. Nat. Perr. pl. 3 et 36. -- Palucornis peristerodes (1868) Finsch Pap. II, p. 74.

Abbildungen: Bonrjot St. Hilaire 1. c. - Fould Birls Asia pt. 10. - Reichenow Vogelbilder t. XIII, f. 3.

Diagnose: Capite, interscapulio, pectore et epigastrio cinereis; ventre crissoque viridiflavis; tergo, uropygio et regione ophthalmica thalassinis; torque collari nigro alteroque latiore thalassino; 
remigibus et tectricibns majoribus cyaneis; tectricibus minoribus obscure virilibus flavescente limbatis, minimis nigricantibus; rectricibus mediis cacruleis, apice flavidis, ceteris viridibus, pogonio interno apiceque flavis; maxilla coccinea, mandibula pallicle brunnescente.

Long. c. 430, ala 140, cauda 240, culmen $24 \mathrm{Mm}$.

o: Absque torque collari thalassino; rostro toto nigricante; epigastrio flavescente.

Juv.: Totus viridis; rectricibus pogonio interno flavis; tergo et uropygio caerulescentibus; rostro nigricante.

Vorkommen: Indische Subregion.

16. Palacornis caniceps. - Graukopfsittich.

Englisch: Gray-headed Parrakeet. - Französisch: Perruche à tête grise.

Pulacomis caniceps (1846) Blyth Journ. As. S. B. XV, p. 23.

Abbildungen: Gould Birds Asia pt. IX. - Reichenow Vogelbilder t. XIII, f. 1.

Diagnose: Olivaceo-viridis; capite cano, pileo caerulescente; fascia frontali ad oculos ducta, mento et fascia lata mystacali nigris; maxilla coccinea, mandibula nigra; pedibus griscis.

Long. c. 500, ala 170, cauda 300, culmen $30 \mathrm{Mm}$.

오: Rostro toto nigro.

Vorkommen: Nördliche Indo-Malayische Subregion (Nicobaren, Malacca).

17. Palacomis derbyanus. - China-Sittich.

Englisch: Derby's Parrakeet. - Französisch: Perruche de la Chine.

Pulucornis derbyanus (1850) Fras. Proc. Zool. Soc. p. 245.

Abbildungen: Proc. Zool. Soc. 1850, pl. 25. - Gould Birds Asia pt. 10. - David et Oustalet Ois: Chine pl. 1.

Diagnose: Viridis, capite dilute riolascente caeruleo, sincipite et periophthalmiis virescentibus; linea frontali ad oculos ducta et fascia utroque lata mystacali nigris; gutture, pectore et epigastrio cyanescente vi:aceis; macula alari flavescente; mandibula nigra, maxilla coccinea; pedibus griseis; iride dilute flava.

Long. c. 500, ala 230, cauda 270, culmen $31 \mathrm{Mm}$.

오: Rostro toto nigro. 
( $P$. fasciato similis sed multo major, colore pectoris vinaceo usque ad epigastrium extenso).

Vorkommen: Nördliche Indo - Chinesische Subregion (SïdChina, nördlich bis ungefähr zum $300^{\circ}$ ).

18. Palaeornis fasciatus. - Bartsittich.

Cochinchina-Sittich. - Englisch: Cochin-China Parrakeet. Französisch: Perruche à moustaches.

Psittaca Indica torquata (1760) Briss. Orn. IV, p. 326. Psittacus fasciatus (1776) S. Müll. S. N. Suppl. p. 74. - Perruche à moustaches (1783) Buff. Hist. Nat. Ois. VII, p. 120.Perruche de Pondichery (1783) id. Pl. Enl. t. 517. - Psittacus vibrissa (1783) Bodd. Tabl. Pl. Enl. p. 30. - Psittacus pondicerianus (1788) Gm. S. N. p. 325. - Palaeornis borneus (1832) Wagl. Mon. Psitt. p. 510. - Palaeornis melanorhynchus (1832) Wagl. Mon. Psitt. p. 511 (우). - Palaeornis nigrirostris (1844) Hodgs. Gray's Zool. Misc. p. 85. - Palacornis barbatus (1850) Blyth. Journ. As. S. Bengal XIX, p. 233. - Palaeornis Lathami (1868) Finsch Pap. II, p. 66.

Abbildungen: Buffon 1. c. - Reichenow Vogelbilder t. V, f. 4 und t. XIII, f. 7 (오).

Diagnose: Viridis; macula alari olivaceo-flava; capite caesio; linea frontali ad oculos ducta et fascia lata mystacali utroque nigris; gutture pectoreque vinaceis; maxilla coccinea, mandibula nigra; pedibus griseis; iride flava.

Long. c. 350 , ala 170 , cauda 200, rostrum $28 \mathrm{Mm}$.

ㅇ: Rostro toto nigro.

(Obs.: A $P$. derbyano, quoad colores simillimo, magnitudine multo minore diversus.)

Vorkommen: Indo-Chinesische Subregion.

19. Palaeornis Alexandri. - Rosenbrustsittich.

Englisch: Javan Parrakeet. - Französisch: Perruche à poitrine rose.

Psittacus javanicus (1757) Osbeck It. Ind. Orn. I, p. 101. Psittacus Alexandri (1766) Lin. S. N. I, p. 141. - Psittacus bimaculatus (1787) Sparrm. Mus. Carls. Fasc. 2, t. 30. Psittacus Osbeckii (1790) Lath. Ind. Orn. I, p. 87. - Psittacus trimaculatus (1812) Shaw Gen. Zool. p. 426. - Psittacus mystaceus ibid. p. 436. 
Diagnose: $\boldsymbol{P}$. fasciato simillimus sed paullo minor, capite cano, rostro toto coccineo.

Long. c. 340 , ala 155 , cauda 180 , culmen $25 \mathrm{Mm}$.

오: A mari non diversa.

Juv.: Viridis, fronte et facie griseis, macula alari flavida; rostro miniato; pedibus fulvis.

Vorkommen: Indo-Malayische Subregion (Java, Borneo).

20. Palacornis erythrogenys. - Rothwangensittich.

Englisch: Red-cheeked Parrakeet. - Französisch: Perruche à joues roses.

Palaeomis erythrogenys (1846) Blyth Journ. As. Soc. Beng. $\mathrm{XV}$, p. 23. - Palaeornis nicobaricus (1857) Gould Birds Asia pt. IX. - Palaeonis affinis (1867) Tytl. Ibis p. 320. - Palaeornis Tytleri (1874) Hume Proc. As. S. Beng. p. 108.

Abbildungen: Gould Birds Asia pt. IX. - Reichenow Vogelbilder t. XIII, f. 2.

Diagnose: Viridis, cervice canescente, pectore olivascente; remigibus primariis eorumque tectricibus et rectricibus duabus mediis coerulescentibus; fascia utroque longa mystacali striaque a naribus ad oculos ducta nigris; capitis lateribus miniato-roseis; maxilla coccinea, mandibula nigra.

Long. c. 420, ala 170, cauda 230, culmen $25 \mathrm{Mm}$.

오: Rostro toto nigricante, cervice viridi.

Vorkommen: Nördl. Indo-Malayische Subregion (Nicobaren und Andamanen).

21. Palaeornis Luciani. - Lucian-Sittich.

Englisch: Red-collared Parrakeet. - Französisch: Perruche Lucien.

Palaeornis modestus (1845) Fras. Zool. typ. (juv.). Palceornis Luciani (1850) Verr. Mag. Zool. p. 598. - Palacornis Fraseri (1856) Moore Horsf. Cat. B. Mus. East. Ind. Comp. II, p. 621 .

Abbildungen: Gould Birds Asia pt. IX. -- Proc. Zool. Soc. 1850, pl. 26.

Diagnose: Viridis, pectore pallescente; rectricibus duabus mediis apice coerulescentibus; capitis lateribus nuchaque miniatoroseis, nucha obscuriore; stria utroque a naribus ad oculum ducta et fascia mystacali nigris; maxilla coccinea, mandibula nigra.

Long. c. 380 , ala 185, cauda 150 , culmen $25 \mathrm{Mm}$. 
(Obs.: $P$. longicaudae similis sed major, cauda breviore, genis rubris dilutioribus, remigibus viridibus; rectricibus apice tantum caeruleis.)

Vorkommen: Indische Subregion.

22. Palaeornis longicauda. - Langschwanzsittich.

Englisch: Malaccan Parrakeet. - Französisch: Perruche à long brings.

La Grande Perruche à long brings (1783) Buff. Hist. Nat. Ois. VII, p. 126. - Perruche de Malac (1783) id. PI. Enl. t. 887. - Psittacus longicauda (1783) Bodd. Tabl. Pl. EnI. p. 53. Psittacus malaccensis (1788) Gmel. S. N. p. 325. - Psittacus barbatulatus (1811-1812) Bechst. Uebers. p. 77. - Psittacus erubescens (1812) Shaw Gen. Zool. VIII, p. 437. - Conurus erythrogenys (1831) Less. Traité d'Orn. p. 215. - Palaeornis viridimystax (1856) Blyth. Journ. As. Soc. p. 446 (juv.). Palaeornis affinis (1858) Gould Birds Asia pt. X (juv.) - Palaeornis longicaudatus (1868) Finsçh Pap. II, p. 77.

Abbildungen: Gould Birds Asia pt. X ( $P$. malaccensis und affinis). - Reichenow Vogelbilder t. V, f. 8.

Diagnose: Viridis, subtus flavescens; pileo obscure viridi; capitis lateribus nuchaque rubro-vinaceis; fascia lata utroque mystacali nigra; tergo et uropygio thalassinis; remigibus primariis eorumque tectricibus cyaneis; rectricibus duabus mediis cyaneis apice viridibus, ceteris viridibus; maxilla coccinea, mandibula pallide brunnescente; pedibus griseis; iride flava.

Long. c. 450 , ala 150 , cauda 260, rectr. minoribus 100 , culmen $26 \mathrm{Mm}$.

오: A mare non diversa.

Juv.: Viridis, capitis lateribus pallide vinaceis, rectricibus duabus mediis et remigibus coerulescentibus; rostro fuscescente.

Vorkommen: Indo-Malayische Subregion (Borneo).

Genus: TANYGNATHUS. Gross s h nabelpapageien.

Tanygnathus (1832) Wagl. Mon. Psitt. p. 501 (Typus: Psittacus macrorhynchus Gm.). - Erythrostomus (1837) Sw. Class. B. II, p. 300 .

Charakter der Gattung: Durch einen unverhältnissmässig grossen Schnabel und einen kurzen, keilförmigen Schwanz ausgezeichnet. Die Form der Wachshaut ist die typische der 
Familie. Die Färbung ist vorherrschend grün. Die Geschlechter sind wenig oder nicht unterschieden.

Wir kennen sieben verschiedene Formen, welche die AustroMalayische und nördliche Indo-Malayische Subregion bewohnen. Sowcit ihre Lebensweise bekannt ist, sind sie weniger gesellig als die Edelsittiche und weniger fluggewandte, ziemlich träge Vögel.

Oberkopf blau:

\section{Schlüssel der Gattung.}

Ueber Stirn und Zügel eine schwarze Binde, Flügeldecken grïn: gramineus.

Keine schwarze Stirnbinde, kleine Deckfedern blau mit goldgelben Säumen, kleinste schwarz mit blauen Säumen: luconensis. Oberkopf grün:

Kleinste Deckfedern blau: Mïlleri (s. auch albirostris u. Everetti). Kleinste Deckfedern grün: affinis.

Kleinste Deckfedern schwarz, blau gesäumt: megalorhynchus.

23. Tanygnathus gramineus. - Schwarzstirniger Edelpapagei.

Englisch: Amboyna Parrot. - Französisch: Perroquet à calotte bleue.

Grand Perroquet verd à tête bleue (1783) Buff. Hist. Nat. Ois. VII, p. 99. - Perroquet d'Amboine (1783) id. Pl. Enl. 1). 862. - Psittacus gramineus (1788) Gmel. S. N. p. 338 . Perroquet à calotte bleue (1801) Levaill. Hist. Nat. Perr. pl. 121.

Abbildungen: Buffon 1. c. - Levaillant 1. c.

Diagnose: Viridis, subtus flavescens; pileo coeruleo; fascia frontali versus oculos ducta nigra; remigibus primariis basin versus corumque tectricibus coeruleis; subalaribus mediis viridiflavescentibus, majoribus fuscis macula apicali flava; rostro albido; pedibus fuscis; iride albo-flava.

Long. tot. c. 430 , ala 260, cauda 175 , culmen $37 \mathrm{Mm}$.

오: Genis superius viridi-cinerascentibus, pileo cinereoviridi, coerulescente.

Vorkommen: Austro-Malayische Subregion (Molukken: Buru).

24. Tanygnathus luconensis. - Blauscheitel-Papagei.

Englisch: Varied-winged Parrot. - Französisch: Perroquet aux ailes chamarées.

Psittucus Lucionensis (1760) Briss. Ornithol. IV, p. 295, 11. 22. - Psittacus luciononsis (1766) Lin. S. N. p. 146. Psittacus marginatus (1776) S. Müll. S. N. Suppl. p. 77. - 
Perruche aux ailes chamarées (1783) Buff. Hist. Nat. Ois. VII, p. 122. - Perroquet de l'Isle de Luçon id. PI. Enl. pl. 287. Psittacus gala (1783) Bodd. Tabl. Pl. Enl. p. 17. - Psittacus pileatus (1786) Scop. Del. Fl. F. Ins. p. 86. - Psittacus olieracens (1788) Gm. S. N. p. 326.

Abbildungen: Perre de l'Isle de Luçon, Sonn. Voy. N. G. pl. 44. - Buffon 1. c.

Diagnose: Viridis, gastraeo et interscapulio flavescentibus; vertice et occipite, nonnunquam quoque tergo, coeruleis; remigibus viridibus; tectricibus minoribus et majoribus coeruleis, illis aurantio-marginatis; tectricibus minimis nigris coeruleo-limbatis; rostro coccineo; pedibus nigricantibus; iride albo-flava.

Long. c. 330 , ala $190--200$, cauda $130-140$, culmen 31 bis $35 \mathrm{Mm}$.

Jun. an or: Tectricibus omnibus viridibus, minoribus aurantio-marginatis.

Vorkommen: Nördliche Indo-Malayische Subregion (Philippinen: Luzon).

25. Tanygnatlus affinis. - Grünschulterpapagei.

Tanygnathus affinis (1863) Wall. Proc. Zool. Soc. London, p. 20. - Tanygnathus intermedius (1864) II. Schleg. Dierentuin p. 70 .

\section{Abbildung fehlt.}

Diagnose: Viridis, subtus flavescens; tergo et uropygio coeruleis; remigibus et testricibus viridibus, tectricibus minoribus aurantio-marginatis; subalaribus flavis; rostro coccineo; pedibus nigricantibus; iride albo-flava.

Long. c. 425, ala 245, cauda 140, culmen $49 \mathrm{Mm}$.

Vorkommen: Westl. Austro-Malayische Subregion (Molukken: Buru, Amboina, Ceram).

26. Tanygnathus Mülleri. - Müller's Edelpapagei.

Engl.: Muiller's Parrot. - Franz.: Perroquet Muller.

Tanygnathus Miilleri (1850) [Temm.] Bonap. Consp. I, p. 5.

Abbildung: Reichenow Vogelbilder t. XXVII, f. 9.

Diagnose: Viridis, gastraeo, auchenio et interscapulio olivascentibus; tergo et uropygio coeruleis; remigibus et tectricibus viridibus, his flavescente marginatis; tectricibus minimis et scapularibus caeruleis; subalaribus viridibus; rostro coccineo; pedibus brunneis; iride albo-flava. 
Long. c. 350, ala 190-200, cauda 130, culmen 35-40 Mm.

Vorkommen: Nordwestliche Austro-Malayische Subregion (Sangir Inseln).

27. Subspecies: albirostris. - W eis sschnabelpapagei.

Englisch: White-billed Parrot. - Französisch: Perroquet à bec blanc.

Psittacus sumatranus (1822) Raffles Trans. Lin. Soc. XIII, p. 281. - Tanygnathus albirostris (1862) Wall. Proc. Zool. Soc. p. 366. - Tanygnathus Burbidgii (1879) R. B. Sharpe Proc. Z. Soc. p. 313.

Diagnose: T. Mülleri simillimus, at interscapulio haud olivaceo-flavo, sed distincte viridi; tectricibus minimis totis viridibus; rostro albido.

Vorkommen: Westl. Austro-Malayische Subregion (Celebes, Sula Inseln).

28. Subspecies: Everetti. - Kl einer We iss schnabelpapagei.

Englisch: Everett's Parrot.

Tanygnathus everetti (1877) Tweeddale Ann. Mag. Nat. Hist. Vol. XX, p. 533.

Diagnose: T. albirostri simillimus sed minor.

Ala 180, cauda $125 \mathrm{Mm}$.

Vorkommen: Nördliche Indo-Malayische Subregion (Philippinen: Samar).

29. Tanygnathus megalorhynchus. - Schwarzschulterpapagei.

Englisch: Great-billed Parrot. - Französisch: Perroquet à bec couleur de sang.

Psittacus fuscus (1760) Briss. Ornith. IV, p. 314. - Perroquet à bec couleur de sang (1783) Buff. Hist. Nat. Ois. VII, p. 98. - Perroquet de la Nouvelle Guinée (1783) id. Pl. Enl. t. 713. - Psittacus megalorhynchos (1783) Bodd. Tabl. Pl. Enl. p. 45. - Psittacus macrorhynchus (1788) Gmel. S. N. I, p. 338. Psittacus nasutus (1790) Lath. Ind. Orn. I, p. 118. - Tanygnathus morotensis (1864) Schleg. Dierentuin p. 70.

Abbildungen: Buffon 1. c. - Shaw Gen. Zool. VIII, 2, pl. 79. - Levaillant Perr. pl. 83. - Reichenow Vogelbilder taf. XI, fig. 6.

Diagnose: Viridis, subtus flavescens; tergo et uropygio caeruleis; remigibus caerulescentibus; tectricibus majoribus caeruleis, minoribus nigris aurantio-marginatis, minimis nigris 
caeruleo-limbatis; subalaribus flavis; iride albo-flava; rostro coccineo; pedibus nigricantibus.

Long. tot. c. 410, ala 240, cauda 160, culmen $50 \mathrm{Mm}$.

오: Rostro minore.

Vorkommen: Austro - Malayische Subregion (Neu-Guinea, Molukken etc.).

Genus: RHODOCEPHALUS. Rothkop f a page ien.

Geoffroyus (1850) Bp. Consp. Av. I, p. 6 (Psittacus personatus Shaw). - Rhodocephalus (1881) Reichenow.

Charakter der Gattung: Schwanz kurz und gerarle, bedeutend kürzer als der Flügel. Schnabelfirste mit Längsrinne, Dille mit schwachem Kiel. Wachshaut unter dem Nasenloch stark eingezogen, in der Regel nach dem Schnabelrande zu sich verengend, in eine Spitze auslaufend. Die Färbung ist vorherrschend grün. Die Männchen zeigen häufig eine rothe Färbung des Kopfes, während die Weibchen sich durch bräunliche Kopffärbung unterscheiden. Es sind zwölf Arten in der Austro-Malayischen Subregion bekannt.

\section{Schlüssel der Gattung:}

Kopf grün, blauer Halsring: simplex. Kopf gelb, grauer Halsring: heteroclitus. Stirn und Kopfseiten roth:

Oberkopf grauviolet, Hinterkopf und Genick hellblau:

Bürzel grün: cyanicollis.

Bürzel braunroth: obiensis.

Ober- und Hinterkopf grauviolet:

Bürzel grün: Geoffroyi (s. auch amensis, Iukesii, keyensis). Bürzel braunroth oder roth: Pucherani (s. auch: jobiensis, mysorensis, dorsalis).

30. Rhodocephatus simplex. - Blauring-Papagei.

Engl.: Simple Parrot. - Franz.: Perroquet simple.

Pionias simplex (1874) Meyer Verh. Zool. Bot. Ges. Wien LXX, p. 39.

Abbildungen: Gould Birds New Guinea pt. V, pl. 7. Reichenow Vogelbilder t. XXVII, f. 1.

Diagnose: Viridis, dorsi alarumque plumis nigrescente marginatis, uropygio nigricante; torque collari caesio; subalaribus coeruleis; remigibus ultimis pogonio interno macula pallida 
flava ornatis; macuia cubitali parum conspicua brunnescente; rostro pedibusque nigris.

Long. tot. c. 250 , ala 160 , cauda 90 , culmen $24 \mathrm{Mm}$.

ㅇ: Pileo paullum coerulescente; torque collari nullo.

Vorkommen: Austro-Malayische Subregion (Neu-Guinea). 31. Rhodocephalus heteroclitus. - Gelb köpfiger Edelpapagei.

Englisch: Yellow-headed Parrot. - Französisch: Perroquet à tête jaune.

Psittacus Geoffroyi heteroclitus (1841) Hombr. et. Jacq. Ann. Sc. Nat. XVI, p. 319. - Pionus cyaniceps (1853) Jacq. et Puch. Voy. Pole Sud. Zool. I, p. 105 (오).

Abbildungen: Voy. Pole Sud pl. 25, f. 1 und 2. - Gould Birds New Guinea pt. VIII, pl. 5. - Reichenow Vogelbilder taf. XXVII, fig. 2.

Diagnose: Viridis, superne paullum olivascens, subtus caerulescens; capite toto flavo-olivaceo; torque collari caesio; gula grisea; macula parva cubitali rubiginosa; remigibus intus subtiliter, ultimis late flavo-limbatis; subalaribus caeruleis; maxilla flava, mandibula fusca; pedibus griseo-virescentibus; iride aurantiaca.

Long. tot. c. 250 , ala 160 , cauda 85, culmen $19 \mathrm{Mm}$.

오: Viridis, pileo caerulescente; genis griseo-caerulescentibus; rostro fusco.

Vorkommen: Oestliche Austro-Malayische Subregion (Salomon Inseln, Neu-Britannien).

32. Rhodocephalus cyanicollis. - Blaunacken-Rothkopf.

Englisch: Gilolo-Parrot.

Psittacus cyanicollis $(1839-1844)$ Müll. Verh. Land- en Volkenk. p. 108.

Abbildung: Reichenow Vogelbilder t. XXVII, f. 7 und 8.

Diagnose: Viridis, interscapulio et pectore olivascentibus; sincipite, capitis lateribus gulaque roseo-coccineis; vertice violascente caesio; nucha coerulea; macula parva cubitali rubiginosa; campterio et subalaribus caeruleis; maxilla coccinea, mandibula fusca; pedibus fuscis; iride flava.

Long. c. 300 , ala 180 , cauda 110 , culmen $24 \mathrm{Mm}$.

ㅇ: Capite fulvescente griseo, pileo cyaneo-lilacino; nucha caerulea; rostro omnino fusco.

Vorkommen: Westl. Austromalayische Subregion (Molukken). 
33. Rhodocephalus obiensis. - Obi-Papagei.

Englisch: Obi Parrot.

Pionias obiensis (1868) Finsch Pap. II, p. 389.

Abbildung fehlt.

Diagnose: Rh. cyanicolli simillimus, sed uropygio cerasino.

Vorkommen: Westliche Austro-Malayische Subregion (Molukken, Obi).

34. Rhodocephalus Geoffroyi. - Rothmasken papapei.

Englisch: Red-faced Parrot. - Franz.: Perroquet Geoffroy.

Psittacus Geoffroyi (1811-1812) Bechst. Uebers. p. 103. Psittacus personatus (1812) Shaw Gen. Zool. VIII, p. 544. Psittacus Geoffroyanus Vieill. N. D. XXV, p. 311. - Psittacus fuscicapillus ibid. p. 316. - Psittacus spadiceocephalus (1820) Kuhl Consp. Psitt. p. 84. - Psittacus Fieldii (1825) Sws. Quart. Journ. Science XIX, p. 198. - Psittacula batavensis (1832) Wagl. Mon. Psitt. p. 624. - Psittacus rhodops (1861) G. R. Gray Pr. Zool. Soc. p. 436. - Geoffroyus Schlegeli (1877) Salv. Ann. Mus. Civ. Gen. X, p. 29.

Abbildung: Levaillant Hist. Nat. Perr. pl. 112 et 113.

Diagnose: Viridis, subtus dilutior; fronte, capitis lateribus gulaque roseo-coccineis; vertice, nucha et regionis paroticae margine posteriore violascente caeruleis; macula parva cubitali badia; subalaribus et axillaribus caeruleis; maxilla coccinea, apice et mandibula albidis; pedibus fuscis; iride flava.

Long. c. 300, ala 180, cauda 100, culmen $24 \mathrm{Mm}$.

ㅇ: Capitis lateribus gulaque fulvescente brumneis, pileo castaneo; rostro omnino fusco.

Vorkommen: Westl. Austromalayische Subregion (Molukken).

35. Subspecies: aruensis. - Aru-Papagei.

Psittacus aruensis (1858) G. R. Gray P. Z. S. p. 183.

Abbildung fehlt.

Diagnose: Rh. personato simillimus sed minor, subalaribus axillaribusque caeruleis laetioribus cobaltino-tinctis.

Long. c. 260, ala 165 , cauda 75 , culmen $22 \mathrm{Mm}$.

오: Capite brunneo, fronte genisque virescentibus.

Vorkommen: Austro-Malayische Subregion (Südost NellGuinea, Aru Inseln).

36. Subspecies: Jukesii. - Kleiner Rothmaskenpapagei.

Geoffroyus Jukesii (1863) Wall. P. Z. S. London p. 484. 
Diagnose: Subspeciei aruensi simillimus quoad magnitudinem et subalarium colorem, sed regione parotica violaceo-imbuta diversus.

Long. c. 270 , ala 170 , cauda 90 , culmen $22 \mathrm{Mm}$.

우: Pileo castaneo, loris, capitis lateribus gulaque obscure virescente brunneis.

Vorkommen: Westl. Austromalayische Subregion (Flores).

37. Subspecies: keyensis. - Grosser Rothmaskenpapagei. Geoffroyus keyensis (1868) [Schleg.] Finsch Pap. II, p. 956. Abbildung fehlt.

Diagnose: $R h$. personato simillimus, sed major et subalaribus axillaribusque caeruleis dilutius tinctis.

Long. c. 320 , ala 200, cauda 105, culmen $25 \mathrm{Mm}$.

오: Capite pallide brunneo, viridi-tincto.

Vorkommen: Austro-Malayische Subregion (Kei-Inseln).

38. Rhodocephalus Pucherani. - Pucheran-Papagei.

Psittacus Geoffroyi (1839-1844) Müll. Verh. Land- en Volkenk. p. 22 (partim!). - Pionus fuscicapillus (1853) Jacq. et Puch. Voy. Pole Sud III, p. 106 (우). - Geoffroyus Pucherani (1856) Bonap. Naumannia Beilage sp. 236.

Abbildung: Hombr. et Jacq. Voy. Pole Sud Zool. t. 25 bis f."3 (우).

Diagnose: Viridis; sincipite, capitis lateribus gulaque roseominiatis, regione parotica violascente; vertice et nucha violascente caeruleis; subalaribus et axillaribus cobaltinis; uropygio cerasino; maxilla coccinea; mandibula fuscescente; pedibus fuscis; iride flava.

Long. c. 260, ala 170 , cauda 80 , culmen $23 \mathrm{Mm}$.

우: Capite fusco, lateribus mentoque virescentibus; rostro omnino fusco.

Vorkommen: Austro-Malayische Subregion (Neu - Guinea, Misol, Waigiou etc.).

39. Subspecies: jobiensis. - Jobi-Papagei.

Pionias Pucherani var. jobiensis (1874) Meyer Sitzungsb. K. Ak. Wiss. Wien LXX, p. 225.

Abbildung fehlt.

Diagnose: Rh. Pucherani simillimus, sed dorso olivaceoflavescente; uropygio dilute rubro; subalaribus et axillaribus dilute caeruleis. 
Vorkommen: Austro-Malayische Subregion (Insel Jobi).

40. Subspecies: mysorensis. - Mis ori-Papagei.

Pionias Pucherani var. mysorensis (1874) Meyer Sitzungsb. K. Ak. Wiss. Wien LXX, p. 225. - Pionias Pucherani var. maforensis (1874) Meyer ibid.

Abbildung fehlt.

Diagnose: Rh. Pucherani simillimus, sed saturatius viriditinctus; macula cubitali cerasina; pileo saturatius tincto; gutture quoque (nec gula sola) roseo-miniato.

Vorkommen: Austro-Malayische Subregion (Insel Misori).

41. Subspecies: dorsalis(:).

Geoffroyus dorsalis (1875) Salv. Ann. Mus. Civ. Gen. VII, p. 758.

[Diese Form, nur in einem weiblichen Exemplare bekannt, bleibt vorläufig noch zweifelhaft].

Diagnose: Viridis; capite brunneo-rubro; fronte et genis antice paullum griseo-tinctis, mento virescente-tincto; interscapulio viridi, paullum lutescente, plumarum marginibus late rubro-brunneis; uropygio rubro-miniato; supracaudalibus et cauda viridi-lutescentibus; subtus viridi-lutescens; alis viridibus, macula cubitali rubro-brunnea; remigibus subtus fuscis; remigibus tertiariis ultimis, margine interno, flavicantibus; subalaribus et axillaribus laete cyaneis; rostro et pedibus fuscis.

Long. c. 260, ala 165, cauda 70, culmen $21 \mathrm{Mm}$. (teste Salvadori).

Gattung: ECLECTUS. Ed elp a pag e i en.

Mascarinus partim (1831) Less. Traité d'Ornith. p. 188. Eclectus (1832) Wagl. Mon. Psitt. p. 495 (Typus: Eclectus linnaei Wagl.). - Psittacodis (1854) Bp. Rev. Mag. Zool. p. 155 (Typus: Psittacus magnus Gm.). - Polychlorus (1857) Sclat. Proc. Zool. Soc. p. 226 (Typus: Psittacus magnus Gm.).

Charakter der Gattung: Kurzer und gerader Schwanz, welcher kürzer ist als der Flügel; glatter Schnabel, Firste ohne Rinne. Die Wachshaut hat die typische Form. Höchst auffallend sind die Geschlechter der hierher gehörenden Arten unterschieden. Während die Männchen vorzugsweise grün gefärbt sind, ist das Gefieder der Weibchen im allgemeinen prächtig roth. Es sind vier Arten in der Austro-Malayischen 
Subregion bekannt. Soweit Nachrichten über die Lebensweise vorliegen, sind die Vögel träge und wenig gesellig, leben paarweise in dichter Waldung.

42. Eclectus pectoralis. - Grün-Edelpapagei.

Englisch: Red-sided Eclectus. - Französisch: Perroquet à flanes rouges.

Psittacus sinensis (1760) Briss. Orn. IV, p. 291. - Psittacus pectoralis (1776) Müll. N. S. Suppl. p. 78. - Psittacus aurantius ibid. p. 80. - Perroquet vert (1783) Buffon Hist. Nat. VII, p. 93. - Perroquet de la Chine (1783) id. Pl. Enl. t. 514. Psittacus polychlorus (1786) Scop. Del. Flor. et Faun. Insubr. p. 87. - Psittacus sinensis (1788) Gm. N. S. p. 337. - Psittacus magnus id. ibid. p. 344. - Psittacus viridis (1790) Lath. Ind. Orn. p. 125. - Perroquet à flancs rouges (1801) Levaill. Perr. t. 132. - Psittanus lateralis (1812) Shaw Gen. Zool. VIII, p. 490. - Mascarinus prasinus (1831) Less. Tr. d'Orn. p. 188. Eclectus Linnaei (1835) Wagl. Mon. Psitt. p. 109, t. 22. Eclectus polychlorus var, aruensis (1858) G. R. Gray Proc. Zool. Soc. p. 183.

Abbildungen: Buffon Pl. Enl. t. 514. - Reichenow Vogelbilder t. XI, f. 3 und 4.

Diagnose: Viridis; hypochondriis et subalaribus coccineis; margine alari coeruleo; remigibus primariis eorumque tectricibus pogonio externo cyaneis; rectricibus medio cyanescentibus, apice flavidis, subtus nigris; maxilla carnea, mandibula nigra; pedibus nigricantibus; iride crocea.

Long. c. 450 , ala 260, cauda 135 , culmen $45 \mathrm{Mm}$.

오: Capite, collo, pectoreque coccineis; dorso, alis, cauda et crisso cerasinis; rectricum apicibus dilute rubris; fascia auchenii, ventre, annulo circa oculum, margine alari et subalaribus cyaneis; remigibus primariis eorumque tectricibus pogonio externo cyaneis; rostro nigro; pedibus nigricantibus; iride crocea.

Vorkommen: Austro-Malayische Subregion (Neu-Guinea und viele der nahe gelegenen Inseln).

43. Eclectus roratus. - Grosser Edelpapagei.

Englisch: Grand Eclectus. - Französisch: Grand Lori.

Psittacus roratus (1776) Müll. Linné's Natursystem. Suppl. p. 77. - Le grand Lori (1783) Buff. Hist. Nat. VII, p. 109. Lori de la nouvelle Guinée (1783) Buff. Pl. Enl. pl. 683. - 
Psittucus ceylonensis (1783) Bodd. Tabl. Pl. Enl. p. 42, No. 683. Psittacus janthinus (1788) Gm. S. N. I, p. 319 (?). - Psittacus grandis (1788) Gmel. S. N. I, p. 335. - Le perroquet Grand Lori (1801) Levaillant Hist. Nat. Perr. pl. 126-128.

Abbildungen: Shaw Gen. Zool. VIII, pl. 80. - Buff. Pl. Enl. 1. c. -- Levaillant 1. c. - Reichenow Vogelbilder aus fernen Zonen t. XXVII, f. 6 (우).

Diagnose: $E$. pectorali simillimus, sed colore laetiore, cauda magis caerulea.

Long. c. 440, ala 275, cauda 150, culmen $45 \mathrm{Mm}$.

오: Cerasina, capite dilutiore; fascia auchenii et abdomine, margine alari et subalaribus violaceo-cyaneis; subcaudalibus et rectricum apicibus croceis; rostro nigro; pedibus nigricantibus; iride crocea.

Vorkommen: Westliche Austro-Malayische Subregion (Molukken: Ternate, Halmahera, Batjan, Obi u. a.).

44. Eclectus cardinalis. - Kardinal-Edelpapagei.

Engl.: Crimson Lory. - Franz.: Lori d'Amboine.

Lorius Amboinensis (1760) Briss. Orn. IV, p. 231. - Lory cramoisi (1783) Buff. Hist. Nat. VII, p. 107. -- Lori d'Amboine (1783) Pl. Enl. pl. 518. - Psittacus cardinalis (1783) Bodd. Tabl. Pl. Enl. p. 30, No. 518. - Psittacus puniceus (1788) Gmel. S. N. I, p. 335. - Psittacus magnus (1788) Gmel. S. N. I, p. 344. - Psittacus intermedius (1850) Bonap. Consp. I, p. 4.

Abbildung: Buffon Pl. Enl. pl. 518.

Diagnose: $E$. pectorali simillimus, sed minor, cauda vix caerulea, margine alari viridi nec caerulea.

Long. c. 380 , ala 240 , cauda 120 , culmen $40 \mathrm{Mm}$.

\&: Cerasina; capite, collo, pectore crissoque dilutioribus; fascia auchenii, ventre, campterio et subalaribus violascente cyaneis; rectricum apicibus dilute rubris; rostro nigro; pedibus nigricantibus; iride crocea.

Vorkommen: Westliche Austro-Malayische Subregion (Molukken: Amboina, Ceram, Buru).

45. Eclectus Corneliae. - Cornelia's Edelpapagei.

Englisch: Cornelia Parrot.

Psittacus orientalis (1790) Lath. Ind. Orn. I, p. 251 (?). Eclectus Corneliae (1849) Bonap. Proc. Z. Soc. p. 143 (ㅇ) . Psittacodis Westermanni (1850) Bonap. Consp. I, p. 4. 
Abbildung: Proc. Zool. Soc. 1849 pl. XI.

Diagnose: $\boldsymbol{E}$. pectorali similis, sed minor et hypochondriis viridibus.

Long. c. 400, ala 240, cauda 130, culmen $40 \mathrm{Mm}$.

오: Punicea; dorso, alis et cauda cerasinis; margine alari et pogonio externo remigum primariorum cyaneis; subalaribus minoribus puniceis, cyaneo-mixtis; subcaudalibus et caudae apice rubris; rostro nigro; pedibus fuscis; iride flava.

Vorkommen unbekannt.

Geuus: PRIONITURUS. S p a t e $\mathrm{lsch}$ wan z p a pa g e i e 1.

Prioniturus (1832) Wagl. Mon. Psitt. p. 490 (Typus: Psittacus platurus Tem.). - Urodiscus (1854) Bp. Rev. Mag. Zool. p. 155.

Charakter der Gattung: Schwanz kurz und gerade, aber die kahlen Schäfte der beiden mittelsten Schwanzfedern über die Fahne hinaus verlängert und mit einem spatelförmigen Bart an dem Ende. Schnabelfirste mit schwacher Längsrinne. Wachshaut unter dem Nasenloch stark eingezogen und nach dem Schnabelrande in eine Spitze verlaufend. Färbung grün. Die Geschlechter scheinen sich nicht zu unterscheiden. Drei Arten in der Westlichen Austro-Malayischen und Nördlichen Indo-Malayischen Subregion.

46. Prioniturus discurus. - Spatelschwanz.

Englisch: Philippine Raçket-tailed Parrot. - Französisch: Perroquet à palettes.

Psittacus discurus (1825) Vieill. Gal. Ois. I, pl. XXVI. Prioniturus discosurus (1850) Bonap. Consp. Av. I, p. 6. Urodiscus spatuliger (1854) Bonap. Rev. Mag. p. 155.

Abbildungen: Bourjot St. Hilaire Hist. Nat. Perr. pl. 53, b. Gould Birds Asia Pt. XIV (Prioniturus spatuliger). - Reichenow Vogelbilder t. XXVII, f. 3.

Diagnose: Flavescente viridis; vertice et occipite caeruleis; rectricum apicibus caerulescente-nigris; pedibus plumbeis; rostro pallide plumbeo; iride brunnea.

Long. c. 260 , ala 160, cauda 85 (rectr. long. 150), culmen $20 \mathrm{Mm}$.

오: Pileo obsolete caerulescente.

Vorkommen: Nördl. Indo-Malayische Subregion (Philippinen). 


\section{Prioniturus flavicans. - Raketen $\mathrm{sch}$ wanz.}

Englisch: Spreat Racket-tailed Parrot.

Prioniturus flavicans (1853) Cass. Proc. Ac. Phil. Vol. VI, p. 373.

Abbildungen: Gould Birds Asia Pt. XIV. - Reichenow Vogelbilder t. XXVII, f. 4.

Diagnose: Viridis; gutture, pectore et auchenio olivaceoflavis; pileo caeruleo, macula media coccinea; rectricum apicibus nigris; rostro et pedibus plumbeis; iride brunnea.

Long. c. 320 , ala 195, cauda 120 (rectr. long. 210), culmen $26 \mathrm{Mm}$.

오: Pileo caerulescente, absque macula coccinea.

Vorkommen: Westl. Austro-Malayische Subregion (Celebes).

48. Prionitums platurus. - Motmot.

Englisch: Racket-tailed Parrot. - Französisch: Perroquet à raquettes.

Psittacus platurus (1817) Vieill. Nouv. Dict. d'Hist. Nat. Tom. XXV, p. 314. - Psittacus setarius (1823) Tem. Pl. Col. Vol. I, pl. 15, p. 43. - Psittacus spatuliger (1837-1838) Bourj. St. Hiiaire Hist. Nat. Perr. pl. 53. - Prioniturus Wallacei (1867) Schleg. Dierent. p. 70.

Abbildungen: Bourj. St. Hil. 1. c. - Gould Birds Asia Pt. XIV (setarius). - Tem. Planch. Col. Vol. I, pl. 15. - Reichenow Vogelbilder t. XXVII, f. 5 .

Diagnose: Viridis; fascia auchenii aurea; macula verticis miniata; occipite et flexura caesiis; tectricibus mediis et minimis flavescente cinereis; rectricum apicibus cyaneo-nigris; rostro plumbeo, apice nigra; pedibus plumbeis; iride brunnea.

Long. c. 310 , ala 180, cauda 100, (rectr. long. 180), culmen $25 \mathrm{Mm}$.

Vorkommen: Westl. Austromalayische Subregion (Celebes).

Gattung: DICHROGNATHUS. Rothachselpapageien.

Psittinus (1842) Blyth Journ. As. Soc. Beng. XI, p. 789.

Charakter der Gattung: Kleine Vögel mit sehr kurzem, geraden Schwanze, welcher kürzer als die Hälfte des Flügels ist. Wachshaut von den Nasenlöchern an nach unten allmälig sich verengend. Firste mit Längsrinne. Von ziemlich bunter, aber matter Färbung. Die Geschlechter sind verschieden ge- 
färbt. Man kennt gegenwärtig nur einen Repräsentanten in der Indo-Malayischen Subregion.

49. Psittinus incertus. - Rothachsel.

Englisch: Blue-rumped Parrakeet. - Französisch: Petit Perroquet de Malacca.

Psittacus incertus (1790) Shaw Nat. Misc. pl. 769. Psittacus malaccensis (1790) Lath. Ind. Orn. I, p. 130. - Psittacus reticulatus (1831) Less. Traité d'Orn. p. 204. - Psittacus azureus (1839) Temm., Müll. Verh. Land- en Volkenk. p. 381. Psittacus macropterus (1868) Mus. Paris, Finsch Pap. II, p. 613. (synon.).

Abbildungen: Swainson Zool. Illustr. III, pl. 154. - Bourj. St. Hil. Hist. Nat. Perr. pl. 92. — Reichenow Vogelbilder aus feruen Zonen t. XV, f. 5 .

Diagnose: Capite caesio; interscapulio nigro; tergo, uropygio et supracaudalibus cyaneis; gastraeo flavo-olivaceo, ventre medio caerulescente; hypochondriis et subalaribus rubris; cauda viridiflava; alis viridibus, tectricibus flavescente marginatis, macula scapulari cerasina; maxilla coccinea, mandibula brunnescente; iride albo-flava; pedibus olivascente-brunneis.

Long. c. 190, ala 120, cauda $48 \mathrm{Mm}$.

ㅇ: Capite genisque badiis, uropygio et tectricibus primariis cyaneis; supracaudalibus viridibus.

Juv.: Viridis, tergo et uropygio coeruleis; tectricibus flavescente-marginatis.

Vorkommen: Indo-Malayische Subregion (Malacca, Borneo, Sumatra).

Genus: AGAPORNIS. Unzertrennliche.

Agapornis (1836) Selby Nat. Libr. p. 117 (Typus: Psittacus pullarius L.). - Poliopsitta (1854) Bp. Rev. Mag. Zool. p. 152 ('Typus: Psittacus canus Gm.).

Charakter der Gattung: Sehr kleine Papageien mit sehr kurzem, aber stark gerundetem Schwanz, welcher nur halb so lang als der Flügel ist. Wachshaut von der typischen Form, fast vollständig befiedert. Fürbung vorherrschend grün. Die Geschlechter sind, so weit bekannt, durch die Färbung unterschieden. Wir kennen fünf Arten in der Aethiopischen Region. Höchst auffallend ist das eigenartige, von der Gewohnheit 
anderer Papageien sowohl, wie der aller anderen Vögel überhaupt abweichende Verfahren einer Art dieser Gattung beim Nestbau. Die Rosenpapageicn (A. roseicollis) verfahren bei Herrichtung ihres Nestes derartig, dass sie Holz in kurze Späne zerspleissen oder weiche Rindenschale zerfasern, die 6 bis 10 Centimeter langen Stïcke zwischen die Bürzelferlern stecken und dieselben auf diese Weise zu Neste tragen, um damit eine Unterlage für die Eier herzurichten.

\section{Schlüssel der Gattung:}

Ganzer Kopf grün: Swindereni.

Ganzer Kopf grau: cana.

Rothe Zeichnung am Kopfe:

Stirn, Ziigel und Augenring scharlachroth: Tarantae.

Stirn, Wangen und Kehle, sowie der Schnabel, scharlachroth: pullaria.

Stirn scharlachroth; Kopfseiten, Kehle und Kropf rosenroth; Schnabel wachsgelb: roseicollis.

50. Agapornis Tarantae. - Gebirgspapagei.

Englisch: Abyssinian Love-bird. - Französisch: Psittacule à masque rouge.

Psittacus Tarante (1814) Stanley Salt's Trav. Abyss. App.

Abbildungen: Bourjot St. Hilaire Hist. Nat. Perr. pl. 99. Lear Illustr. Parr. pl. 39. - Reichenow Vogelb. t. XX, f. 2.

Diagnose: Viridis; sincipite loris et periophthalmiis coccineis; remigibus, tectricibus primariis et pteryllii pluma longissima fuscis; remigibus tectricibus secundariis et tectricibus inferioribus nigris; cauda flavescente - viridi, fascia anteapicali nigra; rostro rubro; pedibus et iride fuscis.

Long. c. 190, ala 110, cauda 55, culmen $20 \mathrm{Mm}$.

오: Sincipite miniato.

Juv.: Sincipite viridi; tectricibus inferioribus, remigibus et tectricibus secundariis fuscis.

Vorkommen: Ostafrikanische Subregion (Abyssinisches Gebirgsland).

\section{Agapornis pullaria. - Unzertrennlicher.}

Englisch: West-African Love-bird. - Franz.: Inséparable.

Psittacula Gruineensis (1760) Briss. Ornith. IV, p. 387. Psittacus pullavius (1764) Lin. Mus. Ad. Fried. II, p. 15. Psittacus guineensis (1776) Müll. Lin. Natursyst. Suppl. p. 81. -

Cab. Journal f. Ornithol. XXIX. Jahrg. No. 155. Juli 1881. 
Perruçhe à tête rouge und Le moineau de Guinée (1783) Buff. Hist. Nat. Ois. VII, p. 133. - Petite Perruche de Guinée id. Pl. Enl. 60. - Agapornis xanthops (1863) v. Heugl. Journ. f. Ornith. p. 271. - Psittacula mbricollis (1837-1838) Bourj. St. Hilaire Hist. Nat. Perr. pl. 90.

Abbildungen: Bourjot St. Hil. Hist. Nat. Perr. pl. 90. Reichenow Vogelbilder t. XX, f. 3.

Diagnose: Viridis; facie coccinea; uropygio cyaneo; flexura et tectricibus inferioribus nigris; rectricibus duabus mediis totis flavo-viridibus, ceteris basi viridi - flavis, medio-coccineis, dein nigris, apice flavo-viridibus; rostro dilute coccineo; pedibus griseis; iride fusca.

Long. c. 170 , ala 85 , cauda 45 , culmen $15 \mathrm{Mm}$.

ㅇ: Facic miniato-coccinea.

Juv.: Facie miniata; tectricibus inferioribus viridibus.

Vorkommen: Aethiopische Region (Tropisches West- und Ost-Afrika).

52. Agapornis roseicollis. - Rosenpapagei.

Engl:: Rosy-faced Love-bird. - Franz.: Psittacule rose.

Psittacus roseicollis (1817) Vieill. N. D. XXV, p. 377. Psittacus parasiticus (1868) Finsch Pap. II, p. 640.

Abbildungen: Bourjot St. Hilaire Hist. Nat. Perr. pl. 91. Reichenow Vogelbilder t. XX, f. 1.

Diagnose: Viridis; sincipite coccineo; genis, temporibus et gutture roseis; uropygio caeruleo, rectricibus duabus mediis viridibus, apice caeruleis, ceteris basi coccineis, ante apicem caerulescentem fascia pogonii interni nigra notatis; rostro flavo; pedibus griseis; inide fusca; periophthalmiis nudis albidis.

Long. c. 190, ala 110, cauda 55, culmen $16 \mathrm{Mm}$.

ㅇ: Sincipitis et gulae colore roseo minus extenso.

Vorkommen: Aethiopische Region (Südwest-Afrika).

53. Agapornis Swindereni. - Liberia Papagei.

Englisch: Liberian Parrot. - Französisch: Psittacule de Van Swindern.

Psittacus Swindernianus (1820) Kuhl Consp. 1) 62.

Abbildungen: Kuhl l. c. t. 2. - Bourjot St. Hilaire Hist. Nat. Perr. pl. 98. - Lear Illustr. Parr. pl. 42. - Journal für Ornithol. 1877, t. 5. - Reichenow Vogelbilder t. XX, f. 4. 
Diagnose: Viridis, pectore flavicante; fascia cervicali nigra; tergo et uropygio cyaneis; rectricibus basi coccineis, medio nigris, apice viridibus; rostro plumbeo, apice et mandibula pallidioribus; pedibus nigricantibus; iride fusca.

Long. c. 150, ala 95, cauda 40, culmen $15 \mathrm{Mm}$.

Vorkommen: Westafrikanische Subregion (Liberia).

54. Agapornis cana. - Grauköpfchen.

Englisch: Grey-headed Love-bird. - Französisch: Psittacule à tête grise.

Psittacula madugascariensis (1760) Briss. Orn. IV, p. 394. Perruche à tête grise (1783) Buff. Hist. Nat. Ois. VII, p. 138. Petite Perruche de Madagascar (1783) id. Pl. Enl. t. 791, f. 2. Psittacus camus (1788) Gmel. S. N. I, p. 350. - Psittacus poliocar (1844) Forst. Lcht. Descr. An. p. 399. - Psittacula madagascarionsis (1863) Finsch Nederl. Tijdschr.

Abbildungen: Bourjot St. Hilaire Hist. Nat. Perr. pl. 96. Briss. 1. c., t. 30, f. 2. - Reichenow Vogelbilder t. XX, f. 5.

Diagnose: Viridis; capite, collo et pectore canis nitore nonnullo virescente-lilacino; subalaribus nigris; rectricibus basi flavidis, fascia mediana lata nigra, apice viridibus; rostro pallido; iride fusca.

Long. c. 150 , ala $90-95$, cauda 50, culmen $12 \mathrm{Mm}$.

ㅇ: Capite, collo, pectore et subalaribus viridibus.

Vorkommen: Madagassische Subreg. (Madagaskar, Mauritius).

\section{Familie: Psittucidae. Graupapageien.}

Charakter der Familie: In dieser Familie vereinigen wir eine kleine Zahl von Papageien, welche der Aethiopischen Region eigenthümlich sind und die gekennzeichnet werden durch eine sehr breite nackte Wachshaut, welche die ganze Basis des Oberkiefer's umgiebt, unterhalb der kreisrunden Nasenlöcher aber sich etwas verschmälert. Dic Augengegend ist nackt, meistens auch der Zügel. Der Schnabel ist glatt, so lang als hoch, hat gerundete Firste ohne Längsrinne und keinen Zahn; der Unterkiefer hat gestreckte Form, ist lïnger als hoch; Feilkerben sind vorhanden. Die Flügel sind ziemlich lang; der gerade oder schwach gerundete Schwanz bald länger, bald kürzer als die Hälfte des Flügels. Die Färbung ist grau oder schwärzlich; die Geschlechter sind nicht unterschieden. Die 
sechs bekannten Arten trennen wir in zwei Gattungen, welche auch verschiedene Verbreitung haben. Die langschwänzigen Vaza-Papageien bewohnen die Madagassische Subregion, während die kurzschwänzigen Graupapageien dem Festlande Afrika angehören. Die Vaza-Papageien schliessen sich an die Plattschweifsittiche und zwar an die Formen der Untergattung Pyrrhulopsis an, welchen sie namentlich in der Schnabelform gleichen und mit denen sie durch die bereits erwähnte ausgestorbene Art, den Maskarenenpapagei, noch enger verbunden waren. Die Gattung Psittacus betrachten wir als die höhere Entwickelungsstufe von Coracopsis und als die höchste Form der altweltlichen Papageien überhaupt.

Die Graupapageien sind schlechte Flieger, bewegen sich auch auf dem Boden sehr unbeholfen, sind hingegen gewandt im klettern und halten sich daher vorzugsweise in Gezweige der Bäume auf. Sie leben gesellig in grossen Schaaren, welche nur zur Brutzeit in einzelne Paare sich auflösen und nähren sich hauptsächlich von Kernfrüchten und Beeren der Bäume und von dem frischen Mais der Neger-Ansiedelungen, nach welchen sie oft weite Streifzüge von ihren Schlafplätzen aus unternehmen.

Bekanntlich eignet sich die höchste Form diescr Familie, der Jako, am besten von allen Papageien für die Gefangenschaft, da er sehr gut ausdauert, die grösste Begabung hat, menschliche Worte nachzusprechen und seine kreischenden Naturlaute vollständig ablegt.

Genus: CORACOPSTS. V a za-P a pag e i en.

Vaza (1831) Less. Traité d'Ornith. p. 197. - Coracopsis (1832) Wagl. Mon. Psitt. p. 501. - Vigorsia (1837) Sws. Class. B. II, p. 304 .

Charakter der Gattung: Schmabel dick, seitlich stark aufgetrieben; Schwanz gerade oder schwach gerundet, länger als die Hälfte, bis zwei Drittel des Flügels. Augengegend nackt; Zügel nackt oder schwach befiedert. Vier Arten in der Madagassischen Subregion.

1. Corctopsis melanorhyncha. - Grosser Vaza-Papagei. Engl.: Vaza Parrakeet. - Franz.: Perroquet Vaza.

Psittacus vaza (1812) Shaw Gen. Zool. VIII, p. 528. Coracopsis melanorhyncha (1863) Finsch Ned. Tijdschr. Dierk. Ber. 
Abbildungen: Levaillant Hist. Nat. Perr. pl. 81. - Rchw. Vogelbilder t. VII, f. 8.

Diagnose: $C$. nigrae simillima, sed major.

Long. c. $540-560$, ala 330 , cauda $210-230$, culmen 45 bis $50 \mathrm{Mm}$.

Vorkommen: Madagassische Subregion (Madagaskar).

2. Coracopsis nigra. - Kleiner Vaza-Papagei.

Eng1.: Smaller Vaza Parrakeet. - Franz.: Petit Vaza.

Vaza (1783) Buff. H. N. Ois. VII, p. 96. - Perroquet noir de Madagascar id. Pl. Enl. pl. 500. Psittacus Madagascroviensis niger (1760) Briss. Orn. IV, p. 317. - Psittacus niger (1766) Lin. S. N. I, p. 145.

Abbildungen: Buffon 1. c. - Levaillant H. N. P. pl. 82.

Diagnose: Nigricante fuliginosa; tectricibus alarum majoribus, remigumque primi ordinis pogoniis externis dimidio basali schistaceo-lavatis; subcaudalibus dilutius fuscis; rostro corneopallente; pedibus nigricantibus; ceroma incarnata; iride fusca; rostro albescente.

Long. c. 360 , ala 250, cauda 140, culmen $24 \mathrm{Mm}$.

Vorkommen: Madagassische Subregion (Madagaskar).

3. Coracopsis comorensis. - Comoren Schwarzpapagei.

Englisch: Mozambique Parrot.

Coracopsis comorensis (1854) Ptrs. Sitz. Berl. Ac. Wiss. p. 371. Abbildung fehlt.

Diagnose: Dilute fuliginosa, remigibus rectricibusque nitore griseo-virente; rostro et cera fuscis; pedibus nigro-fuscis; iride fusca.

Long. c. 190, ala 290, cauda 190, culmen $37 \mathrm{Mm}$.

Vorkommen: Madagassische Subregion (Comoren: Anjouan, Mohilla).

4. Coracopsis Barklyi. - Seychellen-Schwarzpapagei.

Englisch: Barkly's Vaza Parrakeet.

E. Newton Proc. Zool. Soc. 1867, p. 346. - Ibis 1867, p. 341 .

Abbildung: Proc. Zool. Soc. 1867, pl. 22.

Diagnose: $C$. comorensi quoad colorem similis, sed valde minor.

Long. c. 300, ala 175-200, cauda 150, culmen 2:3 Mm.

Vorkommen: Madagassische Subregion (Seychellen: Praslin). 
Genus: PSTTTACUS. Gra u papage ien.

Psittacus (1735) Lin. Syst. Nat. - Jaco (1831) Less. Traité d'Ornith. p. 197. - Rhodurus (1872) Sundevall Tentamen p. 69.

Charakter der Gattung: Schnabel seitlich etwas zusammengedrückt und gestreckter; Schwanz gerade, kürzer als die Hälfte des Flügels; der grösste Theil der Kopfseiten nackt. 2 Arten in dem tropischen West- und Central-Afrika.

5. Psittacus carycinurus. - Timneh-Papagei.

Engl.: Timneh Parrot. - Franz.: Perroquet timneh.

Psittacus timneh (1844) Fras. P. Z. S. p. 38. - Psittacus carycinurus (1881) Reichenow.

Abbildungen: Levaillant Hist. N. P. pl. 102. - Reichenow Vogelbilder t. VII, f. 4.

Diagnose: Nigricante - canus, uropygio, abdomine et facie nuda dilute canis; cauda rubro - fusca; rostro nigro, culmine et maxillae basi pallide carneis; pedibus nigricantibus; iride dilute flava.

Long. c. 310, ala 200, cauda 95, rostrum $35 \mathrm{Mm}$.

Vorkommen: Aethiopische Region (Nördl. West-Afrika).

\section{Psittacus erithacus. - Jako.}

Englisch: Grey Parrot. - Französisch: Perroquet gris.

Psittacus erithacus (1754) Lin. Mus. Ad. Friedr. I, p. 14; (1766) Lin. S. N. I, p. 144. - Cacatua alis et cauda rubris (1760) Briss. Orn. IV, p. 214. - Psittacus Guineensis cinereus ibid. p. 310. - Psittacus Guincensis alis rubris ibid. p. 312. Psittacus Guineensis rubrovarius ibid. p. 313. - Psittacus erythroleucus (1766) Lin. S. N. I, p. 144. - Psittacus ruber (1769) Scop. Ann. I, p. 32. - Jaco (1783) Buff. Hist. Nat. Ois. VII, p. 81. -- Perroquet cendré de Guinée id. Pl. Enl. pl. 311.

Abbildungen: Buffon 1. c. - Levaillant Hist. Nat. Perr. pl. 99-101. - Reichenow Vogelbilder t. VII, f. 5.

Diagnose: Canus; facie et capistro subpapillosis albis; cauda coccinea; rostro nigro; cera alba; pedibus canis; iride dilute flava.

Long. c. 360 , ala 240, cauda 100 , rostrum $40 \mathrm{Mm}$.

Juv.: Obscurius tinctus, iride cinerea.

Vorkommen: Aethiopische Region (West- und Central-Afrika). 


\section{Familie: Conuridae. Keilschwanzsittiche.}

Charakter der Familie: Der stufige und meist lange, nur in einem Falle (Psittacula) kurze und gerade Schwanz unterscheidet diese Sittiche von den anderen neuweltlichen Papageien und ebenso von den meisten altweltlichen Formen. Die einzelnen Schwanzfedern sind am Ende mehr oder weniger verschmälert oder zugespitzt, die beiden mittelsten immer am lïngsten, während bei den ebenfalls stufenschwänzigen Plattschweifsittichen, wie erwähnt, die vier mittelsten Federn in der Regel von gleicher Länge sind. Der Schnabel ist mässig stark, mit Ausnahme eines Falles (Henicognathus) bedeutend höher als lang, mit bald mehr, bald weniger ausgeprägtem, meist nicht deutlichem Zahn und mit Feilkerben, die Firste abgeflacht und mit einer Lüngsrinne versehen oder gerundet und glatt. Die stets deutliche Wachshaut umgiebt als ein fast gleich breites, nur vor den Nasenlöchern etwas hervortretendes Band die ganze Schnabelbasis. Die Nasenlöcher sind frei oder, wie bisweilen die ganze Wachshaut, befiedert. Im Flïgel ist die zweite und dritte (seltener zweite bis vierte) oder erste bis dritte Schwinge am längsten.

Die Familie der Keilschwanzsittiche ist die artenreichste aller Papageien - Gruppen, indem sie 93 Arten und Unterarten umfasst, welche ausschliesslich Amerika und zwar mit einer einzigen Ausnahme Süd- und Mittelamerika angehören. Sie hat ferner die weiteste geographische Verbreitung von Nord nach Süd, indem sie sich von Carolina bis Patagonien, von dem $40^{\circ}$ nördl. Br. bis zum $50^{\circ}$ südl. Br. ausdehnt.

Wir trennen die Arten in sieben Gattungen, welche sich vornehmlich durch die Schnabel- und Schwanzform unterscheiden. Trotz der bedeutenden Artenzahl ist die Mannigfaltigkeit in Formen und Farben verhältnissmässig gering, bedentend weniger auffallend als bei den Plattschweifsittichen. Die Färbung ist vorherrschend grün; nur wenige Arten weichen durch grellere rothe und gelbe oder durch blaue Fïrbung ab. Die Geschlechter sind in der Regel gleich gefärbt.

In der Lebensweise zeigen alle Keilschwanzsittiche grosse Uebereinstimmung. Sie leben gesellig, namentlich ausser der Brutzeit, viele auch während derselben zu grossen Schaaren vereinigt. Von ausserordentlicher Leichtigkeit und Gewandtheit 
ist der Flug; im klettern sind sie geschickt; unbeholfen bewegen sie sich hingegen auf ebener Erde. Die Stimme aller, vielleicht mit alleiniger Ausnahme der kleinsten Formen, ist ein unangenehmes Kreischen. Als auffallend ist die Eigenschaft mancher Arten hervorzuheben, während der Ruhe sich senkrecht wie die Spechte aufzuhängen, wobei sie sich mit Füssen und Schnabel anklammern. Ihr Aufenthalt steht im Verhältniss zu der ausgedehnten Verbreitung; jedes Terrain bietet ihnen geeignete Wohnstätten. Die Pampas ebensowohl wie die gemischte Steppenlandschaft beherbergen sie, der Urwald der Niederungen und die Gebirge bis zu den Grenzen des Baumwuchses. Die Nahrung besteht hauptsächlich in Samen der Grasarten, in Baumfrüchten und Beeren, nebenbei in Insekten. Einige Bewohner der gemässigten Breiten wandern zur Winterszeit in wärmere Gegenden. Die Mehrzahl nistet in Baumlöchern, einzelne in Felshöhlen; von einer Art (Mönchsittich) weiss man, lass sie freistehende Nester baut.

\section{Genus: SITTACE. A raras.}

Ara (1811) Cuv. Illig. Prodromus p. 200 (Ohne Typus). Macrocercus (1816) Vieill. [Teste Gray List Psitt. p. 25] (Ohne Typus). - Anodorhynchus (1824) Spix Av. Bras. p. 25 (Typus: A. Maximiliani Spix). - Sittace (1832) Wagl. Mon. Psitt. p. 499 (partim). - Anodontorhynchus (1848) Agassiz Nomenclator p. 68. Cyanopsitta (1854) Bonap. Rev. Zool. p. 149 (Typus M. glaucus Vieill.). - Ararauna ibid. (Typus: Psittacus Ararauna Lin). Aracanga ibid. (Typus: Psittacus Aracanga Gm.). - Primolius (1857) Bonap. Compt. Rend. (Typus: M. maracana Vieill.). Sittace (1867) Finsch Pap. I, p. 380 (Typus: Psittacus hyarinthinus Lath.). - Anoplorhynchus (1872) Sundevall Tentamen p. 70.

Charakter der Gattung: In vorstehender Gattung werden die grössten Arten der Familie vereinigt, unter welchen sich die stärksten aller Papageien überhaupt befinden. Sie sind stets dadurch von allen anderen Keilschwanzsittichen unterschieden, dass Augengegend und Wangen nackt sind, bisweilen mit einigen Reihen kleiner Federchen bedeckt. Im Flügel ist zweite und dritte Schwinge am längsten, erste deutlich kürzer. Der Schwanz ist meistens länger als cler Flügel. Die gegenwärtig bekannten achtzehn Arten und Unterarten bewohnen die heissen 
Breiten Amerikas, die Brasilianische, Mexicanische und Antillische Subregion.

$$
\text { Schlüssel der Gattung. }
$$

Hauptfärbung blau oder blaugrau:

Ganzes Gefieder kobaltblau: hyacinthina.

Rücken und Flügel kobaltblau; Kopf, Hals und Unterkörper graublau: Leari.

Ganzes Gefieder graublau oder grïnlich graublau:

Augenring und Fleck am Unterkiefer gelb: glauca.

Augenring und Zügel bleigrau: Spixi.

Hauptfärbung roth:

Mit rothem Nacken:

Heller roth, grosse Armdecken goldgelb: soccinea.

Dunkler roth, grosse Armdecken grün: chloroptera.

Mit goldgelbem Nacken: tricolor.

Oben hellblau, unten goldgelb: caerulea und Azarae.

Hauptfärbung grün:

Stirn roth:

Unterkörper einfarbig grün: militaris.

Mit rothem Bauchfleck: Illigeri (s. auch Couloni).

Ganzer Oberkopf roth: Lafresnayi.

Stirnstreif dunkel röthlich braun: severa.

Stirn oder ganzer Oberkopf hellblau oder graublau:

Mit rothem Flügelbug: nobilis (s. auch Hahni).

Mit grünem Flügelbug: modesta.

Oberkopf schwarzbraun, gelbes Nackenband: auricollis.

1. Sittace hyacinthina. - Hyacinth-Arara.

Englisch: Hyazinthine Macaw. - Franz.: Ara hyacinthe.

Psittacus hyacinthinus (1790) Lath. Ind. Orn. p. 84.-Psittacus Augustus (1792) Shaw Lev. Mus. p. 59. - Anodorhynchus Maximiliani (1824) Spix Av. Brasil. t. 11 - Psittacara cobaltina (1837-1838) Bourj. St. Hil. H. N. Perr. pl. 16.

Abbildungen: Spix 1. c. - Bourj. St. Hil. 1. c. - Reichenow Vogelbilder t. IX, f. 2.

Diagnose: Cobaltina; annulo orbitali et macula mandibulari nudis luteis; rostro et pedibus nigricantibus; iride fusca.

Long. c. 900, ala 400, cauda 550, culmen $90 \mathrm{Mm}$.

Vorkommen: Brasilianische Subregion (Brasilien).

2. Sittace Leari. - Kleiner Hyacinth-Arara.

Engl.: Lear's Hyacinthine Macaw. - Franz: Ara Lear. Anodorhynchus Learii (1856) Bonap. Naumannia Heft IV, Beilage. 
Abbildungen: Lear Parr. pl. 9. - Souancé Icon. Perr. pl. I.

Diagnose: Dorso, alis caudaque cobaltinis; capite, collo et abdomine glaucis; annulo orbitali et macula lata mandibulari nudis luteis.

Longitudine $S$. glauco major.

Vorkommen noch nicht festgestellt.

3. Sittace glauca. - Blauarara.

Englisch: Glaucous Macaw. - Französisch: Ara gris-bleu. Macrocercus glaucus (1816) Vieill. Nouv. Dict. II, p. 259.

Abbildungen: Bourjot St. Hil. Hist. Nat. Perr. pl. 14. Souancé Icon. Perr. pl. I. - Wagl. Mon. Psitt. pl. 26. Reichenow Vogelbilder t. IX, f. 1.

Diagnose: Sordide glauca, capite caesio; annulo orbitali maculaque mandibulari nudis luteis; rostro et pedibus nigricantibus; iride fusca.

Long. c. 680, ala 360, cauda 380 , culmen $65 \mathrm{Mm}$.

Vorkommen: Südl. Brasilianische Subregion (Süd-Brasilien, Uruguay, Paraguay).

4. Sittace Spixi. - Kleiner Blauarara.

Engl.: Spix's Blue Macaw. - Franz.: Ara Spix.

Sittace Spixi (1832) Wagl. Mon. Psitt. p. 675. - Psittacare glauca minor var. (1837-1838) Bourjot St. Hilaire Hist. Nat. Perr. pl. 15.

Abbildungen: Bourjot St. Hilaire 1. c. - Spix Av. Brasil. t. 23. - Proc. Zool. Soc. 1878, pl. 61 .

Diagnose: Caesia; pileo thalassino; capitis lateribus canis; annulo orbitali et loris nudis plumbeis; remigibus cyaneis; rostro et pedibus nigricantibus; iride flava.

Ala 270, cauda $350 \mathrm{Mm}$.

Vorkommen: Oestl. Brasilianische Subregion (Ost-Brasilien).

5. Sittace caerulea. - Ararauna.

Engl: Blue-and-Yellow Macaw. - Franz.: Ara bleu.

Ara jamaicensis cyaneo-crocea (1760) Briss. Orn. IV, p.191.Ara brasiliensis cyaneo-crosea ibid. p. 193. - Psittacus ararauna (1766) Lin. S. N. p. 139. - Psittacus caeruleus (1788) Gmel. S. N. p. 314 .

Abbildungen: Buffon Pl. Enl. pl. 36. - Levaillant Hist. Nat. Perr. pl. 3. - Lear Parr. pl. 8. - Shaw Gen. Zool. VIII, pl. 54. - Reichenow Vogelbilder t. II, f. 1. 
Diagnose: Caerulea; colli lateribus et gastraeo toto aurantiacis; sincipite virescente; remigibus et rectricibus subtus olivaceoflavis; genarum limbo et mento nigris; genis et loris nudis carneis; iride virescente incana.

Long. c. 850, ala 390, cauda 500, culmen $65 \mathrm{Mm}$.

Vorkommen: Brasilianische Subregion.

6. Sittace Azarae. - Caninde.

Englisch: Canindé Macaw. - Französisch: Canindé.

Sittace caninde (1832) Wagl. Mon. Psitt. p. 674. - Sittace Azarae (1881) Reichenow.

Abbildung fehlt.

Diagnose: S. caemuleae similis, sed minor, limbo genarum mentoque nigris nullis; tibiis crissoque caeruleis.

Vorkommen: Südliche Brasilianische Subregion (Inneres Brasilien, Paraguay).

7. Sittace chloroptera. - Grünflügel-Arara.

Englisch: Green-winged Macaw. - Französisch: Ara aux ailes verts.

Ara brasiliensis (1760) Briss. Orn. IV, p. 184. - Ara chloroptems (1859) G. R. Gray List Psitt. p. 26.

Abbildungen: Levaillant Hist. Nat. Perr. pl. 1. - Reichenow Vogelbilder t. IX, f. 4.

Diagnose: Punicea; remigibus, tergo, tectricibus alarum majoribus, tectricibus caudae superioribus et inferioribus caeruleis; tectricibus alarum minoribus et scapularibus viridibus; maxilla albicarte, macula triangulari basali et mandibula nigris; genis nudis carneis, plumarum striis puniceis notatis; iride flava.

Long. c. 900, ala 400, cauda 550, culmen $80 \mathrm{Mm}$.

Vorkommen: Brasilianische Subregion.

8. Sittace coccinea. - Aracanga.

Hellrother Arara. - Englisch: Red - and - blue Macaw. Französisch: Ara rouge.

Ara jamaicensis (1760) Briss. Orn. IV, p. 188. - Psittacus Macao (1766) Lin. S. N. p. 139. - Psittacus Aracanga (1788) Gmel. S. N. p. 313. - Sittace coccinea (1881) Reichenow.

Abbildungen: Buffon Pl. Enl. pl. 12. - Levaillant Hist. Nat. Perr. pl. 2 et 2a. - Lear Parr. pl. 7. - Nat. Libr. Vol. VI, pl. 7. - Reichenow Vogelbilder t. IX, f. 5.

Diagnose: Coccinea; remigibus, tergo, tectricibus alarum 
majoribus, tectricibus caudae superioribus et inferioribus caeruleis; tectricibus alarum minoribus et scapularibus luteis, viridi-limbatis; maxilla albicante, macula triangulari et mandibula nigris; pedibus griseis; genis nudis carneis, striis plumarum nullis; iride flava.

Long. c. 900, ala 400, cauda 550, culmen $70 \mathrm{Mm}$.

Vorkommen: Mexicanische und Nördliche Brasilianische Subregion.

9. Sittace tricolor. - Dreifarben-Arara.

Englisch: Tricolor Macaw. - Französisch: Ara tricolor.

Psittacus tricolor (1811-1812) Bechst. Uebers. p. 64.

Abbildungen: Buffon Pl. Enl. pl. 641. - Levaillant Hist. Nat. Perr. pl. 5.

Diagnose: Dilute coccinea; cervice et occipite aurantiis; tergo, uropygio, supra- et subcaudalibus, remigibus, alarum tectricibus majoribus et rectricum apicibus caeruleis; alarum tectricibus, scapularibus caudaque rubiginosis.

Long. c. 500, ala 260, cauda 300, culmen $45 \mathrm{Mm}$.

Vorkommen: Antillische Subregion (Cuba).

10. Sittace militaris. - Soldaten-Arara.

Englisch: Military Macaw, Green Macaw. - Französisch: Ara militaire.

Psittacus militaris (1766) Lin. S. N. I, p. 139. - Psittacus ambiguus (1811-1812) Bechst. Kurze Uebers. p. 65.

Abbildungen: Levaillant Hist. Nat. Perr. pl. 4 et 6 . Reichenow Vogelbilder t. I, f. 1.

Diagnose: Olivaceo - viridis, capite coerulescente; fronte coccinea; mento et genarum plumis rubro-fuscis; tergo, supraet subcaudalibus, remigibus et tectricibus primariis caeruleis; rectricibus rufis, apice caeruleis; remigibus et rectricibus subtus flavescentibus; rostro pedibusque nigricantibus; iride flavescente albida; facie nuda dilute carnea.

Long. c. 730 , ala 360 , cauda 400 , culmen $58 \mathrm{Mm}$.

(Exemplare aus Peru und Neu-Granada sollen sich constant durch geringere Grösse unterscheiden, Subspecies ambigua).

Vorkommen: Mexicanische und Brasilianische Subregion.

11. Sittace severa. - Zwerg-Arara.

Anakan. - Englisch: Small Macaw, Brown-fronted Macaw.Französisch: Ara à front châtain. 
Ara Brasiliensis viridis (1760) Briss. Ornith. IV, p. 198. Ara Brasiliensis erythrochlor ibid. p. 202. - Psittacus severus (1766) Lin. S. N. I, p. 140. - Aru castaneifrons (1847) Lafr. Rev. Zool. p. 66 .

Abbildumgen: Levaillant Hist. Nat. Perr. pl. 8-10. Reichenow Vogelbilder t. IX, f. 3.

Diagnose: Viridis; pileo caerulescente; fronte et genarum margine rubro-fuscis; remigibus et tectricibus primariis caeruleis; subalaribus minimis coccineis; rectricibus cupreo-rufis, virescente limbatis, apice caeruleis; remigibus et rectricibus subtus sordide miniatis; rostro nigro; pedibus fuscis; iride Hava; facie nuda pallide flavescente-carnea.

Long. c. 500, ala 250, cauda 260, culmen $40 \mathrm{Mm}$.

Vorkommen: Brasilianische Subregion.

12. Sitlace Lafresnayi. - Rothbug-Arara.

Engl.: Red-cheeked Macaw. - Franz.: Ara Lafresnay.

Ara rubro-genis (1847) Lafresn. Rev. Zool. p. 65. - Sittace Lafresnayii (1867) Finsch Pap. I, p. 394.

Abbildung: Des Murs Icon. Orn. pl. 72.

Diagnose: Olivaceo-viridis; pileo, fascia suboculari, flexura, alarum tectricibus minimis, hypochondriis, subalaribus et tibiis miniato-coccincis; torque auchenii croceo; remigibus, tectricibus primariis et rectricum apicibus caeruleis; rostro nigro; pedibus fuscis; iride flava; loris et annulo orbitali nudis pallide carneis.

Mensurae S. tricoloris.

Vorkommen: Südwestl. Brasilianische Subregion (Bolivia).

13. Sittace Illigeri. - Marakana.

Rothrückiger Arara. - Englisch: Illiger's Macaw. - Franz.: Ara maracane.

Macrocercus Maracana (1816) Vieill. Nouv. Dict. II, p.260.Psittacus Illigeri (1820) Tem, et Kuhl Consp. Psitt. p. 19. Arara purpureodorsalis (1824) Spix Av. Brasil. p. 26.

Abbildungen: Spix Av. Brasil. t. 24. - Reichenow Vogelbilder t. IX, f. 6 .

Diagnose: Viridis; capite glauco; fronte, macula dorsali et ventre medio dilute coccineis; remigibus et tectricibus primariis caeruleis; rectricibus cupreo - rufis, apice cacruleis, exteriorum pogonio interno et omnibus subtus olivaceo-flavis; rostro nigro; iride rufa; pedibus et facie nuda dilute flavescente carneis. 
Long. c. 430, ala 220, cauda 210, culmen $34 \mathrm{Mm}$. Vorkommen: Südliche Brasilianische Subregion.

14. Subspecies: Couloni. - Gebirgs-Arara. Ara couloni (1876) P. L. Sclater Proc. Zool. Soc. p. 255. Abbildung: Proc. Z. S. 1876, p. 255 (Kopf, Holzschnitt).

Diagnose: S. Illigeri simillima, sed rostro majore, genis solum nudis, area postoculari plumosa, corporis colore rubro nullo certissime diversa (Teste Sclater).

Vorkommen: Südwestliche Brasilianische Subregion (Gebirge Ost-Perus).

15. Sittace modesta. - Rothsteiss-Arara.

Engl.: Parrot Macaw. - Franz.: Ara de Cayenne.

Psittacus manilatus [!] (1783) Bodd. Tabl. Pl. Enl. p. 53, No. 864. - Psittacus Macamuanna (1788) Gmel. S. N. I, p. 314. Sittace modesta (1881) Reichenow.

Abbildungen: Buffon Pl. Enl. pl. 864. - Levaillant Hist. Nat. Perr. pl. 7 et 9 .

Diagnose: Viridis, pileo genisque coerulescentibus, gula pectoreque cinerascentibus; nacula crissi sordide rubra; remigibus et tectricibus primariis coeruleis; rectricibus viridibus; remigibus et rectricibus subtus flavescentibus; rostro pedibusque nigricantibus; facie nuda albida.

Long. c. 410, ala 235, cauda 220, rostrum $28 \mathrm{Mm}$.

Vorkommen: Oestliche Brasilianische Subregion (Brasilien, Guiana).

16. Sittace auricollis. - Goldnacken-Arara.

Englisch: Golden-naped Macaw. -- Französisch: Ara à nuque d'or.

Sittace auricollis (1853) Cass. Proc. Ac. Phil. VI, p. 372. Sittace Primoli (1853) Bonap. Compt. Rend. p. 807. - Ara auritorques (1854) Mass. et Sou. Rev. Mag. Zool. p. 71. Sittace chrysotorques (1854) Licht. Nomencl. p. 73.

Abbildungen: Souancé Iconographie Perr.pl. 2.- Reichenow Vogelbilder t. IX, f. 7.

Diagnose: Viridis, pileo et genarum margine nigro-fuscis; fascia auchenii aurantiaca; remigibus et tectricibus primariis coerulei ; rectricibus cupreo-rufis, apice et exteriorum pogonio interno coeruleis; remigibus et rectricibus subtus flavescentibus; 
rostro fusco, apice pallida; pedibus fulvis; iride flava; facie nuda flavescente carnea.

Long. c. 400, ala 220, cauda 220, culmen $39 \mathrm{Mm}$.

Vorkommen: Südl. Brasilianische Subregion (Süd-Brasilien, Bolivien, Paraguay).

17. Sittace nobilis. - Blaustirn-Arara.

Englisch: Noble Parrot. - Französisch: Ara pavoune.

Psittacus nobilis (1764) Lin. Mus. Ad. Fridr. II, p. 13. Psittacus guianensis (1820) Kuhl Consp. Psitt. p. 19. - Psittacus cumanensis (1823) Licht. Dubl. Verz. p. 6. - Arara macrognathus (1824) Spix Av. Brasil. p. 26. - Psittacara frontatus (1825) Vig. Zool. Journ. II, p. 389. - Arara cayana (1831) Less. Traité d'Ornith. p. 188.

Abbildungen: Bourjot St. Hilaire Hist. Nat. Perr. pl. 22. Spix Av. Brasil. pl. 25. - Reichenow Vogelbilder t. XXII, f. 6.

Diagnose: Viridis; sincipite caeruleo; flexura et subalaribus coccineis; remigibus et rectricibus subtus flavescentibus; maxilla albida, mandibula nigricante; pedibus nigricantibus; iride crocea; facie nuda albicante.

Long. c. 330 , ala 180 , cauda 160 , culmen $30 \mathrm{Mm}$.

Vorkommen: Südliche Brasilianische Subregion (Brasilien).

18. Subspecies: Mahni. - Nördlicher Blaustirn-Arara.

Englisch: Hahn's Macaw. - Franz.: Petit Ara pavouane.

Psittecara Hahni (1856) Sou. Rev. Mag. p. 58. - Conurus cyanothrix (1867) Natt. Finsch Pap. I, p. 427.

Abbildung: Souancé Icon. Perr. pl. 6.

Diagnose: S. nobili simillima, sed minor et rostro toto nigricante.

Long. c. 285, ala 165, cauda 140, culmen $26 \mathrm{Mm}$.

Vorkommen: Nördliche Brasilianische Subregion (Guiana, Venezuela, Neu-Granada, Ecuador).

Genus: CONURUS. Eigentliche Keilschwanzsittiche.

Conurus (1820) Kuhl Consp. Psitt. p. 4 (Ohne bestimmten Typus). - Aratinga (1824) Spix Av. Brasil. (Typus: Aratinga Corolinae Augustae Spix). - Psittceare (1825) Vig. Zool. Journ.II, p. 388. - Guarouba (1831) Less. Traité d'Orn. p. 210 (Typus: Ps. gouarube Gm.). - Rhynchopsitta (1854) Bonap. Rev. Mag. Zool. p. 149 (Typus: M. pachyrhyncha Sws.). - Cyanoliseus ib. 
p. 150 (Typus: Ps. patagonus Vieill.). - Nandayus ibid. (Typus: Ps. melanocephalus Vieill.). - Heliopsitte ibid. (Typus: Psittacus goucuruba Gm.). - Eupsittule ibid. (Typus: S. Petzi Wagl.). Evopsitta ibid. p. 151 (Typus: Ps. euops Wagl.). - Ognorhynohus (1857) Bp. Compt. Rend. (Typus: C. icterotis Mass. et Sou.).

Charakter der Gattung: Enthält die typischen Formen der Familie. Die Zügelgegend ist immer befiedert, ein mehr oder weniger breiter Augenring nackt. Der Schwanz ist so lang als der Flügel oder kürzer, selten länger. Im Flügel ist zweite und dritte Schwinge am längsten, erste deutlich kürzer. Die Färbung ist vorherrschend grün; wenige Arten sind durch vorzugsweise gelbe Färbung ausgezeichnet. Die dreissig jetzt bekannten Arten und Unterarten verbreiten sich über den ungeheuren Landstrich von mehr als 90 Breitengraden. Der nördlichste Keilschwanzsittich, die nördlichste Papageienart überhaupt, ist der Carolina-Sittich, während Felsensittich und Smaragdsittich die äusserste Südgrenze bis zur Magelhansstrasse bewohnen. Mehrere Arten werden ferner in der südlich gemässigten Zone, nördlich des $400^{\circ}$ südl. Br. gefunden, die Mehrzahl aber gehört den Tropen an.

Schlüssel der Gattung.

Hauptfärbung olivengriun: patagonus (s. auch Byroni). Hauptfärbung gelb:

Nur die Schwingen grün: luteus.

Schwingen, grosse Deckfedern und Schwanz grün und blau variirend: solstitialis (s. auch pyrocephalus).

Hauptfärbung grün:

Kopf zum grössten Theile schwarz: armillaris.

Kopf ganz oder zum grössten Theile gelb:

Kropf und Brust hyacinthroth: pyrocephalus.

Kropf undBrust wie der übrige Unterkörper grün: carolinensis. Kropf olivenbräunlich, übriger Unterkörper gelbgrün, Bauchmitte hochgelb: pertinax.

Kopf zum grössten Theile grün, bräunlich oder bläulich: Ganzer Kopf einfarbig grün:

Unterflügeldecken roth: leucophthalmus.

Unterflügeldecken grün:

Kehle und Kropf grün: holochlorus.

Kehle und Kropf oder Kehle allein bräunlich:

Mitte des Bauches hochgelb: cactorum.

Mitte des Bauches bräunlich grün: nanus. 
Mitte des Bauches gelbgrïn, gelbe Federn um die Nasenlöcher: frontalis.

Ganzer Kopf einfarbig graubraun mit bläulichem Anflug: Weddelli.

Oberkopf bläulich, ohne rothe oder gelbe Kopfzeichnung: Kehle grün: acuticaudatus (s. auch haemorrhous). Kehle fahlbraun: aeruginosus.

Gelbe Zeichnung am Kopfe:

Stirn gelb oder rothgelb: aureus (s. auch Petzi).

Stirnbinde, Züigel und Ohrgegend gelb: icterotis.

Augengegend gelb: chrysophrys.

Gelber Strich unter dem Auge: ocularis.

Rothe Zeichnung am Kopfe:

Stirn und Kopfseiten roth: vubilarvatus.

Einzelne Federn am Kopfe roth, Unterflügeldecken roth: euops (s. auch Gundlachi).

Stirn roth, Kopfseiten grün:

F]ügelbug roth:

Grosse Unterflügeldecken schön gelb: pachyrhynchus.

Grosse Unterflïgeldecken grau, gelblich angeflogen: frontatus und Finschi.

Flügelbug grün:

Zuigel und Augenring roth: mitratus.

Zügel und Augenring grün: Wagleri.

19. Conurus pachyrhynchus. - Arara-Sittich.

Englisch: Thick-billed Macaw. - Franz.: Perruche Ara.

Mecrocercus pachyrhynchus (1827) Sws. Phil. Mag. p. 439. Psittacus strenuus (1830) Lcht. Preisverzeichniss der Vögel von Mexico.

Abbildung: Souancé Icon. Perr. pl. 5.

Diagnose: Viridis; sincipite et fascia superciliari, flexura et tibiis inferioribus carmineis; subalaribus majoribus flavis; rostro et pedibus nigricantibus.

Long. c. 440 , ala 280, cauda 180, culmen $42 \mathrm{Mm}$.

Vorkommen: Mexicanische Subregion (Mexico).

20. Conurus mitratus. - Rothmasken-Sittich.

Englisch: Red-masked Parrakeet. - Französisch: Perruche à masque rouge.

Conurus mitratus (1844) Tschudi F. Peru. p. 272. - Comurus hilaris (1860) Burm. Journ. f. Ornith. p. 243.

Abbildungen: Tschudi Fauna Peruana t. 26. - Souncé Icon. Perr. pl. 21.

Cab. Journ. f. Ornithol. XXIX. Jahrg. No, J55. Juli 1881. 
Diagnose; Viridis; sincipite, loris et periophthalmiis dilute coccineis, margine frontali brunnescente; nonnullis plumis capitis, colli, ventris, flexurae, marginis alarum, tibiarum et supracaudalium interdum coccineis; remigibus et rectricibus subtus flavescentibus; rostro albicante, pedibus fulvis; iride flava.

Long. c. 350 , ala 195 , cauda 180 , culmen $32 \mathrm{Mm}$.

Vorkommen: Nördl. Chilenische Subregion (Peru, Bolivien).

21. Conurus frontatus. - Peru-Sittich.

Englisch: Red-fronted Conure. - Französisch: Perruche pérouvienne.

Conurus frontatus (1844) Cab. Tschudi's F. Peru. p. 272. Conurus rubrifrons (1867) Natt. Finsch Pap. I, p. 462.

Abbildung: Reichenow Vogelbilder t. XXII, f. 7.

Diagnose: Olivaceo-viridis; vertice et sincipite, flexura, campterio, tibiis inferioribus et subalaribus coccineis; ventris plumis obsolete coccineo - imbutis; rostro flavo - albido; pedibus nigricantibus; iride fulva.

Long. c. 430, ala 225, cauda 230, culmen $33 \mathrm{Mm}$.

Vorkommen: Nördliche Chilenische Subregion (Peru).

22. Conurus Finschi. - Veragua-Sittich.

Englisch: Finsch's Conure. - Franz.: Perruche Finsch.

Conurus Finschi (1871) Salv. Ibis p. 91.

Abbildung: Ibis 1871 pl. 4 .

Diagnose: Viridis, subtus paullo dilutior; fronte et vertice antico, campterio et subalaribus exterioribus coccineis; macula tibiali rubra; rostro flavido; pedibus pallide corylinis.

Long. c. 300, ala 107, cauda $150 \mathrm{Mm}$.

(Obs. : C. frontato similis sed multo minor).

Vorkommen: Mexicanische Subregion (Veragua).

23. Conurus Wagteri. - Columbia-Sittich.

Englisch: Wagler's Conure. - Franz.: Perruche Wagler.

Conurus Wagleri (1845-1849) Gray Gen. Birds IV, pl. 102. Comurus erythrochlorus (1849) Hartl. Rev. Mag. Zool. p. 274. Psittacus gnatho Lchtst. (teste Gray) List Psitt. p. 31.

Abbildungen: Gray Gen. Birds Pt. IV. - Reichenow Vogelbilder t. XXII, f. 4 .

Diagnose: Viridis; pileo, interdum quoque fascia transversa jugulari, coccineis; remigibus et rectricibus subtus flavescentibus; rostro albicante; pedibus brunnescentibus; iride flava. 
Long. c. 310 , ala 180 , cauda 160 , culmen $27 \mathrm{Mm}$.

(Obs.: C. mitrato similis, sed loris et periophthalmiis virilibus, fronte ut sincipite toto dilute coccinco, et minor).

Vorkommen: Nordwestliche Brasilianische Subregion (Venezuela, Columbia).

24. Conurus rubrolarvatus. - Guayaquil-Sittich.

Englisch: Guayaquil Parraket. - Französisch: Perruche de Guayaquil.

Psittacara erythrogenys (1844) Less. Echo du Monde Savant p. 486. - Conurus rubrolaruetus (1854) Mass. et Souancé Rev. Mag. Zool. p. 71.

Abbildung: Souancé Icon. Perr. pl. 22.

Diagnose: Viridis; pileo, occipite, genis, regione parotica et mento, flexura et subalaribus coccineis (mento et flexura inter(um viridibus); remigilus et rectricibus flavescentibus; rostro et periophthalmiis nudis pallile flavis; iride lutea.

Long. c. 300, ala 165, cauda 130, culmen $27 \mathrm{Mm}$.

Vorkommen: Westl. Brasilianische Subregion (Equador).

25. Conums exops - Cuba-Sittich.

Englisch: Red-shonldered Parrakeet. - Franzïsisch: Perruche de Cuba.

Psittace aquarum lupiamm insulae (1760) Briss. Ornith. IV, 1) 330. - Psittacus grianensis (1785) Gm. S. N. 1). 323. Sittace euops (1832) Wagl. Mon. Psitt. p. 638. - Eiropsitte exops (1854) Bp. Rev. Mag. Zool. p. 151. - Conums guiunensis Ram. de Sagra (teste Gray List Psitt. p. 33).

Abbildungen: Wagl. 1. c. t. 25. - Sonancé Icon. Perr. pl. 7.

Diagnose: Viridis; margine alarum, subalaribus minoribus et minimis, plumis nounullis capitis, colli et tibiarum coccineis; remigibus et rectricibus subtus subalaribusque majoribus flavescentibus; rostro et perlibus flavescente albidis; perlibus carneis; iride lutea.

Long. c. 260, ala 135, canda 110, culmen $21 \mathrm{Mm}$.

Vorkommen: Antillische Subregion (Cuba).

+26. Subspecies: Gundlachi. - Mona-Sittich.

Engl.: Gundlach's Conure. -- Franz.: Perruche Gundlach.

Conurus Gundlachi (1881) Cab. Journ. f. Ornith. p. 107.

Diagnose: Praecedenti simillimus, sed major et subalaribus majoribus coccincis, nec grisesecnte olivaceo-flavis. 
Vorkommen: Antillische Subregion (Mona bei Portorico).

27. Conurus leucophthalmus. - Guiana-Sittich.

Engl.: Pavouane Parrot. -- Franz.: Perruche pavouane.

Psittace guianensis (1760) Briss. Ornithol. IV, p. 331. Psittacus leucophthalmus (1776) St. Müller Linné's Natursystem. Supplem. p. 75. - Psittucus rotatus ibid. 1. 76. - Psittacus panua (1783) Bodd. Tabl. Pl. Enl. p. 10. -- Psittacus guianensis (1788) Gm. S. N. p. 324. - Aratinga nobilis (1824) Spix Av. Brasil. p. 36. - Arara cayana (1831) Less. 'Traité d'Orn. p. 188. Conurus cayanensis (1849) Gray Gen. Birds App. p. 19. Psittacara chloroptera (1856) Souancé Rev. Mag. Zool. p. 59. Psittacara Maugei ibid. - Conumus propinquus (1862) Sclat. Cat. Coll. Am. B. p. 346.

Abbildung: Buffon Pl. Enl. pl. 167 und 407.

Diagnose; Viridis; flexura et campterio, subalaribus minoribus et minimis, interdum colli, capitis et tibiarum plumis nonnullis, coccineis (flexura et campterio interdum viridibus); subalaribus majoribus luteis; remigibus et rectricibus subtus flavescentibus; rostro dilute flevescente carneo; periophthalmiis nudis cinerascente carneis; iride crocea, pedibus fuscis.

Long. c. 340 , ala 170 , cauda 160 , culmen $27 \mathrm{Mm}$.

Vorkommen: Oestliche Brasilianische Subregion (Guiana, Brasilien).

28. Conurus holochlorus. - Guatemala-Sittich.

Engl: Mexican Conure. - Franz.: Perruche de Mexique.

Conurus holochlorus (1859) Sclat. Ann. Mag. N. H. p. 224. Comurus holochlorus var. brevipes (1871) Baird Lyc. N. Y. p. 14 (Socorro Island).

Diagnose: Totus viridis; remigibus et rectricibus subtus flavescentibus; pedibus et periophthalmiis nudis brunnescente carneis; rostro flavescente carneo; iride brunnea.

Long. c. 340, ala 170, cauda 150, culmen $27 \mathrm{Mm}$.

Vorkommen: Mexicanische Subregion (Mexico, Guatemala).

29. Conurus acuticaudatus. -- B lauw angen-Sittich.

Engl.: Blue-faced Conure. - Franz.: Perruche acuticaude.

Psittecus acuticaudatus (1823) Vieill. N. D. XXV, p. 369. Conurus cyanops (1859) Gray List Psitt. p. 33. - Conurus fugav (1860) Burm. Journ. f. Orn. p. 243. - Conurus glaucifrons (1873) Seybold Leopoldina Heft VIII, No. 7, p. 52. 
Abbildungen: Des Murs Icon. Ornith. pl. 31. - Souancé Icon. Perr. pl. 4.

Diagnose: Viridis; pileo genisque glaucis; remigibus, subalaribus majoribus et rectricibus subtus flavidis, his pogonio interno dilute rubris; maxilla flavescente albida, ejus apice et mandibula nigricante; pedibus flavescente - carneis; iride rubra; periophthalmiis nudis albis.

Long. c. 350 , ala 190 , cauda 190 , culmen $26 \mathrm{Mm}$.

Vorkommen: Südl. Brasil. Subregion (Paraguay, Bolivia).

30. Subspecies: haemorrhous. - Bla ustirnsittich.

Englisch: Blue-crowned Conure. - Französisch: Perruche à front bleu.

Aratinga haemorrhous (1824) Spix Av. Brasil. p. 29. Psiltacara coeruleo frontatus (1837-1838) Bourjot St. Hil. Hist. Nat. Perr. pl. 17. - Comurus modestus (1854) Lchst. Nomencl. p. 73 .

Abbildungen: Spix 1. c. t. 13. - Bourjot St. Hil. 1. c. Reichenow Vogelbilder t. II, f. 3.

Diagnose: C. acuticaudato simillimus, sed sincipite et vertice solis glaucis, genis viridibus, rostro toto flavescente albido.

Long. c. 400, ala 200, cauda 200, culmen $27 \mathrm{Mm}$.

Vorkommen: Südl. Brasilianische Subregion (Süd-Brasilien).

31. Conumes patagonus. - Felsensittich.

Englisch: Smaller Patagonian Conure. - Französisch: Perruche de la Patagonie.

Psittacus patagonus (1823) Vieill. N. D. XXV, p. 367. Psittacus patagonicus (1831) Voigt Cuv. Règne An. Uebers. p. 726.

Diagnose: Olivaceo-viridis, fronte, dorso, gutture et pectore brumnescentibus; uropygio, supra- et subcaudalibus, ventre et crisso olivascente sulfureis; ventris macula sordide coccinea; remigibus et tectricibus primariis superne glaucis; rostro nigricante; pedibus fulvis; iride albida.

Long. c. 420, ala 240, cauda 250, culmen $27 \mathrm{Mm}$.

Vorkommen: Oestliche Chilenische Subregion (Patagonien, La Plata).

32. Subspecies: Byroni. - Chilenischer Felsensittich.

Englisch: Larger Patagonian Conure. - Französisch: Perruche de Byron. 
Comuns cycnolyseos (1776) Molina Hist. Nat. Chil. p. 235. -Psittecus Byromi (1844) Childr. Gray's Zool. Misc. p. 12.

Abbildungen: Lear Parr. pl. 10. - Bourjot St. Hil. Hist. Nat. Perr. pl. 19. - Less. Voy. Coqu. pl. 35. -- Jard. et Selhy Vat. Lihr. VI, pl. 14. - Reichenow Vogelbilder t. II, f. 7.

I)iagnose: $\therefore$ patagono simillimus, sed major, fascia pectorali alba; ventre sulfureo, medio coccineo.

Long. c. 450, ala 275, cauda 230, culmen $37 \mathrm{Mm}$.

Vorkommen: Westliche Chilenische Subregion (Chile).

33. Conurus icterotis. - Gelbohr-Sittich.

Englisch: Yellow - eared Parrot. -- Franzisisch: Perruche aux oreilles jaunes.

Conurus icterntis (1854) Mass. et Souancé Rev. Mag. Zool. p. 71. - Conmus Heinei (186t) Cab. Journ. f. Ornith. p. 414. Abbildung: Souancé Icon. Perr. pl. 19.

Diagnose: Viridis, subtus flavescens; fascia frontali, loris et regione parotica flavis; cauda subtus sordide rubra; rostro nigro. Ala 225, cauda 210 (Teste Finsch).

Vorkommen: Nördl. Brasilianische Subregion (Neu-Granada). 34. Conurus luteus. - Goldsittich.

Engl.: Golden Conure. - Franz: Guarouba jaune.

Psittaca loresiliensis lutea (1760) Briss. Orn. IV, 1. 369. -Psittene meculutus (1776) Müll. Lin. Naturs. Suppl. p. 74. Psittacus luteus (1753) Bodl. Tabl. Pl. Enl. 1). 30. - Psittucus

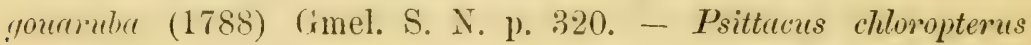
(1823) Vieill. Encycl. Méth. p. 1390. - Aratinga Carolinar Argustae (1824) Spix Av. Bras. t. 12.

Abbildurgen: Buffon Pl. Enl. pl. 525. -- Levaillant Hist. Nat. Perr. pl. 20. - Bourjot St. Hil. Mist. Nat. Perr. pl. 18. Spix Av. Bras. t. 12. - Reichenow Vogelbilder t. II, f. 4.

Diagnose: Luteus; remigibus viridibus, subtus flavescentibus; rostro flavescente albido; pedibus flavescente carneis; iride miniata.

Long. c. 390, ala 215, cauda 170, culmen $39 \mathrm{Mm}$.

Vorkommen: Brasilianische Subregion (Nördl. Brasilien).

35. Comurus solstitialis. - Sonnensittich.

Englisch: Yellow Conure. - Französisch: Perruche jaune.

Psittasa mexicance lutea (1760) Briss. Orn. IV, p. 370. -Psittuca angolensis lutea ibid. p. 371. - Psittacus solstitialis (1766) 
Lin. S. N. p. 141. - Psittacus merulinus (1769) Scop. Ann. I, p. 30. - Aratinga luteus sive guarouba (1824) Spix Av. Brasil. t. $14 \mathrm{a}$.

Abbildungen: Spix 1. c. - Reichenow Vogelbilder t. II, f. 6.

Diagnose: Croceus, capitis lateribus, pectore, ventre et dorso medio miniatis; remigibus et tectricibus primariis basi viridibus apice cyaneis, macula apicali lutea; tectricibus secundariis majoribus viridibus, apice luteis; rectricibus olivaceo-viridibus, apica cyaneis; rostro brunnescente, apice obscuriore; iride crocea; pedibus brunnescentibus.

Long. c. 320, ala 160, cauda 160. culmen $24 \mathrm{Mm}$.

Vorkommen: Nördliche Brasilianische Subregion (Guiana, Amazonenstrom).

36. Conums pyrocephalus. - Jendaya-Sittich.

Hyazinth - Sittich. - Englisch: Yellow - headed Conure. Französisch: Perruche à tête d'or.

Psittacula brasiliensis lutea (1760) Briss. Orn. IV, p. 390. Psittacus jendaya (1788) Gm. S. N. p. 319. -- Psittacus pyrocephalus (1822) Hahn Lief. XIV, f. 1. - Psittacus auricapillus (1823) Lchst. Dubl. Verz. p. 6. - Aratinga chrysocephalus (1824) Spix Av. Brasil. t. 14. - Aratinga aurifrons ibid. t. 16.

Abbildungen: Spix Av. Brasil. t. 14 und 16. -- Bourj. St. Hil. Hist. Nat. Perr. pl. 42 et 42 b. - Reichenow Vogelbilder taf. II, fig. 5 .

Diagnose: Dorso, alarum tectricibus et subcaudalibus viridibus, tergi plumis rubro-limbatis; capite et collo luteis; periophthalmiis, abdomine et subalaribus hyacinthino-rubris; tibiarum plumis viridibus, hyacinthino-limbatis; remigibus pogonio interno nigris, pogonii externi basi viridibus, apice cyaneis; rectricibus basi olivaceo-viridibus, apice cyancis; rostro nigro; pedibus nigricantibus.

Long. c. 320, ala 165, cauda 160, culmen $23 \mathrm{Mm}$.

Vorkommen: Südliche Brasilianische Subregion (Südliches Brasilien).

37. Conurus carolinensis. - Carolinasittich.

Engl.: Carolina Conure. - Franz.: Perruche à tête jaune.

Psittacus carolinensis (1766) Lin. S. N. I, p. 141. - Psittacus ludovicianus (1788) Gm. S. N. p. 347. - Psittacus Thalassimus 
(1823) Vieill. Encycl. Méth. p. 1377. - Psittacus luteocapillus ibid. p. 1402.

Abbildungen: Buffon Pl. Enl. pl. 499. - Levaillant Hist. Nat. Perr. pl. 33. - Audub. B. Amer. IV, pl. 278. - Reichenow Vogelbilder t. II, f. 8.

Diagnose: Viridis; sincipite, loris et periophthalmiis miniatis; pileo, occipite et capitis lateribus flavis; flexura et margine alari croceis; rostro albicante; pedibus flavescente carneis; iride brunnea; annulo orbitali nudo albido.

Long. c. 370, ala 190, cauda 180, culmen $27 \mathrm{Mm}$.

Vorkommen: Alleghanische Subregion.

38. Comurus melanocephalus. - Nanday-Sittich.

Engl.: Black-headed Conure. - Franz.: Perruche Nanday, Psittacus muday [!] ( ) Desmar. Dict. Sc. N. 39, p. 124). Psittacus melanocephalus (1854) Vieill. Bp. Rev. Mag. Zool. p. 150. Psittucus armillaris (1854) Lehtst. Nomencl. p. 73.

Abbildungen: Bourjot St. Hil. Hist. Nat. Perr. pl. 20. Reichenow Vogelbilder t. XXII, f. 5.

Diagnose: Viridis; pileo, loris genisque nigro-fuscis; gutture caesio; subcaudalibus coerulescentibus; tibiis coccineis ; remigibus et tectricibus primariis cyaneis, pogonio interno nigris, remigibus primariis extus viridi-limbatis; rectricibus basi olivaceo-viridibus, apice cyaneis; remigibus, subalaribus majoribus et rectricibus subtus nigris; rostro nigricante, pedibus dilute roseis; iride rubra; annulo orbitali nudo nigricante.

Long. c. 380, ala 190, cauda 200, culmen $27 \mathrm{Mm}$.

Vorkommen: Südl. Brasil. Subregion (Paraguay, Bolivien).

39. Conurus nanus. - Ja maica-Sittich.

Engl.: Dwarf Parrakeet. - Franz.: Perruche de Jamaique.

Psittacara nana (1830) Vig. Zool. Journ. p. 273. - Conurus flaviventer (1847) Gosse B. Jamaica p. 263.

Abbildungen: Lear Parr. pl. 12. - Bourjot St. Hil. Hist. Nat. Perr. pl. 24. - Souancé Icon. P. pl. 12.

Diagnose: Viridis; gutture, pectore et ventre medio olivaceobrumneis, hoc fulvescente; remigibus pogonio interno nigris, pogonio externo vel parte medio scapali cyaneis; remigibus subtus et subalaribus nigris; rectriçibus subtus flavescentibus; rostro albicante; pedibus fuscis; iride crocea. 
Long. c. 260, ala 130, cauda 120, culmen $21 \mathrm{Mm}$.

Vorkommen: Antillische Subregion (Jamaica).

40. Subspecies: frontalis. - Goldnase.

Conurus aztec (1857) Souancé Rev. Mag. Zool. p. 97. Conurus frontalis (1867) Natt. Finsch Pap. I, p. 522.

Abbildung: Souancé Icon. Perr. pl. 12, f. 2.

Diagnose: Viridis, gutture brunnescente, abdomine flavescente; remigibus pogonio interno nigris, externo apice caerulescentibus; remigibus subtus et subalaribus majoribus nigris; rectricibus subtus flavescentibus; plumulis narium aurantiis; rostro fusco; pedibus nigricantibus; iride flava.

Long. c. 230, ala 135, cauda 100, culmen $20 \mathrm{Mm}$.

Vorkommen: Mexicanische Subregion.

41. Subspecies: cactorum. - Kaktus-Sittich.

Englisch: Cactus Conure. - Französisch: Perruche à ventre orange.

Psittacus cactomem (1820) Wied Reise Bras. II, p. 168. Aratinga flaviventer (1824) Spix Av. Bras. p. 33. - Aratinga cairana ibid. p. 34. - Psittacus lepidus (1834) Hahn Orn. Atl. Pap. p. 50.

Abbildungen: Spix Av. Bras. t. 18 und 19. - Souancé Icon. Perr. pl. 10. - Reichenow Vogelbilder t. XVII, f. 3.

Diagnose: Viridis; fronte olivaceo-brunnescente; gutture fulvo, abdomine croceo; rostro albicante; pedibus brunnescentibus; annulo orbitali cinereo; iride crocea.

Long. c. 270, ala 140, cauda 140, culmen $23 \mathrm{Mm}$.

Vorkommen: Brasilianische Subregion (Brasilien).

42. Conurus Weddelli. - Braunkopf-Sittich.

Engl.: Werldell's Conure. - Franz.: Perruche Weddell.

Conurus Weddellii (1851) Deville Rev. Mag. Zool. p. 209. Conumes poliocepluelus (1867) Natt. Finsch Pap. I, p. 498.

Abbildung: Souancé Icon. Perr. pl. 13.

Diagnose: Viridis, dorso olivascente, ventre flavescente; capite toto brumnescente caesio; remigibus et tectricibus primariis cyaneis, pogonio interno nigris; remigibus primariis extus viridilimbatis, rectricibus basi olivascente viridibus, apice cyaneis; remigibus, subalaribus majoribus et rectricibus subtus nigris; rostro et pedibus nigris; periophthalmiis nudis canis.

Long. c. 250 , ala 140 , cauda 125 , culmen $20 \mathrm{Mm}$. 
Vorkommen: Südliche Brasilianische Subregion (Inneres Brasilien, Ost-Peru, Bolivien).

43. Conurus aeruginosus. - Braunangen-Sittich.

Englisch: Brown-throated Conure. - Französisch: Perruche à joues brunes.

Psittaca martinica (1760) Briss. Ornithol. IV, p. 356. Psittacus aeruginosus (1766) Lin. S. N. p. 142. - Psittacus plumbeus (1788) Gm. S. N. p. 326. - Psittacus inornatus (1820) Temm. Kuhl Consp. Psitt. p. 92 (?).

Abbildung: Reichenow Vogelbilder t. XVII, f. 5.

Diagnose: Viridis; pileo caerulescente; capitis lateribus et gutture olivascente fulvis; remigibus et rectricibus apice glaucis; rostro et pedibus griseis; iride flava; periophthalmiis nudis canis.

Long. c. 250, ala 135, cauda 120, culmen $20 \mathrm{Mm}$.

Vorkommen: Nördliche Brasilianische Subregion (Guiana, Venezuela).

44. Subspecies: chrysophrys. - Goldmasken-Sittich.

Englisch: Yellow-cheeked Conure. - Französisch: Perruche à front jaune.

Conurus chrysophrys (1838) Sws. Anim. Menag. Two Cents etc. p. 320. - Conurus chrysogenys (1854) Mass. et Souancé Rev. Mag. Zool. p. 72.

Abbildungen: Levaillant Hist. Nat. Perr. pl. 35. - Souancé Icon. Perr. pl. 11. - Reichenow Vogelbilder t. XVII, f. 4.

Diagnose: Praecedenti simillimus, sed fascia frontali, loris, periophthalmiis ventreque aurantiis (interdum genis quoque aurantio-imbutis).

Vorkommen: Nördliche Brasilianische Subregion (Guiana).

[Diese Form dürfte sich als Alterskleid der vorgenannten herausstellen.]

45. Subspecies: ocularis. -- A ugenband-Sittich.

Conurus ocularis (1864) Sclater et Salvin Pr. Z. S. p. 367.

Abbildung: Reichenow Vogelbilder t. XVII, f. 1.

liagnose: C. aeruginoso simillimus, sed stria suboculari aurantiaca.

Vorkommen: Mexicanische Subregion.

46. Conurus pertinax. - St. Thomas Sittich.

Englisch: St. Thomas Conure.-- Französisch: Perruche à joues oranges. 
Psittace illiniaca (1760) Briss. Ornithol. IV, p. 253. Psittacus pertinax (1766) Lin. S. N. p. 142. - Comurus xanthogenius (1850) Bp. Consp. I, p. 1. - Conurus xantholaemus (1859) Sclater Ann. Mag. N. H. IV, p. 225.

Abbildungen: Buff. Pl. Enl. pl. 528. -- Levaillant H. N. P. pl. 34 et 36. - Reichenow Vogelbilder t. XVII, f. 8.

Diagnose: Viridis; fronte, capitis lateribus gulaque aurantiis; pileo caerulescente; gutture olivaceo - fulvo; rostro, pedibus et iride $C$. aeruginoso simillimis.

Long. c. 260, ala 135, cauda 120, culmen $22 \mathrm{Mm}$.

Vorkommen: Antillische Subregion (St. Thomas).

47. Conurus aureus. - Goldstirnsittich.

Englisch: Golden-crowned Conure. - Franzossisch: Perruche couronnée.

Psittacus brasiliensis (1760) Briss. Orn. IV, p. 337. - Psittucus aureus (1788) Gm. S. N. 1. 329. - Psittacus brasiliensis (1790) Lath. Ind. Orn. p. 103. - Psittacus regulus (1812) Shaw Gen. Zool. VIII, p. 453.

Abbildungen: Buffon Pl. Enl. pl. 838. - Levaillant Hist. Nat. Perr. pl. 41. - Reichenow Vogelbilder t. II, f. 2.

Diagnose: Viridis; sincipite croceo; vertice et loris caesiis; periophthalmiis aurantis; regione parotica dilute caesia; gutture pallide olivascente fulvo; abdomine et subalaribus viridi-flavis; remigibus pogonio interno flavescentibus, primariis apice caerulescentibus, secundariis pogonio externo cyaneis; tectricibus primariis caerulescentibus; remigibus et rectricibus subtus et subalaribus flavescentibus; annulo orbitali nudo cinereo; rostro et pedibus nigricantibus; iride crocea.

Long. c. 320, ala 142, cauda 140, culmen $20 \mathrm{Mm}$.

Vorkommen: Brasilianische Subregion.

48. Subspecies: Petzi. - Elfenbein-Sittich.

Engl.: Petz's Conure. - Franz.: Perruche à front rouge.

Psittacus canicularis (1766) Lin. S. N. p. 142. - Sittace Petzii (1832) Wagl. Mon. Psitt. p. 650. - Psittacus eburnirostrum (1842) Less. Rev. Zool. p. 210.

Abbildungen: Buffon PI. Enl. pl. 767. - Souancé Icon. Perr. pl. 9. - Levaillant Hist. Nat. Perr. pl. 40. - Reichenow Vogelbilder t. XVII, f. 2. 
Diagnose: Viridis; sincipite miniato; vertice caesio; capitis lateribus et gula sordide olivascentibus; pectore, abdomine et subalaribus viridi-flavis; remigibus nigris, pogonio externo cyaneis; rectricibus subtus flavescentibus; subalaribus majoribus nigris; maxilla pallide carnea, mandibula grisea; pedibus griseis; annulo orbitali nudo albo; iride flava.

Long. c. 240, ala 130, cauda 105, culmen $18 \mathrm{Mm}$.

Vorkommen: Mexicanische Subregion.

Genus: HENICOGNATHUS. Langschnabelsittiche.

Leptorhynchus (1837) Sws. Classif. Birds II, p. 300. - Enicognathus (1840) Gray Gen. Birds p. 51. - Stylorlyynchus (1842) Less. Echo du Monde savant p. 211. - Henicognathus (1848) Agassiz Nomencl. p. 512.

Charakter der Gattung: Durch einen gestreckten Schnabel, welcher bedeutend länger als hoch ist, von allen Keilschwanzsittichen leicht $\mathrm{zu}$ unterscheiden. Die Wachshaut ist vollständig befiedert. Durch die rothbraune Färbung des Schwanzes und andere Farbencharaktere an die folgende Gattung sich anschliessend.

Die Gattung wird nur durch eine, der Chilenischen Subregion angehörende Form repräsentirt. Die Art nimmt unter den Keilschwanzsittichen Amerikas in gewissem Sinne die Stellung ein, welche der Nasenkakadu unter den australischen Kakadus vertritt. Wie diesem, leistet ihm der lange Schnabel vorzügliche Dienste beim Ausgraben von Knollen, sowie keimerder Mais- und Getreidekörner; auch bildet derselbe ein geeignetes Werkzeug, um die Kerne der Früchte auszubohren. Der Langschnabelsittich lebt gesellig in den Chilenischen Waldungen und wandert zur Winterszeit nordwärts.

49. Henicognathus leptorhynchus. - Langschnabelsittich.

Englisch: Slight-billed Parrakeet. - Französisch: Perruche it long bec.

Psittacara leptorhyncha (1830) King Pros. Zool. S. p. 14. Psittacara rectirostris (1834) Meyen Verh. Leop. Carol. Ac. Suppl. I des 16. Bd. p. 95. - Leptorhynchus ruficaudus (1837) Sws. Classif. B. II, p. 300. - Conurus erythrofrons Gray Gen. B. II, No. 35 .

Abbildungen: Lear Parr. pl. 11. - Bourj. St. Hil. H. N. P. pl. 21. - Meyen 1. c. t. 15. - Reichenow Vogelb. t. XXII, f. 8. 
Diagnose: Viridis, pilei plumis nigro-limbatis; fronte et loris sordide rubris; rectricibus cupreo-rufis; ventris macula obsolete rufa; remigibus et tectricibus majoribus caesio-imbutis; rostro et pedibus plumbeis; iride aurantiaca.

Long. c. 410 , ala 210 , cauda 205 , culmen $32 \mathrm{Mm}$.

Vorkommen: Westliche Chilenische Subregion (Chile).

Genus: PYRRHURA. Roth s chwanzsit iche.

Microsittace (1854) Bonap. Rev. Mag. Zool. p. 150 (Typus: Psittucus smaragdinus Gm. - Pyrrhura (1856) Bp. Naumannia Beilage (Typus: Psittacus vittatus Shaw):

Charakter der Gattung: Im allgemeinen mit den eigentlichen Keilschwanzsittichen übercinstimmend, aber ausgezeichnet durch rothbraune Färbung des Schwanzes, welche bei einigen Arten in Schwarz übergeht. Der Schwanz hat die Länge des Flügels oder ist kürzer als dieser. Wir kennen gegenwärtig neunzehn Arten, grösstentheils kleine Vögel. Die Mehrzahl gehört den Tropen und zwar der Brasilianischen Subregion an, eine Form ist aus Mexico bekannt, zwei aus der Chilenischen Subregion.

\section{Schlüssel der Gattung.}

Handdecken zinnoberroth:

Schwanz oberseits dunkel rothbraun: Souancét.

Schwanz oberseits grün: rupicola.

Handdecken zinnoberroth mit gelber Spitze, Schwanz schwarz: melanura.

Handdecken rein gelb, Ohrgegend grün: calliptera.

Handdecken gelb mit grüner Spitze, rother Ohrfleck: Hoffmanni. -Handdecken grün oder blau:

Dunkelrother Ohrfleck, Schwanz ober'seits dunkelroth: haematotis. Rothbrauner Ohrfleck, Schwanz oberseits olivengrün: cruentata. Rostbrauner Ohrfleck:

Flügelrand und Unterfïgeldecken scharlachroth: Devillii.

Flïgelrand und Unterfliigeldecken hochgelb: egregia.

Isabellgelber Ohrfleck, Vorderkopf scharlachroth: roseifrons.

Weisser Ohrfleck, Wangen rothbraun: leucotis.

Fahlbrauner Ohrfleck:

Wangen rothbraun: picta (s. auch Luciani).

Wangen graublau: lepida.

Wangen grün:

Oberkopf dunkelbraun: Molinae.

Oberkopf grün, braunrothe Stirnbinde: vittata. 
Ohrgegend grün oder bläulich:

Braumrothe Stirnbinde, Oberkopf grün: smaragdimu.

Braunrothe Stirnbinde, Unterkörper scharlachroth: $v$ hodogaster.

Ganzer Oberkopf rosenroth: rhodocephala.

50. Pyrrhura smaragdina. - Smaragdsittich.

Englisch: Chilian Conure. - Franz.: Perruche Eméraule.

Psittacus fermineus (1776) S. Müll. L. N. S. Suppl. p. 75. Psittacus smaragdinus (1788) Gmel. S. N. p. 322. - Conums pyrhurus (185̃3) Rchb. v. Bibra Denkschr. Ac. Wiss. Wien V, p. 130. - Conurus phoenicurus (1854) Lchst. Nomencl. p. 73.

Abbildungen: Buffon Pl. Enl. pl. 85. - Levaillant Hist. N. Perr. pl. 21. - Reichenow Vogelbilder t. XXII, f. 3.

Diagnose: Viridis, subtus olivascens, plumis singulis nigrolimbatis; fronte, loris, ventre medio et cauda cupreo-rufis; remigibus pogonio interno nigris, flavescente iimbatis, subtus et subalaribus majoribus nigricantibus; rostro et pedibus nigricantibus; iride flava.

Long. c. 350, ala 195, cauda 170, culmen $21 \mathrm{Mm}$.

Vorkommen: Westliche Chilenische Subregion (Chile).

51. Pyrrhura vittata. - Braunohr-Sittich.

Englisch: Red-bellied Conure. - Französisch: Perruche à bandean.

Psittacus vittatus (1812) Shaw Gen. Zool. VIII, p. 404. Psittacus frontalis (1823) Vieill. N. D. XXV, p. 361. - Psittacus undulatus (1823) Ill. Lchtst. Dubl. Verz. p. 7. - Aratinga fasciata (1824) Spix Av. Brasil. p. 35.

Abbildungen: Levaillant Hist. Nat. Perr. pl. 17. - Spix Av. Bras. t. 21. - Reichenow Vogelbilder t. XXII, f. 2.

Diagnose: Viridis; fascia frontali rubro-fusca; gutture et colli lateribus olivascente fulvis, brunneo-fasciatis; regione parotica gilve brunnea, ventre medio et rectricibus subtus cupreorufis; tergi plumis rufescente imbutis; rectricibus superne olivaceoviridibus; apice rufescentibus; remigibus primariis pogonio externo eorumque tectricibus çaerulescentibus; rostro fusco, apice pallida; pedibus nigricantibus; iride brumea.

Long. c. 290, ala 138, cauda 140, culmen $18 \mathrm{Mm}$.

Vorkommen: Südl. Brasilianische Subregion (Süd-Brasilien).

52. Pyrrhura Devillii. - Bolivianischer Rothschwanz-Sittich. Englisch: Deville's Conure. - Franz.: Perruche Deville. 
Conurus Devillei (1854) Mass. et Sou. Rev. Mag. Zool. p. 73. Abbildung: Souancé Icon. Perr. pl. 16.

Diagnose: Viridis; gutture et pectore olivaceo-brunneis; plumis pallide limbatis et tenuissime nigro-terminatis; regione parotica rufa; subalaribus, campterio, pteryllio et flexura coccineis; macula ventrali parva rubra; remigibus primariis eorumque tectricibus pogonio externo cyaneis; cauda superne olivaceo-flava, subtus cupreo-rufa; rostro ct pedibus nigricantibus (teste Finsch).

Vorkommen: Westliche Brasilianische Subregion (Bolivien).

53. Pyrrhura egregia. - Demerara-Sittich.

Conurus egregius (1881) P. L. Sclater Ibis p. 130.

Abbildung: 1. c. pl. IV.

Diagnose: $P$. Devillii similis, sed cauda nigro - rufa, subalaribus partim flavis. Viridis; fronte brunnescente-nigra; regione parotica et macula gulae cupreo-rufis; colli laterum et pectoris plumis albicante flavido marginatis; pteryllio flavo, rubro tincto; campterio coccineo; subalaribus flavis, aurantiomixtis; caula nigro-rufa; tibiis rubris; rostro albicante-corneo; pedibus fuscis (teste Sclater).

Long. c. 250, ala 130, cauda $125 \mathrm{Mm}$.

Vorkommen: Nördl. Brasilianische Subregion (Demerara).

54. Pyrrhura cruentata. -- Blaulatzsittich.

Engl.: Red-eared Conure. - Franz.: Perruche Tiriba.

Psittacus cruentatus (1820) Wied Reise Brasil. I, p. 53. Psittacus squamosus (1820) Kuhl Consp. Psitt. p. 20. - Psittacus erythrogaster (1823) Lchtst. Dubl. Verz. p. 7. -- Aratinga cyanogularis (1824) Spix Av. Bras. p. 33. - Psittacara tiviba (1831) Less. Traité d'Ornith. p. 213.

Abbildungen: Spix 1. c. pl. 17. - Temm. Pl. Col. pl. 388. Bourjot St. Hilaire Hist. Nat. Perr. pl. 25. - Reichenow Vogelbilder t. XXII, f. 1.

Diagnose: Viridis; pileo nuchaque nigro-fuscis; loris, periophthalmiis et regione parotica rufis; macula colli utrinque ochracea; gutture et fascia auchenii caeruleis; ventre merlio rubro; tergi plumis rufo-limbatis; rectricibus superne olivaceoflavis, subtus cupreo-rufis; alarum margine cubitali coccinea; lemigum primariorum eorumque tectricum pogoniis externis cyaneis; rostro brunneo; iride crocea. 
Long. c. 280, alá 145, cauda 135, culmen $20 \mathrm{Mm}$. Vorkommen: Brasilianische Subregion (Brasilien).

\section{Pymhura Hoffmanni. - Gelbgrïner Sittich.}

Engl.: Hoffmann's Conure. - Franz.: Perruche Hoffmann.

Conurus Hoffmanni (1861) Cab. Sitzungsb. Ges. Naturf. Fr. 13. Nov., Journ. f. Ornith. p. 335.

Abbildung: Sclater and Salvin Exotic Ornith. pl. 81.

Diagnose: Viridis; capitis et gutturis plumis, interdum etiam alarum et dorsi plumis, flavo-limbatis; regione parotica rubra; rectricibus superne sordide olivaceo-flavis, subtus sordide cupreorufis; remigibus secundariis et tectricibus primariis flavis, apice viridibus, interdum etiam remigibus primariis basi flavis; rostro pallido; pedibus griseis; annulo orbitali nudo sordide carneo.

Long. c. 270, ala 140, cauda 120, culmen $20 \mathrm{Mm}$.

Vorkommen: Mexicanische Subregion (Veragua, Costarica).

56. Pyrrhura calliptera. - Prachtflügel-Sittich.

Englisch: Golden-winged Conure. - Französisch: Perruche calliptère.

Conurus callipterus (1854) Mass. et Souancé Rev. Mag. Zool. p. 72. - Microsittace flaveola (1867) Verr. Finsch I, p. 554.

Abbildung: Souancé Içon. Perr. pl. XVII.

Diagnose: Viridis; sincipite caerulescente; vertice, occipite, colli lateribus et gutture brunneis, inconspicue transversim fasciolatis; regione parotica et ventre medio obscure cupreo-rufis; tectricibus primariis et pteryllio croceis; flexura coccinea; remigibus primariis pogonio externo caerulescentibus; rectricibus superne et subtus intense rufis; rostro pallido; pedibus brunnescentibus.

Long. c. 240, ala 140, cauda 120, culmen $20 \mathrm{Mm}$.

Vorkommen: Nordwestl. Brasilian. Subregion (Columbien).

57. Pyrrhura Souancéi. - Blutflügel-Sittich.

Engl.: Souancé's Conure. - Franz.: Perruche Souancé.

Microsittace Souancei (1858) Verr. Rev. Mag. Zool. p. 437. Abbildung: Rev. Mag. Zool. pl. 12.

Diagnose: Viridis; pileo fuscescente; mento, gula et colli lateribus brumeis, gilve transversim fasciolatis; pteryllio et 
tectricibus primaris coccineis: rectricibus superne obserre rufis, basi nigricantibus, viridi-limbatis, subtus nigris.

Long. c. 240, ala 130, cauda 120, culmen $18 \mathrm{Mm}$.

Vorkommen: Brasilianische Subregion (Nördliches Brasilien).

58. Pyrrhura rupicola. - Stein-Sittich.

Englisch: Rock Parrakeet.

Conurus rupicolus (1844) T'schudi Fauna Peruana p. 272.

Abbildung: 1. c. t. 26.

Diagnose: Obscure viridis; pileo fusco; gutture et colli latteribus brumneis, pallide fasciolatis; ventre medio rubescente; pteryllio et tectricibus primariis coccincis; cauda superne viridi, subtus nigra; rostro plumbeo; pedibus fuscis; iride flava.

Vorkommen: Nördliche Chilenische Subregion (Peru).

59. Pyrmere melemure. - Schwarzschwanz-Sittich.

Englisch: Black-tailed Conure. - Französisch: Perruche à quene noire.

Aratinga melenure (1824) Spix Av. Bras. 1. 36. - Psitteceree veriegete $(1837-1838)$ Bourjot St. Hilaire Hist. Nat. Perr. pl. 26.

Abbildungen: Spix 1. c. t. 22. - Bourjot 1. c.

Diagnose: Viridis; colli laterum, gutturis et pectoris plumis brunneo-limbatis; cauda nigral, superne rubescente; remigum primariorum tectricibus cimabarinis, apice Havis; fuscia augusta frontali rufescente rubra.

Ala 125, cauda $115 \mathrm{Mm}$.

Vorkommen: Nördliche Brasilianische Subregion (Guiana, Nor(l-Brasilien).

60. Pyroure fretu. - Blanstirniger Rothsehwanzsittich.

Englisch: Bluewinged Conure. - Französisch: Perruche à gorge variée.

Psittente bresiliensis fusce (1760) Briss. Orn. IV, p. 403. Psittacus pictus (1776) S. Müll. L. N. S. Suppl. 1). 75. P'sittacus ayaropterus (1783) Bodd. 'T'abl. Pl. Enl. 1. 9.-Psittacus e'ersicolor (1788) Gm. S. N. 1. 327. -- Psittecus A duecer (1788) Gm. S. N. p. 349. - Aratinga guiunensis (1852) Brehın Mon. Pap. t. 28.

Cab. Journ. f. Ornithol. XXIX. Jahrg. No, 156. October 1881. 
Abbildungen: Buffon Pl. Enl. pl. 144. - Levaillant Hist. Nat. Perr. pl. 16.

Diagnose: Viridis; pileo et nucha fuscis; fronte, loris, fascia auchenii et genis inferioribus glaucis; genis superioribus obscure cerasinis; flexura coccinea; regione parotical gilve brunnea: grutturis et colli laterum plumis fuscis, pallide limbatis; ventre medio, tergo et uropygio, supracaudalibus et rectricibus cerasinis. his basi viridi - limbatis; remigibus primariis pogonio externo corumque tectricibus cacruleis; rostro brumneo.

Long. c. 230, ala 120, cauda 130, culmen $17 \mathrm{Mm}$.

Vorkommen: Nördliche Brasilianische Subregion (Guiana, unterer Amazonenstrom).

61. Subspecies: Luciuni. - Grïnschulter-Sittich.

Engl.: Prince Lucien's Conure. - Franz: Perruche Lucien.

Comme Luciuni (1851) Deville Rev. Mag. Zool. 1) 210. Comurus phaiogenys (1867) Natt. Fiusch Pap. I, p. 542.

Abbildungen: Souancé Icon. Perr. pl. 14. - Reichenow Vogelbilder t. XXVIII, f. 6.

Diagnose: Pracedenti simillimus, sed flexurat viridi; yenis totis intense cerasinis; fascia auchenii glauca nulla.

Vorkonmen: Brasilianische Subregion (Oberer Amazonen strolli).

62. Pyrrhurce leucotis. - Weissohr-Sittich.

Englisch: White-eared Conure. - Französisch: Perruche aux oreilles blanches.

Psittceus squamosus (1790) Lath. Ind. Orn. p. 101 (?). I'sittucus lencotis (1820) I.chtst. Kuhl Cons1. Psitt. 1. 21. - Aratinga ninus (1824) Spix Av. Bras. p. 34.

Abbildungen: Spix Av. Bras. t. 19. - Bourjot St. Hilaire Hist. Nat. Perr. pl. 28. - Reichenow Vogelbilder t. XXVIII. f. s.

Diagnose: Viridis; pileo fuscescente cano: nucha glanca; genis cerasinis; regione parotica alba; gutturis plumis canis, albido-limbatis; ventre medio rubro: Hexura coccinea; uropygio et rectricibus cerasinis, his basi viridi-limbatis; remigibus primariis pogonio externo eorumque tectricibus caeruleis; rostro nigro; pedibus carneis; iride crocea.

Long. c. 220, ala 113, cauda 120, culmen $15 \mathrm{Mm}$.

Vorkommen: Brasilianische Subregion (Brasilien). 
63. Pymluma Molinue. - Grünwangiger Rothschwanzsittich. Engl.: Molina's Conure. - Franz: Perruche Molina.

Herosittace Molinae (1854) Mass. et Souance Rev. Mag. Zool. p. 73. - Conumes phoenicurus (1864) Natt. Schleg. Mus. P. B. Psitt. p. 26.

Abbildung: Souncé Icon. Perr. pl. 15.

Diagnose: Viridis; pileo nuchaque fuscis, hujus plumis coerulescente limbatis; genis viridibus; regione parotica gilve brumnea; gutture et pectore gilve brunneis, pallide - fasciolatis: subcaudalibus glaucis; ventre medio sordide rubro; rectricibus obscure cupreo-rufis, basi viridi-limbatis; remigibus primariis pogronio externo, eorumque tectricibus caeruleis; rostro et pedibus brunneis. Long. c. 230, ala 120, cauda $130 \mathrm{Mm}$.

Vorkommen: Brasil. Subregion (Brasilien, Ost-Bolivien).

64. Pyrmura hatmatotis. - Blutohr-Sittich.

Englisch: Blood-eared Conure. - Französisch: Perruche aux oreilles rouges.

Pyrmhera hremetotis (1857) Sonancé Rev. Mag. Zool. 1. 97. Abbildung: Souancé Icon. Perr. pl. XVIII.

Diagnose: Obscure viridis; pileo fusco; nucha et subcaudalibus glaucis; regione parotica sanguinea; colli lateribus brunnescentibus, gilve - fasciolatis; ventre medio rubescente; rectricibus obscure sanguineis, mediis basi viridi-limbatis; remigibus primariis eorumque tectricibus pogonio externo cyaneis; rostro et pedibus griseis.

Ala 120, cauda $110 \mathrm{Mm}$.

Vorkommen: Nördl. Brasilianische Subregion (Venezucla).

65. Pyrrhura lepida. - Blawwangen-Sittich.

Englisch: Brisk Parrakeet. - Französisch: Perruche perlée.

Aratinga perlatus (1824) Spix Av. Bras. p. 35. - Sittace lepiele (1832) Wagl. Mon. Psitt. 1. 642. - Sittuce chlorogenys ibid. p. 643. - Aratinga pseudoperlatus (1852) Brehin Mon. Pap. Heft 5 .

Abbildungen: Spix Av. Bras. t. 20. - Bourjot St. Hilaire Hist. Nat. Perr. pl. 27.

Diagnose: Viridis; margine frontali, genis, fascia anchenii, pectore medio, hypochondriis, crisso, supra- et subcaudalibus caeruleis; pileo nuchaque nigro-fuscis, hac gilve transversim fasciolata; regione parotica gilvo-brumnea; gutture pallide fulvo, 
brumnescente albido-vario; ventris medii plumis basi rufis; margine alari et subalaribus coccineis; rectricibus superne obscure rufis, subtus nigricantibus; remigibus primaris pogonio externo eorumque tectricibus cyaneis.

Long. c. 250, ala 130, cauda 140 , culmen $18 \mathrm{Mm}$.

Vorkommen: Brasilianische Subregion (Nör(ll. Brasilien).

66. Pyrrhura rodogastra. - Rothbauch-Sittich.

Englisch: Red-bellied Comme. - Französisch: Perruche à ventre rouge.

Conurus rhodogaster (1864) Sclat. Proc. Z. S. 1. 298.

Abbildung: Proc. Zool. Soc. 1864, pl. 24.

Diagnose: Viridis; fronte, regione parotica, anchenio, femoribus et subcaudali? us glaucis; fascia frontali obscure rubro-fusca; pileo, nucha, gutture et colli laterihus gilve olivascente brumneis, pallide fasciolatis; pectore et ventre coccineis; rectricibus superne obscure cupreo-rufis, basi virili - limbatis, subtus nigricantibus; remigibus primariis eorumque tectricibus pogonio externo cyaneis: rostro et pedibus fuscis.

Long. c. 200, ala 125, cauda $100 \mathrm{Mm}$.

Vorkommen: Brasilianische Subregion (Brasilien).

67. Pym rum roseifons. - Rothstirniger Steinsittich.

Englisch: Rosc-fronted Conure.

Comurus roseifrons (1859) G. R. Gray List Psitt. p. 42.

Abbildung fehlt.

Diagnose: Obscure viridis; pileo et loris coccineis; gula sordide brumnea, pallide fasciolata; uropygio, supracaulalibus, reciricibus et macula ventrali sanguineis; regione parotica fulva: remigibus primariis pogonio externo cyancis (T'este Gray).

Vorkommen: Brasilianisehe Subregion (Amazonenstrom)

68. Pyrrhura rhodocephala. - Rothkopf-Sittich.

Engliseh: Rose-capped Conure.

commes rhodocephatus (1870) Sclater et Salvin I'roc. Zool. Soc. p. 787 .

Diagnose: Virirlis: pileo roseo-rubro; ventre meelio of cauda rubiginoso-rufis; remigibus pogonio externo calulescentibus: rostro albicante; pedibus corneis ('T'ste Sclater).

Long. c. 230, ala 125, cauda $115 \mathrm{Mm}$.

Vorkommen: Nördliche Brasilianische Subregion (Venezucla). 


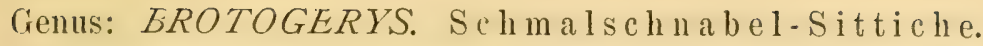

Brotogeris (1825) Vig. Zool. Journ. II, p. 400 (Typus: Ps. P'ym-hopterus Lath.). - Tirica (1854) Bonap. Rev. Mag. Zool. p. 151 (Typus: Ps. mfirostris Gm.). - Psittmius ibid. (Typus: Ps. tovi Gm.)

Charakter der Gattung: Durch einen seitlich zusammengedrückten, auf der Firste fa $t$ scharfen und gestreckteren Schnabel ausgezeichnet. Namentlich ist der Unterkiefer gestreckt, lünger als hoch. In dem stufigen Schwanze, welcher kürzer als der Flügel ist. sind die beiden mittelsten Felern stïrker verlüngert als die übrigen, welche in gleichmässiger Stufenfolge zunehmen. Im Flügel sind die drei ersten Schwingen am längsten. Sämmtliche bekannten 11 Arten sind kleine Vögel, welche an die kleinsten Fornen der cigentlichen lieilschwanzsittiche sich anschliessen und die Brasilianische Subregion bewohnen.

Schlüssel der Gattung:

Grosse Flügeldecken grün:

Kopfseiten weissgrau, Unterfligeldecken mennigroth: merhoptere.

Kopfseiten grün:

Stirn und Kinn grüun: viridissima.

Stirn grün, rothgelber Kinnfleck: chrysopogon.

Stirn rothbraun: fermeincifrons.

Stirn gelblich, rothgelber Kinnfleck: jugularis.

Vorderkopf und Strich unter dem Auge gelh: presserine. Einige der grossen Flïgeldecken weiss, gelb orler gelbroth:

Grosse Armdecken gelb, Schwingen griin: anthoptera.

(irosse Armolecken gelb). mittelste Schwingen weiss: rimperens. Grosse Hamblecken zum Theil mennigroth: motatu (s. auch chrysoptera und chrysosema).

69. Brotogerys viridissima. - Blumenau-Sittich.

Engl.: All-green Parrakeet. - Franz: Petite jaseuse.

Psittacula brasiliensis (1760) Briss. Orn. IV, p. 382. Psitterus tiviacule (1783) Bodl. Tabl. Pl. Enl. p. 51. -- Prittucus tivica (1788) Gm. S. N. p. 351.-- Comurus rupirostris (1815) Illig. Lcht. Abh. Berlin. Acad. p. 167. - Psittacus vio relissimus (1820) T'emm. Kuhl Consp. Psitt. 1. 25. - Hotingle acutirostris (1824) Spix Av. Bras. p. 32.

Abbildungen: Buffon Pl. Enl. pl. 837. - Spix Av. Bras. t. 15. - Reichenow Vogelbilder t. XVII, f. 6. 
Diagnose: Viridis, subtus dilutior; subalaribus flavidis; remigibus primariis pogonio externo corumque tectricibus cyaneis; rectricibus mediis caerulescentibus; rostro pallide carneo; cera albida; pedibus brumnescente carneis; iride grisea.

Long. c. 250, ala 120, cauda 140, culmen $19 \mathrm{Mm}$.

Vorkommen: Brasilianische Subregion (Brasilien, Guiana).

70. Brotogerys pyrrhoptera. - Feuerflügel-Sittich.

Englisch: Orange-flanked Parrakeet. - Französisch: Perruche aux ailes oranges.

Psittacus pyrroptemes (1801) Lath. Ind. Orn. Suppl. II, 1). 22. - Conurus griseocephalus (1831) Less. 'Traité d'Orn. p. 214. Psittacula griseifrons (1837--1838) Bourjot St. Hilaire Hist. Nat. Perr. pl. 86 .

Abbildungen: Selby Nat. Libr. Vol. VI, pl. 22. - Bourjot. St. Hilaire 1. c.

Diagnose: Viridis, subtus flavescens; alarum tectricibus olivaceo-brunnescentibus; pileo glaucescente; fronte et capitis lateribus cinereis; subalaribus miniatis; rostro et pedibus pallide carneis.

Long. c. 200, ala 120, cauda 80, culmen $19 \mathrm{Mm}$.

Vorkommen: Westl. Brasilianische Subregion (Ecuador).

71. Brotogerys vivescens. -- Weissschwingen-Sittich.

Englisch: Yellow-winged Parrakeet. - Franz. Perruche verte de Cayenne.

Psittuca cayennensis (1760) Briss. Ornith. IV, 1. 334. Psithecus versicolurus (1776) S. Müll. Naturs. Suppl. p. $75 .-$ Psittacus virescens (1788) Gm. S. N. p. 326. - Psittacus chiviri (1823) Vieill. N. D. H. N. XXV, p. 360.

Abbildungen: Levaillant Hist. Nat. Perr. pl. 57. - Buffon Pl. Enl. pl. 359.

Diagnose: Viridis, fronte et genis anterioribus dilute caesiis; pteryllio et remigibus, primis exceptis, albis, partim flavescentibus; tectricibus majoribus secundariis luteis; rostro pallide carneo.

Long. c. 220, ala 125, cauda 95, culmen $18 \mathrm{Mm}$.

Vorkommen: Brasilianische Subregion (Paraguay, Brasilien).

72. Brotogerys xanthoptera. - Goldflügel-Sittich.

Englisch: Orange-winged Parrakeet. - Framzösisch: Perruche à miroir jaune. 
Aratinga manthoptera (1824) Spix Av. Brasil. p. 31. -Psittaculus xanthopterygius ibicl. p. 38.

Abbildungen: Spix 1. c., t. 15 und 34. - Bourjot St. Hil. Hist. Nat. Perr. pl. 23 et 47. - Reichenow Vogelbilder t. 28, fig. 7.

l)iagnose: Viridis; pteryllio et tectricibus secundariis majoribus luteis; rostro brumnescente albido.

Long. c. 230, ala 120 , cauda 110 , culmen $17 \mathrm{Mm}$.

Vorkommen: Brasilianische Subregion (Brasilien, Ost-Peru, Bolivia).

73. Brotogerys chrysopogon. -- Goldkinn-Sittich.

Englisch: Tovi-Parrakeet. - Franzisisch: Perruche toui.

Psittacula gutture-luteo (1760) Briss. Ornith. IV, p. 396. Psillacus tori (1788) Gm. S. N. p. 351. - Psittacula chrylsopogon (1842) Less. Rev. Zool. p. 136. - Psittouius subcatruterts (1862) Lawr, Ann. Lyc. New York VII, p. 475 (Varietas!).

Abbildungen: Buffon Pl. Enl. pl. 837. - Bourjot St. Hil. Hist. Nat. Perr. pl. 48. - Reichenow Vogelbilder t. 28, f. 5.

Diagnose: Viridis, subtus flavescens; subalaribus luteis; tectricibus alarum minoribus aurantio-brunneis; mento croceo.

Long. c. 180 , ala 110 , cauda 80 , culmen $18 \mathrm{Mm}$.

Vorkommen: Nördl. Brasilianische und südl. Mexicanische Subregion (Neu-Granada, Panama).

74. Brotogerys fermgineifrons. - Roststirn-Sittich.

Brotogryls fermaineifoms (1880) (i. N. Lawrence Ibis 1). 238.

Abbildung fehlt.

Dingnose: Viridis, subtus flavescens, gutture ochrascente; fascia frontali rufa; genis anterioribus ochraceis; remigibus nigris, pogonio externo viridibus; rostro fusco; pedibus fulvis (teste Lawrence).

Long. c. 200, ala 120, cauda $90 \mathrm{Mm}$.

Vorkommen: Nördl. Brasilianische Subregion (Neu-(iranarla). 75. Brotogerys jugularis. - Goldfleck-Sittich.

Engliseh: Orange-throated Parraket. - Franzïsisch: Perruche ì gorge jaune.

Psittacus jugularis (1776) S. Miiller Lin. Natursystem. Suppl. p. 80.

Abbildungen: Buffon Pl. Enl. pl. 190. - Levaillant Hist. Nat. Perr. pl. 59. 
Diagnose: Viridis: subalaribus obseure cyanescente viridibus: fascia frontali obsolete flavida; mento croceo; rostro et pedibus fuscis.

Long. c. 180 , ala 110 , cauda $85 \mathrm{Mm}$.

Vorkonmen: Brasilianisehe Subregion (Ecuardor, Venezuela, Guiana).

76. Brotogerys notata. - Orangeflïgel-Sittich.

Engliseh: Red-fronted Comme. - Französisch: Peruche it tache souci.

Psittacula brasilimsis mpthrocephala (1760) Briss. Ornith. IV, p. 383. - Psittacus rayenneus (1776) Miill. Lin. Naturs. Suppl. p. 81. - Psittacus notatus (1783) Borld. Tabl. Pl. Enl. p. 27. Psittacus tuipara (1788) Gm. S. N. p. 348. - Psittacus sosore ibid. p. 352. - Psittacus cayanensis (1820) Sws. Zool. Ill. Ileft I, pl. 1. - Psittacus Tuillantii (1821) Sws. Isis p. 65.Psittacus calthopticus (1823) Vieill. Nouv. Dict. XXV, p. 369. - Brotogeris aurifrons (1855) Cass. Journ. Acarl. Phil. III, p. 155. Albildungen: Buffon Pl. Enl. pl. 456. - Levaillant IIist. Nat. Perr. pl. 58. - Journ. Ac. Philad. III, 1855, pl. 14. leichenow Vogelbilder t. XXVIII, f. 3.

Diagnose: Viridis, pileo eacrulescente: fascia frontali, mento. prerylio et tectricibus primariis partim miniatis; ammulo orbitali nudo albo; rostro pallide carneo.

Long. c. 200, ala 110 , cauda 70 , culmen $18 \mathrm{Mm}$.

Vorkommen: Brasilianische Subregion (Brasilien, Guiana).

77. Subspecies: chrysoptera. - Braunkinn-Sittich.

Psittacus chrysopleme (1766) Lin. S. N. p. 149.

Diagnose: Bro motater simillima, sed fascia frontali ot mento fuscis.

Vorkommen: Nörtliche Brasilianische Subregion (Vencytela, Guiana).

78. Subspecies: chrysoseme. - Pampas-Sittich.

Brotogerys dryysosemu (1864) Selater Proc. Zool. S. p. 2!)s. Abbildung: Finsch Pap. II, t. 3.

Diagnose: Br. notatue simillima, sed fronte flavirla, tectricibus primariis partim luteis.

Vorkommen: Brasilianische Subregion (Nord-Brasilien). 
79. Brotogerys passerina. - Goldkopf-Sittich.

Englisch: Golden - headerl Parrakect. - Französisch: Perruche de St. Thomas.

Psittucule brasilionsis irterocephalus (1760) Briss. Ornith. IV, p. 398. - Psittacus St. Thomae (1776) Müll. Lin. Naturs. Suppl. p. 81. - Psittasus passerinus (1783) Bodd. Tabl. Pl. Enl. p. 27. - Psittacus tui (1788) Gm. S. N. p. 352.

Abbildungen: Buffon Pl. Enl. pl. 456. - L Levaillant Hist. Nat. Perr. pl. 70. - Reichenow Vogelbilder t. XXVIII, f. 4.

Diagnose: Viridis, subtus et supracaudalibus dilutioribus: sincipite, vertice et stria suboculari luteis.

Long. c. 180, ala 95, cauda 80, culmen $16 \mathrm{Mm}$.

Vorkommen: Brasilianische Subregion (Nord - Brasilien, Guiana).

Gems: BOLBORHYNCHUS. D i ckschnabel-S it t iche.

Myiopsitta (1854) Bonap. Rev. Mag. Zool. p. 150 (Typus: Ps. murinus Gm.). - Bolborhunchus (1857) Bp. Compt. Rent. ('lypus: B. tigrinus Sou.).

Charakter der Gattung: Im Gegensatze zu der vorgenannten Gattung sind diese Formen durch einen seitlich anfgetridhenen Schnabel mit gerundeter Firste gekennzeichnet. Im Flügel sind die drei crsten Schwingen am lïngsten. Der stufige Schwanz ist etwas kürzer als der Flügel. Wir kennen 7 Arten in der Basilianischen, Nord-Chilenischen und Mexikanischen Subregion. Eine Art dieser Gattung, der Mönchs-Sittich, steht durch Eigenarten in seiner Lebensweise cinzig unter allen Papageien da. W:ïhrend andere in Baumlöchern oder Felshöhlen nisten, haut der Mönchs-Sittich freistehende Nester, welche grosse Ballen in ('inander gefilzten Reisigs darstellen mit seitlichem /ugang zu der im Inneren hefindlichen kleinen Yisthöhlung.

\section{Schlüssel der Gattung.}

Kileinste Flïgeldecken schwar\%, Oberkörper schwarz gebïndert: lineolatus.

Flïgeldecken grün:

Wangen grau:

Oberkopf, Wangen und Vorderhals grau: monochus (s. auch Luchsi).

Oberkopf braum, Wangen und Vorderhals grau: brunneiceps. 
Wangen grün. Yorderhals hell grünlich hlaugrau: rubriqnstris. Vordere Wangen, Stirn und Unterkörper gelb: an rifons.

80. Bolborhynchus monachus. - Mön ch-S it ti ch.

Engl.: Grey-loreasted Parrakect. - Franz: Perruche somris.

Psittacus monacturs (1783) Botld. Tabi. Pl. Enl. p. 48. Psittacus murinus (1788) Gmel. S. N. p. 327. - Psittacus Vomans ibid. p. 337. - Psittacus cinerecollis (1829) Vieill. X. D. H. N. XXV, p. 365. - Psittasus cotomo ibid. p. 372 . Psittacus murinus (1823) Vieill. Ene. Méth. p. 401. - Sittree comicollis (1832) Wagl. Mon. Psitt. p. 640. - Comurus callito (1849) Gray Gen. B. II, Gen. Comurus sp. 40. -- Comums qriseicollis (1855) Desm. Cast. Exp. Am. du Sud p. 16.

Ahbildungen: Buffon Pl. Enl. pl. 768. - Levaillant IIist. Nat Perr. pl. 67. - Reichenow Vogelbilder t. XVII, f. 7.

I)iagnose: Viridis; sincipite, loris, genis, gutture et pectore sordirle canis, gutturis plumis dilutius limbatis; remigibus pogonio externo et tectricibus primariis caerulescentibus; rectricibus pogonio interno flavidis; remigibus subtus pogonio interno et subalaribus dilute raesiis: rostro sordide fulvo; pedibus griseis; iride brumea.

Long. c. 280, ala 150, caurla 130, culmen $22 \mathrm{Mm}$.

Vorkommen: Südliche Brasilianische Stibregion (Bolivia, La Plata, Paraguay, Uruguay).

81. Subspecies: Luchsi. - Westlicher Mïnchsittich.

Englisch: Bolivian Grey-breasted Parrakeet.

Mriopsitta murinoides (1854) Temm., Bp. Rev. Mag. '/ool. p. 150. - Bollwillynchus Jarshi (1868) Finsch Pap. II, p. 121.

Abbildung fehlt.

Diagnose: B. monarho simillimus, sel gutturis plumarum limbis dilutioribus vacuis; subalaribus of hypochomdriis olivaceoflavis.

Vorkommen: Bolivia (?).

82. Bolborhynchus bremeiceps, - Aymara-Sittich.

Engl.: Aymara Parrakeet. - Franz.: Perruche aymara.

Ara aymara (1839) d'Orb. Voy. de l'Am. mér. p. 376. romures bruniceps (1860) Burm. Journ. f. Orn. p. 243.

Abbildung: Souancé Icon. Perr. pl. 23.

Diagnose: Viridis; pileo, regione postoculari et parotica brumescente canis; genis, colli lateribus et gutture pallide 
canis; abdomine medio caesio; hypochondriis flavescente viridibus; crisso et subcaudalibus thalassinis; remigibus subtus et subalaribus majoribus fumigatis, intus flavescente limbatis; remigibus pogonio externo et tectricibus primariis viridibus.

Long. c. 190, ala 98, cauda 100, culmen $12 \mathrm{Mm}$.

Vorkommen: Südliche Brasilianische Subregion (Bolivia, Argentinien).

83. Bolborkynchus mulvostris. - Rothsehnabel-sittich.

Conume rubrirostris (1860) Burm. Journ. f. Orn. p. 243.

Abbildung fehlt.

Diagnose: Viridis; gutture, subalaribus et subcaudalibus dilute glancis; remigibus subtus et subalaribus majoribus fumigatis; remigibus pogonio externo et tectricibus primariis cacrulescentibus; rostro roseo; pedibus carneis.

Long. c. 170, ala 100, cauda 80, culmen $14 \mathrm{Mm}$.

Vorkommen: Südliche Brasilianische Subregion (Argentinien).

84. Bolborhynchus aurifrons, - Citronen-Sittich.

Englisch: Golden-fronted Parraket. - Französisch: Perruche à bandeau jaune.

Psittacus jaguilma (1788) Gm. S. N. p. 288. - Psittucus aurifroms (1830) I.ess. Cent. Zool. P. 63. - Comumes sitophagus (1844) Tschudi F. Per. p. 273. - Comurus agilis (1854) I،chtst. Nomencl. p. 73.

Abbildungen: Souancé Icon. Perr. pl. 24, f. 2. -- Bourjot St. Hilaire Hist. Nat. Perr. pl. 45.

Diagnose: Viridis; fronte, genis anteriorihus et gastraeo flavis, gutture olivascente; remigibus pogonio externo et tectricibus primariis eyanescentibus; rostro pallido; iride flava.

Long. c. 170, ala 95, cauda 85, culmen $13 \mathrm{Mm}$.

Vorkommen: Nördliche Chilenische Subregion (West-Peru).

85. Subspecies: Omignyi. - Grosser Citronen-Sittich.

Englisch: D’Orbigny's Green Parrakeet. - Franzïsisch: Perruche d'Orbigny.

Mriopsitta Orbignesia (1854) Bp. Rev. Mag. Zool. p. 151. Conums Orbignesius (1859) Gray List Psitt. 1. 44. - Bolborhynchus Dorbignyi (1868) Finsch Pap. II, 1) 129.

Abbildıng: Souancé Icon. Perr. pl. 24.

Diagnose: $\boldsymbol{B}$. aurifronti simillimus, sed major. 
Vorkommen: Südliche Brasilianische Subregion (Ost-Peru, Bolivia).

86. Bolborhynchus lineolatus. - Catharina-Sittich.

Engl.: Venezuela Parrakeet. - Franz.: Perruche Catharine.

Psittcecula lineola (1853) Cass. Proc. Ac. Phil. VI, p. 372. Myiopsitte tigrina (1856) Souancé Rev. Mag. Zool. p. 144. Hyiopsitta catharina (1857) Bp. Compt. Rent. p. อ̆38. - Comurus lineolate (1859) Sclater Ibis p. 137.

Abbildung: Reichenow Vogelbilder t. XXVIII, f. 1.

Diagnose: Viridis, subtus flavescens, cervice, dorso, colli et. corporis lateribus nigricante transversim fasciolatis; supra- et subcaulalibus, crissi plumis et tectricibus majoribus macula apicali nigra; rectricibus medio nigris; tectricibus minimis nigris; remigibus pogonio externo et tectricibus primariis viridibus; remigibus subtus et subalaribus majoribus intus caerulescente viridi-limbatis.

Long. c. 160, ala 110, cauda 70, culmen $18 \mathrm{Mm}$.

Vorkommen: Mexicanische Subregion.

Genus: PSITTACULA. S p e r ling s p a pag e i en.

Psittucule (1811) Illiger Prodromus p. 200 (Ohne Typus). Psittaculus (1824) Spix Av. Bras. 1. 30. - Psittacules (1829) Cuv. Règne Anim. 2. Eil. 1. 465. - Psittacult (1832) Wagl. Mon. Psitt. p. 498.

Charakter der Gattung: In der Schnabelform den Dickschmabelsittichen gleichend, mit seitlich anfgetriebenen Kiefern und gerundeter lirste, aber unterschieden durch einen kuren Schwanz, welcher nur halb so lang als der Flïgel und schwach serundet, fast gerade ist, der aber in der Ruhe nicht ausgebreitet getragen wird und daher keilförmig erscheint. Die einzelnen Schwanzfedern sind am Ende scharf zugespitzt. Im Fliiggel erste bis dritte Schwinge am längsten, erste am Ende verschmälert. Sehr kleine Vägel, von welchen gegenwärtig sieben Arten bekannt sind und die die nördliche Brasilianische und Mexicanische Subregion bewohnen.

$$
\text { Schlïssel der Gattung. }
$$

Bürzel griun:

Grosse Flügeldecken und Afterflügel grün: andicola. Grosse Fligeldecken und Afterflügel blau: cyanopter 
Bürzel blau:

Kein blan am Kopfe: pesserine (s. auch cyunopyy u. Siluteri). Blaues Schlätenband: coclestis.

Blauer Augenring: conspicillata.

87. Psittacula andicola. - A n d en-P a p a g e i.

Psittacule andicola (1874) Finsch Proc. Zool. Soc. p. 90.

Diagnose: Viridis, subtus dilutior; mento olivaceo-flavido: rostro canescente corneo (Teste Finsch).

Long. c. 165, ala 115, cauda $60 \mathrm{Mm}$.

Vorkommen: Westl. Brasilianische Subregion (Ost-Peru).

88. ${ }^{+}$Psittacula cyanoptera. - C $0 \mathrm{mp}$ p a $\mathrm{g} 1 \mathrm{on}$.

Englisch: Blue-winged Passerine Parrot. - Französisch: Perruche compagnonne.

Psittacus cycnopterus (1783) Bodd. Tabl. Pl. Enl. p. 27. Psittacus capensis (1788) Gm. S. N. p. 350. - Conurus groyeniuss (1837-18.38) Bourjot St. Hilaire Hist. Nat. Perr. pl. 49. Psitteculu quiunensis (1838) Sws. Two Cent and a (Yuart. p. 320. I'sitteculus Senneti Thomere (1864) Schl. Mus. P. B. Psitt. 1) 31. P'sittecule 'yanochlore (1868) Natt. Finsch Pap. II, 1) 649.

Abbildungen: Buffon Pl. Enl. pl. 455. - Bourjot St. Ilil. Hist. Nat. Perr. pl. 49. - Souancé Icon. Perr. pl. 39. - Spix Av. Bras. t. 34 .

I)iagnose: Viridis, uropygio prasino; tectricibus primariis, pteryllio et subalaribus cyancis; tectricibus majoribus secundariis et remigibus mediis thalassinis; mensuris $P$. jusserine.

Vorkommen: Nördliche Brasilianische Subregion (Guiana. Venezuela).

89.t Psittacula passerina. - S p e r lings pa pag e i.

lingl.: Passerine Parrot. - Franz.: Perruche passerinne.

Psittacula brasiliensis uropygio cyaneo (1760) Briss. Orn. IV, p. 348. — Psittacus passerinus (1766) Lin. S. N. 1. 150. Psittucula simplex' (?) (1820) Kuhl Consp. Psitt. 1) 66. - Psittecula modesta (1854) Lcht. Nomencl. p. 71.

Abbildungen: Spix Av. Bras. t. 33. - Bourjot St. Hilaire IIist. Nat. Perr. pl. 50. - Reichenow Vogelbilder t. XXVIII, f. 2.

Diagnose: Viridis, subtus flavescens; uropygio, subalaribus, campterio, pteryllio. tectricibus primariis et remigibus medii caeruleis; rostro grisescente albo; pedibus pallidis; iride brumnea.

Long. c. 130 , ala 85, cauda 50, culmen $11 \mathrm{Mm}$. 
ㅇ: Sincipite, genis, gutture et pectore flavescentibus, alis totis et uropygio viridibus.

Vorkommen: Brasilianische Subregion (Brasilien). 90. Subspecies: cyunopyga. - Hellfarbiger Sperlingspapatgei. Englisch: Blue-backed Passerine Parrot.

Psittecule cyconopygia (1856) Souancé Rev. Mag. Zool. 1) 157. Abbildung: Souancé Icon. Perr. pl. 42.

Diagnose: Ps. pusserinue simillima, sed major ct dilutius tincta; partibus illius cyaneis laete azureo-tinctis.

Vorkommen: Mexicanische Subregion.

91. Subspecies: Silateri. - 1) unkler Sperlingspapagei.

Englisch: Black-billed Passerine Parrot.

Psittacule Seluteri (1859) Gray List Psitt. 1) 86. - Isitteredet melenorrhynche (1868) Natt. Finsch Pap. II, 1) (560.

Abbildung fehlt.

Diagnose: Ps. pesserince simillima, sed obscurius tincta et maxilla nigricante, mandibula albida; pedibus fuscis.

Vorkommen: Brasilianische Subregion (West-Brasilicu).

92. Psittcule coelestis. - Grauriekiger Sperlingspapagei.

Englisch: Western Passerine Parrot.

Agapornis coclestis (1844) Less. Echo du Monde savant pl. 2.

Abbildungen: 1. c. - Souancé Icon. Perr. pl. 40.

Diagnose: Capite et gastraeo flavo-viridibus; dorso et alis olivaceo-viridi-griseis; tectricibus majoribus, pteryllio, campterio, subalaribus, remigibus secundariis, uropygio et stria temporali cyaneis (Teste Finsch).

Ala 80, cauda $40 \mathrm{Mm}$.

Vorkommen: Westliche Brasilianische Subregion (Ecuador). 93. Psittucula conspicillatu. - A ugen ring-Papagei.

Englisch: Spectacled Passerine Parrot.

Psittecule conspicillete (1848) Lafr. Rev. Nag. Zool. 1) 172. Psittaces ryanopis (1854) Lcht. Nomencl. p. 71. - Psitterule wrbitulu (1862) Rchb. Schaufuss Cat. (Teste Finsch II, p. 663).

Abbildung: Souancé Icon. P. pl. 41.

Diagnose: Viridis; subtus grisescens; periophthalmiis, urolygio, subalaribus, margine alari, pteryllio, tectricibus primariis et remigibus mediis cyaneis.

Long. c. 120, ala 80, cauda 45, culmen 12 Mm.

Vorkommen: Westl. Brasilianische Subregion (Columbia). 


\section{Familie: Pionidac. Stumpfsehwanzapageien.}

Charakter der Familie: Ein kurzer, gerader und breiter Schwanz von ungeführ halber Flügellänge ist für die Irten dieser Familie bezeichnend; nur zwei Formen, der Blaubauch und der Fächerpapagei, machen hicrvon cine dusnahme. Der Schnabel ist von mässiger Stärke, bald gestreckter, bald höher und kürzer, die Firste in der Regel mit einer Längsrinne verschen, dic Spitze meistens mit deutlichem Zalnn und immer mit Feilkerhen versehen. Dic Dille häufig mit Mittelkiel. Dic Wachshaut ungiebt handfürmigr die ganze Schnabelbasis, ist aber vor den Nasenlöchern ausgebogen und stets nackt. Im Fliugel sind in der Regel die \#weite bis vierte Sehwinge die lïngsten. Die liirbung ist vorherrschend grün.

Die Stumpfschwanzapageien bewohnen in der Melnzalıl dic Tropen Amerikas, nur wenige Formen finten sich in den tropischen Breiten Afrikas. Wenn diese letatere Thatsatehe eine auftallende Ausnahme dastellt, indem wir bei den anderen Papageien-Fandien eine gewisse Beschränkug in der "seographischen Verbreitung anf zusammengehörige Ländercomplexe fanden, so ist dieses Vorkommen von Arten derselben (rrupe auf beiden Halbkugehn doch weniger ïberraschemb als es im ersten Augenblicke erscheinen möchte, wenn man bedenkt, wic, in bisher noch nicht genügend erklärter Weise, mehrfach amerikanische Vogelarten durch sehr mahe stehende Formen in Afrika vertreten werden.

Wic den meisten Ordnungsgenossen, so ist auch den Stumpfschwanzpapageien ein Iang zul Geselligkeit eigen, der sie namentlich ausser der Brutzeit zu grossen Schaaren vereinigt, welche zur Nistperiode, wohl mehr durch die Umstïndle gezwungen als freiwillig, in einzelne Paare sich auflösen. Alle nisten in Baumlöchern, halten sich vorzugsweise auf Büuncu auf und nïhren sich von Gesäme, Kiernfrüchten, Beeren und nebenbei von Insekten. Der Flug ist schwerfällig, wenngleich bei viclen Arten reissend schnell, mit kurzen, eiligen Flïgelschlïgen, direct auf das Ziel losstrebend, ohne anmuthige Wendungen, durch welche der Flug der Sittiche sich auszeichnet. Auf dem boden bewegen sich die grösseren Arten schr unbeholfen, viele Ier kleineren laufen hingegen recht geschickt; ebenso sind diese sehr gewandt im klettern, während jene auch im Gezweige sich 
schwerfälliger bewegen. Die Stimme ist rauh und kreischend. Die grösseren Arten, insbesondere die Amazonen, sind befühigt, menschliche Worte nachsprechen zu lernen, einige Arten kommen hicrin sogar dem vorzüglichsten Sprachkünstler, dem Jako, gleich.

Wir unterscheiden gegenwärtig 81 Arten, welche wir in 8 Gattungen einordnen. Unsere Uebersichtstabelle hat an dieser stelle eine Modification zu erfahren, nachdem wir uns überzeugt, dass es geeigneter ist, der Gattung Pionopsittanus nur subgenerische Bedeutung beizulegen und dieselbe mit Euopsittacus zu der neu aufgestellten Gattung Fucinetus zu vereinigen, hingegen Euchrour als Gattung davon zu sondern und ferner die Gattungen Cetica und Poeocephalus als subgenera zu vereinigen.

Genus: TRICLARIA. Sitt i ch pa page i en.

Triclaria (1832) Wagl. Mon. Psitt. p. 499 (Typus: Ps. cyanogaster Wiedl.).

Charakter der Gattung: Ein längerer, geruncleter Schwanz ron etwa drei Viertel der Flügellänge, sowie der kurze und hohe, an der Firste zusanmengedriickte, an der Dille mit drei Kiclen versehene Schmabel unterscheidet diese Gattung von den verwandten Formen. Im Flügel ist zweite bis vierte Schwinge anl lingsten, die erste kürzer als die fünfte. Nur eine $\Delta$ rt in der Brasilianischen Subregion.

1. Triclaria cyanogaster. -- B l a u b a u ch.

Engliseh: Azure-bellied Parrot. - Französisch: Perroquet à ventre bleu.

Psittacus cyunomater (1820) P'l'. V. Wied Reise Bras. I, 1. 263. - - Psittuens maluehituceus (1824) Spix Av. Bras. p. 41 (jun.).

Abbildungen: Spix $\Lambda$ v. Bras. t. 28. - Bourjot St. Hilaire Hist. Nat. Perr. pl. 57. - Reichenow Vogelb. t. XXVI, f. \&.

Diagnose: Viridis; ventre medio cyaneo; rectricum apicibu. et extimarum pogonio externo cyancis; rostro Havescente albidn. iride dilute brunnea.

ㅇ: Macula ventrali cyanea nulla.

Long. c. 330 , ala 165 , cauda 130 , culmen $25 \mathrm{Mm}$.

Vorkommen: Brasilianische Subregion (Brasilien).

Genus: PACHYNUS. Kurzschwanzpa pageien. draydidascalus (1854) Bp. Rev. Mag. Zool. p. 152 (Typus: 
Ps. nividissimus Sws.). - Pachyms (1881) Reichenow (Typus: Ps. brachyurus Temm. Kuhl).

Charaliter der Gattung: Durch einen grossen, hohen und dicken, seitlich aufgetriebenen Schmabel, dessen Dille mit einem Nittelkiel versohen ist und einen schr linrzen Schwanz ausgezeichnet. Im Flügel zweite und dritte Schwinge am längsten; die erste Schwinge kïrzer als die vierte. Nur durch eine Art. in der nördlichen Brasilianischen Subregion repräsentirt.

2. Pachynus brachyurus. - Kurzschwanz-Papagei.

Engl.: Short-tailed Parrot. - Franz.: Perroquet nain.

Psittacus brachyume (1820) Temm, et Kuhl Consp. Psitt. p. 72. - Psiltacus pumilio (1824) Spix Av. Brasil. p. 41. Psittacus viridissimus Sws. Ill. Zool. III, pl. 155. - Psittans memilio Sprivi (1837-1838) Bourjot St. Hilaire H. N. P. pl. 56. Abbildungen: Spix Av. Bras. t. 29. - Bourjot St. Hilaire 1. c. - Sws. Ill. 1. c.

Diagnose: Viridis; remigihus secundariis eorumque tectricibus flaveseente limbatis; rectricum dimidio basali dilute rubro; macula scapulari cerasina, rostro flavo, apice fusco.

Long. c. 250, ala 150, cauda 70, culmen $27 \mathrm{Mm}$.

Vorkommen: Nördliche lrasilianische Subregion (NordBrasilien, Ecuador).

Genus:- EUCINETUS. Z i erpapag e i en.

Pionopsitte (1854) Bp. Rev. Mag. Zool. p. 152 (Typus: Ps. pileate Scop.). - Evopsitta (partim) ibid. p. 151 (Typus: Ps.

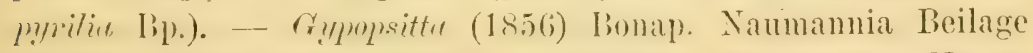
(Typus: 7s. moturinus Illig.). - P'milie (1856) Bonap). Naum. Beilage (Typus: Psittuculu marilie 13p.). - Eucinetus (1881) Reichenow (Typus: Ps. histrio Bodd.).

Charakter der Gattung: Ḱleinere Vügel mit gestreckterem Schnabel, welcher an der Basis so hoeh ist als seine Lünge von dem Grunde bis zur Spitze, namentlich mit lang gestrecktem Unterschnahel, dessen Höhe an der Basis bedeutend kürzer ist als die Entfernung der Spitze von der Mundspalte. Zahn undentlich. Dille mit Mittelkiel. Firste mit Längsrinne. Schwanzfedern mehr oder weniger zugespitzt. Zweite und dritte Schwinge am liingsten, crste kaum so lang als dic vicrte. Wir kennen neun Arten in der Brasilianischen Subregion. Fine 
Form, E. pileutus Borld., weicht durch kürzeren Schnabel, spitzere Schwanzfedern um! spitzeren Flügel, in welchem dic crste bis dritte Schwinge am lïngsten siml, ah, wonach eine subgenerisehe Abtrenumg gerechtfertigt erscheint.

\section{Schlüssel der Gattung.}

Kopf nackt: vulturinus.

Kopf befiedert:

Kopf ganz oder grösstentheils schwarz:

Kopf ganz schwarz: histrio.

Mit gelbem Wangenfleck: Barrabendi.

Rothe Zeichnumg am Kopfe:

Oberkopf roth, Wangen griin: pileatus.

Gesicht roth:

Bauch grïn: amcezoninus.

Bauchmitte roth: pyrrhops.

Oberkouf olivengelbbram, rother Ohrfeck: hucmetutis. Oberkopf bläulich, dlunkelbramer Ohrfleck: melunotis.

Ganzer Kopf gelb: pyrilla.

\section{Subgenus: PIONOPSITTACUS.}

Pionopsitta (1854) Bp. Rev. Mag. Zool. p. 152.

3. Eucinetus pileatus. - Scharlachkopf.

Englisch: Mitred Parrot. - Französisch: Ferroquet mitré.

Psittacus pileatus (1769) Scop. Ann. I, p. 32. - Psittacus mitratus (1820) Neuwied Reise mach Brasilien I, p. 263. Psittacus crythrocephalus (1823) Vieill. N. D. XXV, 1. 372. Psittacus Haitace (1824) Spix Av. Bras. I, p. 41.

Abbildungen: Spix Av. Bras. t. 29 und 30. - Bourj. St. Hilaire Hist. Nat. Perr. pl. 55 et $55 \mathrm{~b}$. - Temm. Pl. Col. pl. 207. - Reichenow Vogelbilder t. XXIV, f. 5.

Diagnose: Viridis; pileo et fascia suboculari coccineis; flexura, campterio tectricibusue primaris, rectricum apicibus et subilaribus cyaneis; rostro plumbero, apice dilutiore; pedibus griseis.

ㅇ: Capite toto viridi, fronte mentoque caerulescentibus.

Long. c. 240, ala 150, cauda 50 , culmen $17 \mathrm{Mm}$.

Vorkommen: Sïdliche Brasilianische Subregion (Paranguay, Süd-Brasilien).

Subgenus: EUCINETUS. Z Z i e r p a p a g e i e 1.

Eucinetus (1881) Reichenow (Typus: Ps. histrio Bodd.). 


\section{Conspectus Psittacorum.}

4. Eucinetus melenotis. - Brannohr-Papagei.

Engliseh: Black-eared Parot. - Französisch: Perroquet i oreillons noirs.

Psittucus melenotis (1847) Lafr. Rev. Mag. Zool. p. 67.

Abbildung: Des Murs Icon. Orn. 1847, pl. 60.

Diagnose: Viridis; pileo, nucha, loris et fascia collari caeruleis; regione parotica brumea; rectricibus apice, extimis fogonio extermo, violasente-acruleis: tortricibus nigris; remicibus primaris corumque tectricibus nigris, poronio externo cacruleis, illis extus tenuiter straminco-limbatis.

Ala 150, cauda $80 \mathrm{Mm}$.

Vorkommen: Sülliche Brasilianische Subregion (Bolivia).

5. Eucinetus huematotis. - Blutohr-Pajagei.

knglisch: Red-eared Parrot. - Französisch: Perroquet à oreillons rouges.

Pionus hacmatotis (1860) Sclat. et Salv. Proc. Z. S. p. 300. -

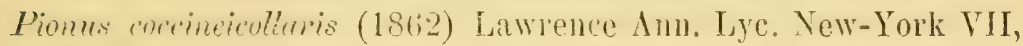
p. 475 .

Abbildung: Ibis 1860, pl. 13.

Diagnose: Virilis: pilen rufercente fusen; auchenio et gutture olivace-fulvis; renione parotica ruhra: genis mentoque nigricantihus: loris albis; hypochomdriis, subalaribus minoribus et plumis nommilis scapularibus aecineis; subalaribus majoribus cyaneis; remigibus nigris, primaris extus tenuiter stramineolimbatis, secundaris pogonio externo cyaneis vel viridibus; Hexura cyancal rectricibus apice eyancis, pognoii interni basi dilute coccincis, cxterioribus poronio externo violascentibus, medis duabus omnino viridibus; rostro flavido.

Long. c. 250, ala 150, cauda 75, culmen $21 \mathrm{Mm}$.

Torkommen: Hexicanische Subregion.

6. Eucinetus cmazonimus. - Z wergamazone.

Engl.: Little Amazon Parrot. -- Franz. Perruche amazonine.

Psittucus amazoninus (1845) Des Murs Rev. Zool. p. 207.

Abbildungen: Des Murs Icon. Orn. pl. 15. - Reichenow Vogelbilder t. XXIV, f. 8.

Diagnose: Viridis; gutture et pectore olvaceo-Havis; facie, flexura, subalanibus minimis et ampterio miniato-coceincis; verticis et regionis paroticae plumis striis scapalibus flavis; recticibus rufis, apice cyancis, extimis pogonio externo cyaneis; 
remigibus primariis corumque tectricibus primariis nigris, pogonio externo cyaneis, illis extus tenuiter stramineo-limbatis.

Long. c. 250, ala 155, cauda 80, culmen $20 \mathrm{Mm}$.

Vorkommen: Nordwestl. Brasilianischn Subregion (Columbia).

7. Eucinetus myrhops. - Scharlachmaske.

Pionopsitta pymhops (1876) Salvin Ibis 1) 495.

Abbildung fehlt.

Diagnose: Prasina, facie, (oculorum ambitu incluso), humeris, subalaribus minoribus et macula ventrali coccineis; vertice antico et regione parotica aureo vix tinctis, vertice postico caeruleo lavato; primariis extus et caudac apice purpurascenti-cacruleis; rostro pallido; perlibus plumbeis (Teste Salvin).

Long. c. 230, ala 140, cauda $90 \mathrm{Mm}$.

Vorkommen: Westl. Brasilianische Subregion (Ecuarlor).

8. Eurinctus histrio. - Kappen-Papagei.

Fuglis h: Hooded Parrot. - Franzissisch: Perroquet caica.

Psittacus histrio (1783) Bodd. Tabl. Pl. Enl. p. 46. Psittacus pileatus (1788) Gm. S. N. p. 347. -. Psittacus caica (1790) Lath. Ind. Orn. p. 128.

Abbildungen: Buffon P1. Enl. pl. 744. - Levaillant Hist. Nat. Perr. pl. 133. - Reichenow Vogelbilder t. XXIV, f. 6.

Diagnose: Prasinus, dorso oliva cente; capite nigro; gula olivace-brumea; auchenii plumis isabellinis, nigro-limbatis; rectricibus apice cyaneis, pogonio interno Havis; remigibus nigris, pogonio externo virilibus, exterioribus tenuter stramineolimbatis; rostro flavido; pedibus fulvis; iride flava.

Long. c. 250, ala 155, cauda 70, culmen $19 \mathrm{Mm}$.

Vorkommen: Nördliche Brasilianische Subregion.

9. Eucinctus pyíllus. - Feuerauge.

Englisch: New Grenada Amazon Parrot. - Französisch: Caïca à tête jaune.

Psittacula pyrilice [!] (1853) Bp. Compt. Rend. p. 807. Pyrilie typice (1856) Bp. Nammannia Beilage. - Pionies p!lpillet (1868) Finsch Pap. II, p. 419.

Abbildung: Souancé Icon. Perr. pl. 26.

Diagnose: Viridis; gutture olivaceo-fulvo; capite toto et macula culitali luteis: subalaribus, axillaribus et tibis coccineis; rectricibus apice, extimis quoque margine cxterno cyaneis, 
pogonio interno flavis; remigibus primariis nigris, pogonio externo cyancis; restro pallislo. - Nagnitudine E. Buraluendi.

Vorkomnen: Nördliche Brasilianische Subregion (Columbia).

10. Eucinetus Barrabandi. - Goldwangen-Papagei.

Engl.: Barraband's Parrot. - Franz: Caica Barraband.

Psittacus Barrabandi (1820) Levaill., Kuhl Consp. Psitt. 1). 61 .

Abbihlungen: Levaillant II. Nat. Perr. pl. 134. - Reichenow Vogelbilder t. XXIV, f. 4.

Diagnose: Viridis; gutture olivacen-flavo; rapite nigro; macula utroque senali et tibiis anrantis; flexura crocea; campterio ef subalaribus coccineis; rectricibus pogonio interno flavis, apice cyancis, extimis pogonio externo calculeis; remigibus primariis eorumque tectricibus nigris, pogonio externo cyaneis.

Long. c. 260, ala 165, cauda 75, culmen $22 \mathrm{Mm}$.

Vorkommen: Nördliche Brasilianische Subregion.

11. Eucinctus vulturinus. - Kahlkopf.

Engl.: Vulturine Parrot. - Franz.: Perroquet vautourin.

Psiltacus vulturinus (1820) Illig. Kuhl Consp. Psitt. 1) 62.

Abbildumgen: Bourjot St. Hil. Hist, Nat. Perr. pl. 59.Reichenow Vogelbilder t. XXIV, f. 7.

Diagnose: Capite nudo nigro, antice carneo; corpore

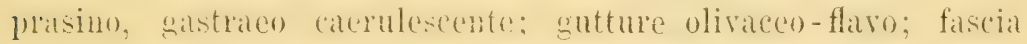

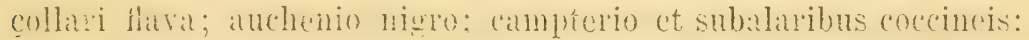

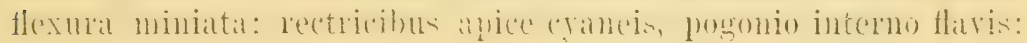
interdum nonnullis plumis tibiarm coccineis; reminibus primaris nigris, pogonio externo ryaneis, tenuiter stramineo-limbatis; rostro flavido, culmine et apice nigricante.

Long. c. 250, ala 150, cauda 75, culmen $22 \mathrm{Mm}$.

Vorkommen: Brasilianische Sulregion (Nord-Brasilien).

Genus: EUCHROUR\%. Buntschw a u papage i en.

Crecheme |!| (1856) Bonap. Namminnia Beilage (Typus: I's. Hueti Temm.). - Euchroure (1881) Reichenow (Typus: Ps. purpuratus Gm.).

Charakter der Gattung: Kleine Vögel, hinsichtlich der Schnabelform mit der Gattung Encinetus übereinstinmend, mit gestrecktem Tinterkief(r), desis'n IHöhe an der Basis bedentend kürzer ist als die Länge, d. h. die Entfernung der Spitze von 
dem Mundwinkel. Hingegen hat die Dille keinen hiel und die Firste leine Iängrinne. Eigenthümlich ist der Crattung die Bildung der unteren Schwanzdecken, welche his zur Suitze der Schwanzfedern reichen. Die Washohat ist um dir Tisenlöcher herum etwas wulstig anfgetrioben. Im Flügel ist erste his drifte Sinwinge am lingsten, die ersten sind in der Trogel an Fnde rerschmälort. Die Srhwanzfedern sind in der ganzen Lünge ziemlich gleich breit mit einer kurzen Spitze am Ende. (harakteristich ist endlich die hunte Firhmog der Schwanzfedern. Wir kemen acht Formen in der Prasilianischen Subregion.

\section{Schlüssel der Gattung.}

Ritcken zwischen den Sclultern schwarz orter schwanbram: Mittelste Schwanzfedern griun, die tibrigen hellroth mit schwarzer. Spitzeubinde: motanotus.

Alle Schwanzedern röthlich rolet, dio äwseren mit schwarzer Spitzenbiude: cingulatus.

Rücken zwischen den Schultern grün:

Schwanzfedern grösstentheils grïn, die äusser'n auf der Innenfahne olivengelblich: stictoptera.

Schwanz goldgelb:

Mittelste Schwanzfedern grïn, kein roth am Kopfe: surchs. Mitielste Schwanzfedern anch woldgelh, drei rothe Stirnflecke: dilectissime.

Schwanz weinroth:

Stirn schwarz, Bürzel grün: Hucti.

Oberkopf braun, Bürzel blain: purpuratns (s. auch vividicauda).

12. Euchroura stictoptera. - Braunsehulter-Papagei.

Englisch: Brown-shouldered Parrakeet. - Französisch: Perruche aux ailes bruns.

Urochroma stictoptern (1862) Sclat. Proc. Zool. Soc. p. 112. Abbildung: 1. c. pl. 11.

Diagnose: Viridis, subtus dilutior: alarum tectricibus nigrofuscis (majoribus interdum miniatis?), rectricibus pogonio interno olivascente flavidis: rosto pallide favito: pedibus grisois (Teste Sclater).

Vorkommen: Westliche Brasilianishe Subreyion (Columbia).

13. Euchoura purpurate. - Purpurschwanz.

Englisch: Purple-tailed Parrakeet. - Französisch: Perruche i queue pourpre. 
Psittracus purpuralus (1788) Gm. S. N. p. 350. - Psittacus porphyoume (1789-1813) Shaw Nat. Misc. p. 547.

Abbildnngen: Shaw Nat. Mise. pl. 16. - Souancé Icon. Perr. pl. 37.

Diagnose: Viridis; pileo olivascente fusco; regione parotica

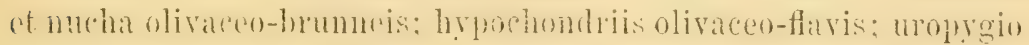
azureo; scapularibus nigio-fuscis; rectricibus vinaceo-rubris margine apicali nigra, mediis duabus viridibus apice nigra, extimis margine exteriore nigro-cyanea: campterio cyanen; rostro pallide flavo, basi plumbeo; pedibus cinereis.

Long. c. 180 , ala 115 , cauda 60, culmen $15 \mathrm{Mm}$.

Vorkommen: Nördliche Brasilianische Suhregion (Guiana).

14. Subspecies: viridiecuda. - Bla ubürzel.

Englisch: Green-banded Parakeet. - Französisch: Perroquet à croupion bleu.

Pritucule viridicuede (1859) Gray List Psitt. p. 88.

Abbildung: Reichenow Vogelbilder t. XXIY, f. 3.

Diagnose: Praecerlenti simillima, sed rectricibus medis apice

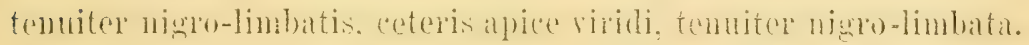

Vorkommen: Brasilianische Subregion (Nord-Brasilien).

15. Euchoura melanonota. - Schwarzräcken-Papagei.

Englisch: Coffec-backed Parrot. - Französisch: Psittacelle à dos noir.

Psittacus melenonotus (1820) Leht., Kuhl Consp. Ps. 1. 59. Psitacuis erythmus (1820) Neuw. Reis. Bras. I, p. 256.

Abbildung: Bourjot St. Hil. Hist. Nat. Perr. pl. 95.

Diagnose: Virilis; gastraco dilute glanco; interscapulio et scapularibus fuscis; macula cubitali nigra; rectricibus dilute

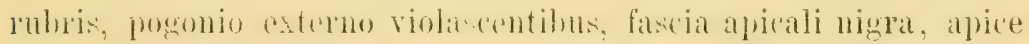
ipsa viridi, mediis totis viridibus.

Long. c. 180, ala 110, cauda 50, culmen $15 \mathrm{Mm}$.

Vorkommen: Brasilianische Sulregion (Brasilien).

16. Enchoura surde. - Goldschwanz-Papagei.

Englisch: Golden-tailed Parrot. - Französisch: Perroquet à queue d'or:

Psiltacus surius (1820) Illig., Kuhl Consp. Psitt. p. 59. Psitutecus nchrurus (1820) Wied Reis. Brasil. - Psittacus chrysurus Sws Zool. Illustr. III, pl 141 . 
Abbildungen: Swains. Zool. Illustr. III, pl. 141. - Solancé Icon. Perr. pi 38. - Reichenow Vogelbilder t. XXIV, f. 1.

Diagnose: Viridis, fronte, loris, periophthalmis et hypochondriis ochrascentibus; scapularibus fuscis; rectricibus aurantis margine apicali nigra, extimis extus nigro-limbatis, medis duabus viridibus, apice nigra; rostro griseo, apice dilutiore; iride grisea.

Long. c. 190, ala 115, cauda 50, culmen $16 \mathrm{Mm}$.

Vorkommen: Oestliche Brasilianis he Sulnegion (Oestliches Brasilien).

17. Euchroura cingulata. -- Trinidad-Papagei.

Englisch: Black-winged Parrakeet. - Französisch: Perroquet aux ailes noirs.

Psittacus batavic (1783) Bodd. Tabl. Pl. Enl. p. 49. Psittacus cingutalus (1786) Scop. Del. F. Fl. Ins. 1). 86. Psittacus melanopterus (1788) Gmel. S. N. p. 350. - Psittacus micropterus (1820) Kuhl Consp). Psitt. 1) 67.

Abbildungen: Buffon Pl. Enl. pl. 791. - Levaillant Hist. Nat. Perr. pl. 69. - Shaw. Nat. Misc. pl. 132. - Reichenow Vogelbilder t. XXIV, f. 2.

Diagnose: Cappite, ventre et subcamdilihus flavesechte virislilus; gutture et peetore dilute glatucis; andhenii plumis olivateotlavis, nigro-limbatis; (horso, mopygio et alarum tectricibus minoribus nigris; reetricibus violateo-roseis, factia apicali nigra; rampterio dilute rubro; subalaribus gilve caculeis; tectricihns prinaris nigris, apice cyaneal tectricibus majoribus secundaniis viridi-flavis, apice craneal rostro et perlibus pallide flavis.

Long. c. 190, ala 115, cauda 60, culmen $16 \mathrm{Mm}$.

Vorkommen: Nördliche Brasilianische Subregion ('Trindat, östliches Venezuela).

18. Euchoura Hueti. - Schwarzstin-Papagei.

Englisch: Huet's Parrot. - Französisch: Perroquet Huet. Psittacus Hucti (1820-1824) T'emm. Pl. Col. p. 491.

Abbildungen: Temminck l. c. - Bourjot St. Hilaire Hist. Nat. Perr. pl. 93.

Diagnose: Viridis, subtus dilutior; pileo et regione parotical olivaceo-flavis; fascia frontali nigral; genis anterioribus, tectricibus primariis et tectricibus minoribus anterioribus cyaneis; campterio et subalaribus coccineis; rectricibus mediis viridibus, 
ceteris violascente rubris, fascia apicali nigra, apice virili; rostro flavido. Ala 110, cauda $15 \mathrm{Mm}$.

Vorkommen: Nördliche Brasilianische Subregion (Guiana, Nord-Brasilien).

19. Euchroura dilectissima. - Kronen-Papagei.

Crochrome dilectissime (1870) Selater and Salvin Proc. Zool. Soc. p. 788 .

Abbildung: 1. c. pl, 47.

Diagnose: Virilis; pileo cranescente; maculis tribus frontalilus et ma utrinque postoctalari, flesura of campterio coceneis; subalaribus luteis; gula flavicante; rectricibus amreis, lateralibus viridi-terminatis, intermedis apice nigris; tectricibus primaris nigris; rostro apice thavicante; basi plumbeo; pedibus obscure plumbeis; iride crocea.

Long. c. 160, ala 110 , cauda $50 \mathrm{Mm}$.

Vorkommen: Nördliche Brasilianische Subregion (Meriela).

Genus: PIONTAS. Eigents. Stumplschwantrageien.

Piomes (1832) Wagl. Mon. Psitt. p. 497 (Typus: Psittacus menstmus L.). - Pionices (1868) Finsch Pap. II, p. 366.

Charakter dex Gattung: Mit mässig starkem Schnabel, der ungefïhr so hoch als lang ist, mit etwas gestrecktem Unterkieíer, der lïnger als hoch ist. Zahn- und Firstenrinne deutlich. Dillenleiste molentlich. Zweite und dritte order zweite bis vierte Selnwinge am lïnssten. Von dïsterer Förbung, in weleher blau vorherseht. mit Metallglanz; Unterschwandecken immer roth gefïrbt. 11 Arten in der Brasilianischen Subregion.

\section{Schïussel der Gattung:}

Unterkörper schwarzblau: chalcopterus.

Unterkörper röthlich' violet: violaceus.

Unterkörper grün, gelblich oder blïulich schimmernd:

Stirn weiss:

Sehwingen blaa: senilis.

Schwingen grün: gerontodes.

Stirn hellroth:

Kopf und Vorderhals blan: Maximilioni.

Ganzer Oberkopf, Kopfseiten und Vorderhals hellroth: tumultuosus.

Stirn blau oder grïn:

Ganzer Kopf und Vorderhals schön blau: menstrus. 
Oberkopf granblan, liopfseiten srïn mit hanen Fentersämmen, Kropffedern grün mit breiten blauen Süumen: flavirostris.

Kopf grün mit schmalen blanen Federsïumen:

Kropf oliven-gelbbräunlich: sordidus.

Blaues Kropfschild: comallinus.

+20. Pionias monstrues. - Schwarzohr-Papagei.

Englisch: Blue-headed Parrot. - Französisch: Perroquet à tite blene.

Psittacus menstrus (1766) Lin. S. N. p. 148. -- Psittacus ryanogula (1783) Bodd. Tabl. Pl. Enl. p. 23.

Abbildungen: Buffon Pl. Enl. pl. 384. - Levaillant Hist. Nat. Perr. pl. 114. -- Reichenow Vogelbilder t. XXYI, f. 4.

Diagnose: Viridis, alarum tectricibus sub certa luce olivacenamantis: capite at collo cyants: loris, regione ophthalmica et parotica nigricantibus, gulac plumis basi dilute rubris; subcaudalibus rubris, apice virulibus; rectricibus pogonii interni busi dilute rubris, pogonii externi basi viridibus vel caeruleis, apice caeruleis; rostro maxillae hasi rubro, culmine, apice et nandibula nigricante; pedibus nigricantibus; iride fusca.

Long. c. 320, ala 190, canda 90, culmen $25 \mathrm{Mm}$.

Vorkommen: Brasilianische Subregion.

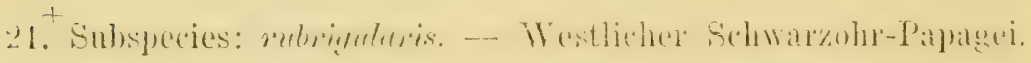

Pionus rubrigularis (1881) Cab. Journ. f. Orn. Heft II, p. 222.

Diagnose: Pracectenti simillimus, sed minor: "appite colloupu dilutius tinctis; macula distincta gulari dilute rubra.

Long. c. 290 , ala 175 , cauda 80 , culmen $25 \mathrm{~mm}$.

Vorkommen: Mexikanische Subregion.

22. Pionias Maximiliani. - Maximilian-Papagei.

Engl.: Maximilian Parrot. -- Franz: Perroquet Maximile.

Psittacus Maximitiani (18:0) Kuhl Consp. Psitt. p. 72. Piomus colaltinus (1854) Bu. Rev. Mag. Zool. p. 74.

Abbildung: Reichenow Vogelbilder t, X, I. 7.

Diagnose: P. menstruo simillimus, sed minor, fronte dilute rubra, cappite colloque lihutius tinctis, abdomine caerulescente et rostro flavo.

Long. c. 280, ala 175, cauda 85, culmen $25 \mathrm{Mm}$.

Vorkommen: Oestl. Brasilianische Subregion (Ost-Brasilien). 
23. Pionias flacirostris. - Gelbschnabel.

Englisch: Yellow-beaked Parrot. - Französisch: Perroquet ì machoires jaunes.

Psittacus fauirostris (1824) Spix Ar. Bras. p. 42. - Pioms Siy (1856) Sonancé Rev. Mag. Zool. p. 15.

Abbildungen: Spix Av. Bras. t. 31. - Bomrjot St. Hilaire H. N. P. pl. 54. - Sounncé Icon. Perr. pl. 34. - Reichenow Yogelbiliter t. XXVI, f. 5.

Diagnose: Viridis, dorso, alarum tectricibus et abdomine sub repta luce olisaceo-aurantiis; gutturis plumis late. genarum tenuiter crane-linbatis; pilit plumarm maninilns canescente cyaneis; loris nigris; subcandalibus dilute rubris, interdum violasente limbatis: rectribus virilibus, esterionibus ponomio externo cyaneis, pogonii intemi basi dilute rubris; rostro flavo.

Long. c. 320, ala 190, canda 100, calmen $27 \mathrm{MIm}$.

Vorkommen: Oestliche und Südliche Brasilianische Subregion.

24. Pionices corcallinus. - Korallenschnabel.

Engliseh: Red-beaked Parrot -- Französiseh: Perroquet à bec rouge.

Pionus corallimus (1854) Bp. Rey. Mag. Zool. p. 148.

Abbildungen: Rowley Ornith. Mise. III, 1. 5. - Reiehenow Vogelbilder t. XXVI, f. 1.

Ditgnose: Viridis, anpitis phunis cranesonte limbatio; scuto gutturali cyanco; subcaudalibus et rostro rubris; iride brumea; pedibus griseis.

Long. tot. c. 290, ala 190, cauda $90 \mathrm{Mm}$.

Vorkommen: Tretliche Brasilianische Subregion (Ecuador).

25. Pionicis sordidus. - Dunenk opf.

Englisch: Sordid Parrot. - Französisch: Perroquet sale.

Psittacus sordidus (1766) Lin. S. N. p. 148.

Abbildung: Reichenow Vogelbilder t. X, f. 4.

Diagnose: Sordide olivacens; pileo et loris nigro-cyaneis,

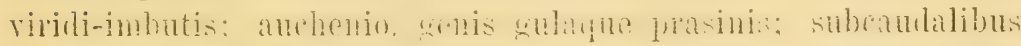
rubris; rectricibus exterioribus extus cyaneis, basi rubris; rostro corallino, basi plumbeo; iride fusca.

Long. c. 280, ala 160, cauda 85, culmen $25 \mathrm{Mm}$.

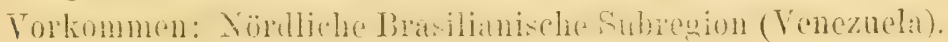

26. Pionias tumultuosus. -- Rosenkopf.

Englisch: Restless Parrot. - Franz.: Perroquet it tete rose. 
Psittacus tumultuosus (1844) Tschudi Fauna Perr. p. 270.

Abbildmgen: Rowley Oruith. Misc. III, p. 5. -- Reichenow Vogelbilder t. XXVI, f. 2.

Diagnose: Virilis; pileo toto dilute rubro; calpitis lateribus pallide roseis; gutture violascente roseo; flexura straminar; rectricibus exterioribus pogmio interno macula dilute rubra; subcaudalibus rubris; rostro Havo. Ala 1, Mo Mn. (T'este Sclater).

Vorkommen: Südl. Brasilianische Subregion (Peru, Bolivia).

27. Pionias gerontodes. - Greis.

Englisch: Massena's Parot. -- Franz.: Perroquet Massena.

Psittacus seniloides (1854) Mass. Souancé Rev. Mag. p. 73. Fionices gerontodes (1868) Finsch Pap. II, p. 455.

Abbildungen: Souancé Icon. Perr. pl. 36. - Reichenow Vogelbilder t. XXVI, f. 7.

Diagnose: Viridis; capite et gutture sordide fuscescente caesiis, plumis basi albis; fronte albat, rosen - imbuta; gentrum plumis albis, nigro-cinereo-limbatis; remigibus virilibus; sulcaudalibus et rectricum pounie interni dimidio basali dilute rubris; rostro flavo; pedibus griseis.

Long. c. 310, ala 190, cauda 85, culmen $28 \mathrm{Mm}$.

Vorkommen: Westliche brasilianische Subregion (Eandor, Columbia).

\section{Pionzics senilis. - Glatzenk opf.}

Engl.: White-headed Parrot. -- Franz: Perroquet sénile.

Psittcus senilis (1824) Spix Av. Bras. I, 1) 12. - Psittucus leucorhynchus (1827) Sws. Phil. Mag. p. 438.

Abbildungen: Bourjot St. Hilaire Hist. Nat. Perr. pl. 60. Spix Av. Bras. t. 31. - Reichenow Vogelbilder t. X, f. 6.

Diagnose: Obscure olivaceo-viridis, capite gulatue cyanescentibus; scapularibus aurantio-brumescentibus; remigibus eyaneis; sincipite albo; subcandalibus dilute rubris; rectricibus cyaneis, pogonii interni basi dilute rubris; subalaribus cacruleis; rostro pallide flavo; iride flava.

Long. c. 300, ala 170, cauda 90, culmen $24 \mathrm{Mm}$.

Vorkommen: Mexicanische Subregion.

\section{Pionias chalcopterus. - Glanzflügel-Papagei.}

Euglisch: Bronze-winged Parrot. - Französisch: Perroquet ani ailes brunes. 
Psittacus chalcopterus (1843) Fras. Proc. Zool. Soc. p. 59.-Psittacus hacmorphous (1854) Lcht. Nomencl. p. 70.

Abbildungen: Souancé Icon. Perr. pl. 35. - Reichenow Vogelbilder t. XXVI, f. 6.

Diagnose: Nigro-cyaneus, uropyrio, remigibus et tectricibus dilutoribus; interseapulio et scap:slaribus obseure fuscis; alarum 1ectricibus dilntius fuscis, olsolete limbatis; subcaudalibus, interdum quoque rectrieum mareine interno, dilute coccincis, violacen-limbatis; rostre Ha"o; pedibus et ammolo orbitali nudo carneis; iride brunnea.

Long. c. 300, ala 190, cauda. 90, culmen $27 \mathrm{Mm}$.

Vorkommen: Westliche Brasilianische Subregion (Ecuador, Columbia).

30. Pionias violacens. - Veilchen-Papagei.

Englisch: Dusky Parrot. - Französisch: Perroquet violet.

Psittacus violacens (1783) Bodd. Tabl. Pl. Enl. p. 25. Psittcicus fuscus [!] (1776) Miill. L. Naturs. p. 78. - Psittacus purpureus (1788) Gm. S. N. p. 346. - Psittacus infuscatus (1789-1813) Shaw Nat. Misc. pl. 789.

Abbildungen: Buffon P'l. Enl. pl. 408. - Shaw Nat. Misc. pl. 789. - Levaillant Hist. Nat. Perr. pl. 115. -- Reichenow Vngelbilder t. XXVI, f. 3.

Diagnose: Dorso et alis fuscis, plumarum marginibus dilutioribus; castitr nigro-cyanescente; fascia tenui frontali sordide rulua: gastraco rubro-violaceo: subcaudalibus dilute rubris, interdum violaceo-laratis; remigihus et rectricibus pogonio externo apiceque nigro-cyancis, pogonio interno rectricum rubro; rostro basi flavo, apice nigricante; perlibus nigrieantibus; iride fusca.

Long. c. 290, ala 170, cauda 80, culmen $26 \mathrm{Mm}$.

Vorkommen: Nördliche Brasilianische Sulnecgion (Guiana, Nor(t-Brasilien).

Genus: ANDROGLOSSA. A m a zon e

Androglossa (1825) Vigors Zool. Journ. II, p. 400 (Ohne Typus). - Amusome (1831) Tiess. Tratió d'Ornith. p. 189 (Typus: Ps. pulvemlentus Gm.). - Tuvouc ibid. p. 195 (Typus: Ps. amazonicus L.). - Chrysotis (1837) Sws. Classif. B. II, p. 300 (Typus: Ps. amasonicus L.). - Oenochrus (1854) Bp. Rev. Mag. Zool. p. 151 ('Typus: Ps. vinacens Pr. v. Wied). 
Charakter der Gattune: Im allgemeinen der Galtung Pionics

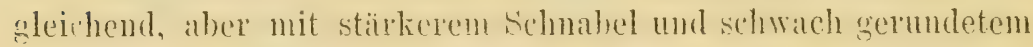
Schwanze. In Flibgel zweite his vierte Schwinge am längsten, erste kürzer als fünfte. Fürhmu im allgemcinen grün. Unterschwanzlecken inmer grün. 3ti Iren in der Brasilianischen und Mexicanischen Subregion.

$$
\text { Schlüssel der Gatung: }
$$

Kopf und Unterseite dunkel Wcimroth: ungustu. Oberkopf und Kopfseiten griunlich orler bläulich:

Kopf grösstentheils grün:

Kein roth an der Innenfahne der Schwanzfedern:

Oberkopf blau: Gruatemalce.

Oberkopf griun oder mit hochelbem Scheitelfeck: furinos. Nit roth anf der Imenfahme der Schwanzfedern:

Oberkopf graublan: agilis.

Oberkopf griin:

Mit gelbem Nackenfleck: auripalliuta.

Hit grauem Halsring: canipalliata.

Ohne Nackentleck oder Halsring, (Oberkopf mod Nackenfedern schwarz gesäumt: mercenuria.

Kopef grösstentheils blangriin, Flïgelbug roth: Vuttereri.

Kopf grösstentheils blau:

Kiropf scharlachoth, Tnterkïrper gelblich grïn: Donqueti.

Unterkörper weinroth: versicolor.

Stirn roth:

Bürzel roth:

Wangen grün, Schwanzfedern ohne roth: festive.

Wangen blüulich, änssere Schwanzfodern an der Basis der

Innenfahne roth: Bodini.

Bürzel griñ :

Ohne rothen Flügelspiegel:

Schwanzferern an der Basis der Innenfahne roth: vittutu.

Schwanzfedern an der anzen Basalhälfte roth: erythrura. Schwanzfedern an der Spitzenhälfte roth: brasiliensis.

Mit rothem Flügelspiegel:

Kropf und Brust hellblau, violet schimmernd: vinacee. Kropf und Brust grün:

Ohne roth an den Schwanzfedern:

Stimbinde dunkelroth, Oberkopf blau: Finschi. Stirnbinde rothgelb, Oberkopf grün oder gelblich: cueruligena.

Roth an der Innenfahne der äusseren Schwanzfedern: Schmale rothe Stirubinde, Federn des Oberkopfes hellblau gesïunt: diudemo.

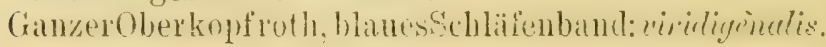


Stirn weiss:

Vorderkopf, Augengegend und Flïgelbug roth: Pretrii. Vorderkopf scharlachroth, Augengegend gelb: cutumnalis.

Vorderkopf memigroth, Ziigel und vordere Wangen gelb: Drivesnayi.

Augengegend roth:

Zitgel roth: allifions.

Zügel gelb: antholora.

Augengegend weiss oder grün:

Kehle und Wangen grïn: ventralis.

Kehle und Wangen rosa: leucocephale (s. auch collevia).

Wangen blan: Gritdingi.

Stirn oder Kopfseiten oder beide gelb:

Stirn blan, Kopfseiten gelb:

Flügelbug grün oder gelb: amazonice.

Flïgelbug roth: aestiva.

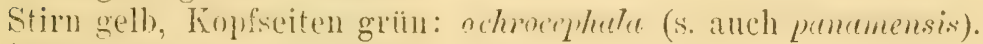

Stirn und Kopfseiten gelb:

Flügelbug grün: vanthops.

Fliigelbug gelb: ochroptera.

Flïgelbug roth: Levcillantii.

31. Androglossa Guatemalae. - Guatemala-Amazone.

Englisch: Guatemalan Amazon. - Französisch: Amazone de Guatemale.

Chrysotis Guatemulae (1844) Hartl. Verz. Brem. Samml. p. 87.

Abbildungen: Finsch Pap. t. 4. - Reichenow Vogelbilder taf. XIX, fig. ?.

Diagnose: Viridis, notaeo cano-farinoso, cervicis plumis

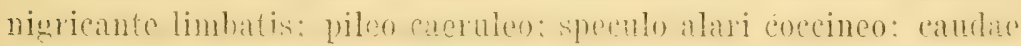

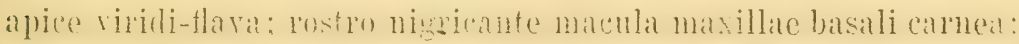
pedibus nigricantibus; iride rufa.

Long. c. 460, ala 230, cauda 140, culmen $38 \mathrm{Mm}$.

Vorkommen: Mexicunische Subregion.

3?. Androglossa agilis. - Rothspiege1-A mazone.

Englisch: Active Amazon. - Französisch: Perroquet crik.

Psittaus cayanensis (1760) Briss. Orn. IV, 1). 237. - Psittucus agilis (1766) Lin. S. N. p. 143. - P'sitturus signatus (1812) Shaw Gen. Zool. VIII, p. 510. - Psitterus virescens (1811-12) Bechst. Kurze Uebers. p. 99. - Psittacus minor (182:3) Vieill. Enc. Méth. p. 1367.

Abbildung: Levaillant Ilist. Nat. Perr. pl. 10 s. 
Diagnose: Viridlis; pileo dilute caesio; tectricibus primariis miniato-coccineis; rectricibus pogonii interni basi flaris, macula rubra, extimis poponio externo caerulescente.

Ala 155, cauda $80 \mathrm{Mm}$.

Vorkommen: Antillische Subregion (Jamaica).

33. Androglossa farinosa. - M ïll er-A mazone.

Englisch: Mealy Amazon. - Französisch: Memicr.

Psittacus farinosus (1783) Bodd. Tabl. Pl. Enl. p. 52. Psittacus pulverulentus (1788) Gm. S. N. p. 341.

Abbildungen: Buffon Pl. Enl. 1)l. 861. - Levaillant Hist. Nat. Perr. pl. 85 et 92. - Reichenow Vogelbilder t. XIX, f. 1.

Diagnose: Viridis, cervicis plumis nigro-limbatis, lorso et cervice cano-farinosis; vertice interdum macula lutea, miniata et violacea ornata; campterio et speculo alari coceineis; rectricibus apice flavidis, extimis pogonii externi basi cyaneis; maxilla. basi carnea, apice et mandibula nigricantihus; pedihus nigricantibus.

Long. c. 450, ala 250, cauda 140, culmen $40 \mathrm{Mm}$.

Vorkommen: Brasilianische Subregion.

34. Androglossa merecnaria. - Soldaten-Amazone.

Englisch: Mercenary Parrot.

Psittacus mercenarius (1844) Tschuli Fauna Per. p. 270.

Abbildungen: Tschudi l. c. t. 27. - Mag. Zool. 1858, pl. 17 (jun.).

Diagnose: Viritis, pilei et ecrieis plumis nigro-limbatis; campterio luteo: rectricibus virilibus, ante apicem flavidam pogonio interno macula rubra notatis, exterioribus pogonio interno usque al apicem rubris, extimis pogonio externo cyanescentibus; speculo alari coccineo.

Long. c. 320, ala 220, cauda 110, culmen $32 \mathrm{Mm}$.

Vorkommen: Nördl. Chilenische und Westl. Brasilianische Subregion (Peru, Ecuador, Nelt-Granada).

35. Androglossa auripalliata. - Goldnacken-Amazone.

Englisch: Golden-maped Amazon.

Psiturus an a-pulliutus (1842) Less. Rev. Mag. Zool. p. 13).. Psittecus flavinuches (1843) Gould Proc. Zool. Soc. p. 104. Chrysotis occipitalis (1854) Bp. Rev. Mag. Zool. p. 151.

Abbildungen: Voy. Sulph. 1844, pl. 27. - Souancé Icon. Perr. pl. 27. 
Diagnose: Tiridis; macula eervicis lutea, interdum quoque pileo flavo: restricibus pogonii externi basi viribus, pownii interui basi rubris, apice viridi-flavis; speculo magno alari coccineo; rostro fulvo, basi flavido.

Long. c. 340, ala 220, cauda 120, culmen $35 \mathrm{Mm}$.

Vorkommen: Mexicanische Subregion.

36. Androglosse cenipalliate. - Halsband-Amazonc.

(Horysotis canipulliate (1874) Cab. Journ. f. Ornith. 1) 10j. Abbildung fehlt.

I)iagnose: Viridis, fronte mentoque. surua- et subcaudalibus Havescentibus: fascia collari, in auchenio latissima, cana: pileo canescente, campterio luteo; rectricibus basi viridibus, pogonio interno macula rubra notatis, apice flavillis, cxtimis pogonio cxterno (acruleis: speculo alari vix distincto rubro: rostro et pedibus nigricantibus.

Long. c. 350, ala 240, cauda 130, culmen $35 \mathrm{Nm}$.

Vorkommen: Nördl. Brasilianische Subregion (Nent-frallatal).

37. Androglossa Nattereri. - Grïne Amazone.

Lngl.: Natterer's Amazon. - Franz.: Amazone Natterer.

Chrysotis Nattereri (1864) Finsch Journ. f. Orn. p. 411.-Chrysotis thalassina (1868) Finsch Pap. II, p. 563.

Abbildung fehlt.

Diagnose: Viridis; fronte. capitis lateribus gulaque cyallescente viridibus; Hexura et speculo alari rubris: caudac apice Havida; rostro pallide fulvo, appee nigricante; annulo orbitali nudo albido; iride crocea.

Ala 220, cauda $140 \mathrm{Mm}$.

Vorkommen: Brasilianische Subregion (Nordwest Drasilien).

38. Androglosere versicolor. - Blaustirn- $\mathrm{maz}$ anc.

Englisch: Blue-fronted Parrot. - Französisch: P'erroguct de la Havane.

Psittacus cmazonicus gutture coemeo (1760) Briss. Orn. IV,

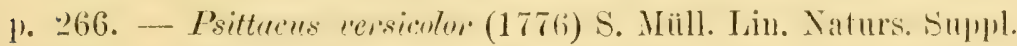
1. 78. - Psittecus chenomplemeches (1783) Ponde. Tabl. I'l. Enl. 1. 22. - Psittueus havenensis (1788) Gu. S. N. 1. 342. Psittacus cyanopis (1823) Vieill. N. 0. XXV, p. 325.

Abbildungen: Bufton Pl. Enl. pl. 360. - I.evaillant Ilist. Nat. Per'r. pl. 122.

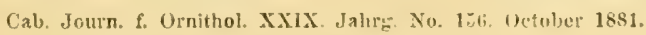


Diagnose: Virielis, notaei plumis nigro-limbatis; pileo, genis mentoque cyaneis; abdomine vinaceo; speculo alari coceineo; rectricibus apice flavidis, exterioribus pogonii externi basi cyancis. interni basi, macula coccinea alteraque cyanea notatis; rostro Havido (Teste Finsch).

Ala 250, cauda $160 \mathrm{Mm}$.

Vorkommen: Antillische Subregion.

39. Androglossc Bouqueti. - IBlankopl.

Englisch: Blue-faced Amazon. - Französisch: Perroquet bouquet.

Psittacus arausiacus [!] (1776) S. Müll. Lin. Naturs. Suppl. p. 79. - Psittceus Bouqueti (1793) Bechst. Lath. Ucbers. p. 99. Psittacus caerulifrons (1812) Shaw Gen. Zool. VIII, p. 515. Psittacus cyaneocapillus (1823) Vieill. Enc. Méth. p. 1373. Chrysotis cyanocephalus (1837) Sws. Classif. B. II, p. 301. cthrysutis nichollsi (1880) Lawrence Ln. St. N. I. 1880 1. 25t ('leste Sclater).

Abbildungen: Levaillant Hist. Nat. Perr. pl. 135. - Proc. Zool. Soc. 1875, pl. 11.

Diagnose: Viridis, notaei plumis nigro-limbatis, abdomine flavescente; capite cyaneo; gutture et speculo alari coccincis; rectricibus apice flavicantibus, exterioribus pogonii interni halsi coccineis, pogonio externo cyancis; rostro nigricante; iride miniata.

Vorkommen: Brasilianische Subregion (Brasilien). 40. Androglossa festiva. - Blaubart.

Engliseh: Festive Amazon. - Franz.: Perroqnet Tavoua.

Psittans festivns (1766) Lin. S. N. p. 147. - Chrysolis chloronote (1856) Sonancé Rev. Mag. Zool. p. 153.

Abbildungen: Buffon Pl. Enl. pl. 840. - Levaillant Ilist. Nat. Perr. pl. 88 et 129. - Sonancé Icon. Perr. pl. 29. Reichenow Vogelbilder t. I, f. 2.

Diagnose: Viridis; fascia frontali et loris sordicle carmincis; tergo et uropygio rubris: mento et fascial supereiliari carrulcis: interdum vertice caerulescente; rectricibus viridibus, apice (lilutioribus; rostro fulvo; pedibus fuscis; iride crocea.

Long. c. 350, ala 200, cauda 110, culmen 32 Mm.

Vorkommen: Irasilianische Subregion (Venezucha, Guiama, Brasilien, Bolivia). 
41. Androplossa Budini. - Rothstirn- Ama\%onc. Englisch: Bodinus' Amazon. - Franz. Amazonc Bodiuts. Chrysotis Bodini (1873) Finsch Proc. Zool. Soc. 1) 569.

Abbildung: Proc. Zool. Soc. 1873, pl. 49.

Diagnose: Viridis, cervicis plumis nigro-marginatis, genis ciacrulescentibus; sincipite miniato-coccineo; tergo et uropygio coceineis: loris nigris; pteryllio et tectricibus primariis viridibus: rectricibus viridibus, extimis pogonii interni basi rubris; rostro et pedibus nigricantibus; iride miniata. Mensuris 4. festiuce.

Yorkonmen: Nördliche Lirasilianische Subregion (Venezuelit).

42. Anciroglossa vittata. - Portorico-Amazonc.

Englisch: Red-fronted Amazon. - Französisch: Perroquet de St. Dominge.

Psittecus vittutes (1783) Bodd. Tabl. Pl. Enl. p. 49. -Psittucus dominicensis (1788) Gm. S. N. p. 343.

Abbildungen: Buffon Pl. Enl. pl. 792. - Levaillant Hist. Nat. Perr. pl. 103 et 108 bis.

Diagnose: Viridis, plumarum maryinibus nigris; fascia tenui frontali rubra; rectricibus pogonii interni basi rubris, intus aluantio - limbatis, extimis pogonio externo caeruleis; pteryllio, tectricibus primaris et remigibus pogonio externo dilute cacruleis; rostro flavido; pedibus brunneis: ammulo orbitali albido.

Long. c. 300, ala 175 , cauda 110 , culmen $28 \mathrm{Mm}$.

Vorkommen: Antillische Subregion (Porto Rico).

43. Androglosse erythrue. - Rothschwanz-A mazone.

Englisch: Red-tailed Anazon. - Französisch: Amazone à quene rouge.

Psittecus erythrurus (1820) Kuhl Consp. Ps. 1) 77.

Abbildung: Proc. Zool. Soc. 1880, pl. 2.

Diagnose: Viridis; sincipite miniato-coccinco; vertice croceo; caphitis lateribus violaceo-caeruleis; campterio et rectricum parte basali rubris, his apice Havidis; rostro fusco; pedibus griseis; iride rufi. Magnitudine A. autumenelis.

Vorkommen noch nicht sicher festgestellt.

4t. Androglosse bresiliensis. - Rothmasken-A mazonc.

Englisch: Brazilian Green Parrot.

Psittecus bresiliensis fronte mube (1760). Briss. Ornith. IV, 1. 245. - Psitteces brecsiliensio (1766) Lin. S. N. 1. 147. - 
Psittecus aganotis (1820) Kuhl Consp. Psitt. 1) 77. - Psittenes crythopis (1823) Vieill. N. D. XXV, 1. 325.

Abbildung: Levaillant Hist. Nat. Perr. pl. 106.

Diagnose: Viridis. subtus flavescens; facie sordide rubra: genis et legione parotica cyancis: campterio et caludac dimidio alpicali rubris: rectricibus extimis pogonio externo violaceis.

Ala 210, cauda $110 \mathrm{Mm}$.

Vorkommen: Brasilianische Subregion (Süd-Bratsilien).

45. Androglossa vinaved. - Taubenhals- A mazone.

Englisch: Vinaceous Amazon. - Französisch: Amazonc it bec couleur de sang.

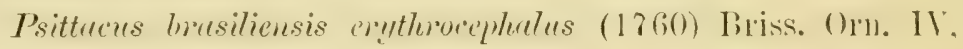
1. 240. - Psittacus tarabe (1788) Gm. S. N. p. 344. - Psittacus vinuceus (1820) Neuw. Reise Bras. II, p. 198. -- Psittucus columbines (1824) Spix Av. Bras. p. 40.

Abbildungen: Spix Av. Bras. t. 27. - Bourjot St. IIilaire Hlist. Nat. Perr. pl. 65. - Reichenow Vogelbilder t. XIX, f. 3.

I)iagnose: Viridis, capritis et dorsi plumis nigro-limbatis: jugulo et pectore caeruleis, violaceo-mieantibus, plumarum marginibus nigricantibus: auchenii plumis caleruleis, nigro-limbatis; loris et campterio dilute coccineis: speculo alari rubro: rectricibus cxterioribus basi rubris, intus aurantio-limbatis; restro rubro: pedibus nigricantibus; iride rufa.

Long. c. 370, ala 210, cauda 120, culmen $30 \mathrm{Mm}$.

Vorkommen: südl. Brasilianische sulnergion (sü̈l-brabilien, Palliguruy).

46. Androglosse diatemute. - Diadem-A mazonc.

Fngl.: Diademed Amazon. - Franz: Perroquet comromué.

Psittecens diculeme (1824) Spix Av. Bras. 1) 43. - Chrysotis diedemete (1868) Finsch Pap. II, p. 545.

Abbildungen: Spix Av. Bras. t. 32. - Souancé Icon. Perr. pl. 32.

Diagnose: Viridis; fronte, loris et speculo alari coccincis: pilai ct nuchate plumis violascente caeruleo-limbatis: rectricibus appice flavo-viridibus, exterioribus pogonii interni basi makula flarva rubla, extimis pogonii externi basi cyanco-limbatis: rostro Havido, culmine et apice nigricantibus.

Long. c. 310, ala 205, cauda 120, culmen $32 \mathrm{Mm}$. 
Vorkommen: Nördliche Brasilianische und Südliche Mrexianische Subregion (Guiana, Columbia, Panama).

47. Amlroglossc Finschi. - Blaukappen-Amazone.

Englisch: Finsch's Amazon. - Franz: Amazone Finsch.

Chrysotis viridigenalis var. (1859) Gray List Ps. p. 82. Chrysotis Finschi (1864) Sclater Proc. Zool. Soc. p. 298.

Abbildungen: Sonancé Icon. Perr. pl. 31. - Proc. Kool. Soc. 1874, pl. 34 .

Diagnose: Viridis, corporis plumis obscure limbatis; fronte jurpurascente rubra; pileo et cervice eaeruleis; speculo alari coccineo; rostro dilute fulvo; pedibus griscis; iride crocen.

Vorkommen: Mexicanische Subregion (Mexico).

48. Ambroglossa viridigenalis. - Grï 11 wangen-A ma\%onc.

lnolisch: Green-ehecked Amazon. - Framzösisch: Perrougut it joures vertes.

Amasona lilacina [!] (1844) Less. Echo du Monde Sar. 1). 394. - Chrysotis viridigenalis (1853) Cass. Pr. Ac. Phil. IV,

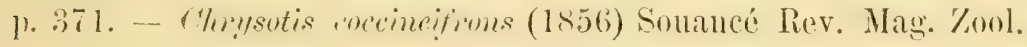
p. 154. - Psittacus vernans (1868) Finsch Pap. II, p. 541.

Abbildungen: Souncé Icon. Perr. pl. 31. - Reichenow Vogelbilder t. XIX, f. 6.

Diagnose: Viridis; plumarum marginibus nigricantibus; pileo et speculo alari rubris; fascia temporali azurea; cauda apice dilute viridi: rostro flavide; pedibus brumeis: iride rufi.

Long. c. 360 , ala 210, cauda 110, culmen $30 \mathrm{Mm}$.

Vorkommen: Wrestiche Brasilianische subremion (columbial, E(mator).

4\%. Amtroglessa Prétrii. - Pracht- $\mathrm{m}$ mannc.

Engl.: Prêtre's Amazon. - Franz: Perroquet de Prêtre.

Prittacus Pretrei (1820-1824) T'emm. Pl. Col. pl. 492. chomsolis remus (1854) Licht. Nomencl. 1) 70.

Abbildumgen: l'emm. 1. c. - Bourjot St. Ililaire IIist. Nat. P(Ir). pl. 66 .

Diagnose: Viridis. plumarum marginibus nigris; sincipite, Ioris ot perioplethalmiis, flexura, campterio et tectricibus primaris rubris; rectricibus omnibus viridibus, apice flavoviridibus; rostro et pedibus flavidis; iride crocea.

Long. c. 350, ala 210, cauda 130, culmen $26 \mathrm{Mm}$. 
Vorkommen: Sïlliche Brasilianische Subregion (SiirlBrasilien, Uruguay).

50. Androglossa caevuligene. - B lauwangen- $\mathrm{m}$ mazone.

Englisch: Blue-cheeked Amazon.

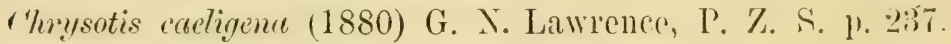

Abbildung: Proc. Zool. Soc. 1880, pl. $\%$

I)iagnose: A. Dufresnii simillima, sed fronte croceal vertier viridi, interdum aurantio-imbuto; speculo alari miniato: rectricibus sine macula miniato-coccinea.

Vorkommen: Nördl. Brasilianische Subregion (Brit. Guiana). 51. Androglossa Jufresnii. - Goldmasken-Amazone.

Engl.: Dufresne's Amazon. - Franz: Perroquet Dufresue.

Psittacus Thufresniame (1820) Lcvaillant, Kuhl Consp). Ps. 1) 78. - Chrysotis Dufresnii (1837) Sws. Class. B. II, p. 301. Psittacus coronatus Lcht. (teste Gray) List Psitt. p. 80.

Abbildungen: Levaillant Hist. Nat. Perr. pl. 91. - Proc. Zool. Soc. 1880, pl. 9.

Diagnose: Viridis, cervicis et dorsi plumis nigro-limbatis: pileo et speculo alari miniato-coccineis; loris, interdum quorpue regione mandibulari huteis; genis gulaque caruleis; rectricibus apiec flavis, pogonio interno macula anteapicali et alteria indistincta basali miniato-coccineis; extimis margine exteriore cyanca; rostro basi rubro, culmine et apice brumneis.

Long. c. 380 , ala 210, cauda 130 , culmen $32 \mathrm{Mm}$.

Vorkommen: Brasilianisehe Subregion (Brasilien).

52. Androglossa autumalis. - Gelbwangen- $\mathrm{Amaz}$ m 1 .

Englisch: Yellow cheeked Amazon. - Franzïsisch: Prrropun i) joures oranges.

Psittacus americanus (1760) Briss. Ornith. IV, 1). 29:3.Psitacus autumalis (1766) Lin. S. N. 1. 147. - Tsillenes anrontius (1823) Vieill. N. 1). XXV, 1) 325. - (thy)stis restivalis (1856) Bp. Nammannia Beilage.

Abbildungen: Ievaill. IList. Nat. Perr. pl. 111. - Roichmow Vogelbilder t. XIX, f. 7 .

J)iagnose: Viridis, cervicis plumis nigro-limbatis: fronte. loris ef speculo alari coccineis; vertice et oecipito dilute cacruleis:

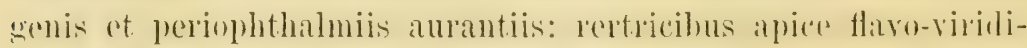

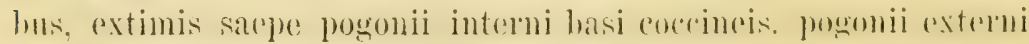
basi careruleis; rostro thavido; iride rufir. 
Long. c. 380, ala 210, cauda 140, culmen $32 \mathrm{Mm}$.

Vorkommen: Mexicanische Subregion.

53. Androglossa albifrons. - W e issstirn-Amazone.

Enelisch: White-browed Amazon. - Französisch: Perrounet it joutes rouges.

Psittacus albifrons (1787) Sparrm. Mus. Carls. t. 52. Psittucus erythrops (1831) Cuv., Less. Tr. d'Orn. 1. 200. -

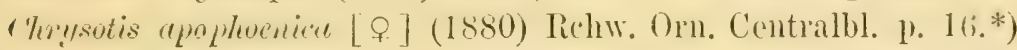

Abbildungen: Souancé Icon. Perr. pl. 30. - Reichenow Vogelbilder t. I, f. 8.

Diagnose: Viridis, plumarum marginibus nigricantibus; loris ('t poriophthalmiis rubris: fronte alba; vertice carulen; tectrieibus mimaris, pteryllio ef rectricum exteriorum basi rubris: rostro flaro: penibus griseis; iride crocea: ammulo orbitali intu albo.

Long. c. 310, ala 185, cauda 110, culmen $29 \mathrm{Mm}$.

우: Tectricibus primariis viridibus, fronte alba et periophlithalmiis rubris angustioribus.

Vorkommen: Mexicanische Subregion.

54. Androglosse rentholora. -- Gelbzü gुel- $\Lambda$ mazone.

Englisch: Yellow-lored Amazon.

Chrysotis acentholore (1859) Gray List Psitt. p. 83.

Abbildungen: Proc. Zool. Soc. 1875, pl. 26. - Reichenow Vogelbilder t. I, f. 9.

Diagnose: Viridis, plumarum marginibus nigris, regione parotical nigra; sincipite albo; loris luteis: regione ophthalmica, matroine cubitali et tectricibus primariis rubis; rectribibus restrionibus balsi luteis, mbro-maleulatis: rostro flaro: perlibus fulvis: iricle crocea.

Long. c. 270 , ala 160 , cauda 85 , culmen $28 \mathrm{Mm}$.

Vorkommen: Mexicanisehe Subregion (Yueatan, Honduras).

55. Ameroglosse ventielis. - blaukrone.

Gnglisch: Sallés Amazon. - Französisch: Perruche ì ventre pourpre.

Psittacus martinicanus ayonoceptalus (1760) Briss. ()'I. IV,

*) Nach Dr. Sclater weisen die Sammlungen Salvin's nach, dass diese Form der weibliche Vogrel zu Androglossa albifrons sei, welcher Ansicht wir unter Vorbehalt folgen. 
p. 251. - Psittacus ventralis (1776) S. Müll. S. N. Supll.

p. 79. - Clmysotis Sallaci (1857) Scl. Pr. Z. S. p. 224.

Abbildungen: Buffon Pl. Enl. pl. 548. - Levaillant Mist. Nat. Perr. pl. 109. - Reichenow Vogelbilder t. XIX, f. 4.

Diagnose: Viridis, plumarum marginibus nigris: fronte of annulo orbitali albis; vertice caterulescente; regione parotica nigra; ventre medio rubro; rectricibus basi coccincis, apico flavidis, margine interiore aurantiis, extimis pogonio externo (aeruleis: pteryllio, tectricibus primariis et remigibus pogonio externo caeruleis; rostro et perlibus flavo-carneis: iride rufa.

Long. c. 350, ala 190, cauda 120, culmen $29 \mathrm{Nm}$.

Vorkommen: Antillische Subregion (St. Domingo).

56. Chrysotis leucocephala. - Kuba-Amazone.

Englisch: White-fronted Amazon. - Franzisisch: Perropuot. à tête blanche.

Psittacus Paradisi (1760) Briss. Ornith. IV, p. 147. -

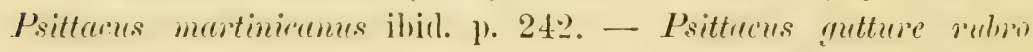
ibid. p. 244. - Psittarus lutens insulae Cubce ibid. p. 308. Psittcuss lencoceptalus (1766) Lim. S. N. p. 145.

Abbildungen: Buffon Pl. Enl. pl. 335. - Levaillant llist. Nat. Perr. pl. 107, 107b und 1:37. - Reichenow Vogelbilder taf. XIX, fig. 5.

biagnose: Viridis, plunarum marginibus nigricantibus; sincipite et ammulo orbitali albis: genis gulaque roseis: ventre medio rubro - violaceo; rostro dilute Havo: rectricibus pogonii interni basi rubris, apice viridi-flavis, extimis pogonio extremo dilute caculcis; perlibus fulvis; iride rufa.

Long. c. 350, ala 175, canda 120, culmen $28 \mathrm{Vm}$.

Vorkommen: Antillische Subregion (Cuba).

57. Subspecies: collaria. - Jamaika-A mazone.

Englisch: Red-throated Amazon. - Franzïsisch: Perrogunt. de la Martinique.

Psiltarts jommicensis gutture vulno (1760) Briss. Ornith. IS, p. 241. - Psittacus collarius (1766) Lin. S. N. p. 149. Psillenes gulturatis (1776) S. Müll. Lin. Naturs. Suppl. p. 78. Piomus vinuecicollis (1846) Lafr. Rev. Zool. p. 321.

Abbildung: Puftion Pl. Enl. pl. 549.

biagnose: Viridis: cervicis plumis tomber nigrieante lim- 
batis; sincipite et loris abbis; capitis lateribus gulaque roseis: rostro flavo; pedibus flavo-carneis.

Ala 180, cauda 105 Mm.

(Obs.: A. leucocephalac simillima, sed macula ventrali rubra nulla).

Vorkommen: Antillische Subregion (Jamnaica).

58. Androglossa amazonica L. - Amazonen-Papagei.

Englisch: Orange-winged Imazon. - Französiseh: Amazone.

Psittacus amasonicus (1760) Briss. Ornith. IV, p. 256. Psittacus amazonicus fronte luter ibid. p. 261. - Psittucus jemaicensis icterocephalus ibid. 1). 233. - Psittacus brasitiensis manocephalnes ibid. p. 234. - Psittacus amasonicus (1766) Linn. S. N. p. 147. - Psittacus luteres (1788) Gm. S. N. p. 341.-Psittacus luteolus (1790) Lath. Ind. Orn. p. 123. - Psittacus Aourou (1812) Shaw Gen. Zool. VIII, p. 508. - Psittacus agilis (1866) Léotaud Ois. Trin. p. 327.

Abbildungen: Buffon Pl. Enl. pl. 547 nt 8:39. - Levaillant Hist. Nat. Perr. pl. 110 et 110 his. - Reichenow Vogelbilder t. I, f. 6 .

Diagnose: Virilis, cervicis plumis nigro-limbatis; froute of liscia supereiliari azureis, vertice, eapitis lateribus ot campterin flavis: speculo alari miniato: rectricibus aptece thavilis, exterioribus pogonio interno miniatis: rostro fulvo, alpice fusco: perlibus fuscis: iride miniata.

Long. c. 360, ala 200, cauda 110, culmen $31 \mathrm{Nm}$.

Vorkommen: Brasilianische Subregion.

50. Androglossa aestine. - liothbug-Amazono.

Englisch: Blue-fronted Amazon. - Französisch: Amazone it ralotte bleue.

Psittens amasonicus jamaicensis (1760) Briss. Ornith. IV. p. 276. - Psittacus rmasonicus verius ibid. p. 281. - Psiltacus lutens ibicl. p. 306. - Psittaens cayemene (1776) Müll. Lin. Naturs. Suppl. 1) 78. - Psittacus guttatus (1783) Bodh. Tahl. PI. Enl. p. 8. - Psittacus aneren (1788) Gm. S. N. 1. 342. Isiltacus aestimes (1790) Lath. Ind. Orn. p) 121. - Amasom.t iderocepleale (1831) Less. Traité d'Oru. p. 190.

Abbilitungen: Buffon Pl. Enl. pl. 312. - Levaillant Ilist. Nat. Perr. pl. 84 und 87. - Reichenow Vogelbilder t. I, f. 7. Llagnose: Viridis, cervicis plumis nigro-limbatis; fronte 
cacrulea; vertice, capitis lateribus, gula et campterio flavis: flexura et speculo alari coccincis; rostro et pedibus nigricantibus; rectricibus apice flavidis, exterioribus pogonii interni basi lilute coceineis, extimis margine externo cyaneo; iride miniata.

Long. c. 420, ala 230, cauda 135, culmen $33 \mathrm{Mm}$.

Torkommen: Brasilianische Subregion (Brasilien, Paraguay). 60. Androglossa ochrocephala. - Gelbscheitel-Amazone.

Englisch: Yellow-fronted Amazon. - Franzö isch: Perroquet de Cayenne.

Psittrens amuranicus poecilorlynachus (1760) Briss. Orn. IV. p. 270. — Psittacus amazonime Irasiliensis ibir. p.272. Psittacus ochrocephahes (1788) Gm. S. N. 1. 339. - Psillacus poikilorhynchus Shaw Gen. Zool. VII, p. 491. - Amusonce icterocephala (1831) Less. Traité d’Orn. p. 190.

Abbildung: Souancé Icon. Perr. pl. 28.

Diagnose: Viridis, subtus Havescens; plumarum mareinihus tenuibus nigricantibus; sincipite flavo; flexuxa et speculo alari rubris; rectricibus apice flavidis, pogonii interni basi rubris: rostro nigricante, basi carneo.

Long. c. 400, ala 230, cauda 130, culmen $35 \mathrm{Mm}$.

Vorkommen: Nörlliche Irasilianische Subregion ((iniana. Surinam, Venezuela).

61. Subspecies: panamensis. - Panama-Amazonc.

Chysotis panamensis (1874) Cab. Journ. f. Ornith. 1. 319.

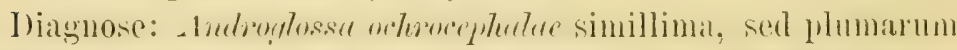
marginibus minime nigris; vertice thalassino; rostro flavido, apicer plumbeo.

Long. c. 320, ala 200, cauta 115, culmen $30 \mathrm{Mm}$.

Vorkommen: Mexicanische Subregion (T'anama, Voramua).

62. Androglossa ochopterce - Gelb kop f.

lingliseh: Yellow-shouhlered Amazon. - Franzisisch: Porrorpuet ì épaulettes jaunes.

Psittacus basbalensis (1760) Briss. Orn. IV, p. 236. Psiltarus amaronicus gutture luteo ibid. p. 287. - Psittacus curolinensis (1769) Scop. Ann. I, p. 29. - Psittuens nchopterus (1788) Gm. S. N. p. 341. - Jsittacus ieterocepladus (1831) Less. l'raité d'Orn. 1) 190. - Psittacus ranthops (1832) Wagl. Mon. P'sitt. 1). 584. - Chrysotis lactirons (1878) G. N. Lawrence Ann.

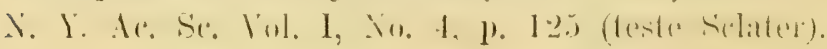


Abbildmingen: Levaillant Hist. N. P. pl. 98 et 98 bis. Reichenow Vogelbilder t. I, f. 5.

Diagnose: Viridis, plumis nigro-limbatis; sincipite, genis. mento et tibis luteis, fronte albida; speculo alari rubro: rectricibus, rostro et pedibus ut in A. Levaillanti tinctis.

Long. c. 400, ala 220, cauda 140 , culmen $32 \mathrm{Mm}$.

Torkommen: Nördliche Brasilianische Suhnegion (Vinezundil).

63. Androglossa Levaillanti. - Grosser Gelbkopf.

Englisch: Levaillant's Amazon. - Französisch: Perroquet à tête jaune.

Chrysotis Levallantii (1859) Gray List Psitt. 1) 79.

Abbildungen: Levaillint Hist. Natt. Per'. pl. 86. - Reichenow Vogelbildler t. I, f. 4.

Diagnose: Viridis; capite toto Havo, facie pallidiore; tibiis (et campterio thavis: flexura et speculo alari coceineis; rectricibus viridilus, apice flavidis, exterioribus hasi pogonii interni rubris, extimis margine externo caculeis: rostro et pedibus pallide: Havicantibus; iride miniata.

Long. c. 420, ala 230, cauda 140, culmen $36 \mathrm{Mm}$.

Vorkommen: Nexicanische Subregion.

64. Androglosse ectuthops. - Goldbauch-Amazone.

Engl.: Yellow-faced Parrot. - Franz.: Amazone à ventre jaune.

Psittecus acthops (1824) Spix Av. Bras. p. 39. - Tsittures hompormelriacus (1832) Leht. Wagl. Mon. I'sitt. p. 590.

Abbildungen: Spix Av. Bras. t. 26. - Souancé Icon. Perr. 1). :3.3.

Diagnose: Viridis; capite toto Havo; fascia lata ventrali lutea, utroque macula miniato-coccinea notata; rectricibus basi dilute miniato-coecincis: rostro flavo.

Long. c. 330, ala 200, cauda 100, culmen 31 Mm.

Vorkommen: Brasilianische Subregion (Brasilien).

65. Androylossa ariguste. - Ka iser- A mazone.

Englisch: August Amazon. - Franz.: Perroquet auguste.

Psittecus Augustus (1836) Vig. Proc. \%ool. Soc. 1) 80. T'sillacus haranensis (1820) Kuhl Consp. Psitt. 1) 79.

Abbildumgen: Bourjot St. Milaire Hist. Nat. Perr. pl. 6\%.Giray Gen. Birts pl. 104.

Diagnose: Viridis, pileo obseure cyanescente; genis et gastraeo 
violaceo-rubentibus; campterio et speculo alari coceineis: rectricihus soldide rubescente fuscis, apice vinaceis, subtus viridibus: rostro dilute fulvo; iride miniata.

Ala 260, cauda $170 \mathrm{Nm}$.

Vorkommen: Antillische Subregion (Dominica).

66. Androglossa Guildingi. - Kï̈n $\mathrm{igs}-\Lambda \mathrm{ma} \% \mathrm{n} \mathrm{c}$.

Englisch: Guilding's Amazon. - Französisch: Perroquet, de Guilding.

Psittucus Guildingi (1836) Vig. Proc. Zool. Soc. p. 80.

Diagnose: Olivaceo-viridis, partim badio imbuta, notaei plumarum marginibus nigricantibus; sincipite albo, postice flavoimbuto; oceipite, capitis lateribus gulaque ditute azureis, plumis hasi rilute flavis: rectricibus hasi croceris, apice luteis, molin azureis; subcaulalibus luteis, viridi-imbutis: remigihus primaris nigris, pogonio externo cyaneis: campterio luteo: rostro ut perlilous pallidis.

Ala 220, cauda $150 \mathrm{Mm}$.

Vorkommen: Antillische Subregion (St. Vincent?).

Genus: DEROPTYUS. F ii e herpa page ien

Meroptyus (18.32) Wagl. Mon. Psitt. 1) 492 (Typus: P'sillums areipitrinus L.).

Charakter der Gattung: Schnabel höher als bei den vorgenamuten, deutlich höher als lang; Unterkiefer an der basis höher als seine Lü̈nge van der Mundspalte bis zur Spitze: Lille ohne Kiel. Schwanz lïnger als dere viertel des Flügels. Zweitr bis vierte schwinge am lïngsten, crste kürzer als fünfte. Fonlern des Kinterkopfes und Xackens verlängert, einen hiagen hildent. Nur eine Art in der Brasilianischen Subregion.

67. Deroptyus accipitrims. - Fïcherpapagei.

Engl.: Hawk-headed Caique. - Franz.: Perroquet maillé.

Psittacus mine indines (1760) Briss. Orn. IV, p. 300. Psillacus accipitrinus (1766) Lin. S. N. 1). 148. - Psittacus comonatus ibid. p. 143. - Psittacus molecers (1788) Gm. S. N. p. 337. - Psittacus Clusii (1812) Shaw Gen. Zool. VIII, 1) 482.

Abbildungen: Bufton Pl. Enl. pl. 526. - Bourjot St. Hil. IIist. Nat. Perr. pl. 62. - Spix Av. Bras. t. 32a. - Reiehenow Vogelbilder t. X, f. 5.

Disgnose: Virilis; eapulo brtmato, fromb gilvo, plumis 


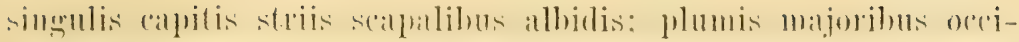
pitis ef nuchac, plumis pectoris et ventris rufeseente rubris, areruleo-limbatis: reminibus primaris ot rectricibus extrioribus nigris, pogonio externo cyanescentibus; rostro fusco; iride blunnea.

I.0ng. c. 350, ala 190, canda 160 , culmen $30 \mathrm{M} / \mathrm{m}$.

Vorkommen: Nördliche Brasilianische Subregion (NorelIivasilien, Guiana, Surnam).

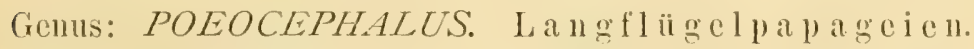

Poioceplectus (1837) Swains. Classif. B. II, 1). 301 (Typus: P's. senegalensis Briss.). - Poeocephalus (1841) Strickl. Ann. Mag. N. H. VII, p 34.

Charakter der Gattumg: Schmabel höher, von derselhen Bildume wic bei der Gattung Deroptyms. Schwanz ungefïlı halb so lang als der Flügel. Ton den verwandten und sehr ähnlichen

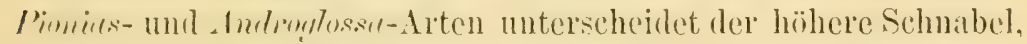
inslesondere rler kurze Lnterlicfer leicht die hierher zgehörenden Formen: in Lelen zeichnet die Luruhe und Schnelligkeit in den Lewegungen diese Vägel vor jenen stilleren, trägeren Papargeien ans. Salch der Flïgel- und Schwanzbildung trennen wir zwei Lintergattungen.

\section{Schlïssel der Gattung:}

Unterkörper griün oder bläulich grïn:

Flïgelbugr mennigroth:

Kopf fahlbraun: volnustus (s. auch firscicullis).

Konf grössteutheils griul Gulielmi.

Fliigelbug gelb, Bürzel hell grüulich blau: Meyeri.

Flügelbug griin:

Kopf braun: fuscicapillus.

Kopf gelb: citrinocapillus.

Vorderkopf und Angengegend golb, ïb:iger 'T'heil des Kopfer sriü: flavifions.

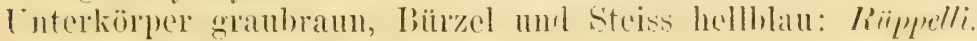

batuch hoshgelb oder gelbroth:

Kopf grau, Unterthigeldecken gelb: seneyulus.

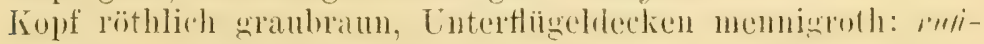
ventris.

Unterkörper weiss oder gelblich weiss:

Oberkopf schwarz: melanocephalus.

Obcrkopf rostbraun, Hosen gelb: ranthomems.

Oberkopf isabellfarb'n, Hosen grün: leacogaster. 


\section{Subgenus: CAICA. Käkas.}

Caice (1831) Less. Traité d'Orn. 1) 198 (vereinigt Psilucus pilcutus Scop., melturinus III. und melenocephatus L.). - Caicu (1850) Bp. Consp. I, p. 5 (Typus: Ps. melanocephalus $\mathrm{L}_{\text {i. }}$ ).

Chatrakter der Lnteroattung: Schwanz etwas linger als dic Inälfte des Flügels. Zweite bis vierte Schwinge am lïnssten, (rrste gleich der fünften. Amerikanische Arten. Drei Formen in der Brasilianischen Subregion.

68. Pococephalus leucogaster. - Weissbauch-Papagei.

Englisch: Pale-headed Caique. - Französisch: Perroquct a ventre blanc.

Psittecus leucogaster (1820) Ill., Kuhl Consp. Psitt. p. 70. I'sittacus badiceps Lear Illustr. Parr. pl. 1. - Psittacus bredins (1864) Schleg. Dierentuin. p. p. 66.

Abbildungen: Lear Ill. P. 1 c. - Bourjot St. Hilaire Hist. Nat. Perr. pl. 58. - Reichenow Vogelbilder t. X, f. 1.

Diagnose: Dorso, alis caudaque riridibus; pileo et cervice dilute isabellinis: capitis lateribus. boris, gulit, erisse ef sulncaudalibus flavis, pectore et ventre Havescente albis: tibiis viridibus; rostro albido; pedibus fulvis; iride flava.

I 011 . c. 240, ala 135, cauda 85, culmen $25 \mathrm{Mm}$.

Vorkommen: Brasilianische Subregion (Brasilien).

(i9.) Pococephalus xenthomerus. - Rostkappen-Papaggei.

Englisch: Yellow-thighed Caique.

Carce acenthomeria (1857) Gray Proc. \%ool. Soc. 1) 266.

Abbildungen: Proc. Zool. Soc. 187!), pl. 28. - Ricichenow Vogelbilder t. X, f. 3.

Diagnose: Dorso, alis caudaque viridibus; pilco nuchaquo formeincis: capitis lateribus, sula, rentre, crisso of subcindalibus luteis: petore et epigastrio Harescente allis: rostro et pedibus albidis; iride rubra. Mensuris $P$. lencogastri.

Vorkommen: Brasilianische Subregion (Brasilien).

70. Pocoreplectus melunocephalus. - Grünzügel-Papagoi.

Englisch: Black-heated Caique. -.. Französisch: Perroruct Maiipouri.

Psittaens mexicenus pectore albo (1760) Briss. Ornith. IV, p. 298. - Psittacus melenocephalus (1766) Lin. S. N. p. 149.

Abbildungen: Buffon Pl. Enl. pl. 527. - Levaillant Hist. 
Nat. Perr. 1)1. 119. - Lear Illustr. Parr. yl. 1. - Reichenow Vogelbilder t. X, f. 2.

Diagnose: Dorso, alis caudaque, loris et stria suboculari viridibus; pileo nigro; capitis lateribus et gula Havis; tibiis. rrisso et subcaudalibus luteis; pectore et ventre flavesente albis: auchenio isabellino: rostro et pedibus nigricantibus; iride fusca: amnulo orbitali nudo nigricante cinereo.

Long. c. 260, ala 140, cauda 80, culmen $25 \mathrm{Mm}$.

Vorkommen: Nërdliche Brasilianische und ('hilenische Subregion (Nord-Brasilien, Guiana, Ecuarlor, Peru).

Sulgenus: POEOCEPHALCS. Eigentl. Langtlïgelpapageien.

Charakter der Untergattung: Schwanz kaum halb so lang als der Flïgel. Kweite mol dritte Schwinge am lingsten, erste gleich der vierten. Afrikanische Arten. Zehn Formen in den Tropen Afrikas.

71. Poeocephalus robustus, - Ka p-Papagei.

Engl.: Levaillant's Parrot. - Franz.: Perroquet Levaillan1.

P'sittecus robustus (1788) Gm. S. N. I, 1). 344. - Psittucus calfor (1793) Leht. Cat. rer. rariss. Hamb. p. 6. -- Psittacus Levcillantii (1801) Lath. Ind. Orn. Suppl. p. 23. - Psittecers flummipes $(1811-1812)$ Bechst. Ueber's. p. 100. - Psittucus

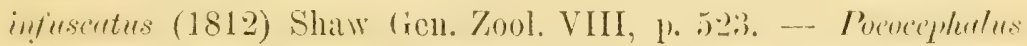
Veillentii (1854) Bp. Rev. Mag. Zool. 1). 154.

Abbildungen: Levaillant Hist. Nat. Perr. 11. 130, 131. Ricichenow Vogelbilder t. VII, f. 6.

Diagnose: Interscapulii, scapularium et alarum plumis plumis fuscis, viridi.. Limbatis; tergo. mopygio et abdomine thalassinis; appite, collo pectoreque fulvescente-brumeis; loris nigricantibus: fronte interdum miniatal Hexura, (ampterio tibiisque miniatis; remigibus primaris cormmque tectricibus et candia fuscis; rostro pallide canneo; perlibus nigricantibus; iride croccia.

Long. c. 350, ala 210, cauda 90, culmon $35 \mathrm{Mm}$.

Vorkommen: Südafrikanische Subregion.

72. Subspecies: fuscicollis. - Benguella-Papa gei.

I'sittacus fuscicollis (1820) Kuhl Consp. Psitt. p. 93. -

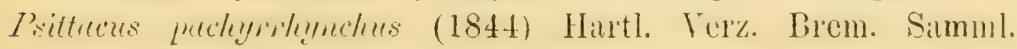


1. 88. - Pococephulus muminostris (1850) Bp. Consp. Psitt. I, P. 5. - Psittacus Lecomtei (1857) Verr., Hartl. W. Nfi. p. 167.

biagnose: $P$. robrsto similis, sed capite colloque matgis cincrascentibus. dorso et alis dilutioribus, tergo et uropygio, matgis Havescentibus, rostro validiore. - Olivaceo-viridis: tere, uroprygio ablomineque lacte Havescente-viridibus; capite. collo pertoreque olivaceo-griseis; loris nigrieantibus: fronte, Hexura tibiisque miniatis: rostro abeseente: pedibus nigricantibus.

Ala 210. cauda 90, eulmen 50 $\mathrm{Mm}$.

Vorkommen: Südliches West-Afrika (Angola).

\section{Pococephatus Gulichio - Kongo-Papagei.}

Englisch: Jardine's Parrot. - Franz, Perroquet Icecompte.

Piomes Gulielmi (1849) Jard. Contr. Orn. p. 64. - P'veoceplectus Aubryanus (1856) Souancé Rev. Mag. p. 216.

Ablildung: Reichenow Vogelbilder t. VII, f. 7.

Diagnose: Viridis; uropygio, crisso et subcaudalibus Havicantibus, dorsi of alarum plumis medio nigro-fuscis: loris nigris: sincipite, flexura, campterio et tibiis miniatis; remigibus primaris erumque tectricibus et cauda nigris: maxilla carnea: culmine et apice maxillac, mandibula et perlibus nigricantihus: iride crocea.

Long. c. 320, ala 190, cauda 80, culmen 31 Mm. Vorkommen: West-Afrikanische Subregion.

\section{Posocephalus senegalus. - Mohrenkopf.}

Engl.: Senegal Parrot. - Franz.: Perroquet de Senegal.

Psitteres Senegulensis (1760) Briss. Ornith. IV, p. 100. -I'sillucus Senegalus (1766) Lin. S. N. I, 1. 149. - Poevecphluelus Senergalensis (1837) Sws. Classif. B. II, p. 301. - Psittecus Tereteri (1863) Geoffir. Neder. Tijdschr. I)ierk. Berigten 1) 16. Perroquet à tête grise (1783) Buff. Pl. Enl. VII, p. 99.

Abbildungen: Buffon Pl. Enl. pl. 288. - Icevaillant Ilist. Nat. Perr. pl. 116, 117. - Reichenow Vogelbilder t. VII, f. 2.

I)iagnose: Viridis; capite toto cano; abdomine et tectricibus inferioribus croceis, ablomine medio miniato: rostro, peribus et ammulo orbitali nudo nigricantibus; iride flava.

Long. c. 260, ala 145, cauda 65, culmen $26 \mathrm{Mm}$.

Vorkommen: liest-Afrika. 
75. Pococephahes Meyeri. - Goldbug-Papagei.

Englisch: Meyer's Parrot. - Französisch: Perroquet it croupion blen.

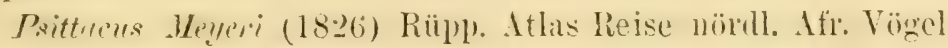
1. 18. - Psittacus deneoscapulutus (1859) Ehrb. Gray List P's. 1. 70. - Phacereghalus renthepterus (1863) v. Heugl. Journ. f. Ornithol. p. 271.

Abbilhungen: Bonrjot St. Hilaire Hist. Nat. Perr. pl. 61. Riippel Atlas t. 11. - Reichenow Vogelbilder t. VII, f. 1.

Diagnose: Capite, collo, interseapulio, alis et cauda brunnois: Hexura, subalaribus, tibis et campterio flavis: abtomine thalassimo: tergo et uropygio dilute virescente catuleis: rostro, pedibus et annulo orbitali nigricantibus; iride lateritia.

Long. c. 250, ala 145 , cauda 75 , culmen $26 \mathrm{Mm}$.

(Varietas pilei macula flava notata saepe invenitur).

Vorkommen: Ostafrikanische Subregion (Ahessinien. Morialllbique, Benguella).

76. Poeocephalus fuscicupillus. - Braunkopf-Papagei.

Englisch: Brown-headed I'arrot. - Französisch: Perruche i tête brune.

Pionus fuscicopillus (1849) Verr. et Des Murs Rev. Mag.

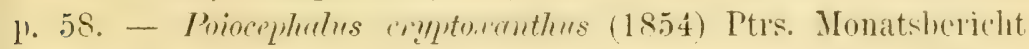
Berl. Ac. Wiss. p. 371. - Psittacus hypoxanthes (1859) Ptrs., Gray List Psitt. 1). 71.

Abbildungen: Finsch is Hartl. O. Afr. t. VII. - Reichenow Vogelbilder t. XX, f. 8 .

Diagnose: Yirilis subtus laetion" capite olivascente.. fuseo. rewione parotica canescente: tectricibus inferioribus luteis: pedihus et maxilla nigricantibus: mandibula albicante: iride flava.

Long. c. 270 , ala 155 , canda $70-75$, rostrum $26 \mathrm{Xm}$.

Vorkommen: Ostafrikanische Subregion (Mossambique, Sambesi, Zanzibar).

77. Poeocephalus Rüppelli. - Blansteiss-Papagei.

Englisch: Riuppell's Parrot. - Franz.: Perroquet Ruppell.

Psittacus Krïppelli (1848) G. R. Gray Proc. Z. S. p. 125.

Abbildungen: Proc. Zool. Soc. 1848, pl. 5. - Reichenow Vogelbilder t. VII. f. 3.

Diagnose: Canescente hrunneus: Hexurae macula magna, ('ab. Journ. f. Ornithol. XxIX. Jahrg. No. 156. October 1881. 
tectricibus inferioribus et braccis flavis; tergo, uropygio, supracaudalibus, ventre, crisso et subcaudalibus cacruleis; rostro et pedibus nigricantibus; iride rubra.

오: Tergo, uropygio, ventre crissoque brumneis, interdum caerulescente lavatis.

Long. c. 250, ala 145, cauda 80, rostrum $25 \mathrm{Mm}$.

Vorkommen: Westafrika (Gabun, Angola).

78. Poeocephalus mfiventris. - Somali-Papagci.

Englisch: Shoa Parrot.

Pionus mefventris (1845) Rüpp. S. Uebers. t. 32.

Abbildungen: Riuppell 1. c. - Reichenow Vogelbililer aus fernen Zonen t. XX, f. 7.

Diagnose: Dorsi et alarum plumis brunneis, pallide thalassino-limbatis: cauda olivace-brunnea; capite, collo pectoreque dilute brumneis, miniato-imbutis; epigastrio, ventre of tectricibus inferioribus miniatis; subciudalibus, braceis crissoque Havescente viridibus: uropygio et supracaudalibus thalassinis: rostro, pedibus et orbitis nigricantibus; iride miniata.

Long. c. 260, ala 160, cauda 80, rostrum $28 \mathrm{MIm}$.

Juv.: Epigastrio et tectricibus inferioribus hrunneis.

Vorkommen: Oestliche Afrikanische Subregion (Nordostund Ost-Afrika).

79. Poeocephahs favifrons. - Schoa-Papagei.

Englisch: Yellow-faced Shoa Parrot.

Pionus flavifrons (1845) Rüpp. S. Ueb. t. 31.

Abbildung: Rüppell 1. c.

Diagnose: Viridis; sincipite, loris et periophthalmiis flavis: maxilla, pedibus et orbitis nigricantibus; mandibula pallide plumbea; iride lateritia.

Long. c. 245, ala 167, cauda 75, rostrum $25 \mathrm{Mm}$.

Vorkommen: Oestl. Afrikanische Subregion (Nordost-Afrika).

80. Pococephalus citrinocapillus. - Citronenkopf.

Englisch: Yellow-headed Parrot.

Pionias citvinocapillus (1868) v. Heugl., Finsch Pap. II, p. 484.

Abbildungen: v. Heugl. Orn. N. O. Afr. I, t. 25. - Reichenow Vogelbilder t. XX, f. 6 .

Diagnose: Viridis, tergo et abdomine cacrulescente; capitc 
toto et campterio flavis; maxilla, amnulo orbitali et pecibus nigricantibus; mandibula albicante; iride lateritia.

Long. c. 245, ala 165, cauda 70, rostrum $30 \mathrm{Mm}$.

Vorkommen: Östl. Afrikanische Subregion (Nortost-Afrika).

\section{Nachträge und Berichtigungen.}

Anf Seite $20 \mathrm{zu}$ Nestor mericlionalis croïnze als synonym: "Nestos" montame Bull. Finsch Pap. II, 1868, p. 961." - Ebenda ist als zweifelhafte Art zu erginzen: Nestor accidentedis (1869) Bull. Ibis p. 40.

Der Autor giebt folgende Diagnose dieser wahrscheinlich nur eine Varietit von $\mathrm{X}$. meridionalis darstellenden Form:

Pileo obscure albicanti-cincreo, nuchae plumis late brumeo marginatis, fronte clarius colorato: regione auriculari sordide aurantiaca, scapis albicantibus: genis brumneis, medialiter albicante striatis, plumis rictalibus anterioribus elongatis, sordide coccineo striatis: dorso toto olivaceo-fusco, ala clarius olivascente, plumis omnibus conspicue nigro marginatis: tectricibus alarum vix flavido tinctis: collo postico sordide coccinco et aurantiaco lavato, torquem collarem vix conspicuam formante: dorso postico et uropygio olivaceo-fuscis, plumis omnibus sordide coccineo lavatis et nigro marginatis: cauda clare olivascenti-brunnea, versus apicem paullo brumesrente, pennis centralibus sub certa luce vix rubescentibus: sultus obscure fuscus, plumis nigro marginatis: pectore imo et hypochondriis olivas ente tinctis et conspicue sordide coccinco lavatis: subalaribus cum plumis axillaribus fuscis, laetius coccineo et aurantiaco lavatis, brunneo transfasciatis. Hab.: George Sound, west coast of South Island.

Auf Seite 26 unter Plissoloplues Goffini ergänze: "Abbildung:

Proc. Zool. Soc. London 1875, pl. 10" und "Vorkommen:

Nordost-Australien."

Auf Seite 33 zu Calyptorhynchus Solandri ergänze unter $A b-$ bildungen: „Bourjot St. Hil. Hist. Nat. Perr. pl. 72 (juv).“ Anf Seite 39 unter Nanodes discolor Abbildungen erginze: "Reichenow Vogelbilder t. XXIII, f. 7."

Auf Seite 40 unter Cyunorhomplus schalte ein: "Bonaparte Ann. Sc. Nat. 1854, p. 108."

Auf Seite 45, 6. Zeile ron oben lies .uropygio" für crisso. -Ebenda unter Abbildungen ergänz: "Reichenow Vogelbilder taf. XXIII, fig. 2."

Inf Seite 56, 7. Zeile von oben lies: "Psittucus icterotis" fün

Platycercus icterotis.

Auf Seite $60 \mathrm{zu}$ Platycercus semitorquelus und somarius ist 
folgendes zu bemerken: .. Nach Untersuchung einer grösseren Reihe von Exemplaren beider Formen selininen keine (röissenunterschiede zu bestehen; ferner kommt die rothe Stirnbindu. wenngleich schwächer und heller, anch bei somurius vor."

Auf Seite 68, 5. Keile von unten lies: „1832" für 1830 und

4. Zeile "1850" für 1849 .

Anf Seite 72, 7. Zeile von unten lies: "Ioxius" für lumulatus.

Auf Seite 73 unter cyclopsittares lowins Abbildungen ergïnze: "Lear Illustr. Parr. pl. 40" und "IBomrjot St. Hilaire Hist. Nat. Perr. pl. 97 ( 9 )."

Auf S. 85 unter Trichoglossus anreicinctus ergïnze als synonym: "Trichoglossus amalilis (1376) E. P. Ramsay P1. Lin. S. N. S. Wales I, 1. 30." - Ebenda ergänze die folgende Art:

6a. Trichoglossus mbriguluris P. I. Sclater Proc Zool. Soc. Iondon 1881 , p. 4.51 .

Supra viridis, alis intus nigris extus dorso concoloribus, subtus dilutior et praecipue in gutture et in lateribus lacte gramineo-viriclihus: alarum pagina inferiore schistaceo-nigra. remigum pogoniis internis ad basin flavo transvittatis; subalaribus flavicanti-viridibus: caula subtus schistareo-nigra. rectriem apicibus latis flavis et harum quatuor utrinque extimarum pogoniis internis ad hasin sanguineo-rubris; rostun flavo: pedibus pallide armeis. Long. t. 6,7. ala 3,4 , reetr. ext. 1,5 med. 3,2. Hab. New Britan. (Selater).

Sach dieser vom Autor gegehenen Iliagnose sollte man dir Art für identisch mit Trichoglossus pygmaeus Gm. halten. Aus dem Vanen, sowie ans diner nachtrïglichen Bemerkung: "chinspot nearly erimson (eoceineo-ruber)" geht indessen hervor, dass gerade das wichtigste Kennzcichen in der gegebenen Iniagnose von Herrn I)r. Sclater vergessen worden mud dass die Art also durch einen rothen Kinnfleck ansgezeichnet ist Beide Geschlechter sollen gleich zefïbt sein. Bei der Ungenanigkeit der Angaben hedarf die Art der Bestïtigung.

Auf Seite 88 unter No. 14 lies: "Trichoglossus Murquritue" für Charmosyna.

Anf S. 91 unter Tridkorlosses iris Abbildmo ergïnze: „Bourjot St. Hilaire Hist. Nat. Perr. pl. 44."

Auf S. 92 letzte Zeile elgänze: „Lear Illustr. Parr. pl. 35." -

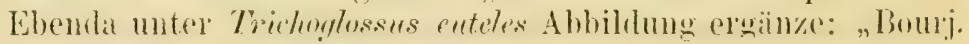
St. Hil. Hist. Nat. Perr. pl. 4\%,"

Aul S. 95 unter Subspecies nigroguleris erginze: ,Abbildung: Report scientif. results Yoy. Challenger Zool. Vol. II, 1881, 11. "20." - Elumba setze an Stelle der gregehenen Iliaguose: 
"Tr. cyanogrammo simillimus, sed pectore rubro dilutius tincto et fasciis nigris parcioribus et angustioribus."

Auf S. 97 unter Trichoglossus muritoryuatus Abbildungen ergïnze: "Lear Illustr. Parr. pl. 34."

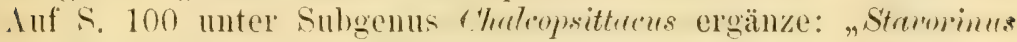
Bonap. 1850 Compt. Rend. T. 30, p. 136."

InfS. 104 unter /momicelle histson Abbildungen ergänze: ,Rowley's ()rnith. Nisce. It. 13, p. 123."

Auf Seite 107 unter Thmirelle atvirepilla Abbildungen ergïnze: "Lear Illustr. Parr. pl. 37."

Auf Seite 108 in der Diagnose von 7hmicella linpormochoroe erg:inze: "cera alba."

Auf S. 109 lies "Genus coriphilne" für Subgenus und „18:32"

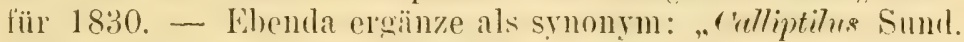
Tentamen p. 71 (1872) Typus: Ps. solitarius L."

Auf S. 112, 4. Zeile von oben lies: „1820" für 1821.

Auf Seite 115 unter Comllis pemenensis zu Abbildung crgänze: „Report scient. results. Voy. Challenger Zool. Vol. II. pl. 1." Auf S. 116, 6. Zeile von unten lies: „89“ für 87.

Auf S. 127 nuter Piduconis peristeroles Abbildungen ergänze: "Lear Illustr. Parr. pl. 31." - Ebenda unter P. Gironieri Abbildung ergänze: "Legge Birds of Ceylon Pt. 1."

Inf S. 141 setze an Stelle der gegebenen Diagnose ron Edectus roratus: ..E. pectorali simillimus, sed colore lactiore, rectricihus exterioribus magis craneis, margine alari vix caerulea." Ebenda an Stelle der Diagnose von $E$. cardinalis setze: "E. we fmali simillimus. sed rectricibus exterioribus vix cyaneis: margine alari vix caerulea."

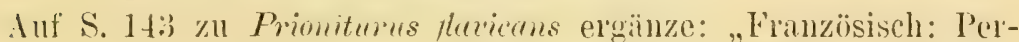
roquet couronné." — Ebenda unter Pr. platurus ergïnze: "O : Viridissima, pileo caerulescente; rectricum apicibus nigro-cyaneis. "

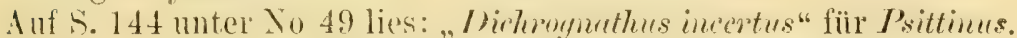
Auf S. 157 unter Sittuce Illigeri Abbildung eroünze: „Bourjot St. Hilaire Hist. Nat. Perr. pl. 13.

Auf S. 163 zu der Diagnose von 'tomms enops eroitize: „annulo orbitali canescente albo."

Auf S. 192, 5. Zeile von oben lies: „80“ für 81.

Zwaifelhaft bleibt, ob zufällige Varietat oder besondere Art: Lurius.s Gulelmi Ramsay (an Lonius hapoenochrous Gray var.): E. P. Ramsay, Proc. Zool. Soc. N. S. Wales Vol. III, 1879, 1). 72: „Difiers in having the whole of the abdomen black and a black band across the interseapular region and in the color of the under tail-coverts; also in the concealed yellow spot near the base of the breast and chest feathers. Hab.: South Coast of New Guinea." 
Schliesslich fügen wir noch die Synonymie und Diagnose des ausgestorbenen Psittacus musurims Gm., welcher offenbar zu den Palaenmithidae zu zïhlen ist und oben unter der Besprechung dieser Familie erwähnt wurle, in der yon Dr. Finsch gegebenen Darstellung an:

Psittecus mascurinus (1798) Gm. S. N. 1).333. - Psittacus mescurinus (1760) Briss. Ornith. IV, p. :315. - Corecopsis mersectine (1832) Wagl. Mon. Psitt. p. 679. - Mascarims. wscurus (1854) Bonap. Rev. Mag. Zool. p. 154. - Mascurinus madagascariensis (1860) Hartl. Journ. f. Ornith. p. 107. Hascarinus Imonisi (1879) Forbes Ibis Vol. 3, No. 11, 1). 30\%.

Diagnose: Brumneus, capistro nigro, eapite caulaspue hasi griseis; rostro rubro.

Bewohnte Madagascar.

\section{Recapitulation.}

\section{Ordo: Psittaci.}

FAMILIA: STRINGOPIDAE.

Genus Stringops (p. 14): 1. habroptilus*). 2. Greyi.

Genus Geopsittacus (p. 15): 3. occidentalis.

Genus Pezoporus (p. 16): 4. formosus.

\section{FAMILIA: PLISSOLOPHIDAE.}

Genus Nestor (p. 19):

Subgenus Nestor (p. 19): 1. meridionalis. 2. superbus. 3. Esslingi. 4. productus. 5. norfolcensis. 6. notabilis.

Subgenus Dasyptilus (p. 22): 7. Pesqueti.

Genus Licmetis (p. 23): 8. nasicus. 9. pastinator.

Genus Plissolophus (p. 23):

Subgenus Camptolophus (p. 24): 10. gymmopis. 11. philippinarum. 12. sanguineus. 13. Goffini. 14. Ducorpsi. 15. roseicapillus. 16. albus. 17. ophthalmicus. 18. moluccensis.

Subgenus Plissolophus (p. 28): 19. Lealbeateri. 20. citrinocristatus. 21. cristatus. 22. Buffoni. 23. galeritus. 24. triton. Genus Calyptorhynchus (p. 31):

Subgenus Callocephala (p. 31): 25. galeatus.

Subgenus Calyptorlunchus (p. 32): 26. Baudini. 27. funcrens. 28. xanthonotus. 29. Solandri. 30. Banksi. 31. stellatus. Genus Microglossus (p. 34): 32. aterrimus.

$$
\text { FAMILIA: PLATYCERCIDAE. }
$$

Genus Melopsittacus (p. 37): 1. undulatus.

*) Die Nummern vor den einzelnen Arten correspondiren mit denen in dem Texte, so dass diese Uebersicht zugleich als Index für die ganze Arbeit zu benutzen ist. 
Genus Callipsittacus (p. 38): 2. Novae-Hollandiac. Genus Nanodes (p. 39): 3. discolor.

Genus Cyanorhamphus (p. 40):

Subgenus Cyanorhamphus (p. 40): 4. unicolor. 5. ulietanus.

6. erythronotus. 7. Novae-Zeelandiae. S. Rowleyi. 9. Rayncri.

10. aucklandicus. 11. erythrotis. 12. Saisseti. 13. Forsteri.

14. auriceps. 15. Nalherbii. 16. intermedius. 17. alpinus.

Subgenus Nymphicus (p. 44): 18. cornutus.

(ienus Exphema (p. 45): 19. Bourki. 20. venusta. 21. elegans.

22. petrophila. 23. chrysogastra. 24. pulchclla. 25. splendida.

Genus Platycercus (p. 49):

Subgeuus Psephotus (p. 51): 26. hacmatonotus 27. multicolor. 28. chrysopterygius. 29. pulcherrimus. 30. hacmatogaster.

31. haematorrhous.

Subgenus Platycerens (p. 54): 32. Browni. 32a. Mastersianus. 33. pallidiceps. 34. Amathusia. 35. icterotis. 36. eximius. 37. splendidus. 38. ignitus. 39. flaveolus. 40. flaviventris. 41. adelaidensis. 42. elegans. 43. Barnardi. 44. semitorquatus. 45. zonarius.

Subgenus Purpureocephalus (p. 61): 46. spurius.

Subgenus Ptistes (p.61): 47. jonquillaceus. 48. erythropterus. 49. coccineopterus.

subenus Aprosmirtus (p. (i3)): 50. insignissinus. 51. scapulatus. 52. amboinensis. 53. sulaensis. 54. burnensis. 5.). dorsalis. 56. callopterus. 57. chloropterus. 58. hypophonius.

Silibenus Pymhulopsis (p. (66): 50. splendens. 60. tabuensis. 61. hysginus. 62. Anna. 63. personatus.

Subgenus Polytelis (p. (88): 64. Alexandrae. 65. Barrabandi. 66. melanurus.

\section{FAMILIA: MUCROPSITTACIDAE.}

Genus Psittacella (p. 71): 1. Brehmi. 2. modesta.

Genus Cyclopsittacus (p. 72): 3. loxia. 4. Salvadorii. 5. Desmaresti. 6. occidentalis. 7. Blythi. 8. cervicalis. 9. Coxeni. 10. Naccori. 11. diophthalmus. 12. aruensis. 13. suavissimus. 14. Gulielmi tertii. 15. melanogenys. (ienus Nasiterna (1. 75b): 16 (11). keiensis. 17 (12). pusio. 18 (13). pusilla. 19(14). Beccarii. 20 (15). misoriensis. 21(16). maforensis. 22(17). pygmaea. 23(18). Bruijnii.

\section{FAMILIA: TRICHOGLOSSIDAE.}

Genus Trichoglossus (p. 81):

Subgenus Glossopsittacus (p. 83): 1. diadema. 2. porphyrcocephalus. 3. concinnus. 4. pusillus.

Subgenus Charmosyna (p. 85): 5. aureicinctus. 6. palmarum. 6a. (im Nachtrag) rubrigularis. 7. pygmaeus. S. subplacens. 
9. placens. 10. rubronotatus. 11. kordoanus. 12. Wilhehminale.

19. pulchellus. 14. Margaritae. 15. papuensis. 16. Josephinac. Subgenus Oreopsittacus (p. 89): 17. Arfaki.

Subgenus Veopsittacus (p. 10): 18. Muschenbrocki. 19. versicolor. 20. iris. 21. Verreauxi. 22. euteles. 23. flavo. viridis. 24. Meyeri. 25. chlorolepidotus.

Subgenus Trichoglossus (p. 93): 26. Forsteni. 27. Massenar. 28. Havicans, 29. cyanogrammus. 30. nigrogularis. 31. caeruleiceps. 32. Rosenbergi. 33. coccineifrons. 34. ornatus. 35. rubritorquatus. 36. Novae-Hollandiae. 37. haematodes. 38. cardinalis. 39. rubiginosus.

Genus Domicella (p. 99):

Subgenus Chalcopsittacus (p. 100): 40. fuscata. 41. atrat. 42. insignis. 43. Stavorini. 44. scintillata.

Subgenus Los (p. 102): 45, riciniata. 46. Wallacii. 47. cranogenys. 48. histrio. 4\%. reticulata. 50. semilarrata. 51. rubrat. subgenus Domicelle (p. 106): 52. gartula. 53. flavopalliata. 54. tibialis. 55. chlorocerca. 56. atricapilla. 57. hypoenochroat. 58. tricolor. 59. erythothorax. 60. jobiensis. 61. cranauchen. (icuts Coriphilus (p. 10!9): 62. australis. 63. Kuhli. 64. s()litarius. 65. taitianus. 66. smaragdinus.

Genus com llis (p. 112): 67. remalis. 68. pusilla. (69). Hosculus. 70. exilis. 71. panayensis. 72. indica. 73. regulus. 74. occipitalis. 75. philippensis. 76. chrysonota. 77. apicalis. 78. tener. 79. galgulus. 80. Sclateri. 81. catamenia. 82. aurantiifrons. 83. Bonapartii. 84. stigmata. 85. quitdricolor. 86 . amabilis.

FAMILIA: PALAEORNITHIDAE.

Genus Palaeornis (p. 121): 1. eupatrius. 2. nipalensis. 3. magnirostris. 4. indobumanicus. 5. Wardi. 6. exsul. 7. torquatus. 8. docilis. 9. Hodgsoni. 10. Finschi. 11. cyanocephalus. 12. rosa. 13. eques, 14. Gironieri. 15. peristerodes. 16. caniceps. 17. derbyanus. 18. fasciatus. 19. Alexandri. 20. erythrogenys. 21. Luciani. 22. longicauda.

Genus Tanygnathus (p. 131): 23. gramineus. 24. luconensis. 25. affinis. 26. Mülleri. 27. albirostris. 28. Everetti. 29. megalorhynchus.

Genus Rhodocephalus (p. 135): 30. simplex. 31. heteroclitus. 32. cyanicollis. 33. obiensis. 34. Geoffroyi. 35. aruensis. 36. Jukesii. 37. keyensis. 38. Pucherani. 39. jobiensis. 40. mysorensis. 41. dorsalis?

Genus Eclectus (p. 139): 42. pectoralis. 4\%. roratus. 44. cardinalis. 45. Cornelias.

(ienus Prioniturus (p. 142): 46. discurus. 47. Havicans. 48. platurus. 
Genus Dichrognathus (p. 143): 49. incertus.

Genus tgapornis (p. 144): 50. Tarantae. 51. pullaria. 52. roseicollis. 53. Swindereni. 54. cana.

\section{FAMILIA: PSITTACIDAE.}

Genus Coracopsis (p. 148): 1. melanorhyncha. 2. nigra. 3. comorensis. 4. Barklyi.

Genus Psittacus (p. 150): 1. carycinurus. 2. crithacus.

\section{FAMILIA: CONURTDAE.}

Genus Sittace (p. 152): 1. hyacinthina. 2. Leari. 3. glauca. 4. Spixi. 5. caerulea. 6. Azarae. 7. chloroptera. 8. coccinca. 9. tricolor. 10. militaris. 11. severa. 12. Lafiesnayi. 13. Hligeri. 14. Couloni. 15. modesta. 16. auricollis. 17. nobilis, 18. Hahni.

(icuus Conurus (1. 159): 19. pachyrhynchus. 20. mitratus. 21. frontatus. 22. Finschi. 29. Wagleri. 2f. rubrolarvatus. 25. cuops. 26. Gundlachi. 27. leucophthalmus. 28. holochlorus. 29. acuticandatus. 30. haemorrhous. 31. patagonus. 32. Byroni. 33. icterotis. 34. luteus. 35, solstitialis. 36. pyrocephalus. 37. carolinensis. 38. melanocephalus. 39. nanus. 40. frontalis. 41. cactorum. 42. Weddelli. 43. aeruginosus. 44. chrysophrys. 45. ocularis. 46. pertinax. 47. aureus. 48. Petzi. Genus Henicognathus (p. 172): 49. leptorhynchus.

Genus Pyrrhura (p. 173): 50. smaragdina. 51. vittata. 52. Devillii. 53. egregia. 54. cruentata. 55. Hoffmanni. 56. calliptera. 57. Souancéi. 58. rupicola. 59. melanura. (i). picta. 61. Lnciani. 62. lencotis. 63. Molinae. (i4. hacmatotis, 65. lepila. li6. rhorlogastra. 67. roseifrons. 68. rhodocephala.

licuus Brotogerys (p. 181): 69, viridissima. 70. pyrrhoptera. 71. virescens. 72. xanthoptera. 73. chrysopogon. 74. ferrugineifrons. 75. jugularis. 76. notata. 77. chrysoptera. 78. chrysosema. 79. passerina.

finus Bollorhynchus (p. 185): 80. munachus. 81. Luchsi. 82. brunneiceps. 83. rubrirostris. 84. aurifrons. 85. Orbignyi.

86. lineolatus.

Genus Psittacula (p. 188): 87. andicola. 88. cyanoptera. 89. passerina. 90. cyanopyga. 91. Sclateri. 92. coelestis. 93. conspicillata.

\section{FAMILIA: PIONIDAE.}

Genus Triclaria (p. 192): 1. cyanogaster.

Genus Pachynus (p. 192): 2. brachyurus.

Genus Eucinetus (1. 193):

Subgenus Pionopsittacus (p. 194): 3. pileatus.

Subgenus Eucinetus (1. 194): 4. melanotis. 5. hatmatotis. 


\section{6. amazoninus. 7. pyrthops. 8. histrio. 9. pyrillus.}

10. Barrabandi. 11. vulturinus.

(iemus Euchrour (p. 197): 12. stictoptera. 13. purpuroptera.

14. viridicaudil. 1.). melanonota. 16. surda. 17. cingulata.

18. Hueti. 19. dilectissima.

Genus Pionias (p. 201): 20. menstruus. 21. rubrigularis. 22. Maximiliani. 23. Havirostris. 24. corallinus. 25. sordidus. 26. tumultuosus. 27. gerontodes. 28. senilis. 29. chalcopterus. 30. violaceus.

(ienus Androglossu (p. 205): 31. Guatemalae. 32. agilis. 33. farinosa. 34. mercenaria. 35. auripalliata. 36. cauipalliata. 37. Nattereri. 38. versicolor 39. Bouqueti. 40. festiva. 41. Bodini. 42. vittata. 43. erythrura. 44. brasiliensis. 45. vinacea. 46. diademata. 47. Finschi. 48. viridigenalis. 49. Prétrii. 50. caeruligena. 51. Dufresnii. 52. autumnalis. 53. albifrons. 54. xantholora. 55. ventralis. 56. Ieucocephala. 57. collaria. 58. amazonica. 59. aestiva. 60. ochrocephala. 61. panamensis. (i2. ochroptera. 63. Levaillanti. (it. xanthops. 65. angusta. 66. Guildingi.

Genus Deroptyus (p. 220): 67, accipitrinus.

Genus Poeoceptalus (p. 221):

Subgenus (aica (1) 222): 68. lenengaster. 6\%. xanthomerus. 70. melanocephalus.

Subgenus Popocephetus (p. 2203): 71. robustus. 72. fuscicollis. 73. Gulielmi. 74. senegalus, 75. Meyeri. 26. fuscicapillus. 77. Rüppelli. 78. rufiventris. 79. flavifrons. 80. citrinocapillus. 




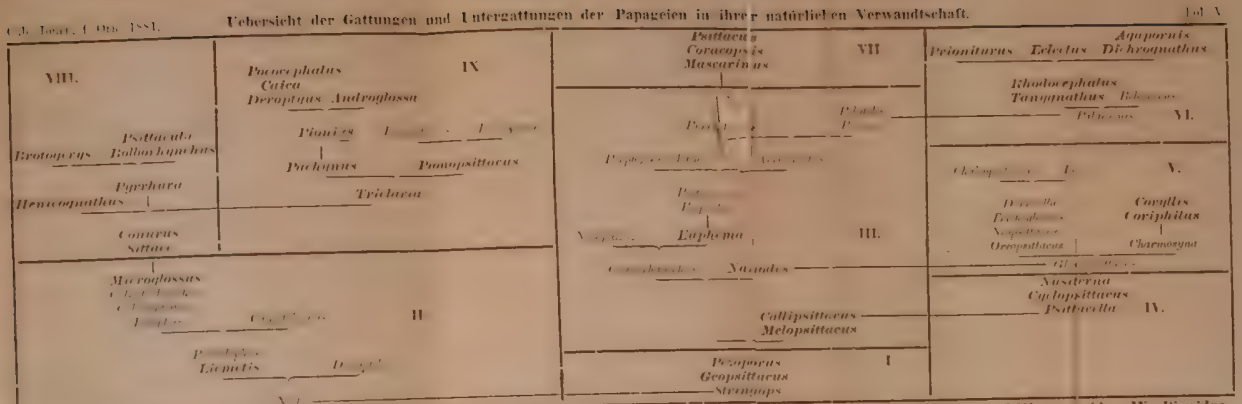

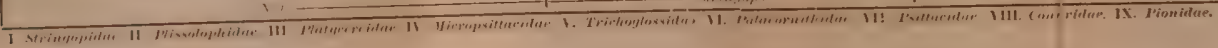










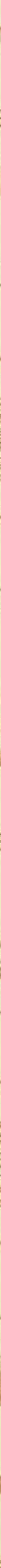


SMITHSONIAN INSTITUTION LIBRARIES 